\title{
EFEITOS DOS ÁCIDOS GRAXOS NA FUNÇÃO DE MACRÓFAGOS DE CAMUNDONGOS COM DIABETES TIPO I INDUZIDO
}

Tese apresentada ao Programa de Pós-Graduação em Fisiologia Humana do Instituto de Ciências Biomédicas da Universidade de São Paulo, para obtenção do Título de Doutor em Ciências. 
MARIANA RODRIGUES DAVANSO

\section{EFEITOS DOS ÁCIDOS GRAXOS NA FUNÇÃO DE MACRÓFAGOS DE CAMUNDONGOS COM DIABETES TIPO I INDUZIDO}

Tese apresentada ao Programa de Pós-Graduação em Fisiologia Humana do Instituto de Ciências Biomédicas da Universidade de São Paulo, para obtenção do Título de Doutor em Ciências.

Área de concentração: Fisiologia e Biofísica

Orientador: Prof. Dr. Rui Curi

Versão original. 
CATALOGAÇÃO NA PUBLICAÇÃO (CIP)

Serviço de Biblioteca e informação Biomédica

do Instituto de Ciências Biomédicas da Universidade de São Paulo

Ficha Catalográfica elaborada pelo(a) autor(a)

Rodrigues Davanso, Mariana

Efeitos dos ácidos graxos na função de macrófagos de camundongos com diabetes tipo I induzido /

Mariana Rodrigues Davanso; orientador Rui Curi. -São Paulo, 2017

$119 \mathrm{p}$.

Tese (Doutorado)) -- Universidade de São Paulo, Instituto de Ciências Biomédicas.

1. Diabetes mellitus tipo I. 2 . Estreptozotocina. 3. Macrófago. 4. Inflamação. 5. Ácidos graxos. I. Curi, Rui, orientador. II. Título. 
Candidata: Mariana Rodrigues Davanso

Título da Tese: Efeitos dos ácidos graxos na função de macrófagos de camundongos com diabetes tipo I induzido

Orientador: Rui Curi

A Comissão Julgadora dos trabalhos de Defesa da Tese de Doutorado, em sessão pública realizada a considerou

\section{( ) Aprovado(a) ( ) Reprovado(a)}

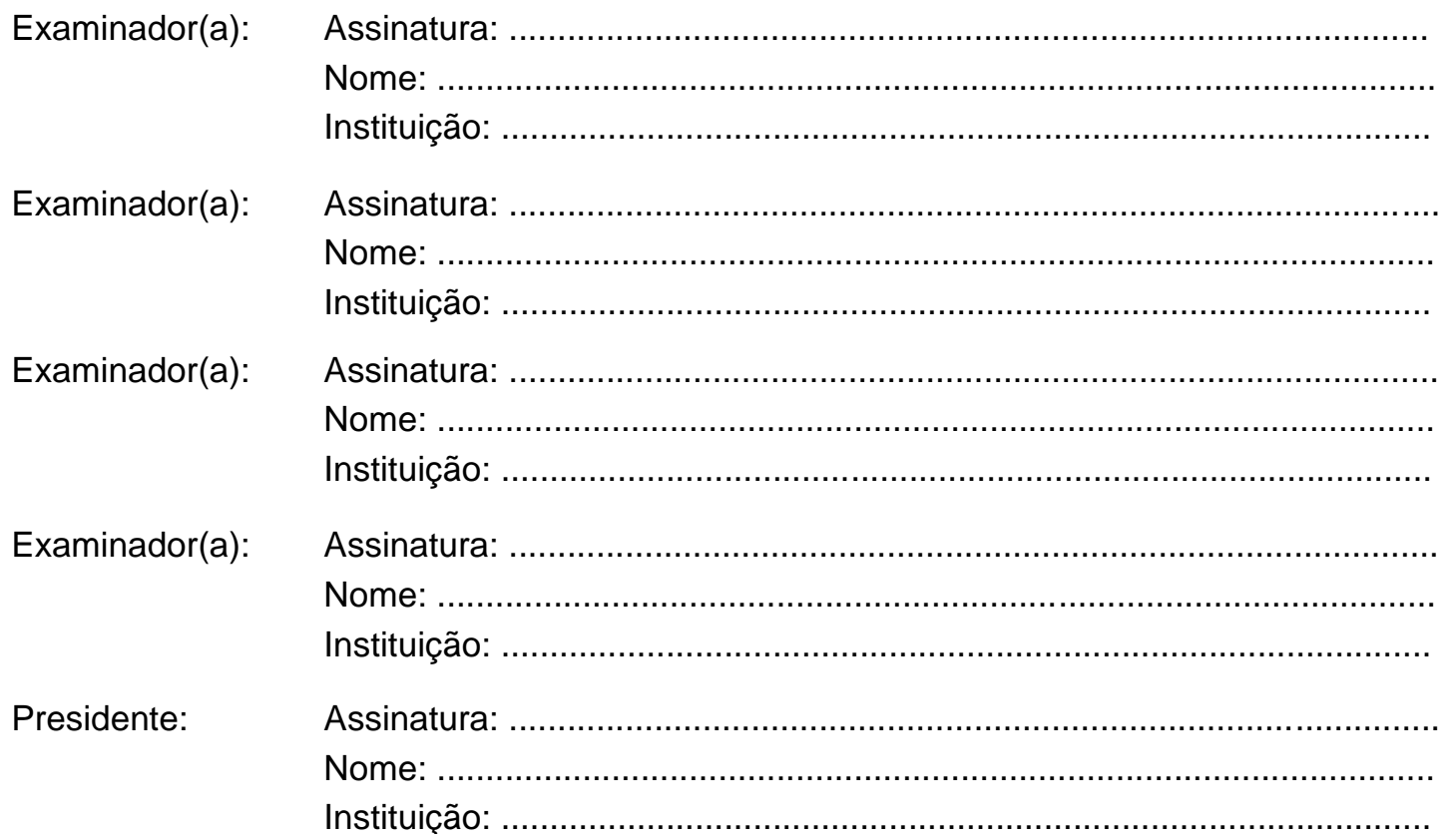




\section{Certificado}

Certificamos que o protocolo registrado sob $n^{\circ} \mathbf{0 0 1}$ nas fls. 02 do livro 03 para uso de animais em experimentação, sob a responsabilidade do Prof(a) $\operatorname{Dr}(a))$ Rui Curi, Coordenador (a) da Linha de pesquisa "Efeito dos ácidos graxos na função de macrófagos de camundongos diabéticos tipo I induzido" do qual participam o(s) aluno(s), Amanda Rabello Crisma, Mariana Rodrigues Davanso e os pesquisadores Tatiana Carolina Alba Loureiro, Niels Olsen S.Camara, está de acordo com os Princípios Éticos de Experimentação Animal adotado pela Sociedade Brasileira de Ciência de Animais de Laboratório (SBCAL) e foi aprovado pela COMISSÃO DE ÉTICA NO USO DE ANIMAIS (CEUA) em 19.02.2013, com validade de 4 anos.

São Paulo, 20 de fevereiro de 2013.
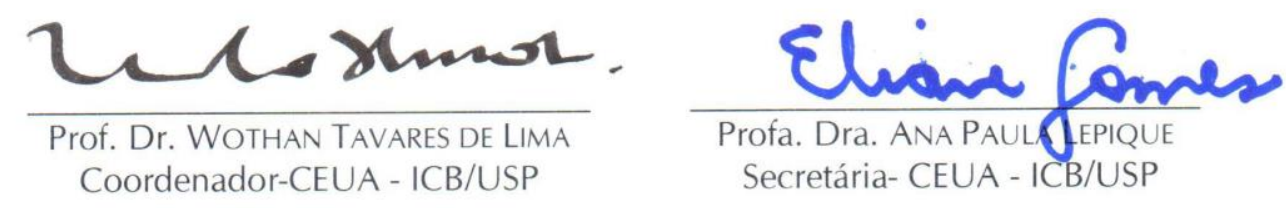
Aos meus lindos e amáveis pais 


\section{Agradecimentos}

Gostaria de agradecer a espiritualidade, aos espíritos de luz, aos nossos mentores e anjos guardiões que me ampararam durante toda esta jornada! À Deus, por permitir que todos Eles cuidem de mim hoje e sempre! Gostaria de agradecer aos meus amigos que tornaram o início da vida em São Paulo mais amena, Jatobá, Matheus (veterano favorito), minha amada amiga Jacu, Gladstone, Lú Medina e Dona Jandira!

Amandão, muito obrigada pelos ensinamentos científicos! Obrigada por me ensinar tudo, por me atender sempre com tanta paciência e atenção, por contar inúmeros macrófagos peritoneais e nunca perder o bom humor! Obrigada por deixar os dias mais leves!

Laure, Amandinha e Tia Cátia, amorecos lindos, obrigada pelos inúmeros momentos de ajuda e risadas!

Hosana e Marco, obrigada pelas orientações e confiança depositada!

Maysinha e Roberts, obrigada por surgirem em nossas vidas e torna-las mais divertidas!

Mit e Takeo, obrigada por deixarem nossa mesa de estudo mais divertida, com assuntos científicos interessantes e não-científicos muito mais interessantes, fizeram toda a diferença nestes anos!

Carol, sua meiguice e seus alunos excepcionais, Eduardo, Mateus e Cláudio, deixam o laboratório especial! Gil, obrigada pelo cuidado especial conosco, pelos cafés e bolos com gostinho de carinho!

Tati, obrigada por me atender sempre, me ouvir e me ajudar nos momentos tensos!

Bobzitcho, obrigada pela disponibilidade de ajudar sempre, em especial com os animais!

Às novatas que já fazem tanta diferença Frhan e Joice! Obrigada meninas pelos papos bons de fim de tarde! Aos meus amigos de laboratório, muito obrigada!!!

Obrigada aos amigos que fizeram a diferença durante o estágio na Alemanha, Wei Wang, Guddi, Olivia, Pia, Max,Victor, Juan e ao supervisor por ter nos recebido, Eicke Latz! Vielen Dank!

Secretarias de Pós-graduação, Zé Maria, Paloma e Eni, obrigada pelas dicas, prazos e dedicação!

Aos amigos lindos que ganhei de presente de Deus nos últimos anos, Reinaldo, Rê, Bia, Felizardo, Marquinhos, Marcela, Cris, Amanda, Valença, Rosana e nossa princesa Teresa. Obrigada por existirem! A eterna tropa da Imuno-Hemocentro Ribeirão, Ju Ueda, Furinhus, Craúdio e o para sempre Barba! Gostaria de agradecer nosso eterno Dr. Júlio César Voltarelli que sempre nos ensinou a verdadeira razão de estudar e fazer ciência, de maneira simples e solidária!

Professor Rui, o mestre que tive o privilégio de conviver durante estes anos e de aprender todos os dias!

Professor, obrigada por me acolher no seu laboratório, por ouvir minhas idéias e torná-las possíveis!

Mamis e Papis, meus dois exemplos de vida, amor, entrega, disciplina, justiça! Obrigada por vocês sempre estarem de braços abertos em Umuarama, nesse pedacinho de céu onde eu encontro aconchego e paz! Obrigada por apoiarem meus sonhos! Obrigada por me amarem tanto! Amo vocês!

Jú, o irmão espiritualmente destinado a mim! Obrigada por ser você! Alegria que contagia! Te amo!

Tárcio, meu marido lindo que eu tanto amo! Meu amigo que sempre esteve e está ao meu lado!

Obrigada por me acalmar, por me fazer sorrir, por me fazer feliz todos os dias, mesmo que eu esteja triste! Seu coração é lindo, e eu gostaria de agradecer por você deixar eu cuidar dele! Cuidarei a vida toda! AMO! 
Obrigada ao Conselho Nacional de Desenvolvimento Científico e Tecnológico (CNPq,), processo 161731/2012-0 pelo apoio financeiro durante o desenvolvimento de Projeto.

Obrigada FAPESP e CAPES. 
Feliz aquele que transfere o que sabe e aprende o que ensina. Cora Coralina

Algo só é impossivel até que alguém duvide e prove o contrário. Albert Einstein 


\section{RESUMO}

Davanso, M.R. Efeitos dos ácidos graxos na função de macrófagos de camundongos com diabetes tipo I induzido. [Tese (Doutorado em Fisiologia Humana)]. São Paulo; Instituto de Ciências Biomédicas, Universidade de São Paulo; 2017.

O diabetes mellitus tipo I (DMI) é uma doença crônica autoimune caracterizada por hiperglicemia devido à destruição das células beta pancreáticas produtoras de insulina. As consequências do diabetes tipo I e os efeitos dos ácidos eicosapentaenóico (EPA) e docosaexaenóico (DHA) na função de macrófagos peritoneais residentes foram investigadas. O quadro de DMI foi induzido por injeção via intraperitoneal de baixas doses de estreptozotocina (STZ) em camundongos C57BL/6 machos. Os animais foram divididos em controles (B6) e diabéticos tipo I (B6+STZ). Ao final de 30 dias da indução do diabetes, os animais foram eutanasiados para coleta de macrófagos do peritônio. Os macrófagos dos animais diabéticos apresentaram aumento de RNAm de citocinas e quimiocinas inflamatórias, da secreção de óxido nítrico, expressão de NLRP3, iNOS e PARP1 e da atividade da via glicolítica quando comparados aos dos animais controles. Perfil pró-inflamatório também foi observado em macrófagos peritoneais de animais NOD (non-obese diabetic). Enquanto que amostras do fígado e músculo sóleo não apresentaram sinais de inflamação. Os macrófagos obtidos de animais diabéticos e controles foram cultivados por 24 horas na presença dos ácidos: palmítico (PA, $100 \mu \mathrm{M})$, DHA, $25 \mu \mathrm{M}$ ou EPA, $25 \mu \mathrm{M}$. O DHA atenuou o perfil inflamatório dos macrófagos de animais diabéticos conforme indicado por diminuição da produção de NO e da expressão de citocinas pró-inflamatórias. Em macrófagos de animais controles, por outro lado, o DHA apresentou efeito pró-inflamatório como indicado pela expressão gênica de marcadores. Camundongos diabéticos deficientes em NLRP3 (NLRP3 KO) apresentaram diminuição na expressão de iNOS, PARP1 e na produção de $\mathrm{NO}$ em relação aos macrófagos dos animais diabéticos selvagens. $\mathrm{O}$ estado diabético tipo I influenciou o perfil dos macrófagos peritoneais residentes, causando aumento na produção de NO, via NLRP3-PARP1-iNOS, expressão de citocinas pró-inflamatórias, receptores de quimiocinas e da atividade glicolítica. $\mathrm{O}$ tratamento com DHA ex-vivo reverteu este perfil e atenuou o quadro pró-inflamatório.

Palavras-chave: Diabetes mellitus tipo I. Estreptozotocina. Macrófago. Inflamação. Ácidos graxos. Ômega-3. DHA. 


\begin{abstract}
Davanso, M.R. Effects of fatty acids in macrophage function from type I diabetic mice. [Ph. D. Thesis (Human Physiology)]. São Paulo; Instituto de Ciências Biomédicas, Universidade de São Paulo; 2017.
\end{abstract}

Type I diabetes mellitus (DMI) is a chronic autoimmune disease characterized by hyperglycemia due to the destruction of insulin-producing pancreatic beta cells. The consequences of hyperglycemia and the effects of eicosapentaenoic acid (EPA) and docosahexaenoic acid (DHA) on resident peritoneal macrophages were investigated. DMI was induced by intraperitoneal injection of low doses of streptozotocin (STZ) in male C57BL/6 mice. Mice were divided into control (B6) and type I diabetic (B6 + STZ) groups. At the end of 30 days after diabetes induction, the animals were euthanized to collect peritoneal macrophages. Macrophages from diabetic animals had increased expressions of inflammatory cytokines and chemokines, secretion of nitric oxide, expression of NLRP3, iNOS and PARP1, and glycolytic activity compared to the cells from control animals. Proinflammatory features was also observed in peritoneal macrophages of NOD (non-obese diabetic) animals. Liver and soleus muscle did not exhibit inflammation. Macrophages were cultured for 24 hours in the presence of palmitic acid $(\mathrm{PA}, 100 \mu \mathrm{M}), \mathrm{DHA}, 25 \mu \mathrm{M}$ or EPA, $25 \mu \mathrm{M})$. DHA attenuated the inflammatory state of macrophages from diabetic mice by reducing NO production and expression of proinflammatory cytokines. On the other hand, DHA had a proinflammatory effect on macrophages from control animals as indicated by the expression of inflammatory markers. Macrophages from NLRP3 deficient diabetic mice (NLRP3 KO) had decreased expression of iNOS, PARP1 and of NO production when compared to cells from wild type animals. The type I diabetic state led to a proinflammatory feature in resident peritoneal macrophages by increasing NO production, via the NLRP3-PARP1-iNOS pathway, expressions of proinflammatory cytokines, chemokine receptors and glycolytic activity. In contrast, ex-vivo treatment with DHA reversed this profile and attenuated the proinflammatory state.

Keywords: Type I diabetes mellitus. Streptozotocin. Macrophage. Inflammation. Fatty acids. Omega-3. DHA. 


\section{LISTA DE FIGURAS}

Figura 1. Evolução da glicemia, massa corporal e insulinemia após 30 dias da indução de diabetes. ........35

Figura 2. Expressão gênica de citocinas e receptores em macrófagos residentes peritoneais de animais controles ou diabéticos.

Figura 3. Ocorrência de macrófagos peritoneais residentes M1 e M2 em animais controles (B6) ou diabéticos (B6+STZ).

Figura 4. Expressão gênica de Il1a, Il1b e Il33 em macrófagos residentes peritoneais de animais controles (B6) ou diabéticos (B6+STZ).

Figura 5. Expressão gênica de quimiocinas em macrófagos residentes peritoneais de animais controles (B6) ou diabéticos (B6+STZ).

Figura 6. Expressão gênica dos receptores de quimiocinas em macrófagos residentes peritoneais de animais controles (B6) ou diabéticos (B6+STZ).

Figura 7. Taxa de acidificação extracelular (A), avaliação da glicólise (B), capacidade glicolítica (C) e da reserva glicolítica (D) nos macrófagos peritoneais residentes de animais C57BL/6 controles e diabéticos.

Figura 8. Atividade citotóxica dos ácidos palmítico (A), eicosapentaenóico - EPA (B) e docosaexaenóico -

DHA (C) em macrófagos residentes obtidos do peritônio de animais controles. ....................................46

Figura 9. Produção de óxido nítrico (NO), IL-1 $\beta$ e IL-6 pelos macrófagos peritoneais residentes de animais controles (B6) e diabéticos (B6+STZ) após tratamento com EPA, DHA ou PA. ..................................48

Figura 10. Expressão gênica de citocinas pró-inflamatórias de macrófagos residentes peritoneais de animais controles e diabéticos tratados com LPS e/ou DHA.

Figura 11. Expressão gênica de quimiocinas de macrófagos residentes peritoneais de animais controles e diabéticos

Figura 12. Expressão gênica dos receptores de quimiocinas em macrófagos residentes do peritônio de animais controles e diabéticos.

Figura 13. Heat map representativo da placa de PCR array dos macrófagos dos animais controles e

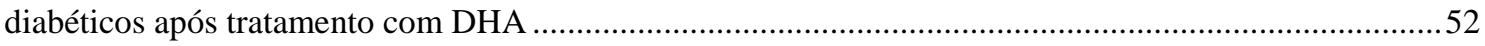

Figura 14. Evolução da glicemia, massa corporal e concentração de insulina e AGEs no soro após 30 dias da indução de diabetes...............................................................................................................53 Figura 15. Quantificação de citocinas e quimiocinas no soro dos animais C57BL/6, NLRP3 KO e RAGE KO após 30 dias da indução de diabetes. .......................................................................................54 Figura 16. Quantificação de citocinas e quimiocinas no meio de cultura de células nucleadas da medula óssea dos animais C57BL/6, NLRP3 KO e RAGE KO após 30 dias de diabetes. ...................................55 Figura 17. Quantificação de nitrito, citocinas e quimiocinas pelos macrófagos peritoneais dos animais C57BL/6, NLRP3 KO e RAGE KO após 30 dias da indução de diabetes. ...........................................57 Figura 18. Expressão da iNOS pelos macrófagos dos animais C57BL/6 e NLRP3 KO após 30 dias da

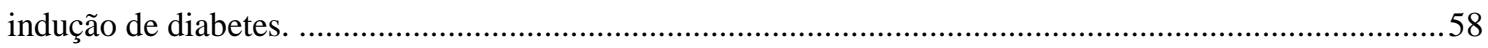
Figura 19. Expressão de NLRP3 nos macrófagos dos animais C57BL/6 e NLRP3 KO após 30 dias da

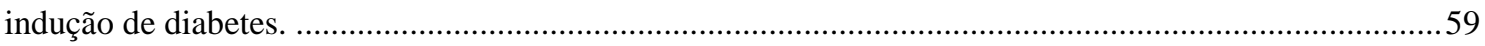
Figura 20. Expressão de PARP1 nos macrófagos dos animais C57BL/6 ou NLRP3 KO após 30 dias da

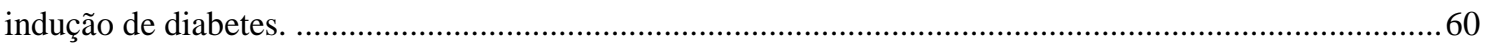
Figura 21. Mecanismos envolvidos na indução do estado inflamatório em macrófagos de camundongos com DMI. 


\section{LISTA DE TABELAS}

Tabela 1. Efeitos do diabetes após 30 dias da indução por administração de estreptozotocina sobre a massa do fígado, atividade da ALT e da AST no soro e concentração de TNF- $\alpha$, IL-6 e IL-1 $\beta$ no fígado de animais controle (WT) e diabéticos (D).

Tabela 2. Efeitos do diabetes após 30 dias da indução por administração de estreptozotocina na expressão gênica de IL-1 $\beta$, IL-6, TNF- $\alpha$, F4/80, MCP-1, CAT, GPX, SOD-1 e SOD-2 no fígado dos animais controles (B6) e diabéticos (B6+STZ).

Tabela 3. Efeitos do diabetes após 30 dias da indução na expressão gênica de IL-1 $\beta$, IL-6, TNF- $\alpha$, F4/80, MCP-1, CAT, GPX, SOD-1 e SOD-2 no músculo sóleo dos animais controles (WT) e diabéticos (D)... 38 Tabela 4. Resumo dos efeitos do diabetes após 30 dias da indução na expressão gênica de IL-1 $\beta$, IL-6, TNF$\alpha$, F4/80, MCP-1, CAT, GPX, SOD-1 e SOD-2 no fígado e músculo sóleo dos animais diabéticos.

Tabela 5. Relação de genes diferencialmente expressos de macrófagos de animais diabéticos sem estímulo em relação às células de animais controles também sem estímulo. .42

Tabela 6. Relação dos genes diferencialmente expressos de macrófagos de animais diabéticos tratados com LPS em relação às células de animais controles também tratados com LPS.

Tabela 7. Relação de genes diferencialmente expressos em macrófagos de animais controles tratados com DHA e LPS em relação às células de animais controles tratados somente com LPS. 50

Tabela 8. Relação de genes diferencialmente expressos em macrófagos de animais diabéticos tratados com DHA e LPS em relação às células de animais diabéticos tratados somente com LPS. 51

Tabela 9. Resumos dos efeitos do tratamento ex-vivo com DHA em relação ao tratamento com LPS .... 60 
AGEs

ALT

AST

CAT

DAMPs

DHA

DMI

EPA

GLUT

GPX

HBA1c

ICAM

iNOS

LPM

$\mathrm{NO}$

NOD

PA

PARP1

PPRs

RAGE

ROS

SOD

SPM

STZ

VCAM produtos finais de glicação avançada

alanina aminotransferase

aspartato aminotransferase

catalase

padrões moleculares associados a perigo

ácido docosaexaenóico

diabetes mellitus tipo I

ácido eicosapentaenóico

transportador de glicose

glutationa peroxidase

hemoglobina glicada

molécula de adesão intercelular-1

óxido nítrico sintase induzível

macrófago peritoneal grande

óxido nítrico

diabético não-obeso

ácido palmítico

Poli (ADP-ribose) polimerase-1

receptores de reconhecimento padrão

receptor de $\mathrm{AGE}$

espécie reativa de oxigênio

superóxido dismutase

macrófago peritoneal pequeno

estreptozotocina

molécula de adesão celular-vascular-1 


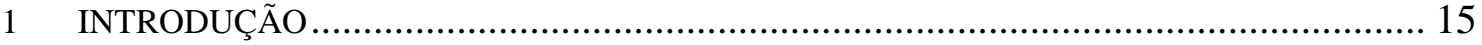

1.1 Diabetes mellitus tipo $\mathrm{I}$..................................................................................................15

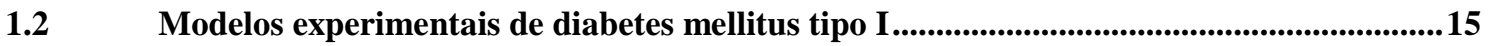

1.3 Componentes pró-inflamatórios no DMI......................................................................11

1.4 Ativação de NLRP3 e diabetes mellitus tipo I ............................................................................19

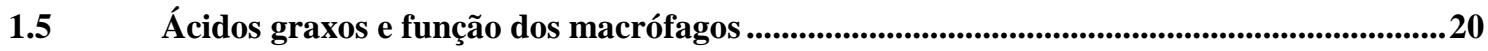

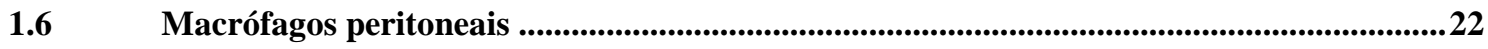

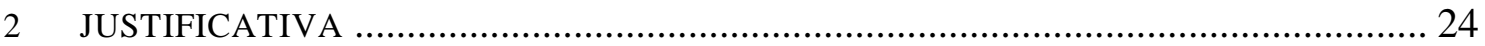

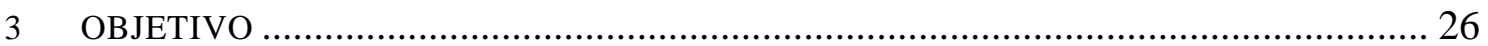

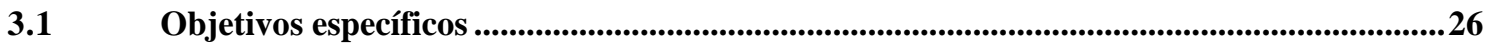

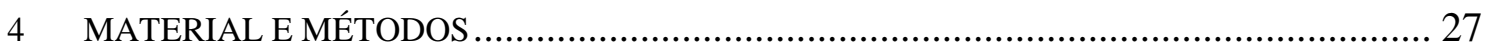

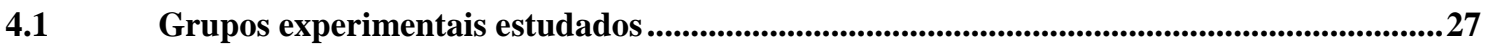

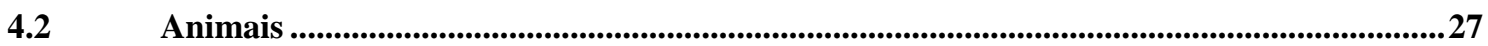

4.3 Modelo experimental de diabetes mellitus tipo I quimicamente induzido por

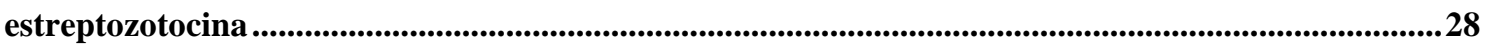

4.4 Modelo de diabetes mellitus tipo I desenvolvido espontaneamente nos camundongos NOD

4.5 Monitoramento da glicemia e da massa corporal dos animais..........................................28

4.6 Isolamento dos macrófagos da cavidade peritoneal dos camundongos ................................29

4.7 Determinação de óxido nítrico (NO) ...........................................................................29

4.8 Determinação de citocinas pró- e anti-inflamatórias ........................................................29

4.9 Determinação das atividades das enzimas hepáticas no soro ...............................................30

4.10 Determinação da expressão gênica de citocinas e enzimas antioxidantes no músculo sóleo,

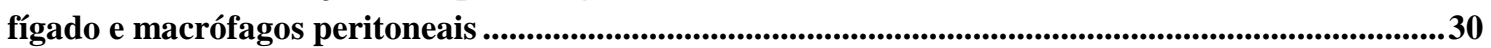

4.11 Imunofenotipagem dos macrófagos ..................................................................................31

4.12 Viabilidade celular ...........................................................................................................3 31

4.13 Tratamento dos macrófagos com os ácidos graxos para avaliação da produção de NO e

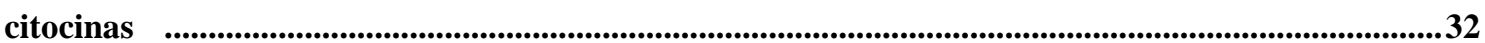

4.14 Tratamento com DHA para avaliação da expressão de genes associadas à resposta

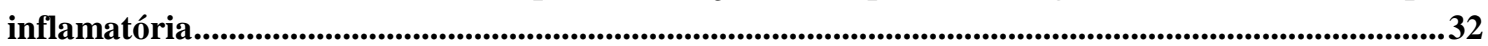

4.15 Preparação de RNA de macrófagos obtidos da cavidade peritoneal ....................................332

4.16 Determinação da expressão gênica por PCR Array .............................................................332

4.17 Taxa de acidificação extracelular (ECAR) ......................................................................33

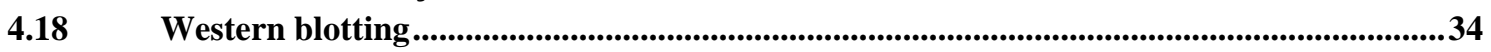

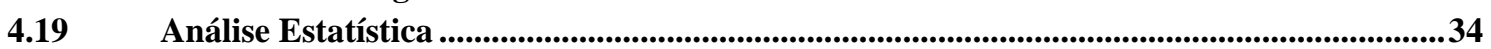

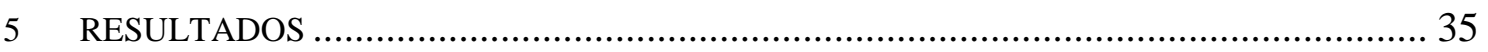

5.1 Caracterização do modelo de diabetes mellitus tipo 1 em camundongos C57BL/6 quimicamente induzido por administração de estreptozotocina ..............................................35

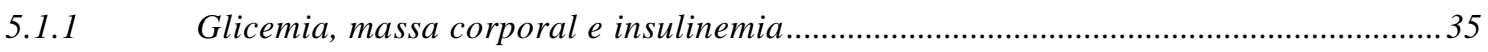

5.1.2 Avaliação de parâmetros metabólicos, expressão de citocinas inflamatórias e enzimas

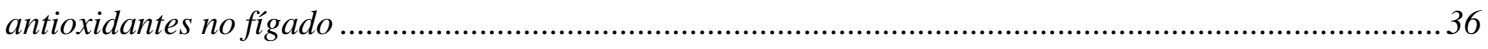

5.1.3 Avaliação da expressão gênica de citocinas inflamatórias e de enzimas antioxidantes no

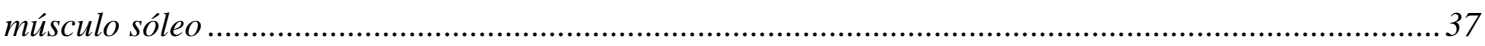

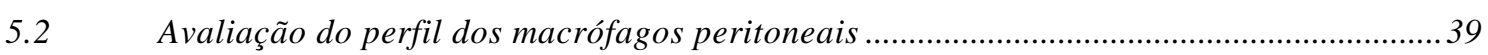

5.2.1 Análise da expressão gênica em macrófagos peritoneais de animais controles e

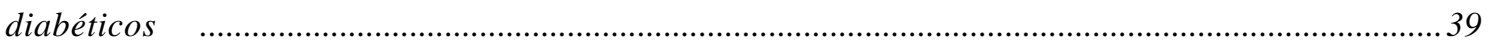

5.2.2 Caracterização imunofenotípica de macrófagos residentes peritoneais em animais

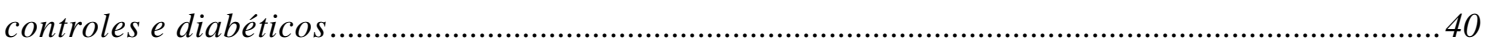

5.2.3 Análise da expressão gênica de citocinas, quimiocinas e receptores de quimiocinas por

PCR array dos macrófagos peritoneais de animais diabéticos .........................................................40 
5.3 Determinação do fluxo glicolítico em macrófagos peritoneais obtidos de animais

C57BL/6 diabéticos .........................................................................................................................45

5.4 Determinação da dose não tóxica dos ácidos palmítico, EPA e DHA para macrófagos

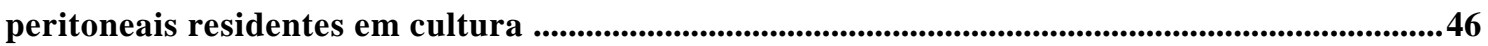
5.5 Avaliação da função dos macrófagos de animais diabéticos após tratamento com os ácidos palmítico, EPA e DHA em cultura.

5.5.1 Determinação do NO e citocinas inflamatórias secretados por macrófagos obtidos de animais controles ou diabéticos após tratamento com os ácidos graxos em cultura por 24 horas .. 47 5.5.2 Análise da expressão gênica de citocinas, quimiocinas e receptores de quimiocinas em macrófagos peritoneais de animais controles ou diabéticos após tratamento com o DHA ................48 5.6 Caracterização do modelo de diabetes mellitus tipo 1 em camundongos C57BL/6, knockout para NLRP3 ou knockout para RAGE quimicamente induzido por administração de estreptozotocina

5.6.1 Glicemia, massa corporal, insulinemia e concentração de AGEs no soro dos animais knockout para NLRP3 ou knockout para RAGE ..................................................................................52 5.6.2 Avaliação das citocinas do soro dos animais diabéticos C57BL/6, NLRP3 knockout e RAGE knockout

5.6.3 Avaliação das citocinas produzidas pelas células nucleadas da medula óssea de animais diabéticos C57BL/6, NLRP3 knockout e RAGE knockout.

5.7 Avaliação da função dos macrófagos de animais diabéticos C57BL/6, NLRP3 knockout ou RAGE knockout após tratamento com DHA em cultura............................................56

5.7.1 Análise da produção de óxido nítrico, citocinas e quimiocinas nos macrófagos peritoneais de animais C57BL/6, NLRP3 KO e RAGE KO controles e diabéticos............................56

5.7.2 Análise da expressão de iNOS nos macrófagos peritoneais de animais C57BL/6 e

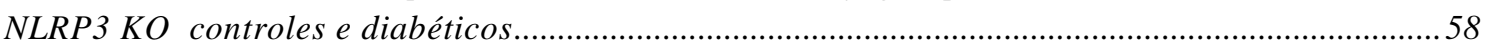

5.7.3 Análise da expressão de NLRP3 nos macrófagos peritoneais de animais C57BL/6

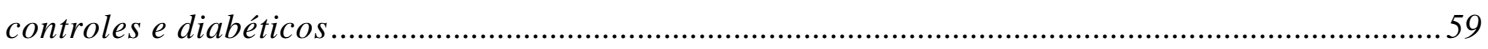

5.7.4 Análise da expressão de PARP1 nos macrófagos peritoneais de animais C57BL/6 e

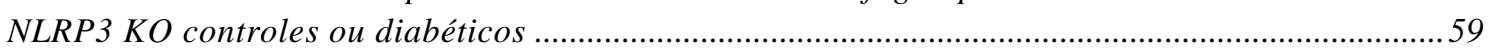

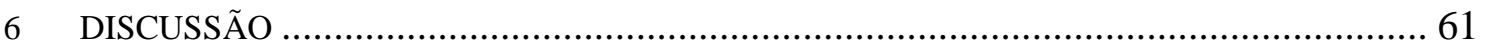

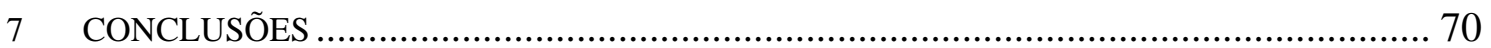

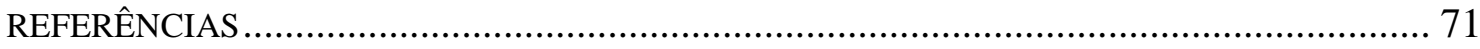

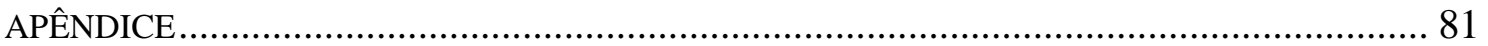

$A$ - Apêndice 1. Valores brutos referentes às tabelas e figuras da tese ...............................................81

B - Apêndice 2. Descrição resumida dos resultados encontrados na avaliação dos efeitos do diabetes mellitus tipo I em macrófagos peritoneais residentes dos animais NODs (non obese diabetic) ........113 C - Apêndice 3. Caracterização dos macrófagos residentes peritoneais e das condições de cultura utilizadas .116 


\section{INTRODUÇÃO}

\subsection{Diabetes mellitus tipo I}

O diabetes mellitus tipo I (DMI) origina-se da destruição de células beta pancreáticas produtoras de insulina por um processo autoimune crônico, seguida pelo quadro de hiperglicemia (1). No DMI, para o desenvolvimento da hiperglicemia, é necessário a associação de um conjunto de fatores, entre eles os fatores genéticos $(2,3)$ e ambientais (4-6).

Devido a susceptibilidade genética, a autoimunidade pode se desenvolver no início da vida (7), sendo possível detectar anticorpos contra insulina meses após o nascimento $(7,8)$. Embora o início do quadro autoimune seja prematuro, o desenvolvimento do DMI ocorre após muitos meses ou até mesmo anos (8).

Em humanos e modelos animais, macrófagos e células dendríticas são as primeiras a infiltrarem as ilhotas pancreáticas quando do estabelecimento da doença. Além de apresentarem antígenos das células $\beta$ aos linfócitos, uma vez ativados, os macrófagos produzem citocinas pró-inflamatórias (IL-1 $\beta$, IL-6 e TNF- $\alpha$ ) e óxido nítrico que contribuem para a destruição das células $\beta$ (9-12).

Além da participação dos macrófagos e células dendríticas na destruição das células pancreáticas, os linfócitos $\mathrm{TCD}^{+}, \mathrm{TCD}^{+}$e $\mathrm{B}$ são células encontradas no infiltrado inflamatório no pâncreas de pacientes diabéticos (13), sendo que as células $\mathrm{TCD}^{+}$citotóxicas formam o conjunto de células mais abundante encontradas no processo de insulite (processo inflamatório das ilhotas pancreáticas) $(14,15)$.

Dados epidemiológicos indicam que a incidência do DMI está aumentando com o passar dos anos $(16,17)$, e de acordo com estudo realizado entre 1989 e 2003, há uma estimativa de que o número de crianças com DMI menores que 5 anos irá duplicar entre 2005 e 2020 na Europa (18). O aumento crescente dos quadros de DMI sugere que fatores ambientes de risco estão sofrendo mudanças ao longo do tempo, de diferentes maneiras e em diversos países (19), arriscando cada vez mais a saúde das crianças e atuando como um dos gatilhos responsáveis pelo desenvolvimento do DMI.

\subsection{Modelos experimentais de diabetes mellitus tipo I}

Os animais NOD (non obese diabetic) foram desenvolvidos a partir do cruzamento de camundongos ICR (Institute of Cancer Research) que apresentavam cataratas (20). 
Inicialmente o cruzamento dos camundongos ICRs originavam duas linhagens, a primeira caracterizada pela presença de catarata (nomeados CTS, catarata de Shionogi); a segunda caracterizada pela ausência de catarata, utilizada como animais controles (NCT) (21). A partir da geração F6, os animais que apresentaram aumento da glicemia e não apresentavam catarata foram separados dos demais animais. Na geração F13, os animais que exibiram níveis normais de glicemia foram separados da linhagem hiperglicêmica. $\mathrm{E}$ por fim, na F20 as fêmeas desenvolveram espontaneamente o diabetes mellitus dependente de insulina (21) e foram nomeadas de NODs.

Desde o seu estabelecimento, a linhagem de camundongos NOD (20) é usada para estudar as características do diabetes autoimune experimental, pois assemelha-se clinicamente ao DMI de humanos. O início do diabetes ocorre entre 12 e 14 semanas após o nascimento em fêmeas e um pouco mais tarde nos machos. A maioria das células dos infiltrados inflamatórios são $\mathrm{T} \mathrm{CD}^{+}$, mas $\mathrm{T} \mathrm{CD}^{+}, \mathrm{NK}, \mathrm{B}$, dendríticas e macrófagos também podem ser observados (22). Em outro estudo, a inativação de macrófagos em camundongos NOD resultou em diminuição do processo de insulite no pâncreas, afetou a habilidade dos linfócitos $\mathrm{T}$ de se diferenciarem em células $\mathrm{T}$ citotóxicas e, consequentemente, evitou o quadro de diabetes (23). A função essencial dos macrófagos no início e durante a progressão do DMI gerando complicações da doença foi bastante estudada.

Além dos camundongos NOD, diabetes experimental pode ser induzido quimicamente pela administração de estreptozotocina (STZ). A STZ é um análogo da Nacetilglucosamina e foi primeiramente isolada do microorganismo Streptomyces achromogenes. Em altas doses, a STZ induz, quase que imediatamente após a injeção, hiperglicemia. Este composto é muito similar à molécula de glicose e pode ser transportado para o interior das células via proteína transportadora de glicose 2 (GLUT 2), mas não é reconhecida pelos demais transportadores de glicose. Isso explica a toxicidade sítio específica em células $\beta$, uma vez que esse tipo celular apresenta expressão elevada do GLUT 2. Entretanto, doses elevadas de STZ promovem citotoxicidade no fígado e rins. Esse efeito tóxico pode ser reduzido pela administração de pequenas e múltiplas doses de STZ. Nesse caso, a hiperglicemia torna-se levemente elevada após 5 dias da última injeção de estreptozotocina (24) e altamente elevada e estável após aproximadamente 12 dias da última dose de administração da droga (25-28). 
A evolução do diabetes no modelo quimicamente induzido com múltiplas doses de STZ é mediada por infiltrado precoce de macrófagos nas ilhotas, apresentação dos antígenos de ilhotas pancreáticas liberados pela ação da droga e recrutamento de células T $(29,30)$. A combinação de IFN- $\gamma$, TNF- $\alpha$, IL-1 $\beta$ e a geração de óxido nítrico pelos macrófagos causa danos à célula $\beta$ pancreática no diabetes induzido por múltiplas doses de STZ em ratos Dark Agouti (revisado por 31).

Fukuda e colaboradores (2008) observaram, em camundongos tratados com múltiplas doses de STZ, que um dia após a administração da última dose ocorre o pico de células $\beta$ pancreáticas em apoptose (32). Por sua vez, o $11^{\circ}$ dia caracteriza-se pelo pico de infiltrado inflamatório nas ilhotas e no $23^{\circ}$ dia observa-se perda drástica de massa das células $\beta$ e hiperglicemia sustentada (33). O diabetes induzido por STZ é mais pronunciado em machos C57BL/6 (linhagem de camundongo mais utilizada) do que em fêmeas da mesma linhagem (revisado por 25).

\subsection{Componentes pró-inflamatórios no DMI}

O nível elevado de glicose, consequente da falta de insulina, é apenas a fonte para a produção de fatores nocivos capazes de comprometer a função de alguns subtipos celulares durante o progresso do DMI. Dentre os compostos liberados após o estabelecimento do quadro hiperglicêmico, sabe-se que pacientes com DMI apresentaram aumento das concentrações de triglicérides e $\operatorname{LDL}$ (low-density lipoprotein) $(34,35)$ no plasma. Sendo que a oxidação do LDL na parede de vasos causa um processo inflamatório envolvendo danos de células endoteliais e recrutamento de monócitos (36).

Os altos níveis de glicose também são responsáveis pela formação de um grupo heterogêneo de compostos formados através da glicação não-enzimática de proteínas, lipídeos ou ácidos nucleicos, nomeados de AGEs (advanced glycation end products) (37, 38). A via clássica, conhecida como reação de Maillard (39), inicia-se com a união de um grupamento amina de uma proteína a um grupo carbonila de açúcar redutor, fomando a base de Schiff instável (40). Uma vez formada, a base de Schiff sofre rearranjos, tornando-se mais estável e nomeado de produtos de Amadori, como exemplo, a hemoglobina glicada (39). Os produtos de Amadori possuem grupos carbonilas ativos, que podem se condensar com grupos de aminas, dando origem aos produtos avançados da reação de Maillard, os AGEs (40). 
Os AGEs se ligam a diferentes receptores celulares, entre eles o RAGE (41). O RAGE pode ser expresso nas membranas das células endoteliais, mesangias, monócitos, macrófagos e neurônios (42). Após a interação RAGE-AGE é possível observar a ativação das vias de sinalização MAP (mitogen-activated protein) quinase e NF-кB (43); e o aumento da produção de ROS (espécies reativas de oxigênio) $(43,44)$.

Desse modo, a presença de AGEs contribui para a patogênese das complicações diabéticas através de diferentes mecanismos. Primeiramente, as proteínas intracelulares modificadas por AGEs tem sua função alterada, os componentes da matrix extracelular modificados por precursores de AGEs interagem de forma não-convencional com receptores (integrinas) em outras células, e por fim, os AGEs se ligam aos receptores em macrófagos ativando fatores de transcrição responsáveis pelo aumento de fatores próinflamatórios (45).

Além da hiperglicemia produzir componentes capazes de induzir um processo inflamatório em macrófagos, este quadro também é capaz de impedir que os macrófagos exerçam apropriadamente suas funções principais. A relação entre alterações na função de macrófagos e DMI foi primeiramente descrita em camundongos NODs. Foi observada redução na capacidade de fagocitar células apoptóticas $(46,47)$ e neutrófilos infectados (48) em macrófagos de camundongos diabéticos comparados aqueles de camundongos não diabéticos.

Também, em camundongos NODs, foi observada diminuição no recrutamento de macrófagos, células dendríticas e monócitos para sítios artificialmente inflamados em camundongos diabéticos (49). Macrófagos de camundongos com DMI induzido por baixas doses de estreptozotocina apresentaram alteração do número, fenótipo, capacidade de apresentação de antígeno $(50,51)$, diminuição da capacidade de fagocitose $(52,53)$. 


\subsection{Ativação de NLRP3 e diabetes mellitus tipo I}

Entre os receptores inatos, os inflamassomas são importantes para a ativação da família das citocinas IL-1. NLR (Nucleotide-binding domain, leucine-rich repeat containing protein) é um grupo de proteínas intracelulares que regula a inflamação.

Entre as NLRs, o NLRP3 tem um amplo espectro de ação. O inflamassoma NLRP3 é um dos complexos da família NOD-like receptors (NLRs) responsáveis pelo controle da clivagem de pró-IL-1 $\beta$ e pró-IL-18 em formas secretadas bioativas por ação da caspase-1 (54). A ativação do NLRP3 ocorre quando há dano tecidual, como na presença de patógenos $(55,56)$, sendo que o processo de ativação de NLRP3 é dependente de dois sinais. O primeiro, denominado de "priming step", é mediado por receptores de reconhecimento padrão (PPRs) ou receptores de citocinas que ativam o fator nuclear $\kappa \mathrm{B}$

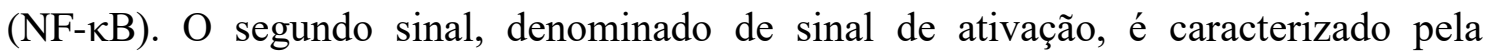
produção de ATP, cristais, danos lisossomais e efluxo de potássio, entre outros (57).

A ativação do inflamassoma NLRP3 (NLR Pyrin-domain-containing 3) está aparentemente envolvida na patogênese dessas doenças e atua como sensor de sinais metabólicos, DAMPs (danger-associated molecular patterns) (55), que estão presentes nos tecidos inflamados. A quebra da homeostase metabólica, observada no DMII, resulta em aumento da concentração de glicose e ácidos graxos saturados na circulação e nos órgãos (58), os quais podem ativar NLRP3 em macrófagos via ROS sendo dependente de AMPK (59, 60). Cristais de sílica ou ácido úrico (61), adenosinas extracelulares, componentes da matriz extracelular, toxinas também ativam o inflamassoma NLRP3 (62, $63)$.

Durante o desenvolvimento das doenças metabólicas (64), incluindo diabetes mellitus do tipo II (65), obesidade (66), aterosclerose (67) e gota (61), é possível observar ativação do inflamassoma NLRP3. Devido a importante relação observada entre ativação de NLRP3 e doenças metabólicas, o estabelecimento e as complicações do DMI podem estar intimamente relacionados com este quadro. De fato, foi demonstrado que a deficiência de NLRP3 em animais NOD previne o desenvolvimento de DMI e diminui a migração de células T para as ilhotas pancreáticas (68). 


\section{5 Ácidos graxos e função dos macrófagos}

Os estudos sobre a influência dos ácidos graxos na função imunológica passaram a ser mais intensamente realizados no início da década de 1970 (69). Os efeitos observados foram atribuídos, em sua maior parte, a modificações das membranas plasmáticas dos leucócitos. De fato, os ácidos graxos são importantes constituintes dos fosfolipídios que compõem as membranas celulares (70). Por outro lado, os ácidos graxos controlam a resposta inflamatória por alteração da síntese de mediadores lipídios com 20 átomos de carbonos e várias insaturações, os eicosanoides (3). Os eicosanoides, prostaglandinas (PGs), tromboxanos (TXs) e leucotrienos (LTs), controlam a intensidade e a duração das respostas inflamatórias atuando em diferentes subtipos celulares tais como: macrófagos, células dendríticas, linfócitos T e eosinófilos $(71,72)$.

O precursor dos eicosanoides é o ácido araquidônico (AA), um ácido graxo de 20 átomos de carbono e quatro duplas ligações na cadeia, além de ser um componente importante da membrana celular (73). Animais de laboratório mantidos em dieta padrão apresentam quantidades elevadas de ácido araquidônico e baixas de ácidos graxos $\omega$-3 $(74,75)$ na membrana plasmática de macrófagos. Esta relação pode ser modificada conforme a composição lipídica da dieta (75) ou adição de ácidos graxos ao meio de cultura (76).

Os ácidos graxos são composto orgânicos com cadeias de carbonos que podem ser saturadas ou insaturadas. Os ácidos graxos insaturados apresentam duplas ligações entre carbonos e as denominações "omega-3", "omega-6" e "omega-9" referem-se à localização da última dupla ligação a partir do hidrocarboneto final (77).

Ácidos graxos $\omega$-3 (omega-3) de cadeias longas e com número elevado de insaturações (ácidos graxos poliinsaturados, PUFAs), como os ácidos eicosapentaenóico (EPA, 20:5) e docosaexaenóico (DHA, 22:6), não são encontrados nos óleos vegetais. As fontes mais importantes de EPA e DHA são os peixes marinhos de águas frias, como, por exemplo, salmão, arenque, atum, sardinha, tainha e cavala (78). EPA e DHA são precursores de resolvinas e protectinas, mediadores lipídicos anti-inflamatórios, que atuam por meio das vias que envolvem as enzimas cicloxigenase e lipoxigenase (79-81). Os PUFAs $\omega-3$ também apresentam efeitos benéficos em pacientes com doenças associadas à inflamação tais como: reduzem o risco de doenças coronarianas $(82,83)$ e diminuem a incidência de diabetes mellitus do tipo II (84). 
O ácido palmítico (16:0) é um dos ácidos graxos saturados de cadeia longa mais abundante no organismo de mamíferos. É encontrado em diversos alimentos de origem animal, dentre eles, gordura da carne, ovos, leite e seus derivados. Os ácidos graxos saturados estão associados ao ganho de massa corporal, inflamação, riscos de desenvolver doenças cardiovasculares e síndrome metabólica (85). Camundongos alimentados com dieta contendo gordura rica em ácidos graxos saturados apresentam número aumentado de células $\mathrm{TCD}^{+}(86)$ e de linfócitos ativados além de conteúdo elevado de IFN- $\gamma$ no tecido adiposo (87). Assim, os ácidos graxos saturados são bem conhecidos pelos seus efeitos pró-inflamatórios.

Em contrapartida, os PUFAs $\omega-3$, conforme mencionado acima, apresentam efeitos anti-inflamatórios. Evidências sobre esses efeitos foram obtidas em culturas de células tratadas com EPA e DHA. EPA e DHA inibem a produção de IL-1 $\beta$ e TNF- $\alpha$ em monócitos (88), TNF- $\alpha$ e IL-6 por macrófagos murinos (89) e de IL-6 e IL-8 por células endoteliais $(90,91)$. Dieta rica em óleo de peixe (rico em EPA e DHA) diminui a produção ex-vivo de IL-1 $\beta$, TNF- $\alpha$ e IL-6 por macrófagos de camundongos (92-94). Além dos estudos em modelos animais, dietas ricas em óleo de peixe também causam diminuição da produção de IL-1 $\beta$, TNF- $\alpha$ e IL-6 por células mononucleares de humanos (95-97).

Alguns mecanismos foram propostos para explicar os efeitos anti-inflamatórios dos PUFAS omega-3 durante a sinalização via NF-кB (98). Um deles, GPR120 (G proteincoupled receptor for long-chain unsaturated fatty acids), recentemente nomeado de receptor de ácido graxo livre 4 (FFA4), quando ativado por ômega-3 é internalizado e liga-se a beta arrestina 2 ( $\beta$-arrestin 2$)(99,100)$. O complexo formado por GPR120 e beta-arrestina 2 sequestra a proteína TAB1 (TGF-beta activated kinase 1 binding protein 1), impedindo a ativação da via NF-кB e subsequentes eventos inflamatórios (101). Outra via utilizada pelos PUFAS omega-3 para conter o processo inflamatório ocorre através da inibição da ativação do inflamassoma NLRP3 $(101,102)$. O tratamento de macrófagos com DHA inibiu a ativação de caspase-1 e a subsequentemente a secreção de IL-1 $\beta$ (101, 103). 


\subsection{Macrófagos peritoneais}

Os macrófagos são células encontradas na maioria dos tecidos no corpo, onde assumem fenótipos e funções distintas de acordo com o ambiente. Os macrófagos teciduais são considerados células sentinelas devido a sua localização estratégica e sua habilidade de iniciar as respostas imunológicas durante infecção patogênica ou dano tecidual, e para contribuir com a manutenção da homeostase do tecido $(104,105)$.

Eles continuam sendo amplamente estudados mesmo após um século do Prêmio Nobel de Fisiologia e Medicina ter sido conferido a Ilya Mechnikov, por descobrir a função de fagocitose do macrófago $(106,107)$. Os macrófagos são células efetoras do sistema imunológico e atuam em três funções importantes: fagocitose, defesa do hospedeiro e remodelamento tecidual (107).

O estudo de macrófagos peritoneais foi iniciado por Cohn e colaboradores (108, 109) na década de 1960 para investigação dos mecanismos de defesa da cavidade peritoneal frente a infecção pelos Staphilococcus aureus e Staphilococcus albus. Recentemente foi descrito a existência de dois subtipos de macrófagos peritoneais (110). Estes macrófagos foram identificados de acordo com o seu tamanho: LPM (large peritoneal macrophage) e SPM (small peritoneal macrophage). Os LPMs constituem aproximadamente $90 \%$ dos macrófagos da cavidade peritoneal em animais não estimulados, mas praticamente desaparecem após o estímulo com LPS. Esta células apresentam altos níveis de expressão de marcadores de superfície clássicos CD11b e F4/80 (110) e o fator de transcrição GATA-6 responsável pela manutenção destas células na cavidade peritoneal (111). Já os SPMs predominam na cavidade peritoneal após o estímulo com LPS, e expressam níveis menores de clássicos CD11b e F4/80. Ambos apresentam capacidade de fagocitose e produção de NO in vivo (110).

Os dois subtipos de macrófagos encontrados na cavidade peritoneal apresentam origem distintas. Os SPMs são gerados a partir de células tronco hematopoiéticas na medula óssea através da diferenciação de monócitos (110). Enquanto os LPMs aparentam ser originados do saco vitelino, independente de progenitores hematopoiéticos (112) e são mantidos através de auto renovação (113).

Sobre condições de homeostasia, a cavidade peritoneal é composta por macrófagos, células B-1, células convencionais B-2, células T, células dendríticas, células natural killers e granulócitos $(110,114)$. As células B1 fazem partem predominante da 
população na cavidade peritoneal, enquanto os LPMs e SPMs representam de 30-35\% da população $(110,114)$. Contudo, depois de um processo inflamatório ou infecioso, pode ocorrer uma dramática alteração celular no compartimento peritoneal.

A relação entre o fenótipo funcional e o meio ambiente em que os macrófagos se encontram está sendo amplamente discutida (115). O macrófago após diferentes estímulos (ex. LPS, IFN- $\gamma$ ) apresenta modificação marcante no consumo de glicose, glutamina e na liberação de lactato e glutamato (116). A ativação de Toll-like receptor 4 muda o perfil metabólico do macrófago com alta atividade da fosforilação oxidativa para preponderantemente glicolítico (116-118). Por outro lado, o fluxo aumentado de glicose em macrófagos eleva a produção de IL-1 $\beta$ após tratamento com LPS (119), através da ativação do inflamassoma NLRP3 (120). 


\section{JUSTIFICATIVA}

Mudanças no estilo de vida resultaram em redução acentuada da atividade física, bem como em mudanças na dieta. Estas alterações estão correlacionadas com aumento na ocorrência de doenças metabólicas, tais como obesidade, aterosclerose e diabetes mellitus tipo II (DMII), as quais são iniciadas por ativação do sistema imune inato. Embora a ativação da imunidade inata evoluiu para proteger o hospedeiro contra os desafios microbianos e para reparar estruturas danificadas, cada vez mais torna-se evidente que o sistema imunológico inato é excessivamente ativado em muitas doenças que podem ter um componente inflamatório (revisado por 121).

Apesar do papel do NLRP3 estar envolvido em diferentes doenças inflamatórias, muito pouco foi descrito sobre o papel do NLRP3 no desenvolvimento do diabetes mellitus tipo I. Além disso, ainda não há evidências se o inflamassoma NLRP3 é a molécula responsável pelo perfil destas células encontradas no estado do DM1, sendo necessário determinar os DAMPs que efetivamente ativariam o NLRP3 durante a progressão do DMI.

Sabe-se que o estado diabético produz uma série de fatores com caráter próinflamatório, como ácidos graxos saturados e AGEs, além disso, alguns estudos relatam a capacidade de AGEs ativarem o inflamassoma NLRP3 e causar um estado próinflamatorio (122). Os macrófagos peritoneais são uma importante população e estão entre as populações de macrófagos mais estudadas em termos de biologia celular, desenvolvimento e resposta inflamatória (104).

Baseado neste cenário, os ácidos graxos influenciam processos inflamatórios por vários mecanismos, conforme descrito acima, incluindo alterações na composição e propriedades das membranas das células. Mudanças na composição de ácidos graxos podem alterar a fluidez da membrana e até mesmo a sinalização celular e a expressão gênica. As células envolvidas na resposta inflamatória são ricas em ácido araquidônico ( $\omega-6)$, mas o conteúdo deste pode ser modificado nas células pela administração oral de ácidos graxos (123).

Vários autores descreveram a modulação da função de macrófagos pelos ácidos graxos, em especial os PUFAs $\omega$-3 (124-128) e alterações nas funções dessas células em estados diabéticos. No presente estudo, propomos investigar os efeitos dos ácidos eicosapentaenóico (EPA) e docosaexaenóico (DHA) na reversão das alterações metabólicas e de função dos macrófagos obtidos de camundongos induzidos 
quimicamente ao diabetes tipo I. O ácido palmítico é sabidamente pró-inflamatório e foi usado como referência nesse estudo. 


\section{OBJETIVO}

O objetivo do estudo é o de investigar os efeitos do estado induzido pelo diabetes mellitus tipo I e dos ácidos eicosapentaenóico (EPA) e docosaexaenóico (DHA) na função de macrófagos peritoneais residentes obtidos de camundongos diabéticos tipo I.

\subsection{Objetivos específicos}

1. Avaliar os efeitos do estado diabético tipo I quimicamente induzido e mantido por 30 dias sobre o perfil inflamatório dos macrófagos peritoneais residentes;

2. Avaliar os efeitos do estado diabético tipo I quimicamente induzido e mantido por 30 dias sobre o fluxo glicolítico dos macrófagos peritoneais residentes;

3. Avaliar os efeitos do estado diabético tipo I quimicamente induzido e mantido por 30 dias sobre o perfil inflamatório do fígado e músculo sóleo;

4. Avaliar os efeitos do tratamento com os ácidos graxos (PA, EPA e DHA) em cultura (ex vivo) quanto as características fenotípicas, a produção de citocinas próinflamatórias e anti-inflamatórias, a expressão de genes associados à inflamação (citocinas, quimiocinas e receptores de quimiocinas) dos macrófagos peritoneais residentes de animais diabéticos;

5. Avaliar a participação do inflamassoma NLRP3 sobre o perfil inflamatório dos macrófagos peritoneais residentes dos animais diabéticos;

6. Esclarecer os mecanismos envolvidos pelos quais o estado diabético tipo I quimicamente induzido altera o perfil inflamatório do macrófago. 


\section{MATERIAL E MÉTODOS}

\subsection{Grupos experimentais estudados}

Os camundongos utilizados no presente estudo foram C57BL/6 e NOD (nonobese diabetic). Os camundongos C57BL/6 foram divididos em dois grupos: diabéticos tipo 1 induzidos por estreptozotocina (B6+STZ) e controles (B6). Completados 30 dias da indução do quadro diabético, os animais foram eutanasiados para posterior coleta de macrófagos do peritônio. Em seguida, os macrófagos foram cultivados em meios suplementados aos ácidos graxos (AGs): palmítico (PA), docosaexaenóico (DHA) ou eicosapentaenóico (EPA).

Os camundongos NODs foram divididos em dois grupos: NOD diabético (NOD D) e NOD não-diabético (NOD ND). Após serem considerados diabéticos, os animais foram eutanasiados, para posterior coleta de macrófagos do peritônio. Em seguida, os macrófagos foram cultivados na presença ou ausência de lipopolissacarídeo (LPS).

\subsection{Animais}

Camundongos C57BL/6 machos (6-8 semanas de idade) foram mantidos em sala com ciclo claro-escuro de 12-12 horas, temperatura de $23 \pm 2{ }^{\circ} \mathrm{C}$, com dieta comercial (ração Nuvital da Nuvilab, Colombo, PR) e água ad libitum durante e após a indução do diabetes. Todos os procedimentos desse estudo seguiram os princípios éticos de experimentação animal e foram submetidos e aprovados pelo Comitê de Ética em Experimentação Animal do Instituto de Ciências Biomédicas da Universidade de São Paulo, registrado sob $\mathrm{n}^{\mathrm{o}} 001$ nas fls. 02 do livro 03, em 19.02.2013, com validade de quatro anos.

Os camundongos NODs fêmeas, NLRP3 knockouts machos e RAGE knockouts machos foram mantidos na Haus für Experimentelle Therapie (HET), na Universidade de Bonn (Bonn, Alemanha). Camundongos NODs fêmeas (15-20 semanas de idade) foram avaliadas durante 63 dias para acompanhamento da evolução glicêmica. Foram mantidos em sala com ciclo claro-escuro de $12-12 \mathrm{~h}$, temperatura de $22 \pm 2^{\circ} \mathrm{C}$, com dieta comercial (ração Ssniff V153 x R/M-H, Soest, Alemanha). Todos os procedimentos desse estudo seguiram os princípios éticos de experimentação animal e foram submetidos e aprovados pelo Comitê de Ética Landesamt für Natur, Umwelt und Verbraucherschutz in North- 
Rhine Westfalia (LANUV-NRW), Alemanha, registrado sob nº 84.02.04.2016.A190, com validade de cinco anos.

\subsection{Modelo experimental de diabetes mellitus tipo I quimicamente induzido por estreptozotocina}

Após jejum de 8 horas, o quadro de diabetes foi induzido por administração intraperitoneal de 5 doses diárias e consecutivas (Sigma, St. Louis, MO, USA) de estreptozotocina (STZ, $42 \mathrm{mg}$ por kg de massa corporal). A STZ foi dissolvida em tampão citrato de sódio a 0,05 M gelado ( $\mathrm{pH} 4,0-4,5$ ) e usada em 15 minutos. Os animais foram considerados diabéticos quando apresentavam, após duas avaliações não consecutivas, glicemia com valores mais elevados que $250 \mathrm{mg} / \mathrm{dL}$ na ausência de jejum. Os animais controles receberam 5 doses diárias e consecutivas de tampão citrato de sódio a 0,05 M gelado ( $\mathrm{pH} 4,0-4,5)$.

\subsection{Modelo de diabetes mellitus tipo I desenvolvido espontaneamente nos camundongos NOD}

Camundongos fêmeas NODs foram acompanhados a partir $15^{\mathrm{a}}$ semana após seu nascimento até o desenvolvimento do diabetes, confirmado após duas avaliações não consecutivas, glicemia com valores mais elevados que $250 \mathrm{mg} / \mathrm{dL}$ sem jejum. Como controles, foram utilizados camundongos fêmeas NODs (da mesma ninhada) que não apresentaram valores mais elevados que $250 \mathrm{mg} / \mathrm{dL}$, na ausência de jejum, durante o período avaliado.

\subsection{Monitoramento da glicemia e da massa corporal dos animais}

A glicemia e a massa corporal dos camundongos quimicamente induzidos por estreptozotocina foram monitoradas semanalmente pela manhã, na ausência de jejum, durante 130 dias. A glicemia dos camundongos NODs foram monitoradas semanalmente durante 63 dias. Para tanto, uma gota de sangue foi retirada da extremidade da cauda de cada animal e a glicemia avaliada utilizando glicosímetro Accu-Check Active (Roche Diagnostics, Abbott Park, IL, USA). 


\subsection{Isolamento dos macrófagos da cavidade peritoneal dos camundongos}

Os animais C57BL/6 foram eutanasiados aos 30, 60, 90 e 120 dias da indução do quadro diabético. Os animais NODs foram eutanasiados após duas avaliações não consecutivas, glicemia com valores mais elevados que $250 \mathrm{mg} / \mathrm{dL}$ na ausência de jejum. As células do lavado peritoneal foram retiradas dos animais por meio da injeção de $6 \mathrm{~mL}$ de RPMI com 10\% soro fetal bovino (SFB) estéril e gelado no interior da cavidade abdominal. As células foram coletadas e centrifugadas a $4{ }^{\circ} \mathrm{C}(500 \mathrm{~g}$ por 10 minutos). Após a centrifugação, foram contadas na câmara de Neubauer.

As células foram ressuspendidas em meio de cultura RPMI (Roswell Park Memorial Institute) 1640 suplementado com 10\% de soro fetal bovino (SFB), $100 \mathrm{U} / \mathrm{mL}$ de penicilina, $100 \mu \mathrm{g} / \mathrm{mL}$ de estreptomicina, $24 \mathrm{mM}$ de bicarbonato de sódio, $2 \mathrm{mM}$ de L-glutamina e $20 \mathrm{mM}$ de HEPES. Os macrófagos foram cultivados (com números variáveis de células conforme o tipo de experimento) em incubadora umidificada, a 37 ${ }^{\circ} \mathrm{C}$, com $5 \%$ de $\mathrm{CO}_{2}$. Os macrófagos foram então obtidos após 2 horas de adesão à placa.

\subsection{Determinação de óxido nítrico (NO)}

Os macrófagos obtidos do peritônio foram diluídos a 1 x 10\% $/ \mathrm{mL}$ em placas de 24 poços. Após duas horas para aderência, os macrófagos foram tratados durante 24 horas com lipopolissacarídeo (LPS, 2,5 $\mu \mathrm{g} / \mathrm{mL}$ ). Os sobrenadantes das culturas foram então coletados. A produção de NO foi avaliada pelo método de Griess (Griess, J.P.,1879) o NO é convertido em nitrito sendo então detectado por espectrometria a $540 \mathrm{~nm}$.

\subsection{Determinação de citocinas pró- e anti-inflamatórias}

As citocinas produzidas pelos macrófagos obtidos do peritônio foram avaliadas nos mesmos sobrenadantes utilizados para a quantificação do NO. As concentrações de TNF$\alpha$, IL-1 $\beta$, IL-6 e IL-10 foram avaliadas por imunoensaio enzimático (ELISA, Kit DuoSet, R\&D System, Minneapolis, MN, EUA). Para avalição das citocinas produzidas pelos macrófagos e pelo soro dos animais NODs (NOD ND e NOD D) foi utilizado a técnica Multiplex (Millipore, Temecula, CA, EUA) de acordo com as instruções do fabricante, e a leitura foi realizada através do MAGPXI® System.

Para avaliação das citocinas do fígado, as proteínas foram extraídas por tampão de lise RIPA (Millipore, Temecula, CA, EUA) adicionado de inibidores de proteases (100 
$\mathrm{mM}$ de fluoreto de sódio, $10 \mathrm{mM}$ de EDTA, $10 \mathrm{mM}$ de ortovanadato de sódio, $10 \mu \mathrm{g} / \mathrm{mL}$ de leupeptina, $10 \mu \mathrm{g} / \mathrm{mL}$ de aprotinina, $10 \mathrm{mM}$ de pirofosfato de sódio e $1 \mathrm{mM}$ de PMSF - phenylmethylsulfonyl fluoride), seguido por centrifugação para coleta do sobrenadante. As concentrações de TNF- $\alpha$, IL-1 $\beta$ e IL- 6 dos sobrenadantes obtidos dos fígados foram avaliadas por imunoensaio enzimático (ELISA, Kit DuoSet, R\&D System, Minneapolis, MN, EUA).

\subsection{Determinação das atividades das enzimas hepáticas no soro}

As atividades das enzimas hepáticas, aspartato aminotransferase (AST) e alanina aminotrasnferase (ALT), foram determinadas no soro ao fim de 30 e 90 dias de diabetes. Os ensaios das enzimas foram realizados conforme protocolo do fabricante (Labtest, Lagoa Santa, MG, Brasil).

\subsection{Determinação da expressão gênica de citocinas e enzimas antioxidantes no músculo sóleo, fígado e macrófagos peritoneais}

Músculo sóleo e fígado foram coletados, congelados em nitrogênio líquido e armazenados em congelador a $-80{ }^{\circ} \mathrm{C}$. Posteriormente, os tecidos foram triturados e homogeneizados em reagente TRIZOL para extração do RNA total. O RNA foi quantificado por leitura em NanoDrop 2000 (Thermo Scientific, Waltham, MA, EUA) e o grau de pureza determinado pela razão $260 / 280 \mathrm{~nm}$. O cDNA foi sintetizado a partir de

$2 \mu \mathrm{g}$ do RNA total extraído utilizando a transcriptase reversa MultiScribe ${ }^{\mathrm{TM}}$ (High Capacity cDNA Reverse Transcription Kits Protocols, Applied Biosystems, Carlsbad, CA, EUA). Os macrófagos peritoneais foram processados em TRIZOL no mesmo dia e a partir de 200 ๆg de RNA total foi sintetizado o cDNA. A expressão gênica foi quantificada por PCR em tempo real, utilizando o aparelho ROTOR GENE 3000 da Corbett Research (Mortlake, NSW, Austrália) e SYBER Green (Invitrogen, Life Technologies, Carlsbad, CA, EUA) como marcador fluorescente. A quantificação da expressão dos genes foi realizada usando o método da $\mathrm{Ct}$ comparativa $(\mathrm{Ct}=$ threshold cycle; número de ciclos no qual o produto da PCR atinge o limiar de detecção), tendo a expressão da beta-2 microglobulina (B2m) sido utilizada como padrão interno(131). Os primers de interesse utilizados foram: IL-1 $\beta$, IL-6, TNF- $\alpha$, F4/80, MCP-1, CAT, GPX, SOD-1 e SOD-2 (Tabela abaixo). 


\begin{tabular}{lll}
\hline Gene & Forward primers & Reverse primers \\
\hline B2m & AATGTGAGGCGGGTGGAACTG & CATGGCTCGCTCGGTGACC \\
IL-1 $\beta$ & GGCAGCTACCTGTGTCTTCCC & ATATGGGTCCGACAGCACGAG \\
IL-6 & CGGAGAGGAGACTTCACAGAG & GGTAGCATCCATCATTTCTTTG \\
TNF- $\alpha$ & TCTTCTCATTCCTGCTTGTGGC & CACTTGGTGGTTTGCTACGACG \\
F4/80 & CCTGAACATGCAACCTGCCAC & GGGCATGAGCAGCTGTAGGATC \\
MCP-1 & ACCTGGATCGGAACCAAATGAG & GAAGTGCTTGAGGTGGTTGTGG \\
CAT & GCAGATACCTGTGAACTGTC & GTAGAATGTCCGCACCTGAG \\
GPX & CCTCAAGTACGTCCGACCTG & CAATGTCGTTGCGGCACACC \\
SOD-1 & AAAGCGGTGTGCGTGCTGAA & CAGGTCTCCAACATGCCTCT \\
SOD-2 & ACTGAAGTTCAATGGTGGGG & GCTTGATAGCCTCCAGCAAC \\
\hline
\end{tabular}

\subsection{Imunofenotipagem dos macrófagos}

A caracterização imunofenotípica dos macrófagos foi realizada por marcação com anticorpos para citometria de fluxo. Os anticorpos F4/80 e CD11b foram utilizados para caracterizar a população de macrófagos da cavidade peritoneal. O anticorpo CD11c foi utilizado para caracterizar o subtipo de macrófago M1 e o anticorpo CD206 para caracterizar o subtipo de macrófago M2. Vinte mil eventos foram adquiridos por amostra em histogramas. Os histogramas foram analisados utilizando o Cell Quest Software (Becton \& Dickinson System, San Juan, Califórnia, EUA).

As seguintes subpopulações de macrófagos foram analisadas: $\mathrm{F} 4 / 80^{+} \mathrm{CD} 11 \mathrm{~b}^{+} \mathrm{CD} 11 \mathrm{c}^{+}$(macrófagos M1) e F4/80 ${ }^{+} \mathrm{CD} 11 \mathrm{~b}^{+} \mathrm{CD} 206^{+}$(macrófagos M2). As análises foram realizadas utilizando-se o FACS Calibur (FACS Calibur, Cell Quest; BD Biosciences, San Jose, California, USA).

\subsection{Viabilidade celular}

A viabilidade celular foi avaliada pelo ensaio colorimétrico de MTT (3-(4,5dimethylthiazol-2-yl)-2,5-diphenyltetrazolium bromide). Este ensaio se baseia na capacidade das células viáveis reduzirem metabolicamente o sal de MTT (amarelo), por ação de desidrogenases, em cristais de formazan de cor púrpura. Em placas de 96 poços, foram colocadas $2 \times 10^{5}$ células ressuspendidas em $200 \mu \mathrm{L}$ de meio RPMI por poço. A placa foi incubada (a $37{ }^{\circ} \mathrm{C}$ e $5 \%$ de $\mathrm{CO}_{2}$ ) por 24 horas. Os efeitos de diferentes concentrações de ácidos graxos foram avaliados. Os ácidos eicosapentaenóico (EPA 20:5) e docosaexaenóico (DHA 22:6) foram testados nas concentrações de 25, 50 e 100 $\mu \mathrm{M}$, o palmítico (PA) em 100, 200, 300, 400 e $500 \mu \mathrm{M}$, durante 24 horas. Após esse período, os meios foram aspirados e as células lavadas com PBS (Phosphate Buffered Saline) para então serem utilizadas nos ensaios seguintes. 


\subsection{Tratamento dos macrófagos com os ácidos graxos para avaliação da produção de NO e citocinas}

Os macrófagos derivados da cavidade peritoneal foram diluídos a 1 × $10^{6}$ por $\mathrm{mL}$ em placas de 24 poços. Após duas horas para aderência, os macrófagos foram tratados durante 2 horas com $100 \mu \mathrm{M}$ de ácido palmítico (PA), $25 \mu \mathrm{M}$ de eicosapentaenóico (EPA 20:5) ou $25 \mu \mathrm{M}$ de docosaexaenóico (DHA 22:6) e depois estimulados com LPS durante 22 horas, totalizando 24 horas de tratamento com os ácidos graxos. Este protocolo de tratamento foi utilizado para determinação da produção de $\mathrm{NO}$ e citocinas no sobrenadante. Os AGs foram dissolvidos em etanol e mantidos no escuro a $-20{ }^{\circ} \mathrm{C}$ para uso posterior. A concentração final de etanol no meio de cultura não excedeu $0,05 \%$.

\subsection{Tratamento com DHA para avaliação da expressão de genes associadas à resposta inflamatória}

Os macrófagos obtidos da cavidade peritoneal foram diluídos a 1 x $10^{6}$ por $\mathrm{mL}$ em placas de 12 poços. Após duas horas para aderência, os macrófagos foram cultivados por 4 horas na presença ou ausência de LPS $(2,5 \mu \mathrm{g} / \mathrm{mL})$ e DHA $(25 \mu \mathrm{M})$. Este protocolo de tratamento foi utilizado para extração de RNA e determinação da expressão gênica. $O$ DHA foi dissolvido em etanol e mantido no escuro a $-20{ }^{\circ} \mathrm{C}$ para uso posterior. A concentração final de etanol no meio de cultura não excedeu $0,05 \%$.

\subsection{Preparação de RNA de macrófagos obtidos da cavidade peritoneal}

Os macrófagos obtidos da cavidade peritoneal foram diluídos a 1 x $10^{6} / \mathrm{mL}$ em placas de 12 poços. Após tratamento na presença ou ausência de LPS $(2,5 \mu \mathrm{g} / \mathrm{mL})$ e DHA $(25 \mu \mathrm{M})$, os macrófagos foram lavados com PBS gelado, lisados e homogeneizados em reagente QIAzol (QIAGEN, Germantown, MD, EUA) para extração do RNA total utilizando RNeasy Mini Kit (QIAGEN, Germantown, MD, EUA). O RNA foi quantificado por leitura em NanoDrop 2000 (Thermo Scientific, Waltham, MA, EUA) e o grau de pureza determinado pela razão 260/280 nm conforme descrito acima.

\subsection{Determinação da expressão gênica por PCR Array}

O cDNA foi sintetizado a partir de 500 ๆg de RNA total extraído dos macrófagos do peritônio utilizando o RT² First Strand Kit (QIAGEN, Germantown, MD, EUA). A expressão gênica foi avaliada por PCR Array, Mouse Inflammatory Cytokines \& 
Receptors $R T^{2}$ Profiler PCR Array (QIAGEN, Germantown, MD, EUA). Este permite avaliar 84 genes que medeiam resposta inflamatória e 5 genes como controle interno (housekeeping genes). Para cada um dos 96 poços, foram adicionados $25 \mathrm{uL}$ da solução de reação baseada em $R T^{2}$ SYBR Green Mastermix (contendo cDNA) (QIAGEN, Germantown, MD, EUA). As ciclagens foram realizadas no aparelho 7500 Real Time PCR System (Applied Biosystems, Carlsbad, CA, EUA) e as condições de ciclagem recomendadas pelo fabricante e utilizadas foram de 10 minutos iniciais em $95^{\circ} \mathrm{C}$, seguido de 40 ciclos: 15 segundos em $95^{\circ} \mathrm{C}$ e 1 minuto em $60^{\circ} \mathrm{C}$. Foram utilizadas 12 placas de Mouse Inflammatory Cytokines \& Receptors RT Profiler PCR Array (QIAGEN, Germantown, MD, EUA) para avaliação de dois grupos experimentais (WT e D). Destas placas, 6 foram destinadas a determinação da expressão gênica de macrófagos do peritônio de animais controles (B6) e as 6 restantes aos animais diabéticos (B6+STZ). Cada placa foi resultado do RNA total extraído dos macrófagos peritoneais de 2-3 animais por grupo experimental. Cada grupo experimental foi avaliado para os seguintes tratamentos: sem estímulo (RPMI), com estímulo (LPS), e com estímulo e ácido graxo (LPS+DHA).

\subsection{Taxa de acidificação extracelular (ECAR)}

A taxa de acidificação extracellular foi realizada através do Seahorse Bioscience XF96 extracellular analyzer (132) (Seahorse Bioscience, North Billerica, MA, EUA). As células peritoneais foram plaquedas ( 1 x $10^{5}$ por poço) em placas XF96, depois de 2 horas de aderência foram lavadas para obtenção de macrófagos peritoneais. Uma hora antes da realização do ensaio, o meio das células foi trocado pelo meio adequado para realização da técnica (sem glicose, $0.8 \mathrm{mM} \mathrm{Mg}^{2+}, 1.8 \mathrm{mM} \mathrm{Ca}^{2+}, 143 \mathrm{mM} \mathrm{NaCl}, 5.4 \mathrm{mM}$ $\mathrm{KCl}, 0.91 \mathrm{mM} \mathrm{NaH} 2 \mathrm{PO} 4$, and $15 \mathrm{mg} / \mathrm{mL}$ Phenol red) por 60 minutos, a $37^{\circ} \mathrm{C}$, na ausência de $\mathrm{CO}_{2}$. Durante estes 60 minutos, foram preparados os compostos para serem injetados nas portas do cartridge. Os compostos utilizados foram: glicose (100 mM), oligomicina $(10 \mathrm{uM})$ e 2-DG (2-Deoxi-D-Glucose, $1 \mathrm{M})$. As concentrações finais foram de $10 \mathrm{mM}$ de glicose, $1 \mathrm{uM}$ de oligomicina e $0.1 \mathrm{M}$ de 2-DG.

O programa utilizado para quantificação da taxa de acidificação extracelular foi: (1) quantificação a cada 3 minutos, 3 vezes; (2) injeção da porta A (100 mM de glicose); (3) quantificação a cada 3 minutos, 3 vezes; (4) injeção da porta B (10 uM de oligomicina); (5) quantificação a cada 3 minutos, 3 vezes; (6) injeção da porta C (2-DG, 
$1 \mathrm{M})$ e (7) quantificação a cada 3 minutos, 6 vezes. Foram avaliados os macrófagos peritoneais residentes dos grupos de animais B6 e B6+STZ, cada amostra foi plaqueada em triplicata. A partir dos valores obtidos no ECAR, foi possível calcular a glicólise e a capacidade glicolítica (132).

\subsection{Western blotting}

As proteínas foram separadas em gel SDS-PAGE (4-12\%) (Novex, Invitrogen) com tampão MES (Novex, Invitrogen), a $150 \mathrm{~V}$, por 60-90 minutos. As proteínas foram transferidas em membranas de PVDF (Millipore, Temecula, CA, EUA) com tampão contendo $10 \%$ de Tris-glicina e $15 \%$ de metanol, a $32 \mathrm{~V}$ por 90 minutos, as quais foram pré-tratadas por 1-2 minutos com metanol antes da transferência. As membranas foram bloqueadas com 3\% de BSA em buffer de Tris com solução salina (TBS) por 60 minutos. Após o bloqueio, as membranas foram incubadas com anticorpos primários específicos com 3\% d BSA em TBS contendo 01.\% de Tween-20, overnight. Anticorpos primários: rabbit anti-NLRP3 (Cell Signaling Technology), mouse anti- beta-actina (Li-Cor), mouse anti-caspase p20 (Adipogen) e rabbit anti-beta-actina (Li-Cor).

As membranas foram lavadas e incubadas com anticorpos secundários (IRDye 800CW ou IrDye 680RD, LI-COR Biosciences, 1:20000), durante 60 minutos. Após lavagem, a marcação foi visualizada no sistema de imagem Odyssey. A quantificação da marcação foi realizada com programa Fiji/Image J (133).

\subsection{Análise Estatística}

Os dados estão apresentados como média \pm erro padrão da média (EPM) e foram analisados pelo teste $t$-Student, one- ou two-way ANOVA, conforme o caso, seguido pelo pós-teste de Bonferroni ( $\mathrm{p}<0,05)$. Os dados foram calculados pelo programa Prism 6 (GraphPad Software, in., La Jolla, CA). 


\section{RESULTADOS}

\subsection{Caracterização do modelo de diabetes mellitus tipo 1 em camundongos C57BL/6 quimicamente induzido por administração de estreptozotocina}

\subsubsection{Glicemia, massa corporal e insulinemia}

Após dez dias da última injeção de estreptozotocina, os animais considerados diabéticos apresentaram em duas avaliações não consecutivas (verificadas com intervalo de dois dias) glicemia acima de $250 \mathrm{mg} / \mathrm{dL}$ pela manhã, sem jejum. Ao final dos 30 dias, os animais C57BL/6 diabéticos (B6+STZ) apresentaram média de 495,83 — 27,24 mg/dL de glicose na corrente sanguínea, enquanto nos animais C57BL/6 controles (B6) este valor foi de 140,50 $\pm 5,95 \mathrm{mg} / \mathrm{dL}$ (Figura 1A). Conforme esperado, os animais diabéticos $(24,60 \pm 0,58 \mathrm{~g})$ induzidos por estreptozotocina deixaram de ganhar massa ao serem comparados com os controles $(27,08 \pm 0,13 \mathrm{~g}$ ) (Figura 1B) e a insulinemia mostrou-se diminuída nos animais diabéticos (Figura 1C).

A

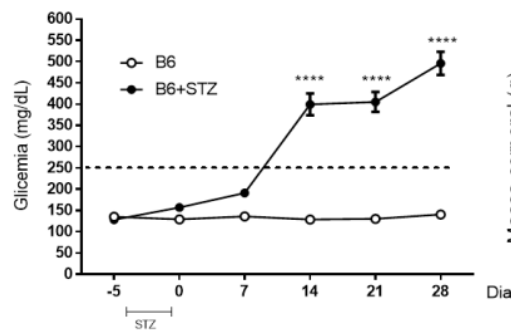

B

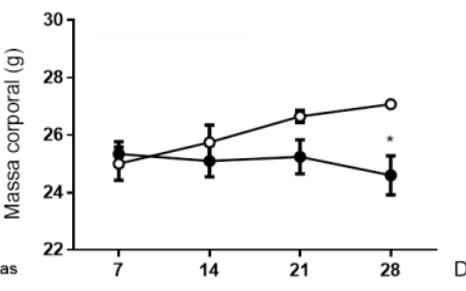

C

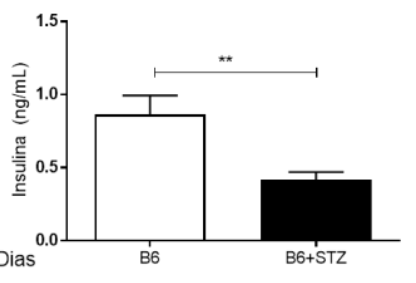

Figura 1. Evolução da glicemia, massa corporal e insulinemia após 30 dias da indução de diabetes. Camundongos C57BL/6 machos adultos foram injetados, por via intraperitoneal, com tampão citrato (controles) ou $42 \mathrm{mg} / \mathrm{Kg}$ de massa corporal de estreptozotocina (STZ) em tampão citrato (diabéticos), durante 5 dias consecutivos. As concentrações plasmáticas de glicose foram determinadas em amostras coletadas da veia da cauda utilizando glicosímetro Accu-Check Active (Roche Diagnostics, Abbott Park, $I L, U S A$ ). A glicemia basal e a massa corporal dos animais foram avaliadas semanalmente pela manhã (não jejum). Ao fim de 30 dias da indução de diabetes, os animais tiveram amostras de sangue coletadas e centrifugadas para obtenção do soro. A concentração de insulina foi determinada por ELISA. STZ: estreptozotocina. Os dados representam a média \pm erro padrão da média de 4-6 animais por grupo experimental. 


\subsubsection{Avaliação de parâmetros metabólicos, expressão de citocinas inflamatórias e enzimas antioxidantes no fígado}

A massa relativa do fígado e a atividade da ALT no soro apresentaram-se aumentados nos animais diabéticos após 30 e dias (Tabela 1). Já a concentração das citocinas IL-6 e TNF- $\alpha$, no fígado apresentou-se aumentada somente após 90 dias de diabetes (Apêndice A18 e A19), enquanto a citocina IL-1 $\beta$ não se alterou (Tabela 1).

Tabela 1. Efeitos do diabetes após 30 dias da indução por administração de estreptozotocina sobre a massa do fígado, atividade da ALT e da AST no soro e concentração de TNF- $\alpha$, IL-6 e IL-1 $\beta$ no fígado de animais controle (WT) e diabéticos (D).

\begin{tabular}{|c|c|c|c|}
\hline & B6 & B6+STZ & $P$ \\
\hline Massa, $\mathrm{g}$ & $31.50 \pm 0.23$ & $24.43 \pm 1.20$ & $<0.0001^{*}$ \\
\hline $\begin{array}{l}\text { ALT, } \\
\text { U/L soro }\end{array}$ & $11.02 \pm 0.75$ & $20.69 \pm 2.13$ & $0.0013 *$ \\
\hline $\begin{array}{l}\text { AST, } \\
\text { U/L soro }\end{array}$ & $27.28 \pm 1.51$ & $34.05 \pm 4.01$ & 0.1695 \\
\hline Triglicerídeos & $88,74 \pm 9,58$ & $76,61 \pm 6,59$ & 0,2981 \\
\hline Colesterol total & $101,7 \pm 8,19$ & $157,6 \pm 22,70$ & 0,0512 \\
\hline $\begin{array}{l}\mathrm{TNF}-\alpha, \mathrm{pg} / \mathrm{mg} \\
\text { proteína de fígado }\end{array}$ & $183.3 \pm 11.9$ & $229.7 \pm 17.3$ & 0.0526 \\
\hline $\begin{array}{l}\text { IL-6, pg/mg } \\
\text { proteína de fígado }\end{array}$ & $72.53 \pm 3.97$ & $82.82 \pm 3.95$ & 0.0948 \\
\hline 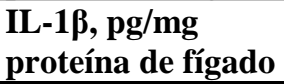 & $45.39 \pm 3.16$ & $47.46 \pm 2.08$ & 0.5784 \\
\hline
\end{tabular}

Camundongos C57BL/6 machos adultos foram injetados com tampão citrato (controles, B6) ou $42 \mathrm{mg} / \mathrm{Kg}$ de massa corporal de estreptozotocina em tampão citrato (diabéticos, B6+STZ), durante 5 dias consecutivos, por via intraperitoneal. Ao fim de 30 dias de diabetes, o fígado foi coletado e congelado em nitrogênio líquido. ALT e AST foram determinados no soro dos animais por métodos colorimétricos. As citocinas TNF- $\alpha$, IL-6 e IL-1 $\beta$ foram quantificadas por ELISA. Os dados representam a média \pm erro padrão da média de 8 animais por grupo experimental. ${ }^{*} \mathrm{p}<0,05$ em relação ao grupo dos animais controles versus animais diabéticos por período. ALT (alanina aminotransferase), AST (aspartato aminotransferase), TNF$\alpha$ (Fator de Necrose Tumoral Alfa), IL-6 (Interleucina 6) e IL-1 $\beta$ (Interleucina-1 beta).

Nos mesmos períodos, foi avaliada no fígado a expressão gênica de citocinas próinflamatórias (TNF- $\alpha$, IL-6 e IL-1 $\beta$ ), de marcador de superfície para macrófagos (F4/80), de proteína quimioatraente de monócitos-1 (MCP-1) e das enzimas antioxidantes catalase, glutationa peroxidase e superóxido dismutases 1 e 2. Após 30 dias de diabetes, a expressão da catalase e superóxido dismutase-2 foi diminuída no fígado (Tabela 2). Após 90 dias, houve aumento da expressão de TNF- $\alpha$ e F4/80 (Apêndice A22), indicativo 
de processo inflamatório, corroborando com o aumento das citocinas observado no mesmo período.

Tabela 2. Efeitos do diabetes após 30 dias da indução por administração de estreptozotocina na expressão gênica de IL-1 $\beta$, IL-6, TNF- $\alpha$, F4/80, MCP-1, CAT, GPX, SOD-1 e SOD-2 no fígado dos animais controles (B6) e diabéticos (B6+STZ).

\begin{tabular}{ccc}
\hline & B6 & B6+STZ \\
\hline IL-1; & $1.129 \pm 0.243$ & $0.974 \pm 0.320$ \\
IL-6 & $1.226 \pm 0.317$ & $1.194 \pm 0.389$ \\
TNF- $\alpha$ & $0.883 \pm 0.147$ & $0.667 \pm 0.233$ \\
F4/80 & $1.053 \pm 0.118$ & $1.416 \pm 0.190$ \\
MCP-1 & $1.474 \pm 0.429$ & $0.616 \pm 0.183$ \\
CAT & $1.033 \pm 0.101$ & $0.585 \pm 0.112^{*}$ \\
GPX & $1.020 \pm 0.075$ & $1.397 \pm 0.190$ \\
SOD-1 & $1.010 \pm 0.059$ & $1.281 \pm 0.238$ \\
SOD-2 & $1.004 \pm 0.036$ & $0.621 \pm 0.101^{*}$
\end{tabular}

Camundongos C57BL/6 machos adultos foram injetados com tampão citrato (controles, B6) ou $42 \mathrm{mg} / \mathrm{Kg}$ de massa corporal de estreptozotocina em tampão citrato (diabéticos, B6+STZ), durante 5 dias consecutivos, por via intraperitoneal. Ao fim de 30 dias de diabetes, o fígado foi coletado e congelado em nitrogênio líquido. Os dados representam a média \pm erro padrão da média de 8 animais por grupo experimental. ${ }^{*} \mathrm{p}<0,05$ em relação ao grupo dos animais diabéticos por período. IL-1 $\beta$ (Interleucina- 1 beta), IL-6 (Interleucina 6), TNF- $\alpha$ (Fator de Necrose Tumoral Alfa), F4/80 (antígeno extracelular marcador de macrófago), MCP-1 (proteína quimioatraente de monócitos-1), CAT (catalase), GPX (glutationa peroxidase), SOD-1 (superóxido dismutase 1) e SOD-2 dismutase (superóxido dismutase 2).

\subsubsection{Avaliação da expressão gênica de citocinas inflamatórias e de enzimas antioxidantes no músculo sóleo}

Além do fígado, após 30 de diabetes, o músculo sóleo dos animais foi retirado e congelado em nitrogênio líquido para avaliações posteriores. Utilizando a PCR em tempo real foi avaliada a expressão gênica de citocinas pró-inflamatórias (TNF- $\alpha$, IL-6 e IL-1 $\beta$ ), de marcador de superfície para macrófagos (F4/80), de proteína quimioatraente de monócitos (MCP-1) e das enzimas antioxidantes catalase, glutationa peroxidase e superóxido dismutases 1 e 2. Observou-se redução da expressão de GPX, IL-1 $\beta$ e MCP1 no músculo sóleo após 30 dias de diabetes (Tabela 3). 
Tabela 3. Efeitos do diabetes após 30 dias da indução na expressão gênica de IL-1 $\beta$, IL6, TNF- $\alpha$, F4/80, MCP-1, CAT, GPX, SOD-1 e SOD-2 no músculo sóleo dos animais controles (WT) e diabéticos (D).

\begin{tabular}{ccc}
\hline & B6 & B6+STZ \\
\hline IL-1及 & $1.678 \pm 0.570$ & $0.328 \pm 0.080^{*}$ \\
IL-6 & $1.664 \pm 0.489$ & $0.975 \pm 0.123$ \\
TNF- $\alpha$ & $1.177 \pm 0.181$ & $0.911 \pm 0.252$ \\
F4/80 & $1.199 \pm 0.260$ & $0.602 \pm 0.112$ \\
MCP-1 & $1.370 \pm 0.439$ & $0.229 \pm 0.079^{*}$ \\
CAT & $1.060 \pm 0.131$ & $1.312 \pm 0.140$ \\
GPX & $1.058 \pm 0.142$ & $0.607 \pm 0.058^{*}$ \\
SOD-1 & $1.028 \pm 0.092$ & $0.972 \pm 0.091$ \\
SOD-2 & $1.126 \pm 0.210$ & $0.990 \pm 0.130$ \\
\hline
\end{tabular}

Camundongos C57BL/6 machos adultos foram injetados com tampão citrato (controles, B6) ou $42 \mathrm{mg} / \mathrm{Kg}$ de massa corporal estreptozotocina em tampão citrato (diabéticos, B6+STZ), durante 5 dias consecutivos, por via intraperitoneal. Ao fim de 30 dias de diabetes, o músculo sóleo foi coletado e congelado em nitrogênio líquido. Os dados representam a média \pm erro padrão da média de 8 animais por grupo experimental. ${ }^{*} \mathrm{p}<0,05$ em relação ao grupo dos animais diabéticos por período. IL-1 $\beta$ (Interleucina- 1 beta), IL-6 (Interleucina 6), TNF- $\alpha$ (Fator de Necrose Tumoral Alfa), F4/80 (antígeno extracelular marcador de macrófago), MCP-1 (proteína quimioatraente de monócitos-1), CAT (catalase), GPX (glutationa peroxidase), SOD-1 (superóxido dismutase 1) e SOD-2 dismutase (superóxido dismutase 2).

Tabela 4. Resumo dos efeitos do diabetes após 30 dias da indução na expressão gênica de IL-1 $\beta$, IL-6, TNF- $\alpha$, F4/80, MCP-1, CAT, GPX, SOD-1 e SOD-2 no fígado e músculo sóleo dos animais diabéticos.

\begin{tabular}{cccc}
\hline Fígado & & Sóleo & \\
\hline IL-1 $\beta$ & - & IL-1 $\beta$ & $\downarrow$ \\
IL-6 & - & IL-6 & - \\
TNF- $\alpha$ & - & TNF- $\alpha$ & - \\
F4/80 & - & F4/80 & - \\
MCP-1 & - & MCP-1 & $\downarrow$ \\
CAT & $\downarrow$ & CAT & - \\
GPX & - & GPX & $\downarrow$ \\
SOD-1 & - & SOD-1 & - \\
SOD-2 & $\downarrow$ & SOD-2 & - \\
\hline
\end{tabular}

Camundongos C57BL/6 machos adultos foram injetados com tampão citrato (controles, B6) ou $42 \mathrm{mg} / \mathrm{Kg}$ de massa corporal estreptozotocina em tampão citrato (diabéticos, B6+STZ), durante 5 dias consecutivos, , por via intraperitoneal. Ao fim de 30 e 90 dias de diabetes, o fígado e o músculo sóleo foram coletados e congelados em nitrogênio líquido. Os dados representam a média \pm erro padrão da média de 8 animais por grupo experimental. ${ }^{*} \mathrm{p}<0,05$ em relação ao grupo dos animais diabéticos por período. IL- $1 \beta$ (Interleucina1 beta), IL-6 (Interleucina 6), TNF- $\alpha$ (Fator de Necrose Tumoral Alfa), F4/80 (antígeno extracelular marcador de macrófago), MCP-1 (proteína quimioatraente de monócitos-1), CAT (catalase), GPX (glutationa peroxidase), SOD-1 (superóxido dismutase 1) e SOD-2 dismutase (superóxido dismutase 2). 


\subsection{Avaliação do perfil dos macrófagos peritoneais}

\subsubsection{Análise da expressão gênica em macrófagos peritoneais de animais controles e diabéticos}

Decorridos 30 dias de diabetes, foi avaliado o perfil de expressão gênica das citocinas inflamatórias IL-1 $\beta$, TNF- $\alpha$, IL-6, do receptor TLR-4 e da enzima iNOS por PCR em tempo real, em macrófagos peritoneais. Não foi observada diferença no conteúdo de RNAm de IL-1 $\beta$, TNF- $\alpha$, IL-6 e TLR-4 (Figura 2A-D) nos macrófagos peritoneais entre os animais C57BL/6 controles (B6) e C57BL/6 diabéticos. Por sua vez, a expressão de iNOS (Figura 2E) apresentou-se 3,26 vezes mais elevada nos macrófagos dos animais diabéticos, na ausência de LPS, e esta diferença aumentou para 3,66 na presença de LPS. A produção de óxido nítrico (NO) pelos macrófagos dos animais diabéticos também aumentou em relação aos dos animais controles na presença de LPS (Figura 2F).
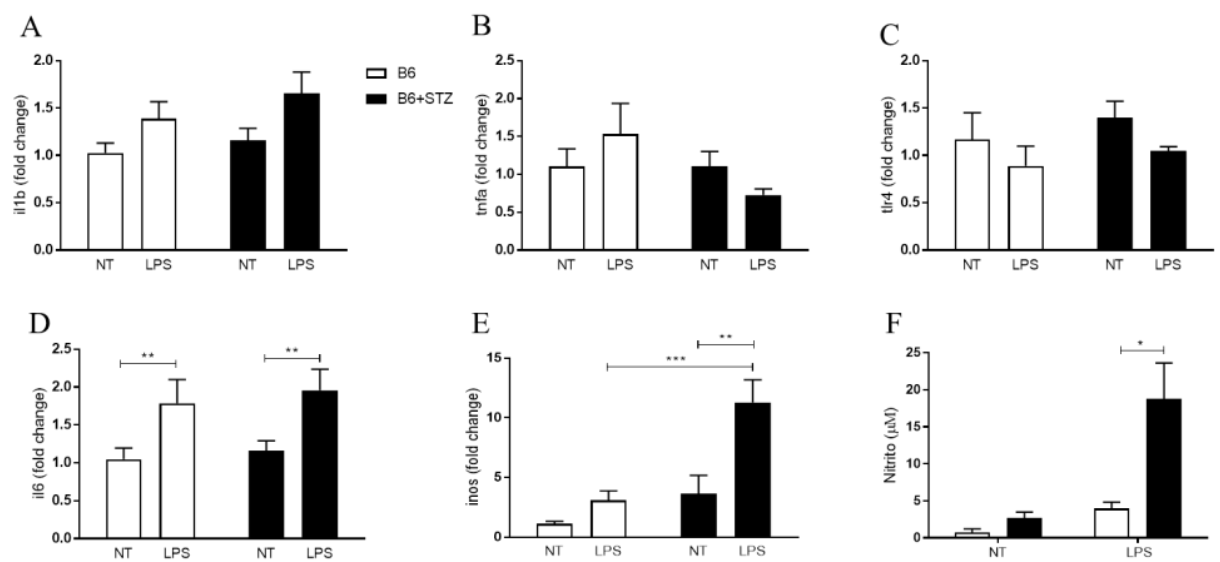

Figura 2. Expressão gênica de citocinas e receptores em macrófagos residentes peritoneais de animais controles ou diabéticos. C57BL/6 machos adultos foram injetados com tampão citrato (controles, B6) ou $42 \mathrm{mg} / \mathrm{Kg}$ de massa corporal de estreptozotocina em tampão citrato (diabéticos, B6+STZ), durante 5 dias consecutivos, por via intraperitoneal. Ao fim de 30 dias de diabetes, os animais tiveram os macrófagos peritoneais residentes coletados e cultivados por 4 horas na ausência ou presença de lipopolissacarídeo LPS $(2,5 \mu \mathrm{g} / \mathrm{mL})$. A expressão gênica foi avaliada por PCR em tempo real. Para avaliação de NO, os macrófagos peritoneais residentes coletados e cultivados por 24 horas na ausência ou presença de LPS. A reação de Griess foi utilizada para quantificação de NO. Os dados representam a média \pm erro padrão da média de 5-6 animais por grupo experimental. *p<0,05 em relação ao grupo dos animais diabéticos por período. Il1b (Interleucina-1 beta), tnfa (Fator de Necrose Tumoral Alfa), tlr4 (receptor de toll like do tipo 4), il6 (Interleucina 6), inos (óxido nítrico induzível). 
5.2.2 Caracterização imunofenotípica de macrófagos residentes peritoneais em animais controles e diabéticos

Após 30 dias da indução de diabetes, foi realizada a caracterização imunofenotípica dos macrófagos por citometria de fluxo. Os anticorpos F4/80 e CD11b foram utilizados para caracterizar a população de macrófagos retirados do peritônio. $\mathrm{O}$ anticorpo CD11c foi utilizado para caracterizar o subtipo de macrófago M1 e o anticorpo CD206 para identificar o subtipo de macrófago M2. As seguintes subpopulações de macrófagos foram analisadas: $\mathrm{F} 4 / 80^{+} \mathrm{CD} 11 \mathrm{~b}^{+} \mathrm{CD} 11 \mathrm{c}^{+} \quad$ (macrófagos $\mathrm{M} 1$ ) e $\mathrm{F} 4 / 80^{+} \mathrm{CD} 11 \mathrm{~b}^{+} \mathrm{CD} 206^{+}$(macrófagos M2). Não foram observadas diferenças estatisticamente significativas entre os tipos celulares analisados no período de 30 dias (Figura 3).
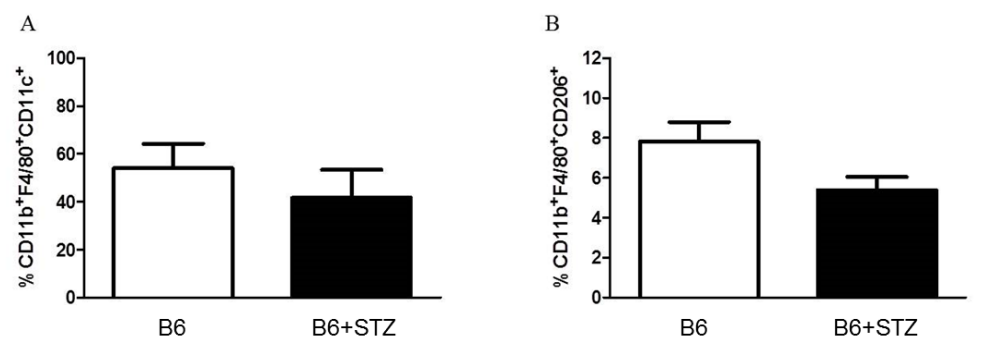

Figura 3. Ocorrência de macrófagos peritoneais residentes M1 e M2 em animais controles (B6) ou diabéticos (B6+STZ). Camundongos C57BL/6 machos adultos foram injetados com tampão citrato (controles, B6) ou $42 \mathrm{mg} / \mathrm{Kg}$ de massa corporal de estreptozotocina em tampão citrato (diabéticos, B6+STZ), durante 5 dias consecutivos, por via intraperitoneal. Ao fim de 30 dias de diabetes, os animais tiveram os macrófagos peritoneais residentes coletados e marcados com anticorpos específicos. Os dados estão indicados como: frequência de macrófagos M1 (A) e frequência de macrófagos M2 (B) e representam a média \pm erro padrão da média de 6 animais por grupo experimental.

\subsubsection{Análise da expressão gênica de citocinas, quimiocinas e receptores de quimiocinas por PCR array dos macrófagos peritoneais de animais diabéticos}

Após 30 dias da indução de diabetes, foi realizado lavado peritoneal nos animais para a obtenção das células. Após duas horas de cultura em meio RPMI suplementado e adesão à placa, em incubadora umidificada a $37^{\circ} \mathrm{C} \operatorname{com} 5 \%$ de $\mathrm{CO}_{2}$, parte dos macrófagos foi estimulada com LPS. Após 4 horas de estímulo, as células foram homogeneizadas em reagente TRIZOL para extração do RNA total. A avaliação da expressão gênica foi realizada em PCR array. 
Os macrófagos dos animais diabéticos, na ausência de estímulo, já apresentaram um perfil pró-inflamatório (Tabela 5). Em destaque, houve aumento da expressão de IL$1 \alpha$, IL-1 $\beta$ e IL-33 e dos fatores estimulantes de colônia de macrófagos (CSF2 e CSF3). A expressão gênica das citocinas da família IL-1 dos macrófagos dos animais diabéticos na ausência de estímulo apresentou perfil semelhante quando comparada com a das células dos animais controles estimulados com LPS (Figura 4).

Corroborando estes resultados, ao estimular com LPS, os macrófagos dos animais diabéticos e compará-los com macrófagos dos animais controles, também estimulados, observou-se que 23 genes apresentaram expressão aumentada (Tabela 6), enquanto apenas 12 genes apresentaram expressão aumentada na ausência do tratamento com LPS (Tabela 5).

A expressão de quimiocinas relacionadas com a migração de macrófagos (CCL2, CCL3, CCL4, CCL5 e CCL7) também foi avaliada (Figura 5). Nota-se que a expressão da quimiocina CCL3 apresentou-se aumentada (Figura 5) nos macrófagos de animais diabéticos em relação aos controles, ambos na presença de LPS. A expressão das quimiocinas CXCL1 e CXCL5 apresentou aumento relevante (Tabela 6).

A expressão gênica de CCR1, CCR3 e CCR5, receptores de quimiocinas, importantes no processo migratório de macrófagos (CCL3, CCL4 e CCL5), também apresentou-se aumentada nas células de animais diabéticos após estimulação com LPS (Figura 6). Por sua vez, nas células dos animais controles, houve diminuição da expressão dos receptores de quimiocinas quando tratados com LPS.

Os resultados obtidos na PCR array, juntamente com os dados encontrados na determinação de NO e citocinas (Figuras 2, 4 e 5), são sugestivos de um perfil inflamatório nos macrófagos peritoneais residentes após 30 dias de diabetes. 
Tabela 5. Relação de genes diferencialmente expressos de macrófagos de animais diabéticos sem estímulo em relação às células de animais controles também sem estímulo.

\begin{tabular}{c|c}
\hline Gene & Fold change (vezes de alteração) \\
\hline Ccl17 & 4,0022 \\
\hline Ccr6 & 2,8147 \\
\hline Csf2 & 2,8281 \\
\hline Csf3 & 5,596 \\
\hline Cxcl1 & 2,8338 \\
\hline Il1a & 2,8077 \\
\hline Il1b & 5,6498 \\
\hline Il1rn & 2,8241 \\
\hline Il33 & 2,834 \\
\hline Il4 & 2,6919 \\
\hline Osm & 2,8021 \\
\hline Vegfa & 5,69 \\
\hline
\end{tabular}

Camundongos C57BL/6 machos adultos foram injetados com tampão citrato (controles) ou $42 \mathrm{mg} / \mathrm{Kg}$ de massa corporal de estreptozotocina em tampão citrato (diabéticos), durante 5 dias consecutivos, intraperitonealmente. Ao fim de 30 dias de diabetes, os animais tiveram os macrófagos peritoneais residentes coletados e cultivados por 4 horas sem estímulo. A expressão gênica foi avaliada em PCR array. Todos os genes listados na tabela apresentaram expressão aumentada nos macrófagos de animais diabéticos sem estímulo, em relação às células de animais controles sem estímulo. Ccl17 (chemokine (C-C motif) ligand 17), Ccr6 (chemokine (C-C motif) receptor 6), Csf2 (colony stimulating factor 2 (granulocytemacrophage)), Csf3 (colony stimulating factor 3 (granulocyte)), Cxcl11(chemokine (C-X-C motif) ligand 11), Il1a (interleukin 1 alpha), Il1b (interleukin 1 beta), Il1 rn (interleukin 1 receptor antagonist), Il33 (interleukin 33), Il4 (interleukin 4), Osm (oncostatin M), Vegfa (vascular endothelial growth factor A). 
Tabela 6. Relação dos genes diferencialmente expressos de macrófagos de animais diabéticos tratados com LPS em relação às células de animais controles também tratados com LPS.

\begin{tabular}{|c|c|}
\hline Gene & Fold Change (vezes de alteração) \\
\hline $\mathrm{Ccl} 24$ & 3,9949 \\
\hline Ccr1 & 3,9862 \\
\hline Ccr3 & 11,2953 \\
\hline Ccr5 & 4,04 \\
\hline Ccr6 & 2,9194 \\
\hline Csf3 & 2,8291 \\
\hline Cxcl1 & 8,0021 \\
\hline Cxcl5 & 31,7126 \\
\hline Ifng & 2,83 \\
\hline Il10ra & 2,8074 \\
\hline Il16 & 2,8919 \\
\hline Il1a & 2,8594 \\
\hline $\mathrm{Il} 1 \mathrm{~b}$ & 2,8088 \\
\hline Il1rn & 5,7199 \\
\hline $\mathrm{I} 127$ & 2,8262 \\
\hline $\mathrm{I} 12 \mathrm{rg}$ & 2,8286 \\
\hline $\mathrm{I} 133$ & 5,6432 \\
\hline $\mathrm{I} 14$ & 2,9057 \\
\hline Il6ra & 3,9712 \\
\hline Il6st & 2,8169 \\
\hline Nampt & 2,8506 \\
\hline Osm & 4,0254 \\
\hline Vegfa & 3,9931 \\
\hline
\end{tabular}

Camundongos C57BL/6 machos adultos foram injetados com tampão citrato (controles) ou $42 \mathrm{mg} / \mathrm{Kg}$ de massa corporal de estreptozotocina em tampão citrato (diabéticos), durante 5 dias consecutivos, por via intraperitoneal. Ao fim de 30 dias de diabetes, os animais tiveram os macrófagos peritoneais residentes coletados e cultivados por 4 horas e estimulados com lipopolissacarídeo - LPS $(2,5 \mu \mathrm{g} / \mathrm{mL})$.. A expressão gênica foi avaliada por PCR array. Os genes listados na tabela apresentaram expressão aumentada nos macrófagos de animais diabéticos estimulados com LPS em relação aos macrófagos de animais controles também estimulados com LPS. Ccl (chemokine ( $C$ - $C$ motif) ligand), Ccr (chemokine $(C$ - $C$ motif) receptor), $\mathrm{Cxcl}$ (chemokine ( $C$ - $X$ - $C$ motif) ligand), Ifng (interferon gamma), Il10ra (interleukin 10 receptor, alpha), Il (interleukin), Il1rn (interleukin 1 receptor antagonist), I12rg (interleukin 2 receptor, gamma chain), Il6ra (interleukin 6 receptor, alpha), Il6st (interleukin 6 signal transducer), Nampt (nicotinamide phosphoribosyltransferase), Osm (oncostatin M), Vegfa (vascular endothelial growth factor A). 


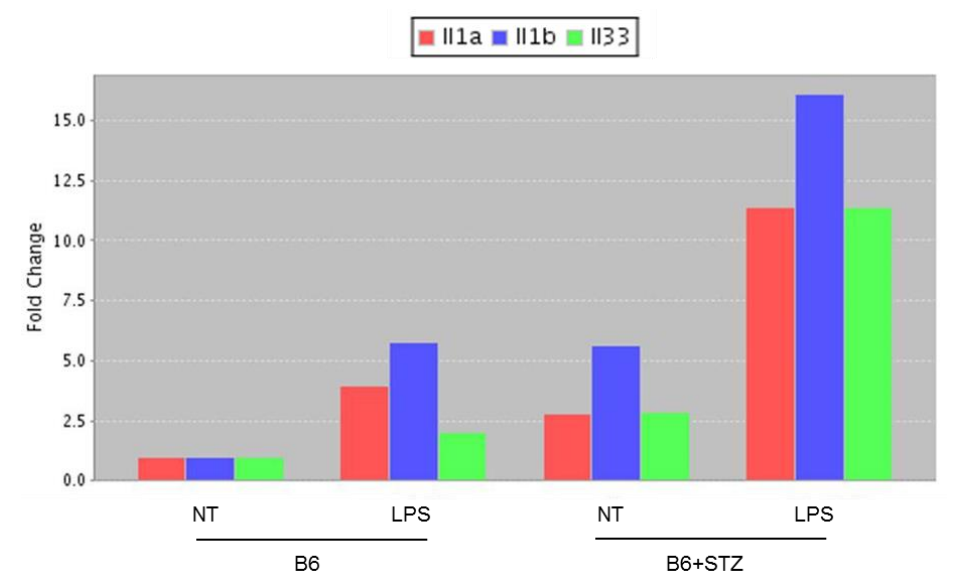

Figura 4. Expressão gênica de Il1a, Il1b e II33 em macrófagos residentes peritoneais de animais controles (B6) ou diabéticos (B6+STZ). Camundongos C57BL/6 machos adultos foram injetados com tampão citrato (controles, B6) ou $42 \mathrm{mg} / \mathrm{Kg}$ de massa corporal de estreptozotocina em tampão citrato (diabéticos, B6+STZ), durante 5 dias consecutivos, por via intraperitoneal. Ao fim de 30 dias de diabetes, os animais tiveram os macrófagos peritoneais residentes coletados e cultivados por 4 horas na ausência ou presença de lipopolissacarídeo - LPS $(2,5 \mu \mathrm{g} / \mathrm{mL})$. A expressão gênica foi avaliada por PCR array. A média da expressão dos genes nos macrófagos peritoneais de animais controles não estimulados (B6) foi considerada como 1. NT: macrófagos não estimulados; LPS: macrófagos estimulados com LPS. Il (interleukin).

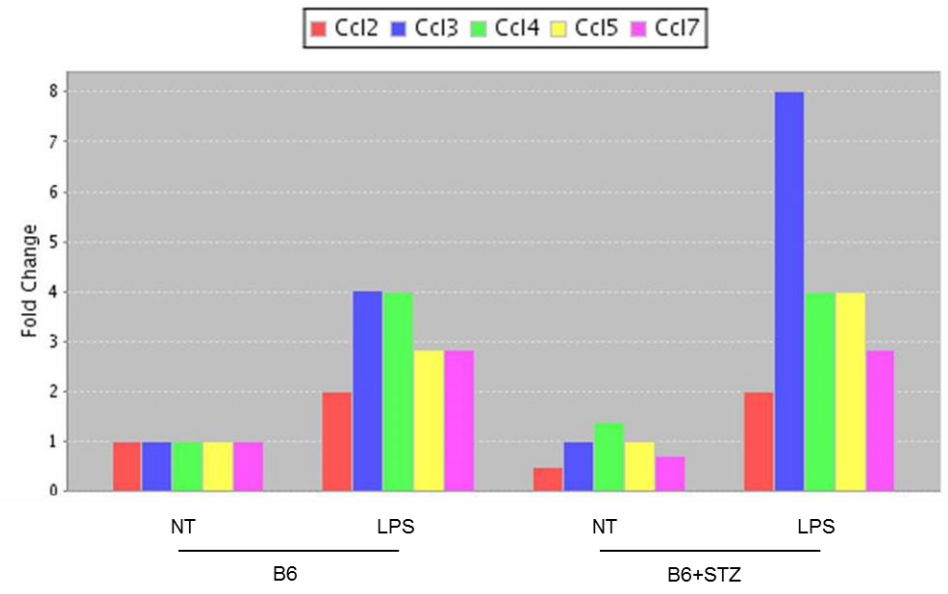

Figura 5. Expressão gênica de quimiocinas em macrófagos residentes peritoneais de animais controles (B6) ou diabéticos (B6+STZ). Camundongos C57BL/6 machos adultos foram injetados com tampão citrato (controles, B6) ou $42 \mathrm{mg} / \mathrm{Kg}$ de massa corporal de estreptozotocina em tampão citrato (diabéticos, B6+STZ), durante 5 dias consecutivos, por via intraperitoneal. Ao fim de 30 dias de diabetes, os animais tiveram os macrófagos peritoneais residentes coletados e cultivados por 4 horas na ausência ou presença de lipopolissacarídeo - LPS $(2,5 \mu \mathrm{g} / \mathrm{mL})$. A expressão gênica foi avaliada por PCR array. A média de expressão dos genes de macrófagos peritoneais de animais controles não estimulados (B6) foi considerada como 1. NT: macrófagos não estimulados; LPS: macrófagos estimulados com LPS. Ccl (chemokine (C-C motif) ligand). 


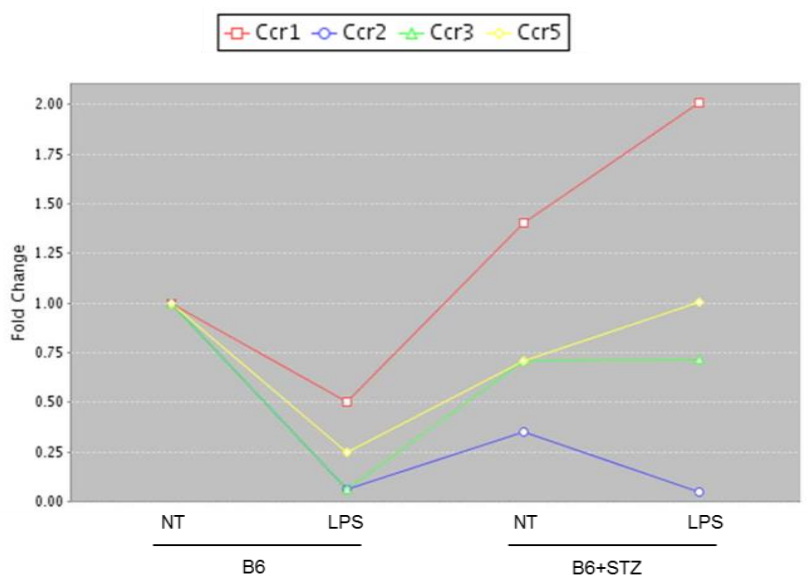

Figura 6. Expressão gênica dos receptores de quimiocinas em macrófagos residentes peritoneais de animais controles (B6) ou diabéticos (B6+STZ). Camundongos C57BL/6 machos adultos foram injetados com tampão citrato (controles, B6) ou $42 \mathrm{mg} / \mathrm{Kg}$ de massa corporal de estreptozotocina em tampão citrato (diabéticos, B6+STZ), durante 5 dias consecutivos, por via intraperitoneal. Ao fim de 30 dias de diabetes, os animais tiveram os macrófagos peritoneais residentes coletados e cultivados por 4 horas na ausência ou presença de lipopolissacarídeo - LPS $(2,5 \mu \mathrm{g} / \mathrm{mL})$. A expressão gênica foi avaliada por PCR array. A média de expressão de genes de macrófagos peritoneais de animais controles não estimulados (B6) foi considerada como 1. NT: macrófagos não estimulados; LPS: macrófagos estimulados com LPS. Ccr (chemokine (C-C motif) receptor).

\subsection{Determinação do fluxo glicolítico em macrófagos peritoneais obtidos de animais C57BL/6 diabéticos}

A determinação da taxa de acidificação extracelular (ECAR) foi realizada para avaliar a atividade da glicólise (ou fluxo glicolítico), capacidade e reserva glicolítica nos macrófagos peritoneais residentes de animais C57BL/6 controles e diabéticos. Isto é possível devido a conversão de glicose a piruvato observada durante o a via glicolítica, e a redução de piruvato a lactato no citoplasma da célula (134). Durante este processo, ocorre um efluxo de íons H, o qual causa uma acidificação do meio extracelular (135). Para a quantificação da glicólise (Figura 7B) foi realizado o cálculo da diferença de valor da ECAR entre o ponto 6 e a média dos pontos de 1-3 (132) (Figuras 7A). Para a quantificação da capacidade glicolítica (Figuras 7C) foi realizado o cálculo da diferença de valor da ECAR entre o ponto 9 e a média dos pontos de 1-3 (Figuras 7A). E por fim, para a quantificação da reserva glicolítica (Figuras 7D) foi realizado o cálculo da diferença de valor da ECAR entre o ponto 9 e o ponto 6 (Figuras 7A). Através da quantificação de acidificação celular observou-se um aumento da glicólise (Figura 7B), 
da capacidade glicolítica (Figura 7C) e da reserva glicolítica (Figura 7D) dos macrófagos dos animais C57BL/6 diabéticos em relação aos controles.

A

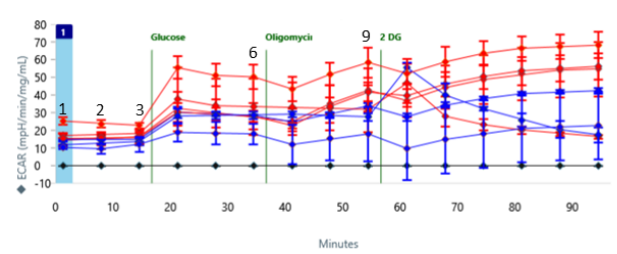

B

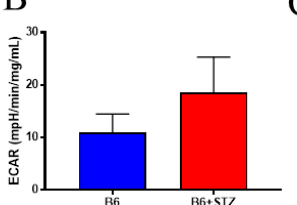

$\mathrm{C}$

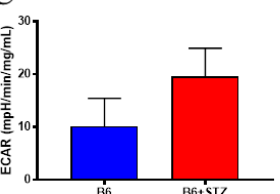

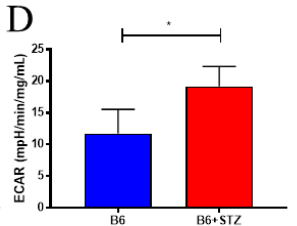

Figura 7. Taxa de acidificação extracelular (A), avaliação da glicólise (B), capacidade glicolítica (C) e da reserva glicolítica (D) nos macrófagos peritoneais residentes de animais $\mathrm{C57BL/6}$ controles e diabéticos. Camundongos C57BL/6 machos adultos foram injetados, por via intraperitoneal com tampão citrato (controles) ou $42 \mathrm{mg} / \mathrm{Kg}$ de massa corporal de estreptozotocina (STZ) em tampão citrato (diabéticos), durante 5 dias consecutivos. Ao fim de 30 dias da indução de diabetes, as células peritoneais foram coletadas, deixadas para aderir em placas XF96 e após 2 horas foram lavadas para obtenção dos macrófagos peritoneais. As concentrações finais utilizadas durante a avaliação da ECAR (taxa de acidificação extracelular) foi de $10 \mathrm{mM}$ de glicose, $1 \mathrm{uM}$ de oligomicina e $0.1 \mathrm{M}$ de 2-DG (2-Deoxi-DGlucose).

\subsection{Determinação da dose não tóxica dos ácidos palmítico, EPA e DHA para macrófagos peritoneais residentes em cultura}

A

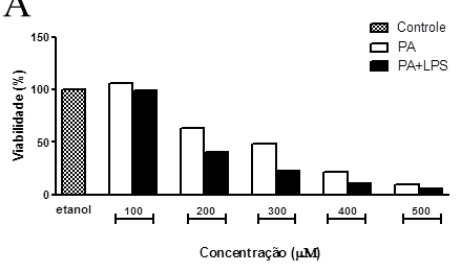

B

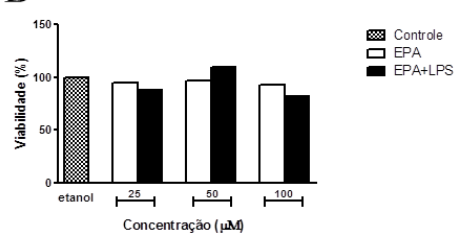

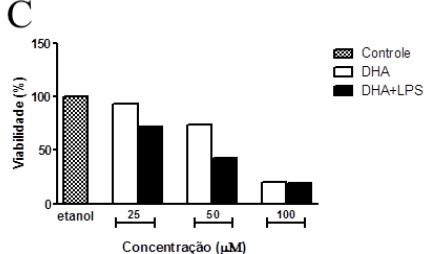

Figura 8. Atividade citotóxica dos ácidos palmítico (A), eicosapentaenóico - EPA (B) e docosaexaenóico - DHA (C) em macrófagos residentes obtidos do peritônio de animais controles. Macrófagos peritoneais residentes foram coletados de camundongos C57BL/6 machos adultos. Após duas horas de cultura e de adesão à placa e 24 horas de cultura com o ácido palmítico em diferentes concentrações, o ensaio de MTT foi realizado. Os dados representam a média da porcentagem de células viáveis calculada a partir do valor das absorbâncias (MTT). Os valores da média de absorbância foram obtidos a partir de triplicatas em dois experimentos individuais. MTT: (3-(4,5-dimethylthiazol-2-yl)-2,5diphenyltetrazolium bromide).

Os resultados do experimento de toxicidade realizado nos macrófagos residentes do peritônio de camundongos machos C57BL/6, após 24 horas de tratamento com diferentes concentrações dos ácidos graxos, estão nas Figuras 8A, B e C. Os ácidos palmítico (PA), eicosapentaenóico (EPA) e docosaexaenóico (DHA) foram diluídos em etanol. Os resultados obtidos são indicativos de que estes não são tóxicos para os macrófagos até uma concentração definida. O PA não foi tóxico até $100 \mu \mathrm{M}$ (Figura A), 
enquanto que EPA (Figura 8B) e DHA (Figura 8C) não foram citotóxicos até $25 \mu \mathrm{M}$. Estas concentrações foram então escolhidas para a realização dos experimentos de tratamento dos macrófagos com os ácidos graxos in vitro.

\subsection{Avaliação da função dos macrófagos de animais diabéticos após tratamento com os ácidos palmítico, EPA e DHA em cultura}

\subsubsection{Determinação do NO e citocinas inflamatórias secretados por macrófagos obtidos de animais controles ou diabéticos após tratamento com os ácidos graxos em cultura por 24 horas}

Após 30 dias da indução de diabetes, os macrófagos peritoneais foram coletados para tratamento ex-vivo. As células foram mantidas em cultura por duas horas para permitir a aderência às placas. Após período para aderência, os macrófagos foram tratados durante 2 horas com $100 \mu \mathrm{M}$ de ácido palmítico (PA), $25 \mu \mathrm{M}$ de ácido eicosapentaenóico (EPA, 20:5) ou com $25 \mu \mathrm{M}$ de ácido docosaexaenóico (DHA, 22:6) e em seguida estimulados com LPS $(2,5 \mu \mathrm{g} / \mathrm{mL})$, durante 22 horas, totalizando 24 horas de tratamento com os ácidos graxos.

A produção de óxido nítrico (NO) pelos macrófagos de animais diabéticos após 30 dias apresentou-se aumentada, independente do tratamento ex-vixo realizado (Figura 9). O tratamento com os ácidos graxos apresentou efeito mais pronunciado nos macrófagos dos animais diabéticos. Isto ocorreu possivelmente devido ao fato destes já se encontrarem em um estado inflamatório pronunciando o efeito dos ácidos graxos.

Houve diminuição significativa na secreção de NO após o tratamento dos macrófagos com EPA e DHA (Figuras 9A). O tratamento com DHA mostrou-se mais potente em modificar a produção de NO dos macrófagos dos animais diabéticos.

O estado diabético por si só aumentou significativamente a produção de IL-1 $\beta$ (Figura 9B) e IL-6 (Figuras 9C) pelos macrófagos após 30 dias de diabetes. O tratamento com DHA diminuiu a produção de óxido nítrico pelos macrófagos de animais diabéticos (Figura 9A) enquanto que o mesmo tratamento diminuiu a produção de citocinas inflamatórias, IL-1 $\beta$ (Figura 9B) e IL-6 (Figura 9C), somente nos macrófagos dos animais controles. Por sua vez, a produção de citocinas pelos macrófagos de animais diabéticos não foi alterada significativamente após tratamento com os ácidos graxos. 

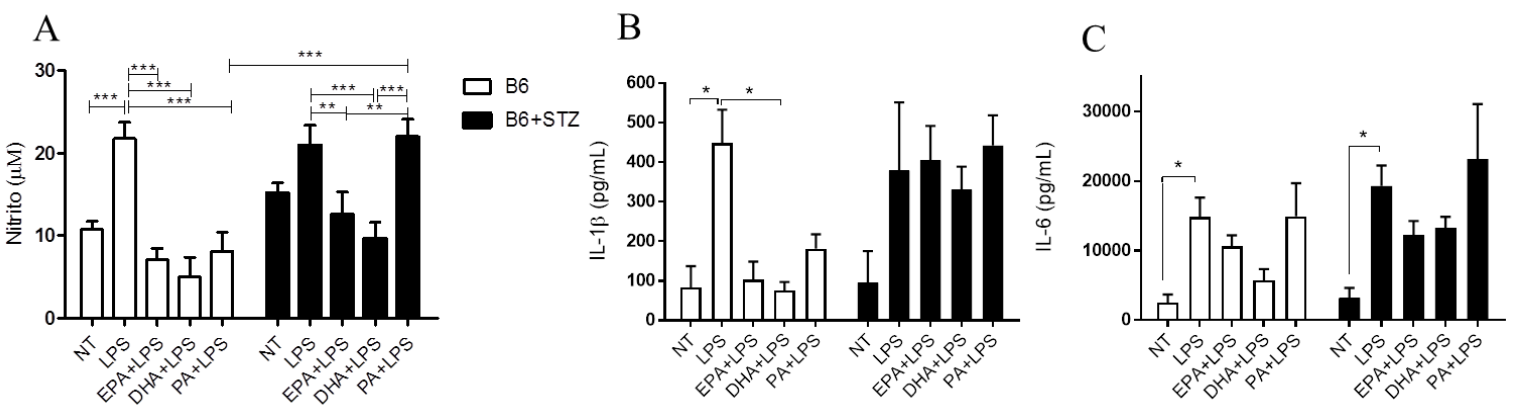

Figura 9. Produção de óxido nítrico (NO), IL-1ß e IL-6 pelos macrófagos peritoneais residentes de animais controles (B6) e diabéticos (B6+STZ) após tratamento com EPA, DHA ou PA. Camundongos C57BL/6 machos adultos foram injetados com tampão citrato (controles) ou $42 \mathrm{mg} / \mathrm{Kg}$ de massa corporal de estreptozotocina em tampão citrato (diabéticos), durante 5 dias consecutivos, por via intraperitoneal. Ao fim de 30 dias de diabetes, os animais tiveram os macrófagos peritoneais residentes coletados e tratados com lipopolissacarídeo - LPS $(2,5 \mu \mathrm{g} / \mathrm{mL})$ e os ácidos graxos. A secreção de NO foi avaliada pela ensaio de Griess. A quantificação de IL-1 $\beta$ e IL-6 foi avaliada por ELISA. Os dados representam a média \pm erro padrão da média de 5 animais por grupo experimental. As condições do experimento foram: NT (nãotratado, meio RPMI suplementado com 10\% soro fetal bovino) ou tratados com ácido eicosapentaenóico EPA $(25 \mu \mathrm{M})$, ácido docosaexaenóico-DHA $(25 \mu \mathrm{M})$ ou ácido palmítico - PA $(100 \mu \mathrm{M})$.

5.5.2 Análise da expressão gênica de citocinas, quimiocinas e receptores de quimiocinas em macrófagos peritoneais de animais controles ou diabéticos após tratamento com o DHA

$\mathrm{O}$ tratamento ex-vivo com DHA mostrou-se mais potente que EPA em diminuir a produção de NO nos macrófagos dos animais diabéticos e por este motivo foi o ácido graxo escolhido para ser estudado nos experimentos posteriores.

Diante da avaliação dos resultados obtidos no PCR array, conclui-se que o tratamento com DHA promoveu um estado pró-inflamatório nos macrófagos de animais controles (Tabela 7 e Figura 10) e anti-inflamatório nas células de animais diabéticos (Tabela 8 e Figura 10).

A expressão das quimiocinas (Figura 11) acompanhou o perfil de expressão das citocinas pró-inflamatórias (Figura 10) nos macrófagos de ambos os grupos. O tratamento com DHA aumentou a expressão das quimiocinas nos macrófagos dos animais controles, enquanto que nas células dos animais diabéticos o DHA diminuiu a expressão dessas (Figura 11). 


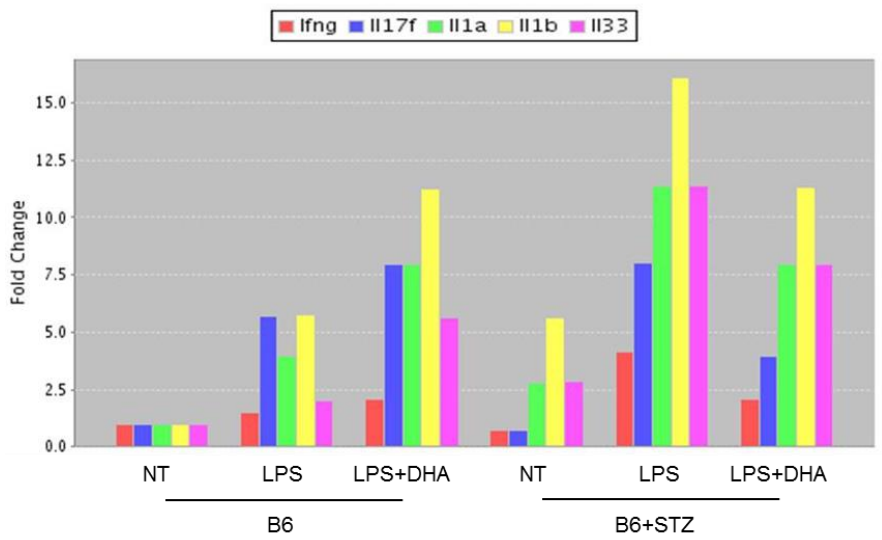

Figura 10. Expressão gênica de citocinas pró-inflamatórias de macrófagos residentes peritoneais de animais controles e diabéticos tratados com LPS e/ou DHA. Camundongos C57BL/6 machos adultos foram injetados com tampão citrato (controles, B6) ou $42 \mathrm{mg} / \mathrm{Kg}$ de massa corporal de estreptozotocina em tampão citrato (diabéticos, B6+STZ), durante 5 dias consecutivos, por via intraperitoneal. Ao fim de 30 dias de diabetes, os animais tiveram os macrófagos peritoneais residentes coletados e cultivados por 4 horas estimulados na ausência ou presença de lipopolissacarídeo - LPS $(2,5 \mu \mathrm{g} / \mathrm{mL})$ e ácido docosaexaenóico DHA $(25 \mu \mathrm{M})$. A expressão gênica foi avaliada por PCR array. A média de expressão de macrófagos peritoneais de animais controles não estimulados foi considerada como 1. NT: macrófagos cultivados em meio suplementado com $10 \%$ soro fetal bovino, LPS: macrófagos estimulados com LPS $(2,5 \mu \mathrm{g} / \mathrm{mL} \mathrm{de}$ lipopolissacarídeo) e LPS+DHA: macrófagos estimulados com LPS $(2,5 \mu \mathrm{g} / \mathrm{mL})$ e DHA $(25 \mu \mathrm{M})$. Ifng (interferon gamma), Il (interleukin).

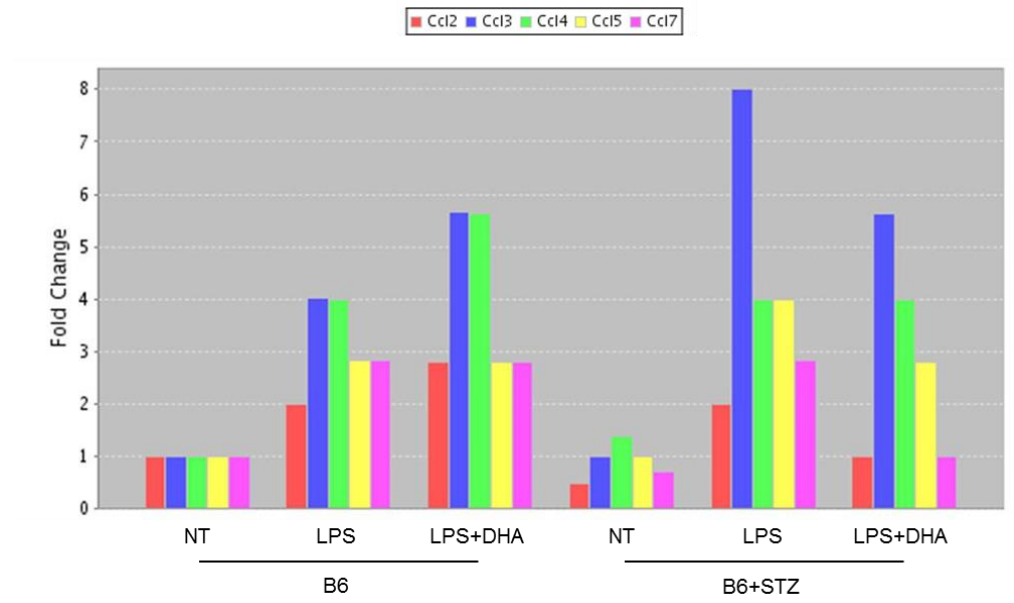

Figura 11. Expressão gênica de quimiocinas de macrófagos residentes peritoneais de animais controles e diabéticos. Camundongos C57BL/6 machos adultos foram injetados com tampão citrato (controles, B6) ou $42 \mathrm{mg} / \mathrm{Kg}$ de massa corporal de estreptozotocina em tampão citrato (diabéticos, B6+STZ), durante 5 dias consecutivos, por via intraperitoneal. Ao fim de 30 dias de diabetes, os animais tiveram os macrófagos peritoneais residentes coletados e cultivados por 4 horas estimulados na ausência ou presença de lipopolissacarídeo - LPS $(2,5 \mu \mathrm{g} / \mathrm{mL})$ e ácido docosaexaenóico - DHA $(25 \mu \mathrm{M})$. A expressão gênica foi avaliada por PCR array. A média de expressão de genes de macrófagos peritoneais de animais controles (B6) não estimulados foi considerada como 1. NT: macrófagos cultivados em meio suplementado com $10 \%$ soro fetal bovino, LPS: macrófagos estimulados com LPS $(2,5 \mu \mathrm{g} / \mathrm{mL})$ e LPS+DHA: macrófagos estimulados com LPS $(2,5 \mu \mathrm{g} / \mathrm{mL})$ e DHA $(25 \mu \mathrm{M})$. Ccl (chemokine $(C$-C motif) ligand).

A expressão dos receptores das quimiocinas foi menor nos macrófagos dos animais controles quando tratados com LPS (Figura 12). Porém, quando estes mesmos 
macrófagos foram tratados com DHA, observou-se aumento na expressão dos receptores (Tabela 7). Já quanto aos macrófagos dos animais diabéticos, observou-se aumento na expressão dos receptores quando estimulados com LPS (Figura 12). O tratamento com DHA não alterou de maneira relevante esse último resultado (Tabela 8 e Figura 12). Podese destacar o fato de que o tratamento com DHA atenuou a intensidade do quadro inflamatório nos macrófagos dos animais diabéticos (Figura 13B).

Os efeitos do tratamento com DHA sobre a expressão gênica dos componentes inflamatórios em macrófagos de animais controles são indicativos de propriedade próinflamatória (Tabela 7, Figura 13A). Contudo, esta característica biológica é revertida para um perfil anti-inflamatório quando os macrófagos tratados com DHA são obtidos de animais diabéticos (Tabela 8 e Figura 13B).

Tabela 7. Relação de genes diferencialmente expressos em macrófagos de animais controles tratados com DHA e LPS em relação às células de animais controles tratados somente com LPS.

\begin{tabular}{c|c}
\hline Gene & Fold Change (vezes de alteração) \\
\hline Ccl22 & 2,7587 \\
\hline Ccr1 & 2,7994 \\
\hline Ccr3 & 11,2386 \\
\hline Ccr5 & 4,0179 \\
\hline Ccr6 & 4,1055 \\
\hline Cxc11 & 5,5792 \\
\hline Cxc15 & 11,2106 \\
\hline I11rn & 2,8415 \\
\hline Il33 & 2,801 \\
\hline Nampt & 2,831 \\
\hline Spp1 & 2,8269 \\
\hline Tnf & 2,7938 \\
\hline Tnfsf10 & 2,7928 \\
\hline
\end{tabular}

Camundongos C57BL/6 machos adultos foram injetados com tampão citrato (controles) ou $42 \mathrm{mg} / \mathrm{Kg}$ de massa corporal de estreptozotocina em tampão citrato (diabéticos), durante 5 dias consecutivos, intraperitonealmente. Ao fim de 30 dias de diabetes, os animais tiveram os macrófagos peritoneais residentes coletados e cultivados por 4 horas sem estímulo. A expressão gênica foi avaliada por PCR array. Todos os genes listados na tabela apresentam expressão aumentada nos macrófagos de animais controles tratados com lipopolissacarídeo - LPS $(2,5 \mu \mathrm{g} / \mathrm{mL})$ e ácido docosaexaenóico - DHA $(25 \mu \mathrm{M})$ em relação aos macrófagos de animais controles tratados somente com LPS. Ccl (chemokine ( $\mathrm{C}$ - $\mathrm{C}$ motif) ligand), $\mathrm{Ccr}$ (chemokine (C-C motif) receptor), $\mathrm{Cxcl}$ (chemokine ( $C-X-C$ motif) ligand), Il (interleukin), Il1rn (interleukin 1 receptor antagonist), Nampt (nicotinamide phosphoribosyltransferase), Spp1 (secreted phosphoprotein 1), Tnf (tumor necrosis factor), Tnfsf10 (tumor necrosis factor (ligand) superfamily, member 10). 
Tabela 8. Relação de genes diferencialmente expressos em macrófagos de animais diabéticos tratados com DHA e LPS em relação às células de animais diabéticos tratados somente com LPS.

\begin{tabular}{c|c}
\hline Gene & Fold change (vezes de alteração) \\
\hline $\mathrm{Ccl} 12$ & $-2,8312$ \\
\hline $\mathrm{Ccl} 7$ & $-2,8342$ \\
\hline $\mathrm{I} 127$ & $-2,8275$ \\
\hline
\end{tabular}

Camundongos C57BL/6 machos adultos foram injetados com tampão citrato (controles) ou $42 \mathrm{mg} / \mathrm{Kg} \mathrm{de}$ massa corporal de estreptozotocina em tampão citrato (diabéticos), durante 5 dias consecutivos, por via intraperitoneal. Ao fim de 30 dias de diabetes, os animais tiveram os macrófagos peritoneais residentes coletados e cultivados por 4 horas sem estímulo. A expressão gênica foi avaliada por PCR array. Todos os genes listados na tabela apresentam expressão diminuída nos macrófagos de animais diabéticos tratados com lipopolissacarídeo - LPS $(2,5 \mu \mathrm{g} / \mathrm{mL})$ e ácido docosaexaenóico - DHA $(25 \mu \mathrm{M})$ em relação aos macrófagos de animais diabéticos tratados somente com LPS. $\mathrm{Ccl}$ (chemokine $(C-C$ motif) ligand), $\mathrm{Ccr}$ (chemokine ( $C$-C motif) receptor), $\mathrm{Cxcl}$ (chemokine ( $C$ - $X$ - $C$ motif) ligand), Il27 (interleukin 27$)$,

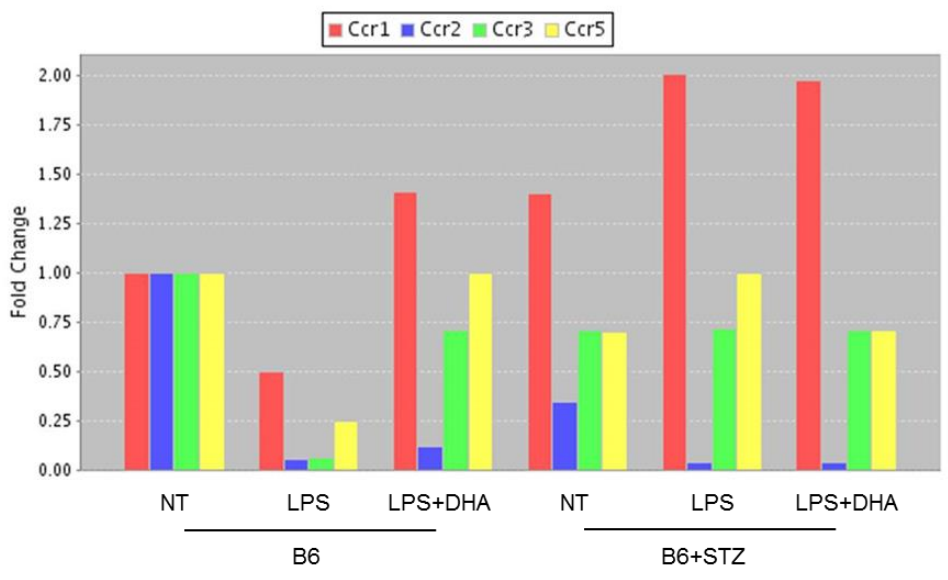

Figura 12. Expressão gênica dos receptores de quimiocinas em macrófagos residentes do peritônio de animais controles e diabéticos. Camundongos C57BL/6 machos adultos foram injetados com tampão citrato (controles) ou $42 \mathrm{mg} / \mathrm{Kg}$ de massa corporal de estreptozotocina em tampão citrato (diabéticos), durante 5 dias consecutivos, por via intraperitoneal. Ao fim de 30 dias de diabetes, os animais tiveram os macrófagos peritoneais residentes coletados e cultivados por 4 horas na presença ou ausência de lipopolissacarídeo - LPS e ácido docosaexaenoico - DHA. A expressão gênica foi avaliada por PCR array. A média de expressão dos genes em macrófagos peritoneais de animais controles não estimulados (B6) foi considerada como 1. NT: macrófagos cultivados em meio suplementado com $10 \%$ soro fetal bovino, LPS: macrófagos estimulados com LPS $(2,5 \mu \mathrm{g} / \mathrm{mL})$ e LPS+DHA: macrófagos estimulados com LPS $(2,5$ $\mu \mathrm{g} / \mathrm{mL})$ e DHA $(25 \mu \mathrm{M})$. Ccr (chemokine (C-C motif) receptor). 
A
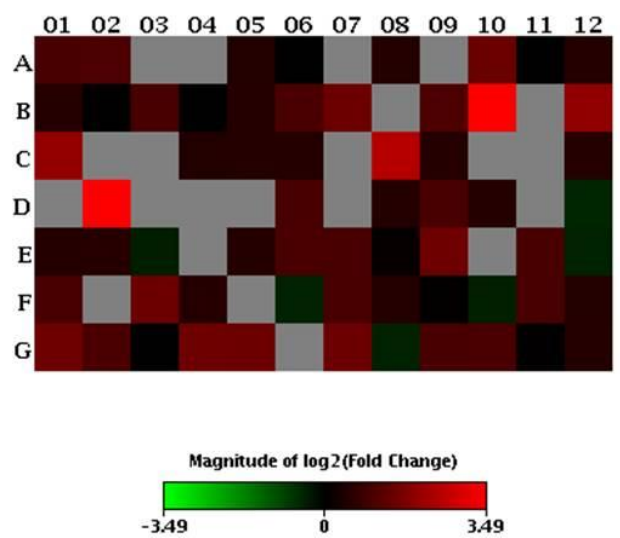

B
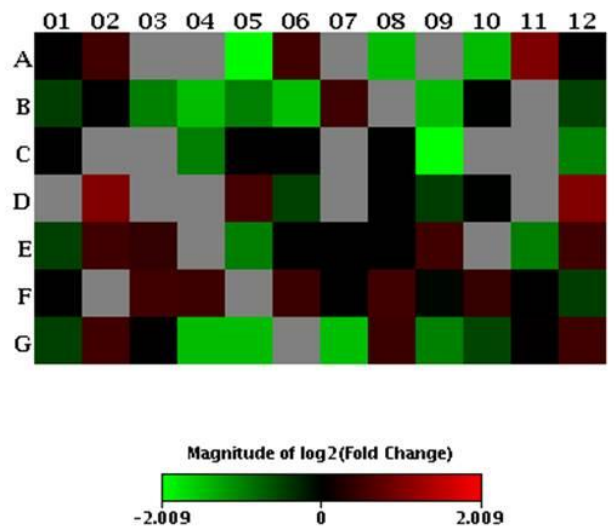

Figura 13. Heat map representativo da placa de PCR array dos macrófagos dos animais controles e diabéticos após tratamento com DHA. A. Regulação da expressão gênica em macrófagos de animais controles tratados com DHA. A expressão gênica de macrófagos de animais controles estimulados somente com lipopolissacarídeo - LPS foi utilizada como controle. B. Regulação da expressão gênica em macrófagos de animais diabéticos tratados com o ácido docosaexaenoico - DHA. A expressão gênica em macrófagos de animais diabéticos estimulados somente com LPS foi utilizada como controle. Camundongos C57BL/6 machos adultos foram injetados com tampão citrato (controles) ou $42 \mathrm{mg} / \mathrm{Kg}$ de massa corporal de estreptozotocina em tampão citrato (diabéticos), durante 5 dias consecutivos, por via intraperitoneal. Ao fim de 30 dias de diabetes, os animais tiveram os macrófagos peritoneais residentes coletados e cultivados por 4 horas na presença de LPS $(2,5 \mu \mathrm{g} / \mathrm{mL})$ e de DHA $(25 \mu \mathrm{M})$ ou somente LPS $(2,5 \mu \mathrm{g} / \mathrm{mL})$.

\subsection{Caracterização do modelo de diabetes mellitus tipo 1 em camundongos C57BL/6, knockout para NLRP3 ou knockout para RAGE quimicamente induzido por administração de estreptozotocina}

5.6.1 Glicemia, massa corporal, insulinemia e concentração de AGEs no soro dos animais knockout para NLRP3 ou knockout para RAGE

A participação das moléculas NLRP3 (NOD-like receptor family-pyrin domains containing 3) e do receptor de AGEs (advanced glycation end products), RAGE, no desenvolvimento do perfil inflamatório dos macrófagos peritoneais dos animais com diabetes mellitus do tipo I foi investigada. Para isso, animais C57BL/6 knockout (KO) para NLRP3 ou RAGE foram submetidos à administração intraperitoneal de 5 doses (42 $\mathrm{mg} / \mathrm{kg}$ de massa corporal) diárias e consecutivas de estreptozotocina diluída em tampão citrato $(25 \mathrm{mM}, \mathrm{pH}=4,2)$. Os animais foram considerados diabéticos após apresentarem duas avaliações não consecutivas (verificadas com intervalo de dois dias) de glicemia mais elevada que $250 \mathrm{mg} / \mathrm{dL}$ pela manhã sem jejum. 
A ausência de NLRP3 ou RAGE não preveniu o desenvolvimento do quadro diabético caracterizado por aumento da glicemia (Figura 14A), diminuição de massa corporal (Figura 14B) e da concentração de insulina sérica (Figura 14C). Como esperado, os animais diabéticos C57BL/6, NLRP3 KO e RAGE KO (com média de massa corpórea de $23.75 \mathrm{~g}, 24.56 \mathrm{~g}, 23.33 \mathrm{~g}$, respectivamente) induzidos por estreptozotocina deixaram de ganhar massa corporal ao serem comparados com os controles (média de 26,55g; 27,55g e 25,8g, respectivamente) (Figura 14B).

Os animais diabéticos C57BL/6 (B6+STZ) apresentaram concentração média de 0,89 $\pm 0,23 \mathrm{ng} / \mathrm{mL}$ de insulina no soro, enquanto os animais controles C57BL/6 (B6) apresentaram 2,72 $\pm 0,45 \mathrm{ng} / \mathrm{mL}$ (Figura 14C). Já os animais diabéticos NLRP3 KO

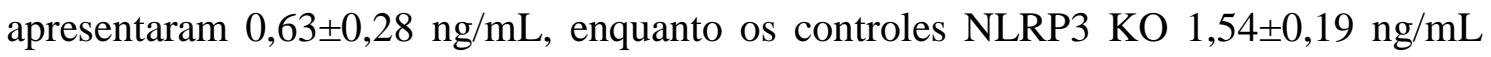
(Figura 14C). A insulinemia avaliada entre os animais controles RAGE KO e diabéticos RAGE KO não apresentou diferenças significativas (Figura 14C).

Além da quantificação de insulina, os níveis de AGEs detectados no soro não foram significativamente alterados ao comparar os grupos experimentais (Figura 14D).
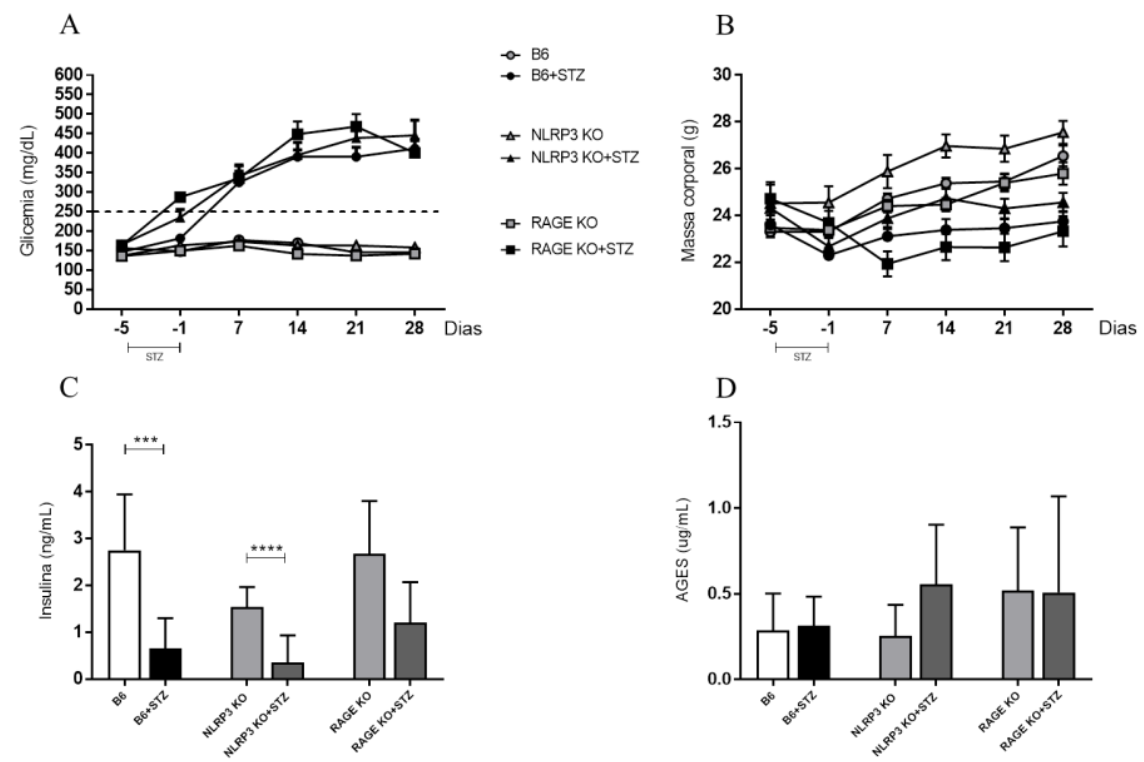

Figura 14. Evolução da glicemia, massa corporal e concentração de insulina e AGEs no soro após 30 dias da indução de diabetes. Camundongos C57BL/6, knockout para NLRP3 (NLRP3 KO) ou RAGE knockout (RAGE KO) machos adultos foram injetados, por via intraperitoneal com tampão citrato (controles) ou $42 \mathrm{mg} / \mathrm{Kg}$ de massa corporal de estreptozotocina (STZ) em tampão citrato (diabéticos), durante 5 dias consecutivos. A concentração plasmática de glicose foi determinada em amostras coletadas da veia da cauda utilizando glicosímetro Accu-Check Active (Roche Diagnostics, Abbott Park, IL, USA). A glicemia basal e a massa corporal dos animais foi avaliada semanalmente pela manhã (não jejum). Ao fim de 30 dias de diabetes, os animais tiveram amostras de sangue coletadas e centrifugadas para obtenção do soro. A concentração de insulina e AGEs foi determinada por ELISA. AGEs: produtos finais de glicação avançada. STZ: estreptozotocina. Os dados representam a média \pm erro padrão da média de 4-8 animais por grupo experimental. 
5.6.2 Avaliação das citocinas do soro dos animais diabéticos C57BL/6, NLRP3 knockout e RAGE knockout

Foi determinada a concentração de IL-1 $\beta$, IL-1 $\alpha$, IL-18, IL-6, TNF- $\alpha$, CXCL1, CCL2 e IL-10 no soro dos animais diabéticos e controles. Não foi observada diferença significativa na concentração das citocinas no soro entre os animais controles e diabéticos. Contudo, a concentração de IL-18 (Figura 15C) e de TNF- $\alpha$ (Figura 15E) observa-se um aumento destas citocinas no soro dos animais diabéticos C57BL/6, NLRP3 KO e RAGE $\mathrm{KO}$.
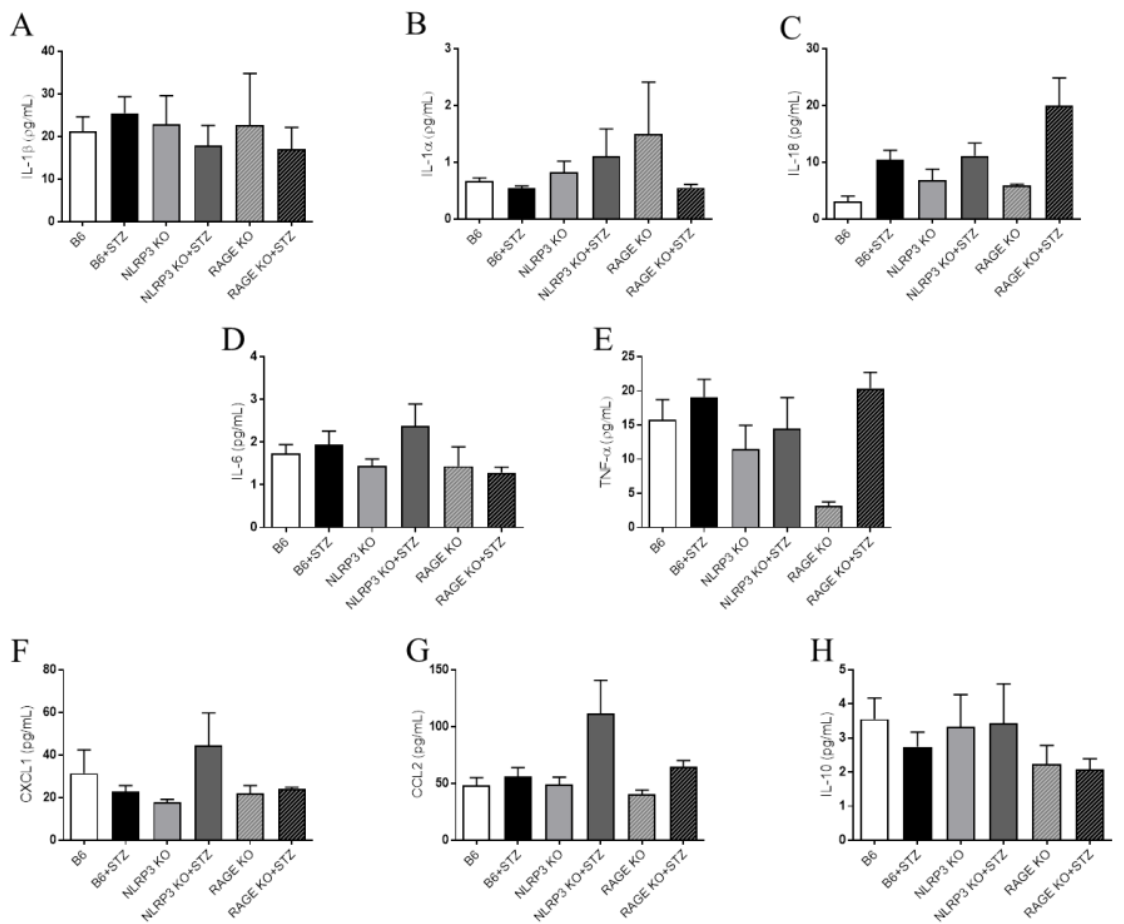

Figura 15. Quantificação de citocinas e quimiocinas no soro dos animais C57BL/6, NLRP3 KO e RAGE KO após 30 dias da indução de diabetes. Camundongos C57BL/6, knockout para NLRP3 (NLRP3 KO) ou RAGE knockout (RAGE KO) machos adultos foram injetados, por via intraperitoneal com tampão citrato (controles) ou $42 \mathrm{mg} / \mathrm{Kg}$ de massa corporal de estreptozotocina (STZ) em tampão citrato (diabéticos), durante 5 dias consecutivos. Ao fim de 30 dias de diabetes, os animais tiveram amostras de sangue coletadas e centrifugadas para obtenção do soro. A concentração de IL-1 $\beta$, IL-1 $\alpha$, IL-18, IL-6, TNF$\alpha$, CXCL1, CCL2 e IL-10 foi determinada em Multiplex. Os dados representam a média \pm erro padrão da média de 4-9 animais por grupo experimental. 
5.6.3 Avaliação das citocinas produzidas pelas células nucleadas da medula óssea de animais diabéticos C57BL/6, NLRP3 knockout e RAGE knockout

Após a avaliação de citocinas no soro, as células da medula óssea foram coletadas após 30 dias do estabelecimento do quadro de diabetes e cultivadas durante 24 horas para avaliação da produção de NO, citocinas e quimiocinas.

Diferentemente dos resultados observados nos macrófagos peritoneais, as células nucleadas da medula óssea dos animais C57BL/6 diabéticos produzem menos NO (Figura 16A) e IL-1 $\beta$ (Figura 16B) após estimulo com LPS. Além disso, a ausência de NLRP3 e RAGE aumentou a produção de NO nas células da medula óssea dos animais diabéticos em relação aos controles (Figura 16A). Na ausência de RAGE a produção de IL-1 $\beta$ (Figura 16B) e TNF- $\alpha$ (Figura 16F) foi mais elevada que nos animais C57BL/6 diabéticos. Em relação à produção de IL-10, houve diminuição da produção pelos macrófagos dos animais C57BL/6 diabéticos (Figura 16I). As citocinas IL-1 $\alpha$, IL-18, IL-6, CXCL1 e CCL2 não foram alteradas pelo estado diabético.

A

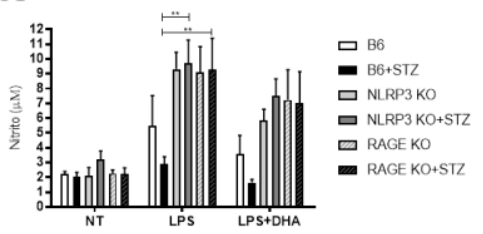

$\mathrm{D}$
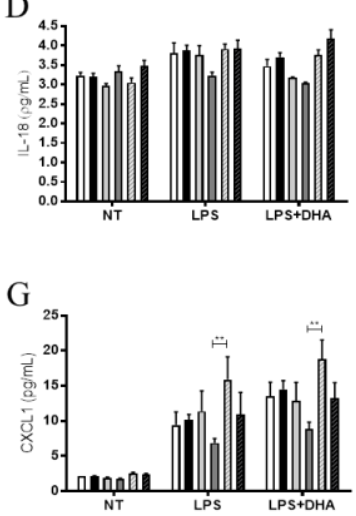

B

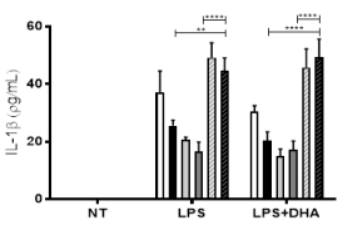

$\mathrm{E}$

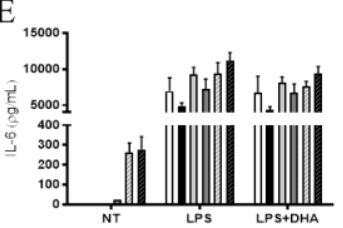

$\mathrm{H}$

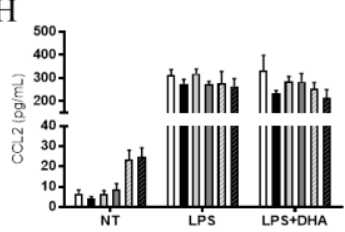

$\mathrm{C}$

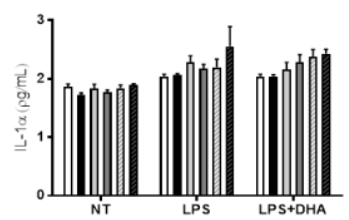

$\mathrm{F}$
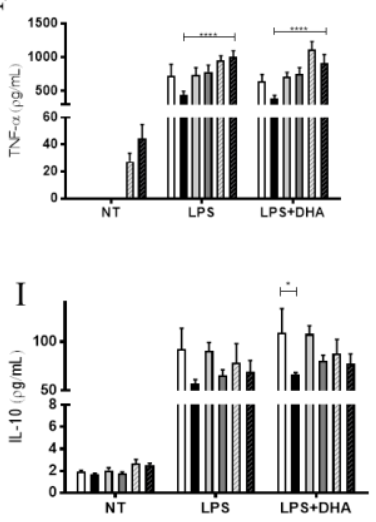

Figura 16. Quantificação de citocinas e quimiocinas no meio de cultura de células nucleadas da medula óssea dos animais C57BL/6, NLRP3 KO e RAGE KO após 30 dias de diabetes. Camundongos C57BL/6, NLRP3 knockout (NLRP3 KO) e RAGE knockout (RAGE KO) machos adultos foram injetados, por via intraperitoneal com tampão citrato (controles) ou $42 \mathrm{mg} / \mathrm{Kg}$ de massa corporal de estreptozotocina (STZ) em tampão citrato (diabéticos), durante 5 dias consecutivos. Ao fim de 30 dias de diabetes, a medula óssea foi retirada, as células vermelhas foram lisadas e as células nucleadas foram cultivadas com lipopolissacarídeo - LPS $(2,5 \mu \mathrm{g} / \mathrm{mL})$ e ácido docosaexaenoico - DHA $(25 \mu \mathrm{M})$ durante 24 horas. A quantificação de IL-1 $\beta$, IL-1 $\alpha$, IL-18, IL-6, TNF- $\alpha$, CXCL1, CCL2 e IL-10 foi determinada utilizando Multiplex. Os dados representam a média \pm erro padrão da média de 4-9 animais por grupo experimental. 


\subsection{Avaliação da função dos macrófagos de animais diabéticos C57BL/6, NLRP3 knockout ou RAGE knockout após tratamento com DHA em cultura}

\subsubsection{Análise da produção de óxido nítrico, citocinas e quimiocinas nos macrófagos peritoneais de animais C57BL/6, NLRP3 KO e RAGE KO controles e diabéticos}

Como descrito previamente, os macrófagos dos animais diabéticos apresentaram produção aumentada de NO na presença de LPS $(24,44 \pm 3,91 \mu \mathrm{M})$ em relação aos controles $(8,90 \pm 0,60 \mu \mathrm{M})$ (Figura 17A). Em contrapartida, a ausência de NLRP3 diminuir a produção de $\mathrm{NO}(11,85 \pm 2,51 \mu \mathrm{M})$ em macrófagos de animais diabéticos na mesma condição (Figura 18A). Além disso, o tratamento com DHA diminuiu drasticamente os valores de NO $(4,83 \pm 1,89 \mu \mathrm{M})$ produzido pelos macrófagos dos animais diabéticos, quando comparado com tratamento ex-vivo somente com LPS $(24,44$ $\pm 3,91 \mu \mathrm{M})$ (Figura 17A).

A produção de IL-1 $\beta$ (Figura 17B) e IL-18 (Figura 17C) por macrófagos dos animais diabéticos, na ausência de NLRP3, e estimulados com LPS apresentou-se diminuída em relação aos animais C57BL/6 diabéticos. A IL-10 apresentou-se diminuída $(47,42 \pm 7,99 \mathrm{pg} / \mathrm{mL})$ quando os macrófagos dos animais diabéticos NLRP3 KO foram estimulados com LPS, em comparação com as células dos animais controles NLRP3 KO (471,3 \pm 164 pg/mL). Não houve alteração na produção de IL-1 $\alpha$, IL-6, CXCL1 e CCL2 no estado diabético e nos tratamento com LPS ou LPS e DHA. A ausência do receptor de AGE (RAGE) não teve efeito significativo nas condições experimentais estudadas, ou seja, indução de diabetes e tratamentos com LPS e DHA em cultura. Por este motivo utilizamos somente os animais C57BL/6 e NLRP3 KO na continuidade do estudo. 
A
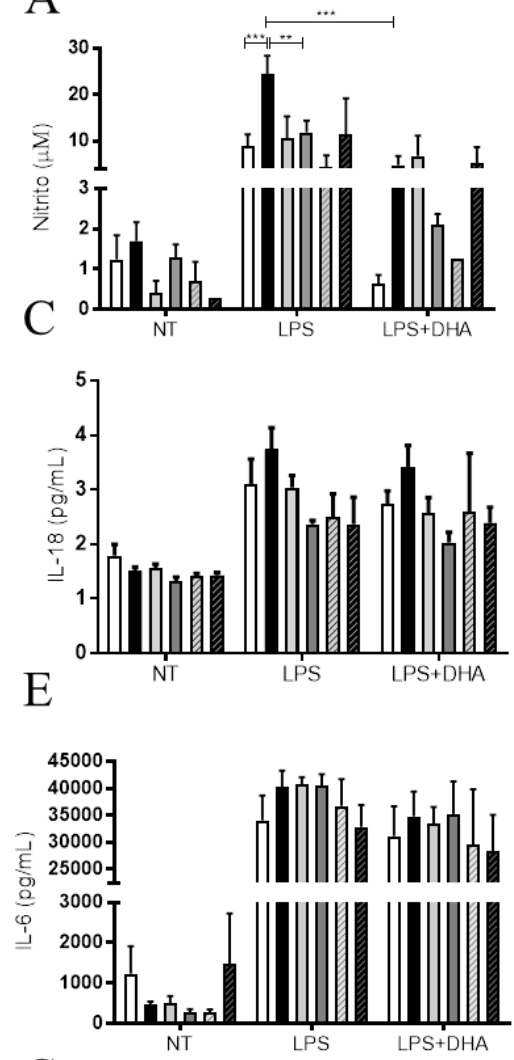

$\mathrm{G}$

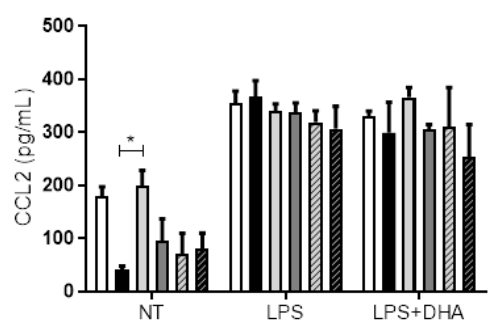

B
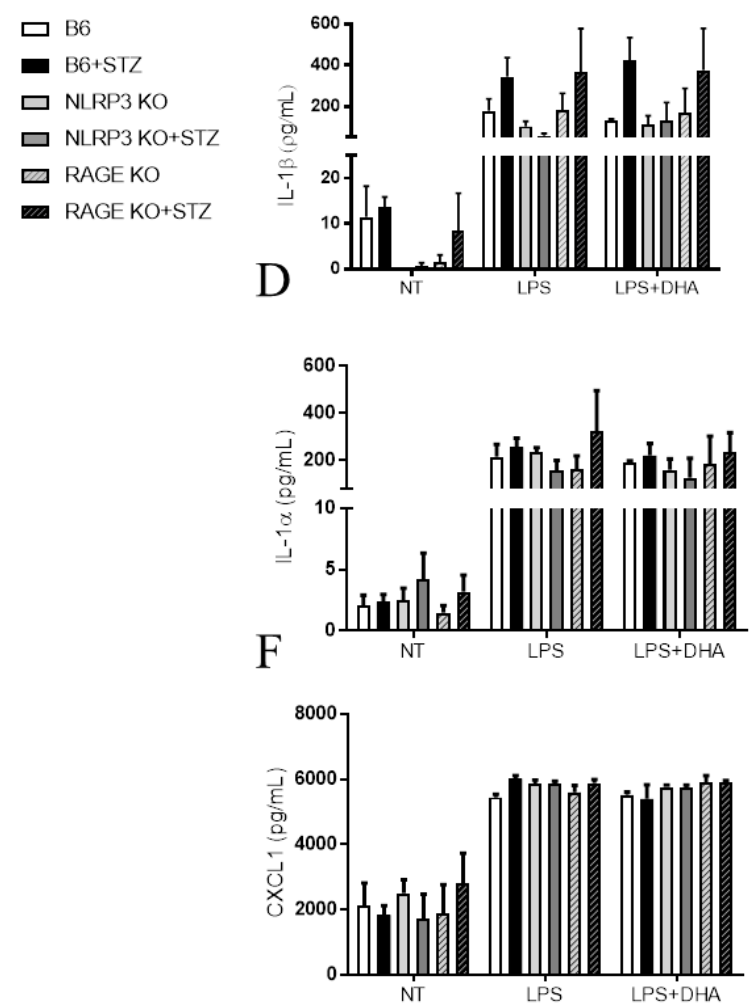

$\mathrm{H}$

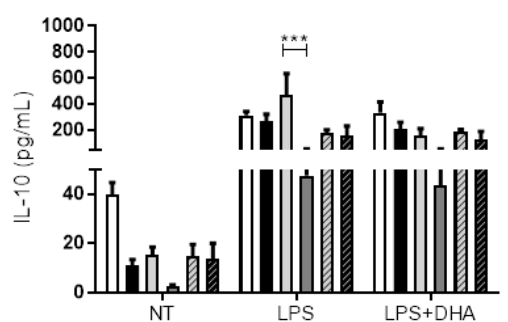

Figura 17. Quantificação de nitrito, citocinas e quimiocinas pelos macrófagos peritoneais dos animais C57BL/6, NLRP3 KO e RAGE KO após 30 dias da indução de diabetes. Camundongos C57BL/6, knockout para NLRP3 (NLRP3 KO) ou RAGE knockout (RAGE KO) machos adultos foram injetados, por via intraperitoneal com tampão citrato (controles) ou $42 \mathrm{mg} / \mathrm{Kg}$ de massa corporal de estreptozotocina (STZ) em tampão citrato (diabéticos), durante 5 dias consecutivos. Ao fim de 30 dias de diabetes, os animais tiveram os macrófagos peritoneais residentes coletados e tratados com lipopolissacarídeo - LPS (2,5 $\mu \mathrm{g} / \mathrm{mL})$ e ácido docosaexaenóico - DHA $(25 \mu \mathrm{M})$ por 24 horas. A secreção de nitrito foi avaliada pelo ensaio de Griess. A quantificação de IL-1 $\beta$ e IL-6 foi avaliada por ELISA. A quantificação de IL-1 $\alpha$, IL18, CXCL1, CCL2 e IL-10 foi avaliada por Multiplex. Os dados representam a média \pm erro padrão da média de 4-6 animais por grupo experimental. 


\subsubsection{Análise da expressão de iNOS nos macrófagos peritoneais de animais C57BL/6 e NLRP3 KO controles e diabéticos}

Evidenciamos que o estabelecimento do quadro diabético por 30 dias está associado com o aumento da produção de NO pelos macrófagos (Figura 2F). Além disso, a presença da molécula NLRP3 tem participação relevante em relação à produção de NO pelos macrófagos peritoneais dos animais diabéticos (Figura 17A). Em vista disso, foi avaliado o envolvimento da iNOS nesses achados. Observou-se que os macrófagos de animais diabéticos apresentam expressão elevada da iNOS (óxido nítrico sintase induzível) e que o tratamento com DHA ex-vivo diminui abruptamente a expressão dessa enzima (Figuras 18A e 18B). Por outro lado, na ausência de NLRP3 não foi detectada expressão de iNOS nos macrófagos dos animais diabéticos (Figuras 18C e 18D), corroborando os resultados descritos previamente em relação à diminuição da produção de NO pelos macrófagos dos animais diabéticos NLRP3 KO.

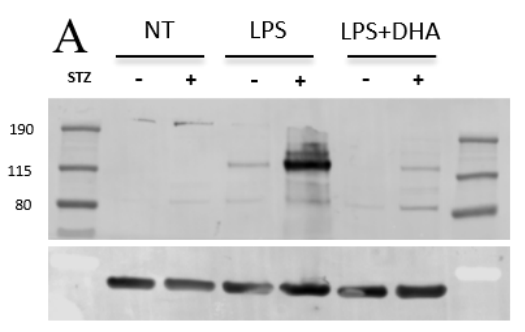

$\mathrm{C}$

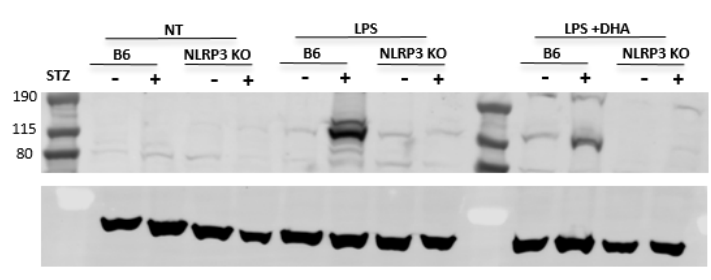

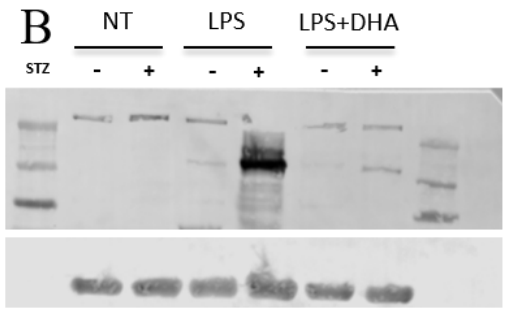

$\mathrm{D}$

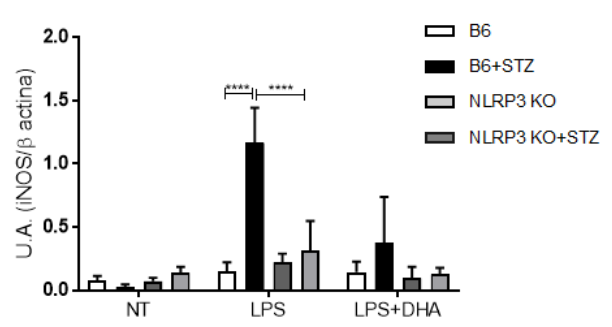

Figura 18. Expressão da iNOS pelos macrófagos dos animais C57BL/6 e NLRP3 KO após 30 dias da indução de diabetes. A e B. Expressão de iNOS nos macrófagos de animais C57BL/6 controles (STZ - ) e C57BL/6 diabéticos (STZ + ). C. Expressão de iNOS em macrófagos de animais C57BL/6 e NLRP3 KO controles (STZ - ), C57BL/6 e NLRP3 KO diabéticos (STZ + ). Camundongos C57BL/6 e knockout para NLRP3 (NLRP3 KO) machos adultos foram injetados, por via intraperitoneal com tampão citrato (controles) ou $42 \mathrm{mg} / \mathrm{Kg}$ de massa corporal de estreptozotocina (STZ) em tampão citrato (diabéticos), durante 5 dias consecutivos. Ao fim de 30 dias de diabetes, os animais tiveram os macrófagos peritoneais residentes coletados e tratados com lipopolissacarídeo - LPS $(2,5 \mu \mathrm{g} / \mathrm{mL})$ e ácido docosaexaenoico - DHA $(25 \mu \mathrm{M})$. Após 24 horas de tratamento, o lisado foi coletado e as proteínas foram quantificadas por western blotting. Os dados foram analisados e normalizados pelos valores de beta actina. U.A.: unidades arbitrárias em relação aos macrófagos dos animais controles não-tratados (B6, NT). Os dados representam a média \pm erro padrão da média de 3-4 animais por grupo experimental. 


\subsubsection{Análise da expressão de NLRP3 nos macrófagos peritoneais de animais C57BL/6 controles e diabéticos}

Para melhor entendimento da participação de NLRP3 no estabelecimento do perfil inflamatório dos macrófagos, caracterizado pela produção de NO, foi investigada a expressão de NLRP3 nos macrófagos após 30 dias da indução de diabetes. Observou-se aumento na expressão de NLRP3 após estimulo de LPS nos macrófagos dos animais diabéticos em relação às células dos controles (Figuras 19 A-C).

A

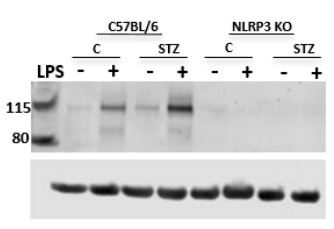

B

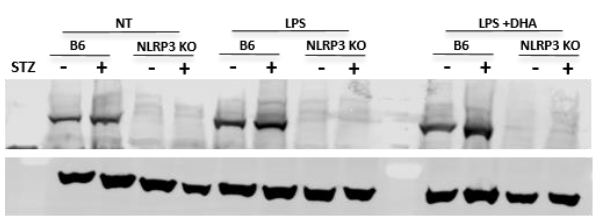

$\mathrm{C}$

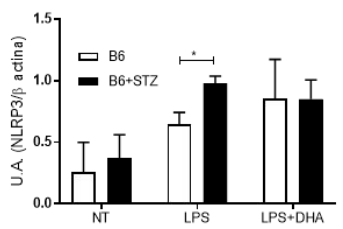

Figura 19. Expressão de NLRP3 nos macrófagos dos animais C57BL/6 e NLRP3 KO após 30 dias da indução de diabetes. Camundongos C57BL/6 e knockout para NLRP3 (NLRP3 KO) foram injetados, por via intraperitoneal com tampão citrato (STZ -) ou $42 \mathrm{mg} / \mathrm{Kg}$ de massa corporal de estreptozotocina (STZ) em tampão citrato (STZ +), durante 5 dias consecutivos. Ao fim de 30 dias de diabetes, os animais tiveram os macrófagos peritoneais residentes coletados e tratados com lipopolissacarídeo - LPS $(2,5 \mu \mathrm{g} / \mathrm{mL})$ e ácido docosaexaenóico - DHA $(25 \mu \mathrm{M})$. Após 24 horas de tratamento, o lisado foi coletado e as proteínas analisadas por western blotting. Os dados foram analisados e normalizados pelos valores de beta actina. U.A.: unidades arbitrárias em relação aos macrófagos dos animais controles não-tratados (B6, NT). Os dados representam a média \pm erro padrão da média de 3-4 animais por grupo experimental.

\subsubsection{Análise da expressão de PARP1 nos macrófagos peritoneais de animais} C57BL/6 e NLRP3 KO controles ou diabéticos

Um dos mecanismos responsáveis pela indução da transcrição do gene inos ocorre pela ativação de PARP1 (poly (ADP-ribose) polymerase-1). Preliminarmente observouse aumento da expressão de PARP-1 total (Figuras 20A e B) e PARP1 clivada (Figuras 20A e C) na condição diabética após tratamento com LPS, tanto nos macrófagos dos animais diabéticos C57BL/6 quanto nos macrófagos dos animais diabéticos NLRP3 KO. Porém, ao comparar a intensidade do sinal das proteínas PARP1 total e clivada, foi possível observar que a ausência de NLRP3 diminuiu a expressão de PARP1 (Figura 20A). Além disso, o tratamento ex-vivo com DHA foi capaz de diminuir a expressão de 
PARP1 total nos macrófagos dos animais diabéticos NLRP3 KO em relação ao tratamento somente com LPS (Figuras 20A e B).

A

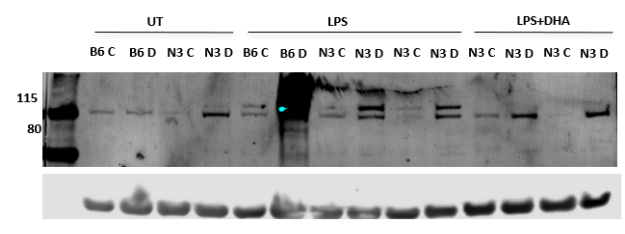

B

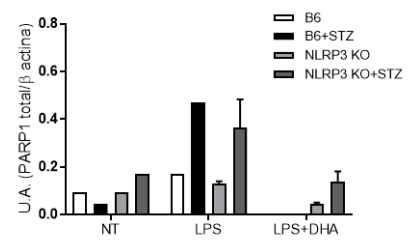

$\mathrm{C}$

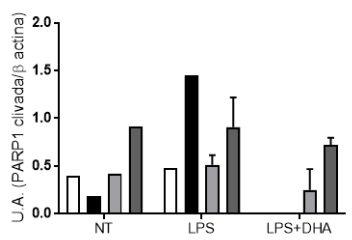

Figura 20. Expressão de PARP1 nos macrófagos dos animais C57BL/6 ou NLRP3 KO após 30 dias da indução de diabetes. Camundongos C57BL/6 e knockout para NLRP3 (NLRP3 KO) machos adultos foram injetados, por via intraperitoneal com tampão citrato (B6) ou $42 \mathrm{mg} / \mathrm{Kg}$ de massa corporal de estreptozotocina (STZ) em tampão citrato (B6+STZ), durante 5 dias consecutivos. Ao fim de 30 dias de diabetes, os animais tiveram os macrófagos peritoneais residentes coletados e tratados com lipopolissacarídeo - LPS $(2,5 \mu \mathrm{g} / \mathrm{mL})$ e ácido docosaexaenóico DHA $(25 \mu \mathrm{M})$. Após 24 horas de tratamento, o lisado foi coletado e as proteínas analisadas por western blotting. Os dados foram analisados e normalizados pelos valores de beta actina. U.A.: unidades arbitrárias em relação aos macrófagos dos animais controles não-tratados (B6, NT). Os dados representam a média \pm desvio padrão da média de 1-3 animais por grupo experimental.

Tabela 9. Resumos dos efeitos do tratamento ex-vivo com DHA em relação ao tratamento com LPS

\begin{tabular}{c|c|c|c}
\hline \multicolumn{2}{c|}{ Macrófagos de controles (B6) } & \multicolumn{2}{c}{ Macrófagos de diabéticos (B6+STZ) } \\
\hline $\mathbf{4}$ horas com DHA & $\mathbf{2 4}$ horas com DHA & $\mathbf{4}$ horas com DHA & $\mathbf{2 4}$ horas com DHA \\
\hline $\begin{array}{c}\uparrow \text { Citocinas pró- } \\
\text { inflamatórias }\end{array}$ & $\begin{array}{c}\downarrow \text { Citocinas pró- } \\
\text { inflamatórias }\end{array}$ & $\begin{array}{c}\downarrow \text { Citocinas pró- } \\
\text { inflamatórias }\end{array}$ & $\begin{array}{c}\leftrightarrow \text { Citocinas pró- } \\
\text { inflamatórias }\end{array}$ \\
\hline$\uparrow$ Quimiocinas & $\leftrightarrow$ Óxido Nítrico & $\begin{array}{l}\downarrow \text { Quimiocinas } \\
\downarrow \text { Óxido Nítrico }\end{array}$ \\
\hline $\begin{array}{c}\uparrow \text { Receptores de } \\
\text { quimiocinas }\end{array}$ & $\begin{array}{c}\leftrightarrow \text { PARPS } \\
\leftrightarrow \text { NLRP3 }\end{array}$ & $\begin{array}{c}\downarrow \text { Receptores de } \\
\text { quimiocinas }\end{array}$ & $\begin{array}{c}\downarrow \text { PARP1 } \\
\leftrightarrow \text { NLRP3 }\end{array}$ \\
\hline
\end{tabular}

Camundongos C57BL/6 machos adultos foram injetados com tampão citrato (B6) ou $42 \mathrm{mg} / \mathrm{Kg}$ de estreptozotocina em tampão citrato (B6+STZ), durante 5 dias consecutivos, por via intraperitoneal. Ao fim de 30 dias da indução de diabetes, os animais tiveram os macrófagos peritoneais residentes coletados e cultivados por 4 ou 24 horas na presença de lipopolissacarídeo - LPS $(2,5 \mu \mathrm{g} / \mathrm{mL})$ ou na presença de LPS e ácido docosaexaenóico - DHA $(25 \mu \mathrm{M})$. A expressão gênica foi avaliada após 4 horas por PCR array. A produção decitocinas e de óxido nítrico foi avaliada após 24 horas de tratamento. A tabela representa o efeito do DHA sobre macrófagos estimulados com LPS. 


\section{DISCUSSÃ̃}

A participação do infiltrado de leucócitos no modelo de diabetes mellitus tipo 1 induzido pela administração de doses baixas de estreptozotocina foi demonstrado em 1988 por análise em microscopia eletrônica do pâncreas (24). Foi então descrita a presença de macrófagos nas ilhotas pancreáticas logo após a administração da droga. Os macrófagos são atraídos para as ilhotas pancreáticas como consequência da destruição de células beta causada pela administração de doses baixas de estreptozotocina. A liberação de citocinas pelos macrófagos aumenta a expressão de moléculas de adesão (VCAM-1 e ICAM-1) no endotélio dos vasos sanguíneos que irrigam as ilhotas (136, 137), contribuindo para o recrutamento de linfócitos.

Modelos de DMI em camundongos são amplamente utilizados como o intuito de reproduzir em animais o estado diabético em pacientes. Os animais NODs (non-obese diabetic) apresentam insuficiência severa de insulina induzida por processo mediado por células T (138) e a macrófagos $(23,139)$. Por sua vez, animais farmacologicamente induzidos por aloxana ou estreptozotocina desenvolvem diabetes devido à toxicidade dessas drogas nas células beta (140). Como já demonstrado em diferentes estudos (141, 142), após o estabelecimento de DMI, por baixas doses de estreptozotocina, os animais apresentam aumento da glicemia e diminuição da insulinemia e da massa corporal. A associação da glicemia com o acúmulo de gordura e o estado inflamatório do fígado e do músculo sóleo dos mesmos animais foi também evidenciada. A esteatose hepática foi relatada pela primeira vez em pacientes diabéticos no ano de 1938 (143). A associação entre o quadro de diabetes tipo 2, obesidade e esteatose hepática está bem estabelecida (144). Contudo, a etiologia, a prevalência e as consequências da esteatose hepática em pacientes com diabetes do tipo 1 ainda permanecem mal compreendidas.

A determinação da atividade da ALT no plasma é utilizada como indicativo da ocorrência de doença hepática gordurosa não-alcoólica (non-alcoholic fatty liver disease (NAFLD)) em pacientes diabéticos (145). A elevação da atividade da ALT no plasma é mais frequente em pacientes diabéticos do tipo 2. Pacientes diabéticos tipo 1 apresentam atividade plasmática de ALT elevada em cerca de 3-4 vezes em relação ao encontrado na população não-diabética (146, 147). A atividade elevada de ALT no plasma, após 30 dias de diabetes, indica que houve dano hepatocelular nos animais. 
Ratos diabéticos induzidos por aloxana apresentam aumento da produção de espécies reativas de oxigênio e redução da atividade das enzimas antioxidantes SOD, CAT e GPX no fígado após 1, 3 e 6 meses de indução da doença (148). Em nosso estudo, também foi observada diminuição da atividade da catalase e SOD-2 no fígado dos animais diabéticos. Por sua vez, nos ratos diabéticos induzidos por estreptozotocina, foi observado aumento da atividade das enzimas ALT e AST no plasma e da atividade de CAT e GPX no fígado após 3 meses (149), sendo que o tratamento de ratos diabéticos com insulina aboliu as alterações na atividade da ALT e AST (150).

No quadro de diabetes, também observa-se danos ao DNA, geralmente associados com o estresse oxidativo, como descrito em ratos diabéticos induzidos por estreptozotocina, o aumento de danos oxidativos ao DNA nuclear no fígado, correlacionado com o aumento da hemoglobina glicada (151). Em pacientes diabéticos tipo 1, aumento do conteúdo de produtos da oxidação de DNA foi reportado em células mononucleares $(152)$ e na urina $(153,154)$.

Corroborando a diminuição na expressão das enzimas antioxidantes no fígado, o músculo sóleo dos animais diabéticos apresentou redução na expressão de GPX. Contudo, para se verificar detalhadamente o estado oxidativo do músculo sóleo, seria necessário avaliar a produção de EROs bem como a atividade de outros sistemas antioxidantes envolvidos. Em músculo esquelético de ratos diabéticos induzidos por estreptozotocina, comparados com animais controles, foi observado aumento na atividade das enzimas SOD e GPX e redução na atividade de CAT (155). Camundongos induzidos ao diabetes por estreptozotocina apresentam aumento nas atividades de CAT, GPX e SOD nos músculos esqueléticos (156).

Tendo caracterizado o modelo de DMI e o perfil inflamatório do fígado e sóleo dos animais diabéticos tipo $\mathrm{I}$, os macrófagos peritoneais residentes foram então estudados. Houve redução da capacidade fagocitária de macrófagos de animais NODs (157), esta deficiência na função dos macrófagos pode ser consequência da menor expressão dos receptores associados ao processo de fagocitose (157). Como consequência da alteração na fagocitose, o clearance de partículas apoptóticas apresenta-se comprometido. Além da menor capacidade fagocitária $(47,50)$, a digestão de partículas englobadas (158) também se apresentou reduzida nos macrófagos dos animais NODs. A avaliação da capacidade fagocitária dos macrófagos obtidos de animais diabéticos 
induzidos por estreptozotocina não apresentou diferenças significativas em relação aos macrófagos dos animais controles no presente estudo (Apêndice 3, tabela A3).

Outros autores avaliaram a influência da variação da concentração de glicose na produção de citocinas pelos macrófagos. Valores glicêmicos elevados alteram a produção de mediadores pró-inflamatórios em macrófagos peritoneais primados com tioglicolato e obtidos de animais diabéticos induzidos por aloxana (159). Os autores verificaram aumento na produção de IL-6, TNF- $\alpha$ e ROS (159). Aumento na expressão e produção de IL-1 $\beta$, IL-6, IL-12 e TNF- $\alpha$ foi observado em macrófagos peritoneais tratados in vitro com diferentes concentrações de glicose e in vivo após indução de diabetes por estreptozotocina (160). Além do aumento na produção de citocinas, os macrófagos do peritônio de camundongos induzidos ao diabetes por administração de doses baixas de estreptozotocina apresentaram produção elevada de óxido nítrico $(53,161)$.

A exposição da linhagem de monócitos humanos THP-1 à hiperglicemia (15 mM) causou elevação da produção de TNF- $\alpha(162,163)$ e de superóxido e ativação da via das MAP quinases aumento de p38, JNK-1 e ERK1/2 fosforiladas (162). Além disso, o tratamento de células THP-1 em cultura com concentrações elevadas de glicose (15 mM) aumentou a expressão de 41 genes e diminuiu de 15, incluindo de citocinas, quimiocinas, receptores de quimiocinas, moléculas de adesão e integrinas. Dentre os genes com expressão aumentada por hiperglicemia destaca-se: MCP-1, TNF- $\alpha$ e IL-1 $\beta$ (163). A exposição de macrófagos peritoneais de camundongos a concentrações elevadas (24 mM) de glicose in vitro por 3, 6, 12 e 18 horas (164), aumentou a produção de IL-18. Corroborando nossos resultados, nos estudos citados, também foi descrito perfil inflamatório dos macrófagos em condições hiperglicêmicas em ambos os modelos, DM quimicamente induzido por estreptozotocina e animais NODs, caracterizado pelo aumento na secreção de NO e na expressão de RNAm de IL-1ß, IL-33 e IL-18.

Não houve diferença significativa na expressão dos marcadores de superfície para M1 e M2 nos macrófagos peritoneais entre os animais controles e diabéticos. Os animais diabéticos apresentaram ligeiro aumento na população M1 conforme indicado pela expressão de iNOS e a secreção de NO. Os macrófagos M1 (ou M (lps+IFN- $\gamma$ )) convertem arginina em NO, pois apresentam expressão elevada de iNOS, enquanto nos macrófagos M2 (ou M (IL-4)) a arginina é metabolizada pela arginase-1, induzida por IL4, resultando na produção de ureia e poliaminas (165-167). 
O aumento da disponibilidade de glicose resultou em elevação do fluxo glicolítico nos macrófagos dos animais diabéticos em relação aos controles, conforme indicado pela taxa de acidificação do meio extracelular (ECAR). O aumento da atividade glicolítica deve estar associado à elevação do fluxo de substratos pelo ciclo das pentoses (não avaliado neste estudo) e a produção de NADPH e consequentemente a produção de NO $(168,169)$.

Recentemente, foi demonstrado que o aumento da expressão da hexoquinase-1, enzima que fosforila a glicose, sendo esta a primeira etapa da via glicolítica, ativa o inflamassoma NLRP3 (120) enquanto que a inibição da piruvatoquinase 2 (170) diminuiu as concentrações de IL-1 $\beta$ no soro dos animais com sepse. Estes achados são indicativos de que alterações no metabolismo celular podem regular a atividade e função dos leucócitos.

A gordura da dieta modula a composição de ácidos graxos na membrana dos leucócitos, função dessas células e a resposta imune e inflamatória (171, 172). Lokesh e colaboradores observaram que os quatro ácidos graxos mais abundantes em macrófagos peritoneais são: palmítico, esteárico, oleico e araquidônico (173).

Avaliamos no presente estudo os efeitos dos ácidos palmítico (PA-saturado), EPA e DHA (poliinsaturados $\omega$-3) sobre o perfil inflamatório dos macrófagos de animais diabéticos. O tratamento com PA diminuiu a capacidade fagocitária de macrófagos de ratos controles e não alterou a capacidade dessas células de digerir bactéria internalizada e gerar ânion superóxido (173). Da mesma forma, macrófagos peritoneais elicitados com tioglicolato e tratados com ácidos graxos saturados (miristato ou palmitato) em cultura apresentaram diminuição da capacidade fagocitária de partículas de zymosan não opsonizadas (76). Embora os macrófagos incorporam ácidos graxos e esses regulam a capacidade de adesão e de fagocitose, a avaliação da capacidade fagocitária dos macrófagos dos animais diabéticos após o tratamento com DHA não foi alterada significativamente (Apêndice 3, tabela A3).

O ácido palmítico é um ligante natural de TLR4 (174) e induz efeitos próinflamatórias em linhagens de macrófagos murinos como a ativação das vias NF- $\kappa B$ (175) e JNK (176) em macrófagos RAW264 e p38 MAP quinase na linhagem J744 (177). Além disso, o tratamento com PA aumenta a expressão de TLR4, TNF- $\alpha$ e IL-1 $\beta$ de maneira dose dependente em macrófagos THP-1 (linhagem de monócitos humanos) (178, 179). Observamos aumento na produção de NO em macrófagos tratados com PA obtidos de 
animais diabéticos e cultivados por 24 horas. Nos animais controles, por sua vez, houve apenas uma tendência em aumentar a produção de NO quando os macrófagos foram tratados com PA. Talvez período mais longo que 24 horas seja necessário para que o PA aumente significativamente a produção de NO nos dois grupos. A produção das citocinas pró-inflamatórias IL-1 $\beta$ e IL-6 também apresentou-se aumentada em macrófagos de animais diabéticos independente do ácido graxo testado (PA, EPA ou DHA).

Ao tratar os macrófagos ex-vivo com ácidos graxos da família ômega-3 (EPA ou DHA), notou-se atenuação do perfil inflamatório (conforme indicado por redução da produção de IL-1 $\beta$ e IL-6) induzido pelo tratamento com LPS em cultura. Essa diminuição, porém, só foi significativa em macrófagos de animais controles e de maneira mais evidente pelo tratamento com DHA. É possível que o estado inflamatório dos macrófagos nos animais diabéticos tipo 1 esteja tão pronunciado que o tratamento com os ácidos graxos da família ômega-3 não consegue reverter a produção elevada das citocinas.

O DHA apresentou efeito anti-inflamatório mais pronunciado que o EPA nas condições do presente estudo, conforme indicado pela diminuição acentuada na produção de NO pelos macrófagos de camundongos diabéticos e aumento da produção de IL-10. Em vista disso, optou-se por investigar o efeito do DHA sobre o estado inflamatório dos macrófagos dos animais diabéticos. O tratamento com DHA em macrófagos de animais controles apresentou caráter pró-inflamatório em relação à expressão gênica de citocinas, quimiocinas e receptores, enquanto que em macrófagos de animais diabéticos esta condição é revertida para um perfil anti-inflamatório.

Conforme mencionado acima o óleo de peixe (adicionado na dieta, contendo aproximadamente $30 \%$ de EPA e $20 \%$ de DHA) modula a composição lipídica dos macrófagos peritoneais mas além disso reduz os valores glicêmicos em camundongos C57BL/6 induzidos ao diabetes por estreptozotocina (180). Há evidências de que em, modelos de diabetes tipo 1 (induzido por estreptozotocina e ou em animais NOD), ácidos graxos da família ômega-3 melhoram o quadro de diabetes $(181,182)$.

Os mamíferos não produzem ácidos graxos ômega-3 naturalmente, por isso é importante adquiri-los por meio da alimentação (183). Com a utilização de engenharia genética, Kang et al (2004) desenvolveram camundongos transgênicos por meio da utilização do gene fat-1 de Caenorhabditis elegans. Este gene codifica a enzima dessaturase ômega-3, convertendo ácidos graxos ômega-6 em ômega-3, o que possibilita 
aumentar de forma marcante o conteúdo de ácidos graxos ômega-3 (EPA e DHA) nos tecidos dos camundongos fat-1, sendo que o DHA é o ácido graxo mais abundante (com exceção do músculo esquelético) (184). Bellenger et al. (2011) demonstraram que camundongos fat- 1 induzidos ao diabetes por estreptozotocina apresentam: diminuição do quadro inflamatório e dano pancreático, além de redução da hiperglicemia.

O estresse oxidativo participa de modo importante no desenvolvimento e progressão do diabetes e suas complicações (185-188). A hiperglicemia causa estresse oxidativo por diferentes mecanismos, dentre eles, podemos destacar: aumento na produção de sorbitol, de glicação avançada e formação de AGEs (produtos de glicação avançada), ativação das isoformas $\beta$ e $\delta$ da proteina quinase $\mathrm{C}$ (PKC) e aumento da atividade da via da hexosamina, que culminam na produção aumentada de ROS (45). O aumento na produção de ROS induzido por hiperglicemia ativa vias de sinalização (NFкB) que promovem maior liberação de citocinas pró-inflamatórias em células endoteliais $(45,189)$. Produtos do estresse oxidativo e marcadores inflamatórios (IL-6 e proteína C reativa) apresentam-se em concentrações elevadas no soro de pacientes diabéticos tipo 1 (190). O aumento do conteúdo de TNF- $\alpha$ e IL-6 no fígado, como observado nos nossos resultados após 90 dias de diabetes (Apêndice 1, tabelas A9 e A10, respectivamente), pode estar associado à produção elevada de AGEs.

Os efeitos do DMI sobre os macrófagos estão também relacionados com a ativação do inflamassoma NLRP3 e a produção de AGEs. Foram utilizados animais deficientes para NLRP3 ou deficientes para RAGE para testar se estas moléculas estão diretamente relacionadas com o perfil pró-inflamatório dos macrófagos peritoneais de animais diabéticos. Os animais NLRP3 KO ou RAGE KO foram quimicamente induzidos ao diabetes pela administração de estreptozotocina. Todos os grupos (C57BL/6, NLRP3 KO ou RAGE KO) apresentaram aumento da glicemia, diminuição da insulinemia e da massa corporal, que indicam o estabelecimento do quadro de DMI. Embora os animais NLRP3 KO desenvolveram hiperglicemia após indução de diabetes com baixas doses de estreptozotocina, a incidência da doença foi menor nos animais deficientes para NLRP3 ao serem comparados com os controles (191).

Embora diferentes estudos relataram o aumento da concentração de AGEs no soro de pacientes com DMI (192, 193), os valores de AGEs detectados no soro dos camundongos não foram diferentes entre os grupos experimentais. Possivelmente, a 
sensibilidade do método de ELISA utilizado para a determinação de AGEs não foi suficiente para detectar diferenças significativas entre os grupos.

Além do estado DMI e de altas concentrações de glicose alterarem o perfil inflamatório dos leucócitos, já descrito anteriormente, foi observado a diminuição da habilidade de formar colônias e o aumento da expressão de iNOS pelas células tronco hematopoiéticas de camundongos com DMI induzidos por estreptozotocina (194). Em contrapartida, a exposição a longos períodos de diabetes reduziu a produção de citocinas pelas células da medula óssea (195), assim como as células nucleadas da medula óssea dos animais C57BL/6 diabéticos estimuladas com LPS diminuíram a secreção de óxido nítrico no presente estudo. Já os animais deficientes para NLRP3 ou RAGE apresentaram aumento significativo da secreção de NO independente do estado diabético. Além disso, os macrófagos dos animais deficientes para RAGE, aumentaram a secreção de IL-1 $\beta$ em relação aos macrófagos dos animais C57BL/6, ambos na presença de LPS. Outros estudos são necessários para explicar este fenômeno.

Conforme já mencionado acima, macrófagos peritoneais dos animais diabéticos apresentaramm aumento significativo na produção de NO. A correlação entre os valores de óxido nítrico (NO) e de hemoglobina glicada (HBA1c) no soro de pacientes diabéticos tipo I (196) sugere que o estado crônico de hiperglicemia está associado ao aumento da produção de NO. A exposição de células endoteliais a 22,2 $\mathrm{mM}$ de glicose durante cinco dias (197) e de linhagem de células murinas RAW264.7 e mesangiais a 25 mM durante 24 horas (198) aumentou a produção de NO. Portanto, produção aumentada de NO por macrófagos foi observada tanto em modelos de diabetes tipo I quimicamente induzidos por estreptozotocina e pacientes, como também após a exposição de diferentes subtipos celulares a altas concentrações de glicose.

A produção de NO durante o desenvolvimento do diabetes por estreptozotocina é um mecanismo importante de destruição das células beta. Ocorre aumento de IL-1 $\beta$ que eleva a expressão de iNOS e consequentemente a liberação de NO pelos macrófagos no pâncreas $(199,200)$, causando toxicidade para as células beta pancreáticas. A utilização de inibidores de NOS (L-arginina, ou L-NAME) atenua o quadro diabético, diminuindo os valores glicêmicos dos animais induzidos por estreptozotocina (201-203).

A participação do NO proveniente dos macrófagos do pâncreas no desenvolvimento do diabetes quimicamente induzido por estreptozotocina foi descrita em estudos anteriores. No presente trabalho, observamos aumento da expressão de iNOS e 
secreção de NO pelos macrófagos peritoneais dos animais diabéticos, após 30 dias da indução de diabetes, e a ausência de NLRP3 diminuiu a secreção deste, indicando o envolvimento do inflamassoma NLRP3 neste processo. Corroborando estes dados, pesquisadores descreveram que a ausência de NLRP3 ou caspase-1 em camundongos resulta em aumento da parasitemia no sangue e de parasitas no interior dos macrófagos devido à diminuição da produção de NO durante infecção por Trypanossoma cruzi (204).

Por outro lado, outros descreveram o NO como um potente inibidor de NLRP3 por mecanismo de nitrosilação (205), descrito através do modelo de infecção por Mycobaterium tuberculosis (206), onde foi relatado que o NO inibe a montagem do inflamassoma NLRP3 e consequentemente a produção de IL-1 $\beta$. Nesta mesma linha de pesquisa, o tratamento com o inibidor de NOS (L-NAME) e utilização de animais iNOS deficientes durante choque séptico induzido por LPS, diminuiu significativamente a secreção de IL-1 $\beta$ e IL-18 no soro (207).

No primeiro estudo sobre a importância do inflamassoma no desenvolvimento de DMI foi relatada que a deficiência de NLRP3 causa diminuição da migração de células T para as ilhotas pancreáticas e a incidência de diabetes em animais NODs (68). Recentemente foi demonstrado que o cultivo de macrófagos derivados de medula óssea com DNA mitocondrial circulante do sangue dos animais diabéticos, induzidos por estreptozotocina, foi capaz de aumentar a produção de IL-1 $\beta$, ao ser comparado com DNA mitocondrial de animais controles, dependente de caspase-1 e NLRP3 (191).

Animais deficientes em NLRP3 ou caspase-1 apresentam-se de maneira semelhante aos deficientes em iNOS frente a infecção por T. Cruzi. A secreção de NO pelos macrófagos de animais deficientes em caspase-1 também foi inibida (204), confirmando a existência de uma via de secreção de NO envolvendo NLRP3, conforme observado no presente estudo. Até o momento, não foi possível comprovar, por análises de western blotting (dados preliminares), se a produção de NO ocorre via caspase-1 nos macrófagos dos animais diabéticos.

Recentemente foi descrito que a caspase-7 atua como substrato da caspase-1 (208) em macrófagos, sugerindo a existência da cascata NLRP3/caspase-1/caspase-7, como consequência a caspase-1 é ativada e cliva PARP1 (Poli (ADP-ribose) polimerase-1) (209). O processo de ativação do inflamassoma NLRP3 foi descrito como sendo essencial para a clivagem de PARP1 durante o processo de piroptose (210). Com a clivagem de PARP1, ocorre liberação de PARP1 da cromatina, reduzindo assim a condensação desta 
e aumentando a transcrição de genes dependentes de NF-kB (209), como a iNOS (211, 212).

O aumento da expressão de NLRP3 e iNOS, observado nos macrófagos dos animais diabéticos, independente da produção de IL-1 $\beta$ e IL-18, está de acordo com a resposta de macrófagos peritoneais à infecção por T. cruzi (204). Foi observado aumento da expressão de PARP1 total e clivada na condição de diabetes em relação aos macrófagos dos animais controles, enquanto que na ausência de NLRP3 houve redução da expressão de PARP1 nos macrófagos dos animais diabéticos.

Aumento na expressão de iNOS e PARP1 nos rins de ratos após nove dias da indução de diabetes mellitus tipo I por estreptozotocina (213) e na expressão de PARP1 no córtex cerebral de ratos recém-nascidos expostos a períodos de hiperglicemia (214) foi reportado. Estudos relacionando a cascata NLRP3-PARP1-iNOS com o estado diabético precisam ser realizados.

O tratamento ex-vivo com DHA causou efeito similar ao da ausência de NLRP3, isto é, diminuição da expressão de iNOS e da secreção de NO pelos macrófagos dos animais diabéticos $(215,216)$. O tratamento com DHA também reduziu PARP1 total e não alterou a expressão de PARP1 clivada nos macrófagos dos animais diabéticos. Em estudos anteriores foi demonstrado que deficiência de PARP1 atenua o quadro inflamatório em camundongos com hipersensibilidade de contato e aumenta as concentrações de DHA e EPA na pele dos animais (217). Em um estudo com neurônios in vitro, o tratamento com ômega-3 diminuiu a expressão de PARP1 total e clivada (218), corroborando os resultados observados nos macrófagos dos animais diabéticos. 


\section{CONCLUSÕES}

O estado diabético induz fenótipo inflamatório nos macrófagos peritoneais residentes, apresentando aumento da produção de NO, expressão de citocinas próinflamatórias, receptores de quimiocinas e da capacidade glicolítica. A ativação do inflamassoma NLRP3 e de PARP1, e o aumento da atividade glicolítica estão associados com o estado inflamatório do macrófago mencionado. Este estado induzido pelo quadro diabético é atenuado pelo tratamento com DHA.

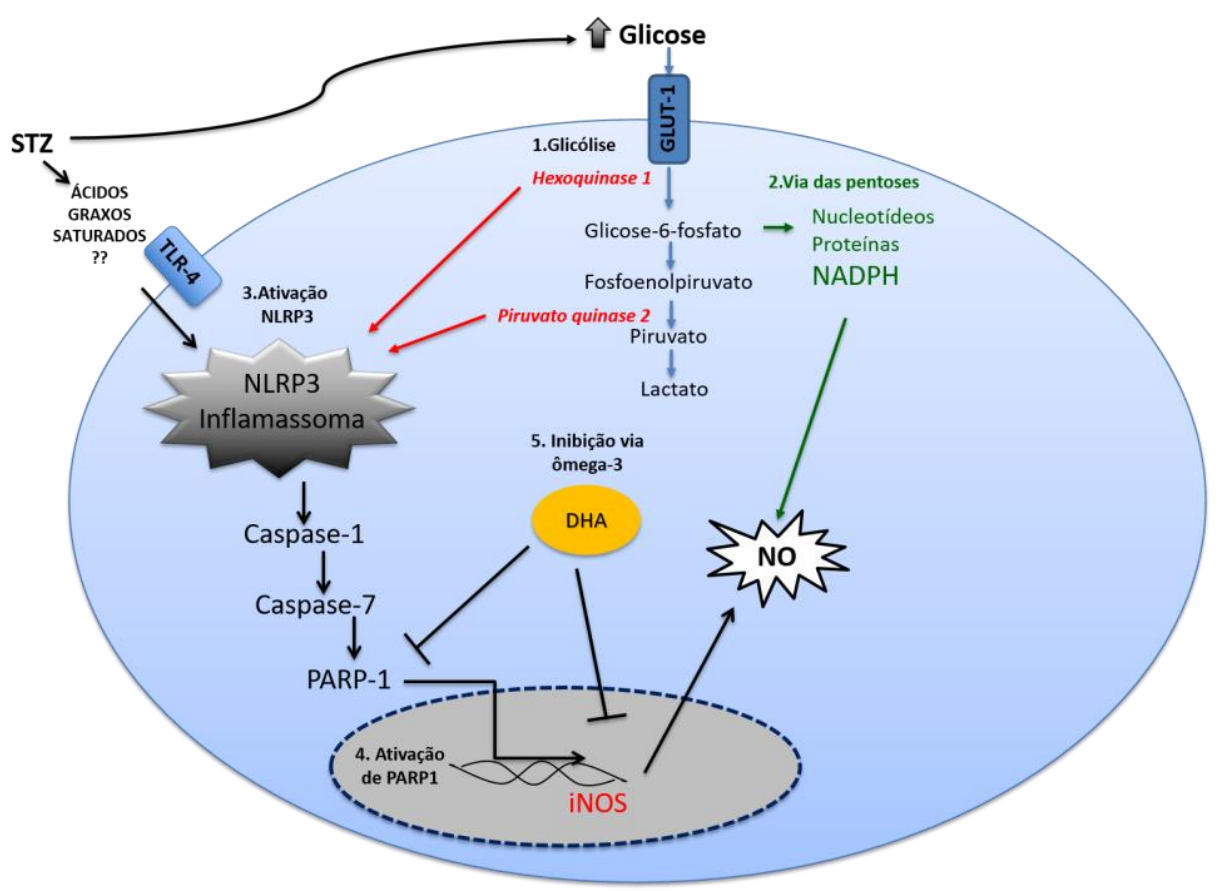

Figura 21. Mecanismos envolvidos na indução do estado inflamatório em macrófagos de camundongos com DMI. (1) Aumento da atividade via glicolítica e possivelmente da (2) via das pentoses e da produção de NADPH; (3) aumento da expressão/atividade das enzimas hexoquinase-1 e piruvato quinase-2 que ativam o inflamassoma NLRP3; (4) ativação de PARP1 pela caspase-1/7 que induz a expressão de iNOS e (5) o tratamento com DHA diminui a expressão de PARP1 e iNOS. NADPH: fosfato de dinucleotídeo de adenina; NLRP3: receptores do tipo NOD contendo pirina 3; TLR-4: receptor do tipo toll 4 GLUT-1: transportador de glicose 1, PARP1: Poly (ADP-ribose) polymerase; iNOS: óxido nítrico sintase induzível; NO: óxido nítrico, DHA: ácido docosaexaenoico. 


\section{REFERÊNCIAS *}

1. Eisenbarth GS. Type I diabetes mellitus. A chronic autoimmune disease. N Engl J Med. 1986;314(21):1360-8.

2. Davies JL, Kawaguchi Y, Bennett ST, Copeman JB, Cordell HJ, Pritchard LE, et al. A genome-wide search for human type 1 diabetes susceptibility genes. Nature. 1994;371(6493):130-6.

3. Steck AK, Rewers MJ. Genetics of type 1 diabetes. Clin Chem. 2011;57(2):176-85.

4. von Herrath M. Can we learn from viruses how to prevent type 1 diabetes?: the role of viral infections in the pathogenesis of type 1 diabetes and the development of novel combination therapies. Diabetes. 2009;58(1):2-11.

5. Roivainen M, Klingel K. Virus infections and type 1 diabetes risk. Curr Diab Rep. 2010;10(5):350-6.

6. Zaccone P, Cooke A. Infectious triggers protect from autoimmunity. Semin Immunol. $2011 ; 23(2): 122-9$.

7. Roll U, Christie MR, Füchtenbusch M, Payton MA, Hawkes CJ, Ziegler AG. Perinatal autoimmunity in offspring of diabetic parents. The German Multicenter BABY-DIAB study: detection of humoral immune responses to islet antigens in early childhood. Diabetes. 1996;45(7):967-73.

8. Verge CF, Gianani R, Kawasaki E, Yu L, Pietropaolo M, Jackson RA, et al. Prediction of type I diabetes in first-degree relatives using a combination of insulin, GAD, and ICA512bdc/IA-2 autoantibodies. Diabetes. 1996;45(7):926-33.

9. Mathis D, Vence L, Benoist C. beta-Cell death during progression to diabetes. Nature. $2001 ; 414(6865): 792-8$.

10. Lehuen A, Diana J, Zaccone P, Cooke A. Immune cell crosstalk in type 1 diabetes. Nat Rev Immunol. 2010;10(7):501-13.

11. Yoon JW, Jun HS, Santamaria P. Cellular and molecular mechanisms for the initiation and progression of beta cell destruction resulting from the collaboration between macrophages and T cells. Autoimmunity. 1998;27(2):109-22.

12. Appels B, Burkart V, Kantwerk-Funke G, Funda J, Kolb-Bachofen V, Kolb H. Spontaneous cytotoxicity of macrophages against pancreatic islet cells. $\mathrm{J}$ Immunol. 1989;142(11):3803-8.

13. Willcox A, Richardson SJ, Bone AJ, Foulis AK, Morgan NG. Analysis of islet inflammation in human type 1 diabetes. Clin Exp Immunol. 2009;155(2):173-81.

14. In't Veld P. Insulitis in human type 1 diabetes: The quest for an elusive lesion. Islets. $2011 ; 3(4): 131-8$.

15. Hänninen A, Jalkanen S, Salmi M, Toikkanen S, Nikolakaros G, Simell O. Macrophages, $\mathrm{T}$ cell receptor usage, and endothelial cell activation in the pancreas at the onset of insulindependent diabetes mellitus. J Clin Invest. 1992;90(5):1901-10.

16. Waldron-Lynch F, von Herrath M, Herold KC. Towards a curative therapy in type 1 diabetes: remission of autoimmunity, maintenance and augmentation of beta cell mass. Novartis Found Symp. 2008;292:146-55; discussion 55-8, 202-3.

17. Maahs DM, West NA, Lawrence JM, Mayer-Davis EJ. Epidemiology of type 1 diabetes. Endocrinol Metab Clin North Am. 2010;39(3):481-97.

18. Patterson CC, Dahlquist GG, Gyürüs E, Green A, Soltész G, Group ES. Incidence trends for childhood type 1 diabetes in Europe during 1989-2003 and predicted new cases 2005-20: a multicentre prospective registration study. Lancet. 2009;373(9680):2027-33.

19. Patterson CC, Gyürüs E, Rosenbauer J, Cinek O, Neu A, Schober E, et al. Trends in childhood type 1 diabetes incidence in Europe during 1989-2008: evidence of non-uniformity over time in rates of increase. Diabetologia. 2012;55(8):2142-7.

20. Makino S, Kunimoto K, Muraoka Y, Mizushima Y, Katagiri K, Tochino Y. Breeding of a non-obese, diabetic strain of mice. Jikken Dobutsu. 1980;29(1):1-13.

21. Kikutani $\mathrm{H}$, Makino $\mathrm{S}$. The murine autoimmune diabetes model: NOD and related strains. Adv Immunol. 1992;51:285-322.

*De acordo com:

International Committee of Medical Journal Editors. [Internet]. Uniform requirements for manuscripts submitted to biomedical journals. [2011 Jul 15]. Available from:

http://www.nlm.nih.gov/bsd/uniform_requirements.htlm 
22. Anderson MS, Bluestone JA. The NOD mouse: a model of immune dysregulation. Annu Rev Immunol. 2005;23:447-85.

23. Jun HS, Yoon CS, Zbytnuik L, van Rooijen N, Yoon JW. The role of macrophages in T cell-mediated autoimmune diabetes in nonobese diabetic mice. J Exp Med. 1999;189(2):347-58. 24. Kolb-Bachofen V, Epstein S, Kiesel U, Kolb H. Low-dose streptozocin-induced diabetes in mice. Electron microscopy reveals single-cell insulitis before diabetes onset. Diabetes. 1988;37(1):21-7.

25. Tesch GH, Nikolic-Paterson DJ. Recent insights into experimental mouse models of diabetic nephropathy. Nephron Exp Nephrol. 2006;104(2):e57-62.

26. Chow FY, Nikolic-Paterson DJ, Atkins RC, Tesch GH. Macrophages in streptozotocininduced diabetic nephropathy: potential role in renal fibrosis. Nephrol Dial Transplant. 2004;19(12):2987-96.

27. Qi Z, Fujita H, Jin J, Davis LS, Wang Y, Fogo AB, et al. Characterization of susceptibility of inbred mouse strains to diabetic nephropathy. Diabetes. 2005;54(9):2628-37.

28. Karabatas LM, Pastorale C, de Bruno LF, Maschi F, Pivetta OH, Lombardo YB, et al. Early manifestations in multiple-low-dose streptozotocin-induced diabetes in mice. Pancreas. 2005;30(4):318-24.

29. Leiter EH. Multiple low-dose streptozotocin-induced hyperglycemia and insulitis in C57BL mice: influence of inbred background, sex, and thymus. Proc Natl Acad Sci U S A. 1982;79(2):630-4.

30. Paik SG, Fleischer N, Shin SI. Insulin-dependent diabetes mellitus induced by subdiabetogenic doses of streptozotocin: obligatory role of cell-mediated autoimmune processes. Proc Natl Acad Sci U S A. 1980;77(10):6129-33.

31. Mensah-Brown E, Shahin A, Parekh K, Hakim AA, Shamisi MA, Hsu DK, et al. Functional capacity of macrophages determines the induction of type 1 diabetes. Ann $\mathrm{N}$ Y Acad Sci. 2006;1084:49-57.

32. O'Brien BA, Harmon BV, Cameron DP, Allan DJ. Beta-cell apoptosis is responsible for the development of IDDM in the multiple low-dose streptozotocin model. J Pathol. 1996;178(2):176-81.

33. Fukuda K, Tesch GH, Nikolic-Paterson DJ. c-Jun amino terminal kinase 1 deficient mice are protected from streptozotocin-induced islet injury. Biochemical and biophysical research communications. 2008;366(3):710-6.

34. Vergès B. Lipid disorders in type 1 diabetes. Diabetes Metab. 2009;35(5):353-60.

35. Mattock MB, Cronin N, Cavallo-Perin P, Idzior-Walus B, Penno G, Bandinelli S, et al. Plasma lipids and urinary albumin excretion rate in Type 1 diabetes mellitus: the EURODIAB IDDM Complications Study. Diabet Med. 2001;18(1):59-67.

36. Mazière $\mathrm{C}$, Mazière JC. Activation of transcription factors and gene expression by oxidized low-density lipoprotein. Free Radic Biol Med. 2009;46(2):127-37.

37. Vlassara $\mathrm{H}$. Recent progress in advanced glycation end products and diabetic complications. Diabetes. 1997;46 Suppl 2:S19-25.

38. Vlassara H, Palace MR. Glycoxidation: the menace of diabetes and aging. Mt Sinai J Med. 2003;70(4):232-41.

39. Monnier VM. Intervention against the Maillard reaction in vivo. Arch Biochem Biophys. 2003;419(1):1-15.

40. Ahmed N. Advanced glycation endproducts--role in pathology of diabetic complications. Diabetes Res Clin Pract. 2005;67(1):3-21.

41. Neeper M, Schmidt AM, Brett J, Yan SD, Wang F, Pan YC, et al. Cloning and expression of a cell surface receptor for advanced glycosylation end products of proteins. J Biol Chem. 1992;267(21):14998-5004.

42. Takahashi HK, Mori S, Wake H, Liu K, Yoshino T, Ohashi K, et al. Advanced glycation end products subspecies-selectively induce adhesion molecule expression and cytokine production in human peripheral blood mononuclear cells. J Pharmacol Exp Ther. 2009;330(1):8998.

43. Yan SD, Schmidt AM, Anderson GM, Zhang J, Brett J, Zou YS, et al. Enhanced cellular oxidant stress by the interaction of advanced glycation end products with their receptors/binding proteins. J Biol Chem. 1994;269(13):9889-97.

44. Wautier MP, Chappey O, Corda S, Stern DM, Schmidt AM, Wautier JL. Activation of NADPH oxidase by AGE links oxidant stress to altered gene expression via RAGE. Am J Physiol Endocrinol Metab. 2001;280(5):E685-94. 
45. Brownlee M. Biochemistry and molecular cell biology of diabetic complications. Nature. 2001;414(6865):813-20.

46. Maree AF, Komba M, Finegood DT, Edelstein-Keshet L. A quantitative comparison of rates of phagocytosis and digestion of apoptotic cells by macrophages from normal (BALB/C) and diabetes-prone (NOD) mice. J Appl Physiol. 2008;104(1):157-69.

47. O'Brien BA, Huang Y, Geng X, Dutz JP, Finegood DT. Phagocytosis of apoptotic cells by macrophages from NOD mice is reduced. Diabetes. 2002;51(8):2481-8.

48. Hanses F, Park S, Rich J, Lee JC. Reduced neutrophil apoptosis in diabetic mice during staphylococcal infection leads to prolonged Tnfalpha production and reduced neutrophil clearance. PLoS One. 2011;6(8):e23633.

49. Bouma G, Nikolic T, Coppens JM, van Helden-Meeuwsen CG, Leenen PJ, Drexhage HA, et al. NOD mice have a severely impaired ability to recruit leukocytes into sites of inflammation. Eur J Immunol. 2005;35(1):225-35.

50. $\quad$ Ma H, Liu G, Ding W, Wu Y, Cai L, Zhao Y. Diabetes-induced alteration of F4/80+ macrophages: a study in mice with streptozotocin-induced diabetes for a long term. J Mol Med (Berl). 2008;86(4):391-400.

51. Sun C, Sun L, Ma H, Peng J, Zhen Y, Duan K, et al. The phenotype and functional alterations of macrophages in mice with hyperglycemia for long term. J Cell Physiol. $2011 ; 227(4): 1670-9$.

52. Sun N, Yang G, Zhao H, Savelkoul HF, An L. Multidose streptozotocin induction of diabetes in BALB/c mice induces a dominant oxidative macrophage and a conversion of $\mathrm{TH} 1$ to TH2 phenotypes during disease progression. Mediators Inflamm. 2005;2005(4):202-9.

53. Catanzaro OL, Dziubecki D, Labal E, Sirois P. Activation of peritoneal macrophages during the evolution of type 1 diabetes (insulitis) in streptozotocin-treated mice. Peptides. 2010;31(10):1884-7.

54. Dinarello CA. Immunological and inflammatory functions of the interleukin-1 family. Annu Rev Immunol. 2009;27:519-50.

55. Schroder K, Tschopp J. The inflammasomes. Cell. 2010;140(6):821-32.

56. Tschopp J, Martinon F, Burns K. NALPs: a novel protein family involved in inflammation. Nat Rev Mol Cell Biol. 2003;4(2):95-104.

57. Bauernfeind FG, Horvath G, Stutz A, Alnemri ES, MacDonald K, Speert D, et al. Cutting edge: NF-kappaB activating pattern recognition and cytokine receptors license NLRP3 inflammasome activation by regulating NLRP3 expression. J Immunol. 2009;183(2):787-91.

58. Donath MY, Shoelson SE. Type 2 diabetes as an inflammatory disease. Nat Rev Immunol. 2011;11(2):98-107.

59. Wen H, Gris D, Lei Y, Jha S, Zhang L, Huang MT, et al. Fatty acid-induced NLRP3-ASC inflammasome activation interferes with insulin signaling. Nat Immunol. 2011;12(5):408-15.

60. L'homme L, Esser N, Riva L, Scheen A, Paquot N, Piette J, et al. Unsaturated fatty acids prevent activation of NLRP3 inflammasome in human monocytes/macrophages. J Lipid Res. 2013;54(11):2998-3008.

61. Martinon F, Pétrilli V, Mayor A, Tardivel A, Tschopp J. Gout-associated uric acid crystals activate the NALP3 inflammasome. Nature. 2006;440(7081):237-41.

62. Mariathasan S, Weiss DS, Newton K, McBride J, O'Rourke K, Roose-Girma M, et al. Cryopyrin activates the inflammasome in response to toxins and ATP. Nature. 2006;440(7081):228-32.

63. Kanneganti TD, Body-Malapel M, Amer A, Park JH, Whitfield J, Franchi L, et al. Critical role for Cryopyrin/Nalp3 in activation of caspase-1 in response to viral infection and doublestranded RNA. J Biol Chem. 2006;281(48):36560-8.

64. De Nardo D, Latz E. NLRP3 inflammasomes link inflammation and metabolic disease. Trends Immunol. 2011;32(8):373-9.

65. Masters SL, Dunne A, Subramanian SL, Hull RL, Tannahill GM, Sharp FA, et al. Activation of the NLRP3 inflammasome by islet amyloid polypeptide provides a mechanism for enhanced IL-1 $\beta$ in type 2 diabetes. Nat Immunol. 2010;11(10):897-904.

66. Vandanmagsar B, Youm YH, Ravussin A, Galgani JE, Stadler K, Mynatt RL, et al. The NLRP3 inflammasome instigates obesity-induced inflammation and insulin resistance. Nat Med. 2011;17(2):179-88.

67. Duewell P, Kono H, Rayner KJ, Sirois CM, Vladimer G, Bauernfeind FG, et al. NLRP3 inflammasomes are required for atherogenesis and activated by cholesterol crystals. Nature. 2010;464(7293):1357-61. 
68. Hu C, Ding H, Li Y, Pearson JA, Zhang X, Flavell RA, et al. NLRP3 deficiency protects from type 1 diabetes through the regulation of chemotaxis into the pancreatic islets. Proc Natl Acad Sci U S A. 2015;112(36):11318-23.

69. Meade CJ, Mertin J. Fatty acids and immunity. Adv Lipid Res. 1978;16:127-65.

70. Calder PC, Yaqoob P, Harvey DJ, Watts A, Newsholme EA. Incorporation of fatty acids by concanavalin A-stimulated lymphocytes and the effect on fatty acid composition and membrane fluidity. Biochem J. 1994;300 ( Pt 2):509-18.

71. Calder PC. Polyunsaturated fatty acids, inflammatory processes and inflammatory bowel diseases. Mol Nutr Food Res. 2008;52(8):885-97.

72. Tilley SL, Coffman TM, Koller BH. Mixed messages: modulation of inflammation and immune responses by prostaglandins and thromboxanes. J Clin Invest. 2001;108(1):15-23.

73. Calder PC, Bevan SJ, Newsholme EA. The inhibition of T-lymphocyte proliferation by fatty acids is via an eicosanoid-independent mechanism. Immunology. 1992;75(1):108-15.

74. Lokesh BR, Hsieh HL, Kinsella JE. Peritoneal macrophages from mice fed dietary $(n-3)$ polyunsaturated fatty acids secrete low levels of prostaglandins. J Nutr. 1986;116(12):2547-52.

75. Brouard C, Pascaud M. Effects of moderate dietary supplementations with n-3 fatty acids on macrophage and lymphocyte phospholipids and macrophage eicosanoid synthesis in the rat. Biochim Biophys Acta. 1990;1047(1):19-28.

76. Calder PC, Bond JA, Harvey DJ, Gordon S, Newsholme EA. Uptake and incorporation of saturated and unsaturated fatty acids into macrophage lipids and their effect upon macrophage adhesion and phagocytosis. Biochem J. 1990;269(3):807-14.

77. Calder PC, Yaqoob P. Omega-3 polyunsaturated fatty acids and human health outcomes. Biofactors. 2009;35(3):266-72.

78. Sidhu KS. Health benefits and potential risks related to consumption of fish or fish oil. Regul Toxicol Pharmacol. 2003;38(3):336-44.

79. Serhan CN, Clish CB, Brannon J, Colgan SP, Chiang N, Gronert K. Novel functional sets of lipid-derived mediators with antiinflammatory actions generated from omega-3 fatty acids via cyclooxygenase 2-nonsteroidal antiinflammatory drugs and transcellular processing. J Exp Med. 2000;192(8):1197-204.

80. Serhan CN, Chiang N, Van Dyke TE. Resolving inflammation: dual anti-inflammatory and pro-resolution lipid mediators. Nat Rev Immunol. 2008;8(5):349-61.

81. Serhan CN, Hong S, Gronert K, Colgan SP, Devchand PR, Mirick G, et al. Resolvins: a family of bioactive products of omega-3 fatty acid transformation circuits initiated by aspirin treatment that counter proinflammation signals. J Exp Med. 2002;196(8):1025-37.

82. de Deckere EA, Korver O, Verschuren PM, Katan MB. Health aspects of fish and n-3 polyunsaturated fatty acids from plant and marine origin. Eur J Clin Nutr. 1998;52(10):749-53.

83. Rosenberg IH. Fish -- food to calm the heart. N Engl J Med. 2002;346(15):1102-3.

84. Malasanos TH, Stacpoole PW. Biological effects of omega-3 fatty acids in diabetes mellitus. Diabetes Care. 1991;14(12):1160-79.

85. Cnop M. Fatty acids and glucolipotoxicity in the pathogenesis of Type 2 diabetes. Biochem Soc Trans. 2008;36(Pt 3):348-52.

86. Nishimura S, Manabe I, Nagasaki M, Eto K, Yamashita H, Ohsugi M, et al. CD8+ effector $\mathrm{T}$ cells contribute to macrophage recruitment and adipose tissue inflammation in obesity. Nat Med. 2009;15(8):914-20.

87. Strissel KJ, DeFuria J, Shaul ME, Bennett G, Greenberg AS, Obin MS. T-cell recruitment and Th1 polarization in adipose tissue during diet-induced obesity in C57BL/6 mice. Obesity (Silver Spring). 2010;18(10):1918-25.

88. Chu AJ, Walton MA, Prasad JK, Seto A. Blockade by polyunsaturated n-3 fatty acids of endotoxin-induced monocytic tissue factor activation is mediated by the depressed receptor expression in THP-1 cells. J Surg Res. 1999;87(2):217-24.

89. Oliver E, McGillicuddy FC, Harford KA, Reynolds CM, Phillips CM, Ferguson JF, et al. Docosahexaenoic acid attenuates macrophage-induced inflammation and improves insulin sensitivity in adipocytes-specific differential effects between LC n-3 PUFA. J Nutr Biochem. $2011 ; 23(9): 1192-200$.

90. De Caterina R, Cybulsky MI, Clinton SK, Gimbrone MA, Jr., Libby P. The omega-3 fatty acid docosahexaenoate reduces cytokine-induced expression of proatherogenic and proinflammatory proteins in human endothelial cells. Arterioscler Thromb. 1994;14(11):1829-36. 
91. Khalfoun B, Thibault F, Watier H, Bardos P, Lebranchu Y. Docosahexaenoic and eicosapentaenoic acids inhibit in vitro human endothelial cell production of interleukin-6. Adv Exp Med Biol. 1997;400B:589-97.

92. Billiar TR, Bankey PE, Svingen BA, Curran RD, West MA, Holman RT, et al. Fatty acid intake and Kupffer cell function: fish oil alters eicosanoid and monokine production to endotoxin stimulation. Surgery. 1988;104(2):343-9.

93. Renier G, Skamene E, DeSanctis J, Radzioch D. Dietary n-3 polyunsaturated fatty acids prevent the development of atherosclerotic lesions in mice. Modulation of macrophage secretory activities. Arterioscler Thromb. 1993;13(10):1515-24.

94. Yaqoob P, Calder P. Effects of dietary lipid manipulation upon inflammatory mediator production by murine macrophages. Cell Immunol. 1995;163(1):120-8.

95. Meydani SN, Endres S, Woods MM, Goldin BR, Soo C, Morrill-Labrode A, et al. Oral (n3) fatty acid supplementation suppresses cytokine production and lymphocyte proliferation: comparison between young and older women. J Nutr. 1991;121(4):547-55.

96. Gallai V, Sarchielli P, Trequattrini A, Franceschini M, Floridi A, Firenze C, et al. Cytokine secretion and eicosanoid production in the peripheral blood mononuclear cells of MS patients undergoing dietary supplementation with n-3 polyunsaturated fatty acids. J Neuroimmunol. 1995;56(2):143-53.

97. Trebble T, Arden NK, Stroud MA, Wootton SA, Burdge GC, Miles EA, et al. Inhibition of tumour necrosis factor-alpha and interleukin 6 production by mononuclear cells following dietary fish-oil supplementation in healthy men and response to antioxidant co-supplementation. $\mathrm{Br} \mathrm{J}$ Nutr. 2003;90(2):405-12.

98. Im DS. Functions of omega-3 fatty acids and FFA4 (GPR120) in macrophages. Eur J Pharmacol. 2015.

99. Hirasawa A, Tsumaya K, Awaji T, Katsuma S, Adachi T, Yamada M, et al. Free fatty acids regulate gut incretin glucagon-like peptide-1 secretion through GPR120. Nat Med. 2005;11(1):904.

100. Oh DY, Talukdar S, Bae EJ, Imamura T, Morinaga H, Fan W, et al. GPR120 is an omega3 fatty acid receptor mediating potent anti-inflammatory and insulin-sensitizing effects. Cell. 2010;142(5):687-98.

101. Yan Y, Jiang W, Spinetti T, Tardivel A, Castillo R, Bourquin C, et al. Omega-3 fatty acids prevent inflammation and metabolic disorder through inhibition of NLRP3 inflammasome activation. Immunity. 2013;38(6):1154-63.

102. Snodgrass RG, Huang S, Choi IW, Rutledge JC, Hwang DH. Inflammasome-mediated secretion of IL-1 $\beta$ in human monocytes through TLR2 activation; modulation by dietary fatty acids. $\mathrm{J}$ Immunol. 2013;191(8):4337-47.

103. Williams-Bey Y, Boularan C, Vural A, Huang NN, Hwang IY, Shan-Shi C, et al. Omega-3 free fatty acids suppress macrophage inflammasome activation by inhibiting NF-kappaB activation and enhancing autophagy. PLoS One. 2014;9(6):e97957.

104. Cassado AoA, D'Império Lima MR, Bortoluci KR. Revisiting mouse peritoneal macrophages: heterogeneity, development, and function. Front Immunol. 2015;6:225.

105. Taylor PR, Gordon S. Monocyte heterogeneity and innate immunity. Immunity. 2003;19(1):2-4.

106. The Nobel lectures in immunology. The Nobel prize for physiology or medicine, 1908, awarded to Elie Metchnikoff \& Paul Ehrlich "in recognition of their work on immunity.". Scand J Immunol. 1989;30(4):383-98.

107. Nathan C. Metchnikoff's Legacy in 2008. Nat Immunol. 2008;9(7):695-8.

108. COHN ZA. Determinants of infection in the peritoneal cavity. II. Factors influencing the fate of Staphylococcus aureus in the mouse. Yale J Biol Med. 1962;35:29-47.

109. COHN ZA. Determinants of infection in the peritoneal cavity. I. Response to and fate of Staphylococcus aureus and Staphylococcus albus in the mouse. Yale J Biol Med. 1962;35:1228.

110. Ghosn EE, Cassado AA, Govoni GR, Fukuhara T, Yang Y, Monack DM, et al. Two physically, functionally, and developmentally distinct peritoneal macrophage subsets. Proc Natl Acad Sci U S A. 2010;107(6):2568-73.

111. Rosas M, Davies LC, Giles PJ, Liao CT, Kharfan B, Stone TC, et al. The transcription factor Gata6 links tissue macrophage phenotype and proliferative renewal. Science. 2014;344(6184):645-8. 
112. Hoeffel G, Chen J, Lavin Y, Low D, Almeida FF, See P, et al. C-Myb(+) erythro-myeloid progenitor-derived fetal monocytes give rise to adult tissue-resident macrophages. Immunity. 2015;42(4):665-78.

113. Cain DW, O'Koren EG, Kan MJ, Womble M, Sempowski GD, Hopper K, et al. Identification of a tissue-specific, C/EBP $\beta$-dependent pathway of differentiation for murine peritoneal macrophages. J Immunol. 2013;191(9):4665-75.

114. Cassado AoA, de Albuquerque JA, Sardinha LR, Buzzo CeL, Faustino L, Nascimento R, et al. Cellular renewal and improvement of local cell effector activity in peritoneal cavity in response to infectious stimuli. PLoS One. 2011;6(7):e22141.

115. El Kasmi KC, Stenmark KR. Contribution of metabolic reprogramming to macrophage plasticity and function. Semin Immunol. 2015;27(4):267-75.

116. Rodríguez-Prados JC, Través PG, Cuenca J, Rico D, Aragonés J, Martín-Sanz P, et al. Substrate fate in activated macrophages: a comparison between innate, classic, and alternative activation. J Immunol. 2010;185(1):605-14.

117. Krawczyk CM, Holowka T, Sun J, Blagih J, Amiel E, DeBerardinis RJ, et al. Toll-like receptor-induced changes in glycolytic metabolism regulate dendritic cell activation. Blood. 2010;115(23):4742-9.

118. Palsson-McDermott EM, Curtis AM, Goel G, Lauterbach MA, Sheedy FJ, Gleeson LE, et al. Pyruvate kinase M2 regulates Hif- $1 \alpha$ activity and IL-1 $\beta$ induction and is a critical determinant of the warburg effect in LPS-activated macrophages. Cell Metab. 2015;21(1):65-80.

119. Tannahill GM, Curtis AM, Adamik J, Palsson-McDermott EM, McGettrick AF, Goel G, et al. Succinate is an inflammatory signal that induces IL-1 $1 \beta$ through HIF-1 $\alpha$. Nature. 2013;496(7444):238-42.

120. Moon JS, Hisata S, Park MA, DeNicola GM, Ryter SW, Nakahira K, et al. mTORC1Induced HK1-Dependent Glycolysis Regulates NLRP3 Inflammasome Activation. Cell Rep. 2015;12(1):102-15.

121. Haneklaus M, O'Neill LA. NLRP3 at the interface of metabolism and inflammation. Immunol Rev. 2015;265(1):53-62.

122. Yeh WJ, Yang HY, Pai MH, Wu CH, Chen JR. Long-term administration of advanced glycation end-product stimulates the activation of NLRP3 inflammasome and sparking the development of renal injury. J Nutr Biochem. 2017;39:68-76.

123. Calder PC. Omega-3 fatty acids and inflammatory processes. Nutrients. 2010;2(3):35574.

124. Calder PC. Polyunsaturated fatty acids and inflammation. Biochem Soc Trans. 2005;33(Pt 2):423-7.

125. Hayashi N, Tashiro T, Yamamori H, Takagi K, Morishima Y, Otsubo Y, et al. Effects of intravenous omega-3 and omega- 6 fat emulsion on cytokine production and delayed type hypersensitivity in burned rats receiving total parenteral nutrition. JPEN J Parenter Enteral Nutr. 1998;22(6):363-7.

126. Yaqoob P. Lipids and the immune response. Curr Opin Clin Nutr Metab Care. 1998;1(2):153-61.

127. Adolph S, Fuhrmann H, Schumann J. Unsaturated Fatty Acids Promote the Phagocytosis of P. aeruginosa and R. equi by RAW264.7 Macrophages. Curr Microbiol. 2012.

128. de Lima-Salgado TM, Alba-Loureiro TC, do Nascimento CS, Nunes MT, Curi R. Molecular mechanisms by which saturated fatty acids modulate TNF-alpha expression in mouse macrophage lineage. Cell Biochem Biophys. 2011;59(2):89-97.

129. Nguyen D, Ping F, Mu W, Hill P, Atkins RC, Chadban SJ. Macrophage accumulation in human progressive diabetic nephropathy. Nephrology (Carlton). 2006;11(3):226-31.

130. Hightower KR, Reddan JR, Dziedzic DC. Susceptibility of lens epithelial membrane SH groups to hydrogen peroxide. Invest Ophthalmol Vis Sci. 1989;30(3):569-74.

131. Livak KJ, Schmittgen TD. Analysis of relative gene expression data using real-time quantitative PCR and the 2(-Delta Delta C(T)) Method. Methods. 2001;25(4):402-8.

132. Pike Winer LS, Wu M. Rapid analysis of glycolytic and oxidative substrate flux of cancer cells in a microplate. PLoS One. 2014;9(10):e109916.

133. Schindelin J, Arganda-Carreras I, Frise E, Kaynig V, Longair M, Pietzsch T, et al. Fiji: an open-source platform for biological-image analysis. Nat Methods. 2012;9(7):676-82.

134. Brooks GA. What does glycolysis make and why is it important? J Appl Physiol (1985). 2010;108(6):1450-1. 
135. Kemp G. Lactate accumulation, proton buffering, and $\mathrm{pH}$ change in ischemically exercising muscle. Am J Physiol Regul Integr Comp Physiol. 2005;289(3):R895-901; author reply R4-10.

136. Kusterer K, Ludwig R, Hochschulz $P$, Stegmüller M, Bojunga J, von Minckwitz G. Macrophage and lymphocyte homing in experimental diabetes. Exp Clin Endocrinol Diabetes. 1999;107 Suppl 3:S102-7.

137. Ludwig R, Kretschmer M, Caspar G, Bojunga J, Oldenburg A, Schumm-Draeger P, et al. In vivo microscopy of murine islets of Langerhans: increased adhesion of transferred lymphocytes to islets depends on macrophage-derived cytokines in a model of organ-specific insulitis. Immunology. 1999;98(1):111-5.

138. Yoon JW, Jun HS. Cellular and molecular pathogenic mechanisms of insulin-dependent diabetes mellitus. Ann N Y Acad Sci. 2001;928:200-11.

139. Jun HS, Santamaria P, Lim HW, Zhang ML, Yoon JW. Absolute requirement of macrophages for the development and activation of beta-cell cytotoxic CD8+ T-cells in T-cell receptor transgenic NOD mice. Diabetes. 1999;48(1):34-42.

140. Leiter EH, Schile A. Genetic and Pharmacologic Models for Type 1 Diabetes. Curr Protoc Mouse Biol. 2013;3(1):9-19.

141. Karunanayake EH, Hearse DJ, Mellows G. The synthesis of [14C] streptozotocin and its distribution and excretion in the rat. Biochem J. 1974;142(3):673-83.

142. Yaochite JN, Caliari-Oliveira C, Davanso MR, Carlos D, Malmegrim KC, Cardoso CR, et al. Dynamic changes of the Th17/Tc17 and regulatory $\mathrm{T}$ cell populations interfere in the experimental autoimmune diabetes pathogenesis. Immunobiology. 2013;218(3):338-52.

143. Connor CL. Fatty infiltration of the liver and the development of cirrhosis in diabetes and chronic alcoholism. Am J Pathol. 1938;14(3):347-64.9.

144. Farrell GC, Larter CZ. Nonalcoholic fatty liver disease: from steatosis to cirrhosis. Hepatology. 2006;43(2 Suppl 1):S99-S112.

145. Schindhelm RK, Diamant M, Dekker JM, Tushuizen ME, Teerlink T, Heine RJ. Alanine aminotransferase as a marker of non-alcoholic fatty liver disease in relation to type 2 diabetes mellitus and cardiovascular disease. Diabetes Metab Res Rev. 2006;22(6):437-43.

146. West J, Brousil J, Gazis A, Jackson L, Mansell P, Bennett A, et al. Elevated serum alanine transaminase in patients with type 1 or type 2 diabetes mellitus. QJM. 2006;99(12):871-6.

147. Leeds JS, Forman EM, Morley S, Scott AR, Tesfaye S, Sanders DS. Abnormal liver function tests in patients with Type 1 diabetes mellitus: prevalence, clinical correlations and underlying pathologies. Diabet Med. 2009;26(12):1235-41.

148. Lucchesi AN, Freitas NT, Cassettari LL, Marques SF, Spadella CT. Diabetes mellitus triggers oxidative stress in the liver of alloxan-treated rats: a mechanism for diabetic chronic liver disease. Acta Cir Bras. 2013;28(7):502-8.

149. Evelson P, Susemihl C, Villarreal I, Llesuy S, Rodríguez R, Peredo H, et al. Hepatic morphological changes and oxidative stress in chronic streptozotocin-diabetic rats. Ann Hepatol. 2005;4(2):115-20.

150. Nolasco EL, Zanoni FL, Nunes FP, Ferreira SS, Freitas LA, Silva MC, et al. Insulin Modulates Liver Function in a Type I Diabetes Rat Model. Cell Physiol Biochem. 2015;36(4):146779.

151. Andican G, Burçak G. Oxidative damage to nuclear DNA in streptozotocin-diabetic rat liver. Clin Exp Pharmacol Physiol. 2005;32(8):663-6.

152. Dandona P, Thusu K, Cook S, Snyder B, Makowski J, Armstrong D, et al. Oxidative damage to DNA in diabetes mellitus. Lancet. 1996;347(8999):444-5.

153. Goodarzi MT, Navidi AA, Rezaei M, Babahmadi-Rezaei H. Oxidative damage to DNA and lipids: correlation with protein glycation in patients with type 1 diabetes. J Clin Lab Anal. 2010;24(2):72-6.

154. Wu LL, Chiou CC, Chang PY, Wu JT. Urinary 8-OHdG: a marker of oxidative stress to DNA and a risk factor for cancer, atherosclerosis and diabetics. Clin Chim Acta. 2004;339(1-2):19.

155. Matsunami T, Sato Y, Sato T, Ariga S, Shimomura T, Yukawa M. Oxidative stress and gene expression of antioxidant enzymes in the streptozotocin-induced diabetic rats under hyperbaric oxygen exposure. Int J Clin Exp Pathol. 2009;3(2):177-88.

156. Kurt O, Ozden TY, Ozsoy N, Tunali S, Can A, Akev N, et al. Influence of vanadium supplementation on oxidative stress factors in the muscle of STZ-diabetic rats. Biometals. $2011 ; 24(5): 943-9$. 
157. Marée AF, Komba M, Dyck C, Łabecki M, Finegood DT, Edelstein-Keshet L. Quantifying macrophage defects in type 1 diabetes. J Theor Biol. 2005;233(4):533-51.

158. Marée AF, Komba M, Finegood DT, Edelstein-Keshet L. A quantitative comparison of rates of phagocytosis and digestion of apoptotic cells by macrophages from normal (BALB/C) and diabetes-prone (NOD) mice. J Appl Physiol (1985). 2008;104(1):157-69.

159. Ptak W, Klimek M, Bryniarski K, Ptak M, Majcher P. Macrophage function in alloxan diabetic mice: expression of adhesion molecules, generation of monokines and oxygen and NO radicals. Clin Exp Immunol. 1998;114(1):13-8.

160. Wen Y, Gu J, Li SL, Reddy MA, Natarajan R, Nadler JL. Elevated glucose and diabetes promote interleukin-12 cytokine gene expression in mouse macrophages. Endocrinology. 2006;147(5):2518-25.

161. Sun C, Sun L, Ma H, Peng J, Zhen Y, Duan K, et al. The phenotype and functional alterations of macrophages in mice with hyperglycemia for long term. J Cell Physiol. 2012;227(4):1670-9.

162. Guha M, Bai W, Nadler JL, Natarajan R. Molecular mechanisms of tumor necrosis factor alpha gene expression in monocytic cells via hyperglycemia-induced oxidant stress-dependent and -independent pathways. J Biol Chem. 2000;275(23):17728-39.

163. Shanmugam N, Reddy MA, Guha M, Natarajan R. High glucose-induced expression of proinflammatory cytokine and chemokine genes in monocytic cells. Diabetes. 2003;52(5):125664.

164. Zhang $\mathrm{C}$, Bi Y, Jin G, Gan H, Yu L. High and fluctuating glucose levels increase the expression and secretion of interleukin-18 in mouse peritoneal macrophages. Mol Med Rep. 2015.

165. Van den Bossche J, O'Neill LA, Menon D. Macrophage Immunometabolism: Where Are We (Going)? Trends Immunol. 2017.

166. Galván-Peña S, O'Neill LA. Metabolic reprograming in macrophage polarization. Front Immunol. 2014;5:420.

167. Van den Bossche J, Lamers WH, Koehler ES, Geuns JM, Alhonen L, Uimari A, et al. Pivotal Advance: Arginase-1-independent polyamine production stimulates the expression of IL4-induced alternatively activated macrophage markers while inhibiting LPS-induced expression of inflammatory genes. J Leukoc Biol. 2012;91(5):685-99.

168. O'Neill LA, Kishton RJ, Rathmell J. A guide to immunometabolism for immunologists. Nat Rev Immunol. 2016;16(9):553-65.

169. Tan Z, Xie N, Cui H, Moellering DR, Abraham E, Thannickal VJ, et al. Pyruvate dehydrogenase kinase 1 participates in macrophage polarization via regulating glucose metabolism. J Immunol. 2015;194(12):6082-9.

170. Yang L, Xie M, Yang M, Yu Y, Zhu S, Hou W, et al. PKM2 regulates the Warburg effect and promotes HMGB1 release in sepsis. Nat Commun. 2014;5:4436.

171. Wallace FA, Neely SJ, Miles EA, Calder PC. Dietary fats affect macrophage-mediated cytotoxicity towards tumour cells. Immunol Cell Biol. 2000;78(1):40-8.

172. Yaqoob P, Newsholme EA, Calder PC. Influence of cell culture conditions on diet-induced changes in lymphocyte fatty acid composition. Biochim Biophys Acta. 1995;1255(3):333-40.

173. Lokesh BR, Wrann M. Incorporation of palmitic acid or oleic acid into macrophage membrane lipids exerts differential effects on the function of normal mouse peritoneal macrophages. Biochim Biophys Acta. 1984;792(2):141-8.

174. Hwang D. Modulation of the expression of cyclooxygenase-2 by fatty acids mediated through toll-like receptor 4-derived signaling pathways. FASEB J. 2001;15(14):2556-64.

175. Suganami T, Tanimoto-Koyama K, Nishida J, Itoh M, Yuan X, Mizuarai S, et al. Role of the Toll-like receptor 4/NF-kappaB pathway in saturated fatty acid-induced inflammatory changes in the interaction between adipocytes and macrophages. Arterioscler Thromb Vasc Biol. 2007;27(1):84-91.

176. Samokhvalov V, Bilan PJ, Schertzer JD, Antonescu CN, Klip A. Palmitate- and lipopolysaccharide-activated macrophages evoke contrasting insulin responses in muscle cells. Am J Physiol Endocrinol Metab. 2009;296(1):E37-46.

177. Talbot NA, Wheeler-Jones CP, Cleasby ME. Palmitoleic acid prevents palmitic acidinduced macrophage activation and consequent p38 MAPK-mediated skeletal muscle insulin resistance. Mol Cell Endocrinol. 2014;393(1-2):129-42. 
178. Liu SP, Li XY, Li Z, He LN, Xiao Y, Yan K, et al. Octanoylated Ghrelin Inhibits the Activation of the Palmitic Acid-Induced TLR4/NF-kappaB Signaling Pathway in THP-1 Macrophages. ISRN Endocrinol. 2012;2012:237613.

179. Haversen L, Danielsson KN, Fogelstrand L, Wiklund O. Induction of proinflammatory cytokines by long-chain saturated fatty acids in human macrophages. Atherosclerosis. 2009;202(2):382-93.

180. Linn T, Noke M, Woehrle M, Kloer HU, Hammes HP, Litzlbauer D, et al. Fish oil-enriched diet and reduction of low-dose streptozocin-induced hyperglycemia. Inhibition of macrophage activation. Diabetes. 1989;38(11):1402-11.

181. Kagohashi $Y$, Otani $H$. Diet with a low $n-6 / n-3$ essential fatty acid ratio when started immediately after the onset of overt diabetes prolongs survival of type 1 diabetes model NOD mice. Congenit Anom (Kyoto). 2010;50(4):226-31.

182. Canetti L, Werner $\mathrm{H}$, Leikin-Frenkel A. Linoleic and alpha linolenic acids ameliorate streptozotocin-induced diabetes in mice. Arch Physiol Biochem. 2014;120(1):34-9.

183. Simopoulos AP. Overview of evolutionary aspects of omega 3 fatty acids in the diet. World Rev Nutr Diet. 1998;83:1-11.

184. Kang JX, Wang J, Wu L, Kang ZB. Transgenic mice: fat-1 mice convert n-6 to n-3 fatty acids. Nature. 2004;427(6974):504.

185. Ha H, Lee HB. Reactive oxygen species as glucose signaling molecules in mesangial cells cultured under high glucose. Kidney Int Suppl. 2000;77:S19-25.

186. Bonnefont-Rousselot D. Glucose and reactive oxygen species. Curr Opin Clin Nutr Metab Care. 2002;5(5):561-8.

187. Ceriello A. New insights on oxidative stress and diabetic complications may lead to a "causal" antioxidant therapy. Diabetes Care. 2003;26(5):1589-96.

188. Rolo AP, Palmeira CM. Diabetes and mitochondrial function: role of hyperglycemia and oxidative stress. Toxicol Appl Pharmacol. 2006;212(2):167-78.

189. Funk SD, Yurdagul A, Orr AW. Hyperglycemia and endothelial dysfunction in atherosclerosis: lessons from type 1 diabetes. Int J Vasc Med. 2012;2012:569654.

190. Snell-Bergeon JK, West NA, Mayer-Davis EJ, Liese AD, Marcovina SM, D'Agostino RB, et al. Inflammatory markers are increased in youth with type 1 diabetes: the SEARCH CaseControl study. J Clin Endocrinol Metab. 2010;95(6):2868-76.

191. Carlos D, Costa FR, Pereira CA, Rocha FA, Yaochite JN, Oliveira GG, et al. Mitochondrial DNA Activates the NLRP3 Inflammasome and Predisposes to Type 1 Diabetes in Murine Model. Front Immunol. 2017;8:164.

192. Hwang JS, Shin $\mathrm{CH}$, Yang SW. Clinical implications of $\mathrm{N}$ epsilon-(carboxymethyl)lysine, advanced glycation end product, in children and adolescents with type 1 diabetes. Diabetes Obes Metab. 2005;7(3):263-7.

193. Berg TJ, Clausen JT, Torjesen PA, Dahl-Jørgensen K, Bangstad HJ, Hanssen KF. The advanced glycation end product Nepsilon-(carboxymethyl)lysine is increased in serum from children and adolescents with type 1 diabetes. Diabetes Care. 1998;21(11):1997-2002.

194. Hazra S, Jarajapu YP, Stepps V, Caballero S, Thinschmidt JS, Sautina L, et al. Longterm type 1 diabetes influences haematopoietic stem cells by reducing vascular repair potential and increasing inflammatory monocyte generation in a murine model. Diabetologia. 2013;56(3):644-53.

195. Orlandi A, Chavakis E, Seeger F, Tjwa M, Zeiher AM, Dimmeler S. Long-term diabetes impairs repopulation of hematopoietic progenitor cells and dysregulates the cytokine expression in the bone marrow microenvironment in mice. Basic Res Cardiol. 2010;105(6):703-12.

196. Chiarelli F, Cipollone F, Romano F, Tumini S, Costantini F, di Ricco L, et al. Increased circulating nitric oxide in young patients with type 1 diabetes and persistent microalbuminuria: relation to glomerular hyperfiltration. Diabetes. 2000;49(7):1258-63.

197. Cosentino F, Hishikawa K, Katusic ZS, Lüscher TF. High glucose increases nitric oxide synthase expression and superoxide anion generation in human aortic endothelial cells. Circulation. 1997;96(1):25-8.

198. Sharma K, Danoff TM, DePiero A, Ziyadeh FN. Enhanced expression of inducible nitric oxide synthase in murine macrophages and glomerular mesangial cells by elevated glucose levels: possible mediation via protein kinase C. Biochem Biophys Res Commun. 1995;207(1):808. 
199. Corbett JA, Wang JL, Misko TP, Zhao W, Hickey WF, McDaniel ML. Nitric oxide mediates IL-1 beta-induced islet dysfunction and destruction: prevention by dexamethasone. Autoimmunity. 1993;15(2):145-53.

200. Corbett JA, McDaniel ML. Does nitric oxide mediate autoimmune destruction of betacells? Possible therapeutic interventions in IDDM. Diabetes. 1992;41(8):897-903.

201. Kolb H, Kiesel U, Kröncke KD, Kolb-Bachofen V. Suppression of low dose streptozotocin induced diabetes in mice by administration of a nitric oxide synthase inhibitor. Life Sci. 1991;49(25):PL213-7.

202. Catanzaro OL, Marina-Prendes MG, Hope SI, Zuccollo A, Dominguez A. Streptozotocininduced hyperglycemia is decreased by nitric oxide inhibition. Braz $\mathrm{J}$ Med Biol Res. 1994;27(8):2043-7.

203. Haluzík M, Nedvídková J, Skrha J. The influence of methylene blue and L-NAME on the development of streptozotocin-induced diabetes in rats. Sb Lek. 1999;100(3):213-7.

204. Gonçalves VM, Matteucci KC, Buzzo CL, Miollo BH, Ferrante D, Torrecilhas AC, et al. NLRP3 controls Trypanosoma cruzi infection through a caspase-1-dependent IL-1R-independent NO production. PLoS Negl Trop Dis. 2013;7(10):e2469.

205. Kovacs I, Lindermayr C. Nitric oxide-based protein modification: formation and sitespecificity of protein S-nitrosylation. Front Plant Sci. 2013;4:137.

206. Mishra BB, Rathinam VA, Martens GW, Martinot AJ, Kornfeld H, Fitzgerald KA, et al. Nitric oxide controls the immunopathology of tuberculosis by inhibiting NLRP3 inflammasomedependent processing of IL-1 $\beta$. Nat Immunol. 2013;14(1):52-60.

207. Mao K, Chen S, Chen M, Ma Y, Wang Y, Huang B, et al. Nitric oxide suppresses NLRP3 inflammasome activation and protects against LPS-induced septic shock. Cell Res. 2013;23(2):201-12.

208. Lamkanfi M, Kanneganti TD, Van Damme P, Vanden Berghe T, Vanoverberghe I, Vandekerckhove $\mathrm{J}$, et al. Targeted peptidecentric proteomics reveals caspase-7 as a substrate of the caspase-1 inflammasomes. Mol Cell Proteomics. 2008;7(12):2350-63.

209. Erener S, Pétrilli V, Kassner I, Minotti R, Castillo R, Santoro R, et al. Inflammasomeactivated caspase 7 cleaves PARP1 to enhance the expression of a subset of NF-KB target genes. Mol Cell. 2012;46(2):200-11.

210. Malireddi RK, Ippagunta S, Lamkanfi M, Kanneganti TD. Cutting edge: proteolytic inactivation of poly(ADP-ribose) polymerase 1 by the Nlrp3 and Nlrc4 inflammasomes. J Immunol. 2010;185(6):3127-30.

211. Chiarugi A, Moskowitz MA. Poly(ADP-ribose) polymerase-1 activity promotes NFkappaB-driven transcription and microglial activation: implication for neurodegenerative disorders. J Neurochem. 2003;85(2):306-17.

212. Pétrilli V, Herceg Z, Hassa PO, Patel NS, Di Paola R, Cortes U, et al. Noncleavable poly(ADP-ribose) polymerase-1 regulates the inflammation response in mice. J Clin Invest. 2004;114(8):1072-81.

213. Ošina K, Rostoka E, Isajevs S, Sokolovska J, Sjakste T, Sjakste N. Effects of an Antimutagenic 1,4-Dihydropyridine AV-153 on Expression of Nitric Oxide Synthases and DNA Repair-related Enzymes and Genes in Kidneys of Rats with a Streptozotocin Model of Diabetes Mellitus. Basic Clin Pharmacol Toxicol. 2016;119(5):458-63.

214. Gisslen T, Ennis K, Bhandari V, Rao R. Recurrent hypoinsulinemic hyperglycemia in neonatal rats increases PARP-1 and NF-KB expression and leads to microglial activation in the cerebral cortex. Pediatr Res. 2015;78(5):513-9.

215. Khair-El-Din T, Sicher SC, Vazquez MA, Chung GW, Stallworth KA, Kitamura K, et al. Transcription of the murine iNOS gene is inhibited by docosahexaenoic acid, a major constituent of fetal and neonatal sera as well as fish oils. J Exp Med. 1996;183(3):1241-6.

216. Komatsu W, Ishihara K, Murata M, Saito H, Shinohara K. Docosahexaenoic acid suppresses nitric oxide production and inducible nitric oxide synthase expression in interferongamma plus lipopolysaccharide-stimulated murine macrophages by inhibiting the oxidative stress. Free Radic Biol Med. 2003;34(8):1006-16.

217. Kiss B, Szántó M, Szklenár M, Brunyánszki A, Marosvölgyi T, Sárosi E, et al. Poly(ADP) ribose polymerase-1 ablation alters eicosanoid and docosanoid signaling and metabolism in a murine model of contact hypersensitivity. Mol Med Rep. 2015;11(4):2861-7.

218. Kim SJ, Zhang Z, Saha A, Sarkar C, Zhao Z, Xu Y, et al. Omega-3 and omega- 6 fatty acids suppress ER- and oxidative stress in cultured neurons and neuronal progenitor cells from mice lacking PPT1. Neurosci Lett. 2010;479(3):292-6. 


\section{APÊNDICE}

\section{A - Apêndice 1. Valores brutos referentes às tabelas e figuras da tese}

Tabela A1. Valores individuais, média, desvio padrão (DP) e erro padrão da média (EPM) referentes à Figura 1 da seção Resultados: Evolução da glicemia (mg/dL) ao longo do período de estudo dos animais C57BL/6 controles (B6).

\begin{tabular}{|c|c|c|c|c|c|c|c|}
\hline \multicolumn{6}{|c|}{ Evolução da glicemia dos animais C57BL/6 controles ao longo do período estudado } \\
\hline Dias & Animal 1 & Animal 2 & Animal 3 & Animal 4 & Média & DP & EPM \\
\hline-5 & 132 & 148 & 143 & 125 & $\mathbf{1 3 7 , 8}$ & $\mathbf{9 , 2 8 7}$ & $\mathbf{4 , 6 4 4}$ \\
\hline-1 & 139 & 143 & 120 & 110 & $\mathbf{1 2 7 , 3}$ & $\mathbf{1 4 , 7 7}$ & $\mathbf{7 , 3 8 7}$ \\
\hline 7 & 162 & 143 & 127 & 121 & $\mathbf{1 3 7 , 8}$ & $\mathbf{1 7 , 5}$ & $\mathbf{8 , 7 5}$ \\
\hline 14 & 127 & 135 & 140 & 123 & $\mathbf{1 3 1 , 3}$ & $\mathbf{7 , 6 7 6}$ & $\mathbf{3 , 8 3 8}$ \\
\hline 21 & 137 & 128 & 132 & 120 & $\mathbf{1 2 9 , 3}$ & $\mathbf{7 , 1 8 2}$ & $\mathbf{3 , 5 9 1}$ \\
\hline 28 & 141 & 157 & 130 & 132 & $\mathbf{1 4 0}$ & $\mathbf{1 2 , 3}$ & $\mathbf{6 , 1 5 1}$ \\
\hline
\end{tabular}

Tabela A2. Valores individuais, média, desvio padrão (DP) e erro padrão da média (EPM) referentes à Figura 1 da seção Resultados: Evolução da glicemia (mg/dL) ao longo do período de estudo dos animais C57BL/6 diabéticos (B6+STZ).

\begin{tabular}{|c|c|c|c|c|c|c|c|c|c|}
\hline \multicolumn{8}{|c|}{ Evolução da glicemia dos animais C57BL/6 diabéticos (B6+STZ) ao longo do período estudado } \\
\hline Dias & Animal 1 & Animal 2 & Animal 3 & Animal 4 & Animal 5 & Animal 6 & Média & DP & EPM \\
\hline-5 & 140 & 130 & 135 & 142 & 120 & 150 & $\mathbf{1 3 6 , 2}$ & $\mathbf{1 0 , 4 0}$ & $\mathbf{4 , 2 5}$ \\
\hline-1 & 162 & 142 & 188 & 152 & 130 & 171 & $\mathbf{1 5 7 , 5}$ & $\mathbf{2 0 , 7 8}$ & $\mathbf{8 , 4 8}$ \\
\hline 7 & 176 & 189 & 220 & 170 & 181 & 203 & $\mathbf{1 8 9 , 8}$ & $\mathbf{1 8 , 6 9}$ & $\mathbf{7 , 6 3}$ \\
\hline 14 & 456 & 342 & 476 & 439 & 396 & 308 & $\mathbf{4 0 2 , 8}$ & $\mathbf{6 6 , 6 8}$ & $\mathbf{2 7 , 2 2}$ \\
\hline 21 & 448 & 301 & 454 & 432 & 381 & 415 & $\mathbf{4 0 5 , 2}$ & $\mathbf{5 7 , 3 9}$ & $\mathbf{2 3 , 4 3}$ \\
\hline 28 & 520 & 513 & 578 & 519 & 504 & 305 & $\mathbf{4 8 9 , 8}$ & $\mathbf{9 4 , 2 7}$ & $\mathbf{3 8 , 4 9}$ \\
\hline
\end{tabular}

Tabela A3. Valores individuais, média, desvio padrão (DP) e erro padrão da média (EPM) referentes à Figura 1 da seção Resultados: Evolução da massa corporal (g) ao longo do período de estudo dos animais C57BL/6 controles (B6).

\begin{tabular}{|c|c|c|c|c|c|c|c|}
\hline \multicolumn{6}{|c|}{ Evolução da massa corporal dos animais C57BL/6 controles (B6) ao longo do período do estudo } \\
\hline Dias & Animal 1 & Animal 2 & Animal 3 & Animal 4 & Média & DP & EPM \\
\hline-5 & 25,6 & 25,2 & 25,0 & 26,9 & $\mathbf{2 5 , 7}$ & $\mathbf{0 , 8 5}$ & $\mathbf{0 , 1 4}$ \\
\hline-1 & 26,0 & 26,7 & 27,4 & 28,6 & $\mathbf{2 7 , 2}$ & $\mathbf{1 , 1 1}$ & $\mathbf{0 , 1 8}$ \\
\hline 7 & 26,4 & 27,1 & 28,0 & 26,0 & $\mathbf{2 6 , 9}$ & $\mathbf{0 , 8 8}$ & $\mathbf{0 , 1 4}$ \\
\hline 14 & 26,5 & 27,4 & 29,8 & 26,8 & $\mathbf{2 7 , 6}$ & $\mathbf{1 , 5 0}$ & $\mathbf{0 , 2 4}$ \\
\hline 21 & 27,2 & 28,0 & 29,0 & 28,0 & $\mathbf{2 8 , 1}$ & $\mathbf{0 , 7 4}$ & $\mathbf{0 , 1 2}$ \\
\hline 28 & 28,4 & 29,0 & 30,2 & 31,0 & $\mathbf{2 9 , 7}$ & $\mathbf{1 , 1 7}$ & $\mathbf{0 , 1 9}$ \\
\hline
\end{tabular}


Tabela A4. Valores individuais, média, desvio padrão (DP) e erro padrão da média (EPM) referentes à Figura 1 da seção Resultados: Evolução da massa corporal (g) ao longo do período de estudo dos animais C57BL/6 diabéticos (B6+STZ).

\begin{tabular}{|c|c|c|c|c|c|c|c|c|c|}
\hline \multicolumn{7}{|c|}{ Evolução da massa corporal dos animais C57BL/6 diabéticos (B6+STZ) ao longo do período do estudo } \\
\hline Dias & Animal 1 & Animal 2 & Animal 3 & Animal 4 & Animal 5 & Animal 6 & Média & DP & EPM \\
\hline-5 & 24,2 & 26,2 & 24,4 & 25,0 & 25,0 & 25,5 & $\mathbf{2 5 , 1}$ & $\mathbf{0 , 7 3}$ & $\mathbf{0 , 3 0}$ \\
\hline-1 & 24 & 27,8 & 24,0 & 26,4 & 26,0 & 25,9 & $\mathbf{2 5 , 7}$ & $\mathbf{1 , 4 7}$ & $\mathbf{0 , 6 0}$ \\
\hline 7 & 24,4 & 28,4 & 24,6 & 27,2 & 26,6 & 26,6 & $\mathbf{2 6 , 3}$ & $\mathbf{1 , 5 4}$ & $\mathbf{0 , 6 3}$ \\
\hline 14 & 25,6 & 26,8 & 25,2 & 28,0 & 27,4 & 27 & $\mathbf{2 6 , 7}$ & $\mathbf{1 , 0 7}$ & $\mathbf{0 , 4 4}$ \\
\hline 21 & 25,2 & 26,2 & 25,6 & 27,0 & 27,6 & 26,8 & $\mathbf{2 6 , 4}$ & $\mathbf{0 , 9 0}$ & $\mathbf{0 , 3 7}$ \\
\hline 28 & 25 & 27,6 & 27,2 & 27,4 & 27,0 & 26,5 & $\mathbf{2 6 , 8}$ & $\mathbf{0 , 9 5}$ & $\mathbf{0 , 3 9}$ \\
\hline
\end{tabular}

Tabela A5. Valores individuais, média, desvio padrão (DP) e erro padrão da média (EPM) referentes à Figura 1 da seção Resultados: Determinação de insulina (ng/mL) no soro dos animais C57BL/6 controles e diabéticos ao fim de 30 dias de indução da doença.

\begin{tabular}{|c|c|c|}
\hline & \multicolumn{2}{|c|}{30 Dias } \\
\hline Insulina (ng/mL) & B6 & B6+STZ \\
\hline Animal 1 & 0,401 & 0,325 \\
\hline Animal 2 & 1,852 & 0,270 \\
\hline Animal 3 & 0,295 & 0,283 \\
\hline Animal 4 & 0,298 & 0,157 \\
\hline Animal 5 & 2,068 & 0,195 \\
\hline Animal 6 & 0,211 & 0,239 \\
\hline Animal 7 & 1,218 & 0,154 \\
\hline Animal 8 & 0,388 & 0,465 \\
\hline Animal 9 & 1,065 & 0,076 \\
\hline Animal 10 & 0,929 & 0,449 \\
\hline Animal 11 & 1,593 & 0,311 \\
\hline Animal 12 & 0,713 & 0,160 \\
\hline Animal 13 & 0,646 & 0,068 \\
\hline Animal 14 & 0,593 & 0,547 \\
\hline Animal 15 & 0,686 & 0,632 \\
\hline Animal 16 & 0,645 & 0,731 \\
\hline Animal 17 & 1,343 & 0,727 \\
\hline Animal 18 & 0,591 & 0,733 \\
\hline Animal 19 & - & 0,663 \\
\hline Animal 20 & - & 0,625 \\
\hline Animal 21 & - & 0,909 \\
\hline Média & $\mathbf{0 , 8 6 3}$ & $\mathbf{0 , 4 1 5}$ \\
\hline DV & $\mathbf{0 , 5 5 1}$ & $\mathbf{0 , 2 5 4}$ \\
\hline EPM & $\mathbf{0 , 1 3 0}$ & $\mathbf{0 , 0 5 5}$ \\
\hline & & \\
\hline
\end{tabular}


Tabela A6. Valores individuais, média, desvio padrão (DP) e erro padrão da média (EPM) referentes à Tabela 1 da seção Resultados: Efeitos do diabetes induzido por estreptozotocina após 30 ou 90 dias sobre a massa absoluta do fígado de animais controles (B6) e diabéticos (B6+STZ).

\begin{tabular}{|c|c|c|c|c|}
\hline & \multicolumn{2}{|c|}{ 30 Dias } & \multicolumn{2}{c|}{ 90 Dias } \\
\hline & B6 & B6+ZTZ & B6 & B6+STZ \\
\hline Animal 1 & 1,69 & 1,76 & 1,36 & 1,96 \\
\hline Animal 2 & 1,67 & 1,65 & 1,51 & 1,76 \\
\hline Animal 3 & 1,95 & 1,48 & 1,34 & 1,64 \\
\hline Animal 4 & 1,82 & 1,71 & 1,44 & 1,31 \\
\hline Animal 5 & 1,58 & 1,41 & 1,43 & 1,39 \\
\hline Animal 6 & 1,78 & 1,54 & 0,93 & 1,89 \\
\hline Animal 7 & 1,65 & 1,74 & 1,59 & 1,76 \\
\hline Animal 8 & 1,79 & 1,55 & 1,56 & 1,72 \\
\hline Animal 9 & & 1,48 & 1,41 & - \\
\hline Animal 10 & & 1,21 & 1,38 & - \\
\hline Média & $\mathbf{1 , 7 4}$ & $\mathbf{1 , 5 5}$ & $\mathbf{1 , 3 9}$ & $\mathbf{1 , 6 8}$ \\
\hline DP & $\mathbf{0 , 1 2}$ & $\mathbf{0 , 1 7}$ & $\mathbf{0 , 1 8}$ & $\mathbf{0 , 2 1}$ \\
\hline EPM & $\mathbf{0 , 0 4}$ & $\mathbf{0 , 0 5}$ & $\mathbf{0 , 0 6}$ & $\mathbf{0 , 0 7}$ \\
\hline
\end{tabular}

(-): dado perdido

Tabela A7. Valores individuais, média, desvio padrão (DP) e erro padrão da média (EPM) referentes à Tabela 1 da seção Resultados: Efeitos do diabetes induzido por estreptozotocina após 30 ou 90 dias sobre a atividade da ALT no soro (U/L) de animais controles (B6) e diabéticos (B6+STZ).

\begin{tabular}{|c|c|c|c|c|}
\hline & \multicolumn{2}{|c|}{ 30 Dias } & \multicolumn{2}{c|}{ 90 Dias } \\
\hline & B6 & B6+STZ & B6 & B6+STZ \\
\hline Animal 1 & 7,86 & 27,94 & 7,86 & 16,59 \\
\hline Animal 2 & 10,48 & 29,68 & 9,60 & 20,95 \\
\hline Animal 3 & 10,48 & 17,46 & 10,48 & 25,32 \\
\hline Animal 4 & 13,10 & 7,86 & 11,35 & 32,30 \\
\hline Animal 5 & 13,10 & 26,19 & 9,60 & 28,81 \\
\hline Animal 6 & 9,60 & 14,84 & 10,48 & 15,71 \\
\hline Animal 7 & 9,60 & 16,59 & 12,22 & 38,41 \\
\hline Animal 8 & 13,97 & 19,21 & 14,84 & 29,68 \\
\hline Animal 9 & & 22,70 & 8,73 & 12,22 \\
\hline Animal 10 & & 24,44 & 10,48 & 22,70 \\
\hline Média & $\mathbf{1 1 , 0 2}$ & $\mathbf{2 0 , 6 9}$ & $\mathbf{1 0 , 5 6}$ & $\mathbf{2 4 , 2 7}$ \\
\hline DP & $\mathbf{2 , 1 4}$ & $\mathbf{6 , 7 5}$ & $\mathbf{1 , 9 5}$ & $\mathbf{8 , 2 1}$ \\
\hline EPM & $\mathbf{0 , 7 5}$ & $\mathbf{2 , 1 4}$ & $\mathbf{0 , 6 2}$ & $\mathbf{2 , 6 0}$ \\
\hline
\end{tabular}


Tabela A8. Valores individuais, média, desvio padrão (DP) e erro padrão da média (EPM) referentes à Tabela 1 da seção Resultados: Efeitos do diabetes induzido por estreptozotocina após 30 ou 90 dias sobre a atividade da AST no soro (U/L) de animais controles (B6) e diabéticos (B6+STZ).

\begin{tabular}{|c|c|c|c|c|}
\hline & \multicolumn{2}{|c|}{ 30 Dias } & \multicolumn{2}{c|}{ 90 Dias } \\
\hline & B6 & B6+STZ & B6 & B6+STZ \\
\hline Animal 1 & 23,57 & 45,40 & 13,97 & 18,33 \\
\hline Animal 2 & 29,68 & 41,90 & 21,83 & 20,08 \\
\hline Animal 3 & 25,32 & 34,92 & 23,57 & 16,59 \\
\hline Animal 4 & 33,17 & 13,10 & 31,43 & 56,75 \\
\hline Animal 5 & 25,32 & 53,25 & 20,08 & 28,81 \\
\hline Animal 6 & 20,95 & 26,19 & 27,94 & 24,44 \\
\hline Animal 7 & 32,30 & 18,33 & 21,83 & 75,08 \\
\hline Animal 8 & 27,94 & 28,81 & 34,92 & 49,76 \\
\hline Animal 9 & & 34,05 & 20,08 & 24,44 \\
\hline Animal 10 & & 44,52 & 20,08 & 33,17 \\
\hline Média & $\mathbf{2 7 , 2 8}$ & $\mathbf{3 4 , 0 5}$ & $\mathbf{2 3 , 5 7}$ & $\mathbf{3 4 , 7 5}$ \\
\hline DP & $\mathbf{4 , 2 7}$ & $\mathbf{1 2 , 6 7}$ & $\mathbf{6 , 1 9}$ & $\mathbf{1 9 , 4 4}$ \\
\hline EPM & $\mathbf{1 , 5 1}$ & $\mathbf{4 , 0 1}$ & $\mathbf{1 , 9 6}$ & $\mathbf{6 , 1 5}$ \\
\hline
\end{tabular}

Tabela A9. Valores individuais, média, desvio padrão (DP) e erro padrão da média (EPM) referentes à Tabela 1 da seção Resultados: Efeitos do diabetes induzido por estreptozotocina após 30 ou 90 dias sobre a concentração de TNF- $\alpha$ no fígado (pg/mg de proteína) de animais controles (B6) e diabéticos (B6+STZ).

\begin{tabular}{|c|c|c|c|c|}
\hline & \multicolumn{2}{|c|}{ 30 Dias } & \multicolumn{2}{c|}{ 90 Dias } \\
\hline & B6 & B6+STZ & B6 & B6+STZ \\
\hline Animal 1 & 159,99 & 222,36 & 167,41 & 233,33 \\
\hline Animal 2 & 191,66 & 148,85 & 212,04 & 253,63 \\
\hline Animal 3 & 157,57 & 201,80 & 229,54 & 221,81 \\
\hline Animal 4 & 206,18 & 162,62 & 226,11 & 264,89 \\
\hline Animal 5 & 157,12 & 309,52 & 166,64 & 241,12 \\
\hline Animal 6 & 181,82 & 220,00 & 219,98 & 228,01 \\
\hline Animal 7 & 158,58 & 314,97 & 249,65 & 255,21 \\
\hline Animal 8 & 253,09 & 251,97 & 194,89 & 279,04 \\
\hline Animal 9 & & 210,90 & 230,18 & 267,22 \\
\hline Animal 10 & & 254,04 & 158,58 & 188,67 \\
\hline Média & $\mathbf{1 8 3 , 3}$ & $\mathbf{2 2 9 , 7}$ & $\mathbf{2 0 5 , 5}$ & $\mathbf{2 4 3 , 3}$ \\
\hline DP & $\mathbf{3 3 , 7 4}$ & $\mathbf{5 4 , 8 2}$ & $\mathbf{3 1 , 7 8}$ & $\mathbf{2 6 , 5 6}$ \\
\hline EPM & $\mathbf{1 1 , 9 3}$ & $\mathbf{1 7 , 3 4}$ & $\mathbf{1 0 , 0 5}$ & $\mathbf{8 , 3 9 9}$ \\
\hline
\end{tabular}


Tabela A10. Valores individuais, média, desvio padrão (DP) e erro padrão da média (EPM) referentes à Tabela 1 da seção Resultados: Efeitos do diabetes induzido por estreptozotocina após 30 ou 90 dias sobre a concentração de IL-6 no fígado (pg/mg proteína) de animais controles (B6) e diabéticos (B6+STZ).

\begin{tabular}{|c|c|c|c|c|}
\hline & \multicolumn{2}{|c|}{ 30 Dias } & \multicolumn{2}{c|}{ 90 Dias } \\
\hline & B6 & B6+STZ & B6 & B6+STZ \\
\hline Animal 1 & NR & NR & 63,01 & 73,07 \\
\hline Animal 2 & 63,92 & 82,81 & 75,45 & 79,17 \\
\hline Animal 3 & 75,45 & 81,25 & NR & NR \\
\hline Animal 4 & 88,19 & 77,04 & 59,54 & 104,54 \\
\hline Animal 5 & 60,63 & 87,51 & 61,08 & 118,76 \\
\hline Animal 6 & 73,84 & NR & 71,55 & 76,32 \\
\hline Animal 7 & NR & 80,24 & 58,78 & NR \\
\hline Animal 8 & 73,14 & 102,43 & 58,76 & 70,73 \\
\hline Animal 9 & & 68,47 & 57,22 & 67,27 \\
\hline Animal 10 & & NR & 52,15 & 57,76 \\
\hline Média & $\mathbf{7 2 , 5 3}$ & $\mathbf{8 2 , 8 2}$ & $\mathbf{6 1 , 9 5}$ & $\mathbf{8 0 , 9 5}$ \\
\hline DP & $\mathbf{9 , 7 1 2}$ & $\mathbf{1 0 , 4 5}$ & $\mathbf{7 , 2 5 2}$ & $\mathbf{2 0 , 3 6}$ \\
\hline EPM & $\mathbf{3 , 9 6 5}$ & $\mathbf{3 , 9 4 9}$ & $\mathbf{2 , 4 1 7}$ & $\mathbf{7 , 1 9 9}$ \\
\hline
\end{tabular}

NR: não realizado

Tabela A11. Valores individuais, média, desvio padrão (DP) e erro padrão da média (EPM) referentes à Tabela 1 da seção Resultados: Efeitos do diabetes induzido por estreptozotocina após 30 ou 90 dias sobre a concentração de IL-1 $\beta$ no fígado (pg/mg proteína) de animais controles (B6) e diabéticos (B6+STZ).

\begin{tabular}{|c|c|c|c|c|}
\hline & \multicolumn{2}{|c|}{ 30 Dias } & \multicolumn{2}{c|}{ 90 Dias } \\
\hline & B6 & B6+STZ & B6 & B6+STZ \\
\hline Animal 1 & 40,79 & 42,08 & 29,59 & 33,08 \\
\hline Animal 2 & 35,32 & 50,50 & 43,44 & 40,89 \\
\hline Animal 3 & 44,61 & 44,68 & 50,14 & 41,22 \\
\hline Animal 4 & 54,45 & 44,55 & 33,47 & 67,60 \\
\hline Animal 5 & 34,28 & 50,64 & 30,35 & 63,94 \\
\hline Animal 6 & 43,04 & 51,35 & 38,91 & 39,59 \\
\hline Animal 7 & 59,00 & 42,86 & 31,95 & 48,21 \\
\hline Animal 8 & 51,60 & 59,13 & 34,50 & 40,77 \\
\hline Animal 9 & & 36,18 & 30,71 & 31,60 \\
\hline Animal 10 & & 52,62 & 30,34 & 31,97 \\
\hline Média & $\mathbf{4 5 , 3 9}$ & $\mathbf{4 7 , 4 6}$ & $\mathbf{3 5 , 3 4}$ & $\mathbf{4 3 , 8 9}$ \\
\hline DP & $\mathbf{8 , 9 2 8}$ & $\mathbf{6 , 5 9}$ & $\mathbf{6 , 8 1 1}$ & $\mathbf{1 2 , 6 4}$ \\
\hline EPM & $\mathbf{3 , 1 5 7}$ & $\mathbf{2 , 0 8 4}$ & $\mathbf{2 , 1 5 4}$ & $\mathbf{3 , 9 9 6}$ \\
\hline
\end{tabular}


Tabela A12. Valores individuais, média, desvio padrão (DP) e erro padrão da média (EPM) referentes à Tabela 2 da seção Resultados: Efeitos do diabetes após 30 e 90 dias na expressão gênica de IL-1 $\beta$ e IL-6 no fígado dos animais controles (B6) e diabéticos (B6+STZ).

\begin{tabular}{|c|c|c|c|c|c|c|c|c|c|}
\hline Fígado & \multicolumn{2}{|c|}{30 Dias } & \multicolumn{2}{|c|}{90 Dias } & \multirow{2}{*}{$\begin{array}{c}\text { Fígado } \\
\text { IL-6 (Fold Change })\end{array}$} & \multicolumn{2}{|c|}{30 Dias } & \multicolumn{2}{|c|}{90 Dias } \\
\hline IL-1及 (Fold Change) & B6 & B6+STZ & B6 & B6+STZ & & B6 & B6+STZ & B6 & B6+STZ \\
\hline Animal 1 & 1,20 & 0,27 & 2,15 & 0,93 & Animal 1 & 1,20 & 0,27 & 2,15 & 0,93 \\
\hline Animal 2 & 2,44 & 2,26 & 2,35 & 0,51 & Animal 2 & 2,44 & 2,26 & 2,35 & 0,51 \\
\hline Animal 3 & 0,67 & 2,48 & 0,54 & 1,46 & Animal 3 & 0,67 & 2,48 & 0,54 & 1,46 \\
\hline Animal 4 & 1,06 & 0,76 & CNR & 1,65 & Animal 4 & 1,06 & 0,76 & CNR & 1,65 \\
\hline Animal 5 & 1,26 & 1,03 & 1,01 & 0,47 & Animal 5 & 1,26 & 1,03 & 1,01 & 0,47 \\
\hline Animal 6 & 0,80 & 0,28 & 0,37 & 1,80 & Animal 6 & 0,80 & 0,28 & 0,37 & 1,80 \\
\hline Animal 7 & CNR & 0,47 & 1,03 & 0,30 & Animal 7 & CNR & 0,47 & 1,03 & 0,30 \\
\hline Animal 8 & 0,48 & 0,23 & 0,96 & 0,33 & Animal 8 & 0,48 & 0,23 & 0,96 & 0,33 \\
\hline Média & 1,13 & 0,97 & 1,20 & 0,93 & Média & 1,13 & 0,97 & 1,20 & 0,93 \\
\hline DP & 0,64 & 0,91 & 0,76 & 0,62 & DP & 0,64 & 0,91 & 0,76 & 0,62 \\
\hline EPM & 0,24 & 0,32 & 0,29 & 0,22 & EPM & 0,24 & 0,32 & 0,29 & 0,22 \\
\hline
\end{tabular}

CNR: cinética não responsiva

Tabela A13. Valores individuais, média, desvio padrão (DP) e erro padrão da média (EPM) referentes à Tabela 2 da seção Resultados: Efeitos do diabetes após 30 e 90 dias na expressão gênica de TNF- $\alpha$ e F4/80 no fígado dos animais controles (B6) e diabéticos (B6+STZ).

\begin{tabular}{|c|c|c|c|c|c|c|c|c|c|}
\hline Fígado & \multicolumn{2}{|c|}{30 Dias } & \multicolumn{2}{|c|}{$\mathbf{9 0}$ Dias } & \multicolumn{2}{c|}{ Fígado } & \multicolumn{2}{c|}{ 30 Dias } & \multicolumn{2}{c|}{ 90 Dias } \\
\hline TNF- $\boldsymbol{\alpha}$ (Fold Change) & B6 & B6+STZ & B6 & B6+STZ & F4/80 (Fold Change) & B6 & B6+STZ & B6 & B6+STZ \\
\hline Animal 1 & 0,63 & 0,36 & 1,06 & 0,80 & Animal 1 & 1,09 & 0,63 & 1,05 & 1,38 \\
\hline Animal 2 & 1,05 & CNR & 0,25 & 1,13 & Animal 2 & 0,99 & 0,80 & 0,61 & 1,15 \\
\hline Animal 3 & CNR & CNR & 0,09 & 2,35 & Animal 3 & 0,45 & 1,27 & 0,81 & 1,18 \\
\hline Animal 4 & 0,86 & 0,23 & 0,64 & 3,64 & Animal 4 & 1,14 & 1,54 & 1,30 & 3,42 \\
\hline Animal 5 & 0,94 & 1,18 & 0,44 & 0,95 & Animal 5 & 1,25 & 2,34 & 1,13 & 1,90 \\
\hline Animal 6 & 1,44 & 1,29 & CNR & 1,74 & Animal 6 & 0,99 & 1,75 & 1,32 & 2,52 \\
\hline Animal 7 & CNR & CNR & 0,44 & 0,31 & Animal 7 & CNR & 1,47 & 1,05 & 1,43 \\
\hline Animal 8 & 0,38 & 0,28 & 0,17 & 0,56 & Animal 8 & 1,47 & 1,54 & 0,96 & CNR \\
\hline Média & $\mathbf{0 , 8 8}$ & $\mathbf{0 , 6 7}$ & $\mathbf{0 , 4 4}$ & $\mathbf{1 , 4 4}$ & Média & $\mathbf{1 , 0 5}$ & $\mathbf{1 , 4 2}$ & $\mathbf{1 , 0 3}$ & $\mathbf{1 , 8 5}$ \\
\hline DP & $\mathbf{0 , 3 6}$ & $\mathbf{0 , 5 2}$ & $\mathbf{0 , 3 3}$ & $\mathbf{1 , 1 1}$ & DP & $\mathbf{0 , 3 1}$ & $\mathbf{0 , 5 4}$ & $\mathbf{0 , 2 4}$ & $\mathbf{0 , 8 4}$ \\
\hline EPM & $\mathbf{0 , 1 5}$ & $\mathbf{0 , 2 3}$ & $\mathbf{0 , 1 3}$ & $\mathbf{0 , 3 9}$ & EPM & $\mathbf{0 , 1 2}$ & $\mathbf{0 , 1 9}$ & $\mathbf{0 , 0 8}$ & $\mathbf{0 , 3 2}$ \\
\hline
\end{tabular}

CNR: cinética não responsiva 
Tabela A14. Valores individuais, média, desvio padrão (DP) e erro padrão da média (EPM) referentes à Tabela 2 da seção Resultados: Efeitos do diabetes após 30 e 90 dias na expressão gênica de MCP-1 e CAT no fígado dos animais controles (B6) e diabéticos (B6+STZ).

\begin{tabular}{|c|c|c|c|c|c|c|c|c|c|}
\hline Fígado & \multicolumn{2}{|c|}{ 30 Dias } & \multicolumn{2}{c|}{ 90 Dias } & \multicolumn{2}{c|}{ Fígado } & \multicolumn{2}{|c|}{ 30 Dias } & \multicolumn{2}{c|}{ 90 Dias } \\
\hline MCP-1 (Fold Change) & B6 & B6+STZ & B6 & B6+STZ & CAT (Fold Change $)$ & B6 & B6+STZ & B6 & B6+STZ \\
\hline Animal 1 & 0,26 & 0,36 & 0,77 & 0,55 & Animal 1 & 1,62 & 0,54 & 0,90 & 0,69 \\
\hline Animal 2 & 2,77 & CNR & 0,46 & 0,74 & Animal 2 & 0,89 & 0,09 & 1,01 & 1,08 \\
\hline Animal 3 & 0,30 & 1,63 & 0,24 & 0,87 & Animal 3 & 1,01 & 0,25 & 0,95 & 0,78 \\
\hline Animal 4 & 2,33 & 0,38 & 3,02 & CNR & Animal 4 & 0,95 & 0,63 & 0,94 & 0,71 \\
\hline Animal 5 & 1,42 & 0,67 & 0,92 & 0,97 & Animal 5 & 1,12 & 1,07 & 1,17 & 0,65 \\
\hline Animal 6 & 2,73 & 0,31 & 1,49 & 2,57 & Animal 6 & 1,09 & 0,50 & 0,88 & 0,75 \\
\hline Animal 7 & CNR & 0,73 & 2,81 & 0,74 & Animal 7 & 0,61 & 0,88 & 0,90 & 0,85 \\
\hline Animal 8 & 0,51 & 0,24 & CNR & 2,24 & Animal 8 & 0,97 & 0,71 & 1,35 & 0,48 \\
\hline Média & $\mathbf{1 , 4 7}$ & $\mathbf{0 , 6 2}$ & $\mathbf{1 , 3 9}$ & $\mathbf{1 , 2 4}$ & Média & $\mathbf{1 , 0 3}$ & $\mathbf{0 , 5 9}$ & $\mathbf{1 , 0 1}$ & $\mathbf{0 , 7 5}$ \\
\hline DP & $\mathbf{1 , 1 4}$ & $\mathbf{0 , 4 8}$ & $\mathbf{1 , 1 2}$ & $\mathbf{0 , 8 1}$ & DP & $\mathbf{0 , 2 9}$ & $\mathbf{0 , 3 2}$ & $\mathbf{0 , 1 6}$ & $\mathbf{0 , 1 7}$ \\
\hline EPM & $\mathbf{0 , 4 3}$ & $\mathbf{0 , 1 8}$ & $\mathbf{0 , 4 2}$ & $\mathbf{0 , 3 1}$ & EPM & $\mathbf{0 , 1 0}$ & $\mathbf{0 , 1 1}$ & $\mathbf{0 , 0 6}$ & $\mathbf{0 , 0 6}$ \\
\hline
\end{tabular}

CNR: cinética não responsiva

Tabela A15. Valores individuais, média, desvio padrão (DP) e erro padrão da média (EPM) referentes à Tabela 2 da seção Resultados: Efeitos do diabetes após 30 e 90 dias na expressão gênica de GPX e SOD-1 no fígado dos animais controles (B6) e diabéticos (B6+STZ).

\begin{tabular}{|c|c|c|c|c|c|c|c|c|c|}
\hline Fígado & \multicolumn{2}{|c|}{ 30 Dias } & \multicolumn{2}{c|}{90 Dias } & \multicolumn{2}{c|}{ Fígado } & \multicolumn{2}{c|}{ 30 Dias } & \multicolumn{2}{c|}{90 Dias } \\
\hline GPX (Fold Change) & B6 & B6+STZ & B6 & B6+STZ & SOD-1 (Fold Change) & B6 & B6+STZ & B6 & B6+STZ \\
\hline Animal 1 & 1,15 & 1,17 & 0,72 & 0,89 & Animal 1 & 1,25 & 0,82 & 0,63 & 0,63 \\
\hline Animal 2 & 1,39 & 2,06 & 1,03 & 1,23 & Animal 2 & 1,02 & 2,49 & 0,97 & 0,96 \\
\hline Animal 3 & 0,84 & 2,33 & 1,30 & 1,21 & Animal 3 & 0,86 & 1,94 & 1,08 & 0,95 \\
\hline Animal 4 & 0,98 & 0,94 & 1,46 & 1,65 & Animal 4 & 1,18 & 0,75 & 1,07 & 1,25 \\
\hline Animal 5 & 1,14 & 1,29 & 1,05 & 1,51 & Animal 5 & 1,00 & 1,74 & 1,16 & 1,00 \\
\hline Animal 6 & 0,96 & 1,52 & 0,75 & 0,94 & Animal 6 & 0,82 & 0,91 & 1,07 & 1,25 \\
\hline Animal 7 & 0,68 & 0,91 & 1,15 & 2,38 & Animal 7 & CNR & 0,82 & 1,08 & 1,05 \\
\hline Animal 8 & 1,02 & 0,96 & 0,79 & 1,21 & Animal 8 & 0,96 & 0,79 & 1,05 & 0,80 \\
\hline Média & 1,02 & 1,40 & 1,03 & 1,38 & Média & 1,01 & 1,28 & 1,02 & 0,98 \\
\hline DP & 0,21 & 0,54 & 0,27 & 0,48 & DP & 0,16 & 0,68 & 0,17 & 0,21 \\
\hline EPM & 0,08 & 0,19 & 0,10 & 0,17 & EPM & 0,06 & 0,24 & 0,06 & 0,07 \\
\hline
\end{tabular}


Tabela A16. Valores individuais, média, desvio padrão (DP) e erro padrão da média (EPM) referentes à Tabela 2 da seção Resultados: Efeitos do diabetes após 30 e 90 dias na expressão gênica de SOD-2 no fígado dos animais controles (B6) e diabéticos (B6+STZ).

\begin{tabular}{|c|c|c|c|c|}
\hline Fígado & \multicolumn{2}{|c|}{ 30 Dias } & \multicolumn{2}{c|}{ 90 Dias } \\
\hline SOD-2 (Fold Change) & B6 & B6+STZ & B6 & B6+STZ \\
\hline Animal 1 & 1,04 & 0,49 & 1,04 & 0,71 \\
\hline Animal 2 & 0,87 & 0,32 & 1,03 & 1,32 \\
\hline Animal 3 & 1,02 & 0,59 & CNR & 1,24 \\
\hline Animal 4 & 0,93 & 0,63 & 0,99 & 1,89 \\
\hline Animal 5 & 1,18 & 1,29 & 1,06 & 1,22 \\
\hline Animal 6 & 1,02 & 0,50 & 0,67 & 1,27 \\
\hline Animal 7 & CNR & 0,63 & 1,09 & 1,28 \\
\hline Animal 8 & 0,98 & 0,53 & 1,23 & 1,42 \\
\hline Média & 1,00 & 0,62 & 1,02 & 1,30 \\
\hline DP & 0,10 & 0,29 & 0,17 & 0,32 \\
\hline EPM & 0,04 & 0,10 & 0,07 & 0,11 \\
\hline
\end{tabular}

CNR: cinética não responsiva

Tabela A17. Valores individuais, média, desvio padrão (DP) e erro padrão da média (EPM) referentes à Tabela 3 da seção Resultados: Efeitos do diabetes após 30 e 90 dias na expressão gênica de IL-1 $\beta$ e IL-6 no músculo sóleo dos animais controles (B6) e diabéticos (B6+STZ).

\begin{tabular}{|c|c|c|c|c|c|c|c|c|c|}
\hline Músculo Sóleo & \multicolumn{2}{|c|}{30 Dias } & \multicolumn{2}{|c|}{90 Dias } & Músculo Sóleo & \multicolumn{2}{|c|}{30 Dias } & \multicolumn{2}{|c|}{90 Dias } \\
\hline IL-1及 (Fold Change) & B6 & B6+STZ & B6 & B6+STZ & IL-6 (Fold Change) & B6 & B6+STZ & B6 & B6+STZ \\
\hline Animal 1 & 0,45 & 0,42 & 1,98 & 1,06 & Animal 1 & 0,06 & 1,35 & 2,42 & 1,42 \\
\hline Animal 2 & 1,62 & 0,58 & CNR & 0,55 & Animal 2 & 1,40 & 1,17 & CNR & 3,31 \\
\hline Animal 3 & 4,45 & 0,61 & 2,58 & 2,10 & Animal 3 & 3,70 & 1,07 & 0,74 & 2,47 \\
\hline Animal 4 & 3,40 & 0,16 & $\mathrm{CNR}$ & 0,53 & Animal 4 & 2,53 & 0,56 & 3,40 & 1,20 \\
\hline Animal 5 & 0,30 & CNR & 0,65 & 2,38 & Animal 5 & 0,90 & CNR & 1,18 & 2,12 \\
\hline Animal 6 & 0,42 & 0,07 & 0,32 & 0,37 & Animal 6 & 0,55 & 0,56 & 1,63 & 3,27 \\
\hline Animal 7 & 2,50 & 0,29 & 0,41 & 0,45 & Animal 7 & 2,51 & 0,84 & 0,08 & 1,31 \\
\hline Animal 8 & 0,29 & 0,17 & 2,28 & CNR & Animal 8 & CNR & 1,27 & 1,04 & CNR \\
\hline Média & 1,68 & 0,33 & 1,37 & 1,06 & Média & 1,66 & 0,98 & 1,50 & 2,16 \\
\hline DP & 1,61 & 0,21 & 1,02 & 0,84 & $\mathrm{DP}$ & 1,30 & 0,33 & 1,11 & 0,90 \\
\hline EPM & 0,57 & 0,08 & 0,42 & 0,32 & EPM & 0,49 & 0,12 & 0,42 & 0,34 \\
\hline
\end{tabular}

CNR: cinética não responsiva 
Tabela A18. Valores individuais, média, desvio padrão (DP) e erro padrão da média (EPM) referentes à Tabela 3 da seção Resultados: Efeitos do diabetes após 30 e 90 dias na expressão gênica de TNF- $\alpha$ e F4/80 no músculo sóleo dos animais controles (B6) e diabéticos (B6+STZ).

\begin{tabular}{|c|c|c|c|c|c|c|c|c|c|}
\hline Músculo Sóleo & \multicolumn{2}{|c|}{ 30 Dias } & \multicolumn{2}{c|}{ 90 Dias } & Músculo Sóleo & \multicolumn{2}{c|}{ 30 Dias } & \multicolumn{2}{c|}{ 90 Dias } \\
\hline TNF- $\boldsymbol{\alpha}$ (Fold Change) & B6 & B6+STZ & B6 & B6+STZ & F4/80 (Fold Change) & B6 & B6+STZ & B6 & B6+STZ \\
\hline Animal 1 & 1,46 & CNR & 0,68 & 0,54 & Animal 1 & 0,61 & 0,89 & 1,66 & 0,78 \\
\hline Animal 2 & 0,97 & 1,23 & CNR & 0,42 & Animal 2 & 0,69 & 0,14 & CNR & 1,25 \\
\hline Animal 3 & 1,49 & 1,74 & 1,11 & 1,14 & Animal 3 & 1,52 & 0,58 & 1,19 & 0,75 \\
\hline Animal 4 & 0,18 & 1,32 & 1,52 & 0,33 & Animal 4 & CNR & 0,80 & 1,66 & 1,41 \\
\hline Animal 5 & 1,29 & CNR & 1,76 & 0,67 & Animal 5 & 0,32 & CNR & 0,96 & 0,45 \\
\hline Animal 6 & 1,29 & 0,35 & 1,71 & 1,24 & Animal 6 & 1,24 & 0,45 & 0,55 & 0,58 \\
\hline Animal 7 & CNR & 0,67 & 1,45 & 1,45 & Animal 7 & 2,09 & 0,96 & 0,46 & 0,65 \\
\hline Animal 8 & 1,57 & 0,15 & 0,20 & CNR & Animal 8 & 1,94 & 0,38 & 1,27 & CNR \\
\hline Média & 1,18 & 0,91 & 1,20 & 0,83 & Média & 1,20 & 0,60 & 1,11 & 0,84 \\
\hline DP & 0,48 & 0,62 & 0,58 & 0,44 & DP & 0,69 & 0,30 & 0,48 & 0,36 \\
\hline EPM & 0,18 & 0,25 & 0,22 & 0,17 & EPM & 0,26 & 0,11 & 0,18 & 0,13 \\
\hline
\end{tabular}

CNR: cinética não responsive

Tabela A19. Valores individuais, média, desvio padrão (DP) e erro padrão da média (EPM) referentes à Tabela 3 da seção Resultados: Efeitos do diabetes após 30 e 90 dias na expressão gênica de MCP-1 e CAT no músculo sóleo dos animais controles (B6) e diabéticos (B6+STZ).

\begin{tabular}{|c|c|c|c|c|c|c|c|c|c|}
\hline Músculo Sóleo & \multicolumn{2}{|c|}{ 30 Dias } & \multicolumn{2}{c|}{ 90 Dias } & Músculo Sóleo & \multicolumn{2}{|c|}{ 30 Dias } & \multicolumn{2}{c|}{ 90 Dias } \\
\hline MCP-1 (Fold Change) & B6 & B6+STZ & B6 & B6+STZ & CAT (Fold Change) & B6 & B6+STZ & B6 & B6+STZ \\
\hline Animal 1 & 0,34 & 0,12 & 0,68 & 0,79 & Animal 1 & 1,48 & 1,65 & 2,00 & 1,46 \\
\hline Animal 2 & 0,92 & 0,14 & 1,17 & 0,74 & Animal 2 & 0,97 & 1,90 & 0,55 & 2,12 \\
\hline Animal 3 & 1,80 & 0,15 & CNR & 1,75 & Animal 3 & 0,71 & 1,12 & CNR & 0,00 \\
\hline Animal 4 & 3,63 & 0,13 & 1,79 & 0,64 & Animal 4 & 0,69 & 0,90 & 0,87 & 1,67 \\
\hline Animal 5 & CNR & CNR & 0,89 & 1,79 & Animal 5 & 1,24 & CNR & 0,92 & 2,52 \\
\hline Animal 6 & 0,74 & 0,68 & 0,59 & 0,66 & Animal 6 & 1,25 & 1,16 & 0,82 & 1,24 \\
\hline Animal 7 & 1,80 & 0,31 & 1,32 & 0,75 & Animal 7 & 0,59 & 1,48 & 0,85 & 1,69 \\
\hline Animal 8 & 0,37 & 0,07 & CNR & CNR & Animal 8 & 1,54 & 0,98 & 1,65 & CNR \\
\hline Média & 1,37 & 0,23 & 1,08 & 1,02 & Média & 1,06 & 1,31 & 1,09 & 1,53 \\
\hline DP & 1,16 & 0,21 & 0,45 & 0,52 & DP & 0,37 & 0,37 & 0,53 & 0,80 \\
\hline EPM & 0,44 & 0,08 & 0,18 & 0,20 & EPM & 0,13 & 0,14 & 0,20 & 0,30 \\
\hline
\end{tabular}

CNR: cinética não responsiva 
Tabela A20. Valores individuais, média, desvio padrão (DP) e erro padrão da média (EPM) referentes à Tabela 3 da seção Resultados: Efeitos do diabetes após 30 e 90 dias na expressão gênica de GPX e SOD-1 no músculo sóleo dos animais controles (B6) e diabéticos (B6+STZ).

\begin{tabular}{|c|c|c|c|c|c|c|c|c|c|}
\hline Músculo Sóleo & \multicolumn{2}{|c|}{ 30 Dias } & \multicolumn{2}{c|}{ 90 Dias } & Músculo Sóleo & \multicolumn{2}{|c|}{ 30 Dias } & \multicolumn{2}{c|}{ 90 Dias } \\
\hline GPX (Fold Change $)$ & B6 & B6+STZ & B6 & B6+STZ & SOD-1 (Fold Change $)$ & B6 & B6+STZ & B6 & B6+STZ \\
\hline Animal 1 & 0,72 & 0,75 & 1,05 & 0,80 & Animal 1 & 0,99 & 0,93 & 1,19 & 1,00 \\
\hline Animal 2 & 1,07 & 0,53 & 0,72 & 0,86 & Animal 2 & 0,95 & 1,01 & 0,76 & 1,24 \\
\hline Animal 3 & 1,42 & 0,76 & CNR & 1,16 & Animal 3 & 1,03 & 0,91 & CNR & 1,54 \\
\hline Animal 4 & 1,07 & 0,60 & 1,00 & 0,67 & Animal 4 & 0,73 & 0,68 & 0,93 & 0,87 \\
\hline Animal 5 & 0,72 & CNR & 1,01 & 0,79 & Animal 5 & 1,09 & CNR & 1,21 & 2,17 \\
\hline Animal 6 & 0,71 & CNR & 0,96 & 0,79 & Animal 6 & 1,23 & 1,09 & 0,80 & 1,40 \\
\hline Animal 7 & 0,90 & 0,76 & 1,35 & 0,94 & Animal 7 & 0,70 & 1,42 & 1,23 & 1,13 \\
\hline Animal 8 & 1,86 & 0,42 & CNR & CNR & Animal 8 & 1,50 & 0,77 & CNR & CNR \\
\hline Média & 1,06 & 0,61 & 1,02 & 0,86 & Média & 1,03 & 0,97 & 1,02 & 1,33 \\
\hline DP & 0,40 & 0,16 & 0,20 & 0,16 & DP & 0,26 & 0,24 & 0,21 & 0,43 \\
\hline EPM & 0,14 & 0,06 & 0,08 & 0,06 & EPM & 0,09 & 0,09 & 0,09 & 0,16 \\
\hline
\end{tabular}

CNR: cinética não responsiva

Tabela A21. Valores individuais, média, desvio padrão (DP) e erro padrão da média (EPM) referentes à Tabela 3 da seção Resultados: Efeitos do diabetes após 30 e 90 dias na expressão gênica de SOD-2 no músculo sóleo dos animais controles (B6) e diabéticos (B6+STZ).

\begin{tabular}{|c|c|c|c|c|}
\hline & \multicolumn{2}{|c|}{ 30 Dias } & \multicolumn{2}{c|}{90 Dias } \\
\hline SOD-2 (Fold Change) & B6 & B6+STZ & B6 & B6+STZ \\
\hline Animal 1 & 2,38 & 0,77 & 1,06 & 1,12 \\
\hline Animal 2 & 0,96 & 1,05 & 1,07 & 1,57 \\
\hline Animal 3 & 0,59 & 1,20 & 1,09 & 1,41 \\
\hline Animal 4 & 1,32 & 0,76 & 0,88 & 0,48 \\
\hline Animal 5 & 1,14 & CNR & 0,93 & 1,19 \\
\hline Animal 6 & 0,97 & 1,42 & CNR & 1,43 \\
\hline Animal 7 & 0,42 & 1,29 & CNR & 1,67 \\
\hline Animal 8 & 1,23 & 0,45 & CNR & CNR \\
\hline Média & 1,13 & 0,99 & 1,00 & 1,27 \\
\hline DP & 0,59 & 0,34 & 0,09 & 0,40 \\
\hline EPM & 0,21 & 0,13 & 0,04 & 0,15 \\
\hline
\end{tabular}

CNR: cinética não responsiva 
Tabela A22. Valores individuais, média, desvio padrão (DP) e erro padrão da média (EPM) referentes à Figura 2 da seção Resultados: Efeito do lipopolissacarídeo (LPS) na expressão gênica de citocinas (illb e tnfa) e receptores em macrófagos residentes peritoneais de animais controles (B6) e diabéticos (B6+STZ).

\begin{tabular}{|c|c|c|c|c|c|c|c|c|c|}
\hline il1b & B6 & B6 (LPS) & B6+STZ & B6+STZ (LPS) & tnfa & B6 & B6 (LPS) & B6+STZ & B6+STZ (LPS) \\
\hline Animal 1 & 0,84 & 2,02 & 1,51 & 1,61 & Animal 1 & 0,85 & 2,07 & 1,09 & 0,72 \\
\hline Animal 2 & 0,72 & 0,98 & 1,19 & 2,47 & Animal 2 & 2,14 & 2,97 & 1,62 & 0,97 \\
\hline Animal 3 & 0,92 & 1,14 & 0,97 & 1,56 & Animal 3 & 1,32 & 1,82 & 0,61 & 0,46 \\
\hline Animal 4 & 1,29 & 1,21 & 0,78 & 1,09 & Animal 4 & 1,00 & 0,15 & 1,47 & 0,69 \\
\hline Animal 5 & 1,00 & 1,14 & 1,33 & 1,56 & Animal 5 & 0,54 & 0,80 & 0,73 & 0,80 \\
\hline Animal 6 & 1,38 & 1,86 & & & Animal 6 & 0,77 & 1,39 & & \\
\hline Média & $\mathbf{1 , 0 3}$ & $\mathbf{1 , 3 9}$ & $\mathbf{1 , 1 6}$ & $\mathbf{1 , 6 6}$ & Média & $\mathbf{1 , 1 0}$ & $\mathbf{1 , 5 3}$ & $\mathbf{1 , 1 0}$ & $\mathbf{0 , 7 3}$ \\
\hline DP & $\mathbf{0 , 2 6}$ & $\mathbf{0 , 4 3}$ & $\mathbf{0 , 2 9}$ & $\mathbf{0 , 5 0}$ & DP & $\mathbf{0 , 5 7}$ & $\mathbf{0 , 9 9}$ & $\mathbf{0 , 4 5}$ & $\mathbf{0 , 1 8}$ \\
\hline EPM & $\mathbf{0 , 1 0}$ & $\mathbf{0 , 1 8}$ & $\mathbf{0 , 1 3}$ & $\mathbf{0 , 2 2}$ & EPM & $\mathbf{0 , 2 3}$ & $\mathbf{0 , 4 0}$ & $\mathbf{0 , 2 0}$ & $\mathbf{0 , 0 8}$ \\
\hline
\end{tabular}

Tabela A23. Valores individuais, média, desvio padrão (DP) e erro padrão da média (EPM) referentes à Figura 2 da seção Resultados: Efeito do lipopolissacarídeo (LPS) na expressão gênica de citocinas (i16) e receptores (tlr4) em macrófagos residentes peritoneais de animais controles (B6) e diabéticos (B6+STZ).

\begin{tabular}{|c|c|c|c|c|c|c|c|c|c|}
\hline tlr4 & B6 & B6 (LPS) & B6+STZ & B6+STZ (LPS) & il6 & B6 & B6 (LPS) & B6+STZ & B6+STZ (LPS) \\
\hline Animal 1 & 0,68 & 1,66 & 1,65 & 1,20 & Animal 1 & 0,748 & 3,099 & 1,615 & 2,66 \\
\hline Animal 2 & 0,45 & 0,55 & 0,87 & 0,97 & Animal 2 & 0,684 & 1,073 & 1,15 & 2,606 \\
\hline Animal 3 & 0,70 & 0,27 & 1,83 & 0,93 & Animal 3 & 0,921 & 1,241 & 1,233 & 1,638 \\
\hline Animal 4 & 1,95 & 1,20 & 1,13 & 1,08 & Animal 4 & 1,571 & 1,339 & 0,928 & 1,507 \\
\hline Animal 5 & 1,13 & 0,59 & 1,51 & 1,05 & Animal 5 & 0,967 & 1,731 & 0,878 & 1,368 \\
\hline Animal 6 & 2,09 & 1,07 & & & Animal 6 & 1,396 & 2,237 & & \\
\hline Média & $\mathbf{1 , 1 7}$ & $\mathbf{0 , 8 9}$ & $\mathbf{1 , 4 0}$ & $\mathbf{1 , 0 5}$ & Média & $\mathbf{1 , 0 5}$ & $\mathbf{1 , 7 9}$ & $\mathbf{1 , 1 6}$ & $\mathbf{1 , 9 6}$ \\
\hline DP & $\mathbf{0 , 6 9}$ & $\mathbf{0 , 5 1}$ & $\mathbf{0 , 3 9}$ & $\mathbf{0 , 1 0}$ & DP & $\mathbf{0 , 3 6}$ & $\mathbf{0 , 7 7}$ & $\mathbf{0 , 2 9}$ & $\mathbf{0 , 6 3}$ \\
\hline EPM & $\mathbf{0 , 2 8}$ & $\mathbf{0 , 2 1}$ & $\mathbf{0 , 1 8}$ & $\mathbf{0 , 0 5}$ & EPM & $\mathbf{0 , 1 5}$ & $\mathbf{0 , 3 1}$ & $\mathbf{0 , 1 3}$ & $\mathbf{0 , 2 8}$ \\
\hline
\end{tabular}


Tabela A24. Valores individuais, média, desvio padrão (DP) e erro padrão da média (EPM) referentes à Figura 2 da seção Resultados: Efeito do lipopolissacarídeo (LPS) na expressão gênica de iNOS em macrófagos residentes peritoneais de animais controles (B6) e diabéticos (B6+STZ).

\begin{tabular}{|c|c|c|c|c|}
\hline inos & B6 & B6 (LPS) & B6+STZ & B6+STZ (LPS) \\
\hline Animal 1 & 0,7702151 & 3,371366 & 1,3692 & 5,630774 \\
\hline Animal 2 & 1,733074 & 1,127661 & 1,52979 & 9,021287 \\
\hline Animal 3 & 0,9159453 & 1,936341 & 1,251218 & 11,10651 \\
\hline Animal 4 & 1,119872 & 6,742733 & 4,901874 & 14,15592 \\
\hline Animal 5 & 1,733074 & 2,934945 & 9,14722 & 16,48787 \\
\hline Animal 6 & 0,4214208 & 2,351096 & & \\
\hline Média & $\mathbf{1 , 1 2}$ & $\mathbf{3 , 0 8}$ & $\mathbf{3 , 6 4}$ & $\mathbf{1 1 , 2 8}$ \\
\hline DP & $\mathbf{0 , 5 3}$ & $\mathbf{1 , 9 6}$ & $\mathbf{3 , 4 4}$ & $\mathbf{4 , 2 6}$ \\
\hline EPM & $\mathbf{0 , 2 2}$ & $\mathbf{0 , 8 0}$ & $\mathbf{1 , 5 4}$ & $\mathbf{1 , 9 0}$ \\
\hline
\end{tabular}

Tabela A25. Valores individuais, média, desvio padrão (DP) e erro padrão da média (EPM) referentes à Figura 2 da seção Resultados: Efeito do lipopolissacarídeo (LPS) na secreção de NO pelos macrófagos residentes peritoneais de animais controles (B6) e diabéticos (B6+STZ).

\begin{tabular}{|c|c|c|c|c|}
\hline NO $(\mathrm{uM})$ & B6 & B6 (LPS) & B6+STZ & B6+STZ (LPS) \\
\hline Animal 1 & 1,82 & 5,13 & 3,75 & 35,69 \\
\hline Animal 2 & 1,25 & 1,35 & 2,36 & 15,45 \\
\hline Animal 3 & 0,53 & 4,78 & 4,56 & 6,17 \\
\hline Animal 4 & 0,26 & 4,63 & 2,95 & 26,38 \\
\hline Animal 5 & & & & 7,96 \\
\hline Animal 6 & & & & 33,04 \\
\hline Animal 7 & & & & 6,88 \\
\hline Média & $\mathbf{0 , 7 7}$ & $\mathbf{3 , 9 7}$ & $\mathbf{3 , 4 0}$ & $\mathbf{1 8 , 7 9}$ \\
\hline DP & $\mathbf{0 , 9 2}$ & $\mathbf{1 , 7 6}$ & $\mathbf{0 , 9 6}$ & $\mathbf{1 2 , 7 6}$ \\
\hline EPM & $\mathbf{0 , 4 6}$ & $\mathbf{0 , 8 8}$ & $\mathbf{0 , 4 8}$ & $\mathbf{4 , 8 2}$ \\
\hline
\end{tabular}


Tabela A26. Valores individuais, média, desvio padrão (DP) e erro padrão da média (EPM) referentes à Figura 3 da seção Resultados: Ocorrência de macrófagos peritoneais residentes M1 e M2 em animais controles (B6) e diabéticos (B6+STZ).

\begin{tabular}{|c|c|c|c|c|c|}
\hline \multirow[b]{2}{*}{ M1 $\left(\% \mathrm{CD} 11 \mathrm{~b}^{+} \mathrm{F} 4 / \mathrm{80}^{+} \mathrm{CD}^{2} 1 \mathrm{c}^{+}\right)$} & \multicolumn{2}{|c|}{30 Dias } & \multirow[b]{2}{*}{$\mathrm{M2}\left(\% \mathrm{CD}^{2} \mathrm{~b}^{+} \mathrm{F} 4 / \mathbf{8 0}^{+} \mathrm{CD206}^{+}\right)$} & \multicolumn{2}{|c|}{30 Dias } \\
\hline & B6 & B6+STZ & & B6 & B6+STZ \\
\hline Animal 1 & 68,19 & 85,85 & Animal 1 & 5,75 & 4,27 \\
\hline Animal 2 & 86,02 & 66,55 & Animal 2 & 11,09 & 5,49 \\
\hline Animal 3 & 63,65 & 72,84 & Animal 3 & 7,13 & - \\
\hline Animal 4 & 95,73 & 87,18 & Animal 4 & 11,88 & 4,21 \\
\hline Animal 5 & 13,49 & 7,77 & Animal 5 & 3,4 & 2,67 \\
\hline Animal 6 & 62,75 & 14,56 & Animal 6 & 6,82 & 5,36 \\
\hline Animal 7 & 61,53 & 12,32 & Animal 7 & 6,91 & 5,29 \\
\hline Animal 8 & 13,41 & 18,25 & Animal 8 & 5,66 & 6,84 \\
\hline Animal 9 & 21,32 & 8,95 & Animal 9 & 11,61 & 8,95 \\
\hline Média & 54,01 & 41,59 & Média & 7,806 & 5,385 \\
\hline DV & 30,72 & 35,32 & DV & 3,007 & 1,884 \\
\hline EPM & 10,24 & 11,77 & EPM & 1,002 & $\mathbf{0 , 6 6 6}$ \\
\hline
\end{tabular}

(-): número insuficiente de células

Tabela A27. Valores individuais, média, desvio padrão (DP) e erro padrão da média (EPM) referentes à Figura 7 da seção Resultados: Avaliação temporal da acidificação do meio extracelular, fluxo de substratos pela glicólise, capacidade glicolítica e reserva glicolítica nos macrófagos peritoneais residentes de animais controles (B6) e diabéticos (B6+STZ).

\begin{tabular}{|c|c|c|c|c|c|c|}
\hline & \multicolumn{2}{|c|}{$\begin{array}{c}\text { Glicólise } \\
(\mathbf{m p H} / \mathbf{m i m} / \mathbf{m g} / \mathbf{m L})\end{array}$} & \multicolumn{2}{c|}{$\begin{array}{c}\text { Reserva Glicolitíca } \\
(\mathbf{m p H} / \mathbf{m i m} / \mathbf{m g} / \mathbf{m L})\end{array}$} & \multicolumn{2}{c|}{$\begin{array}{c}\text { Capacidade Glicolítica } \\
\text { (mpH/mim/mg/mL) }\end{array}$} \\
\hline & $\mathrm{B} 6$ & $\mathrm{~B} 6+\mathrm{STZ}$ & $\mathrm{B} 6$ & $\mathrm{~B} 6+\mathrm{STZ}$ & $\mathrm{B} 6$ & $\mathrm{~B} 6+\mathrm{STZ}$ \\
\hline Animal 1 & 10,69 & 17,49 & 12,79 & 15,07 & 11,08 & 15,06 \\
\hline Animal 2 & 7,68 & 13,46 & 7,46 & 22,81 & 4,46 & 16,98 \\
\hline Animal 3 & 14,62 & 28,35 & 14,91 & 19,54 & 14,91 & 27,27 \\
\hline Animal 4 & & 14,72 & & 19,17 & & 18,9 \\
\hline Média & $\mathbf{1 1 , 0 0}$ & $\mathbf{1 8 , 5 1}$ & $\mathbf{1 1 , 7 2}$ & $\mathbf{1 9 , 1 5}$ & $\mathbf{1 0 , 1 5}$ & $\mathbf{1 9 , 5 5}$ \\
\hline DP & $\mathbf{3 , 4 8}$ & $\mathbf{6 , 7 8}$ & $\mathbf{3 , 8 4}$ & $\mathbf{3 , 1 7}$ & $\mathbf{5 , 2 9}$ & $\mathbf{5 , 3 8}$ \\
\hline EPM & $\mathbf{2 , 0 1}$ & $\mathbf{3 , 3 9}$ & $\mathbf{2 , 2 2}$ & $\mathbf{1 , 5 9}$ & $\mathbf{3 , 0 5}$ & $\mathbf{2 , 6 9}$ \\
\hline
\end{tabular}


Tabela A28. Valores individuais das médias das porcentagens de células viáveis (em relação às células tratadas com o veículo, etanol) obtidas a partir de dois experimentos referentes à Figura 8A da seção Resultados: Atividade citotóxica do ácido palmítico (PA), na presença ou não de lipopolissacarídeo (LPS), em macrófagos residentes obtidos do peritônio de animais controles.

\begin{tabular}{|c|c|c|c|c|c|c|c|c|c|c|}
\hline $\begin{array}{c}\text { Em relação ao } \\
\text { etanol (\%) }\end{array}$ & \multicolumn{2}{|c|}{$\mathbf{1 0 0} \mathbf{~ u M}$} & \multicolumn{2}{|c|}{$\mathbf{2 0 0} \mathbf{~ u M}$} & \multicolumn{2}{c|}{$\mathbf{3 0 0} \mathbf{u M}$} & \multicolumn{2}{|c|}{$\mathbf{4 0 0} \mathbf{u M}$} & \multicolumn{2}{|c|}{$\mathbf{5 0 0}$ uM } \\
\hline Palmítico & PA & PA+LPS & PA & PA+LPS & PA & PA+LPS & PA & PA+LPS & PA & PA+LPS \\
\hline Média Exp. 1 & 106,12 & 114,78 & 95,73 & 60,11 & 57,37 & 27,27 & 24,24 & 10,09 & 8,05 & 7,16 \\
\hline Média Exp. 2 & 105,28 & 84,17 & 30,15 & 21,61 & 39,45 & 18,09 & 19,35 & 11,81 & 11,06 & 5,28 \\
\hline
\end{tabular}

Tabela A29. Valores individuais das médias das porcentagens de células viáveis (em relação às células tratadas com o veículo, etanol) obtidas a partir de dois experimentos referentes à Figura 8B da seção Resultados: Atividade citotóxica do ácido eicosapentaenóico (EPA), na presença ou não de lipopolissacarídeo (LPS), em macrófagos residentes obtidos do peritônio de animais controles.

\begin{tabular}{|c|c|c|c|c|c|c|}
\hline Em relação ao etanol (\%) & \multicolumn{2}{|c|}{$\mathbf{2 5}$ uM } & \multicolumn{2}{c|}{$\mathbf{5 0}$ uM } & \multicolumn{2}{c|}{$\mathbf{1 0 0}$ uM } \\
\hline Eicosapentaenóico & EPA & EPA+LPS & EPA & EPA+LPS & EPA & EPA+LPS \\
\hline Média Exp. 1 & 100,96 & 76,57 & 120,43 & 136,70 & 121,01 & 99,23 \\
\hline Média Exp. 2 & 89,51 & 99,50 & 73,12 & 82,54 & 63,51 & 64,26 \\
\hline
\end{tabular}

Tabela A30. Valores individuais das médias das porcentagens de células viáveis (em relação às células tratadas com o veículo, etanol) obtidas a partir de dois experimentos referentes à Figura $8 \mathrm{C}$ da seção Resultados: Atividade citotóxica do ácido docosaexaenóico (DHA), na presença ou não de lipopolissacarídeo (LPS), em macrófagos residentes obtidos do peritônio de animais controles.

\begin{tabular}{|c|c|c|c|c|c|c|}
\hline Em relação ao etanol (\%) & \multicolumn{2}{|c|}{25 uM } & \multicolumn{2}{c|}{$\mathbf{5 0}$ uM } & \multicolumn{2}{c|}{$\mathbf{1 0 0}$ uM } \\
\hline Docosaexaenóico & DHA & DHA+LPS & DHA & DHA+LPS & DHA & DHA+LPS \\
\hline Média Exp. 1 & 128,83 & 103,98 & 106,20 & 51,21 & 38,75 & 35,25 \\
\hline Média Exp. 2 & 56,91 & 39,95 & 40,33 & 34,67 & 1,32 & 3,20 \\
\hline
\end{tabular}


Tabela A31. Valores individuais, média, desvio padrão (DP) e erro padrão da média (EPM) referentes à Figura 9A da seção Resultados: Produção de óxido nítrico pelos macrófagos peritoneais residentes de animais controles (B6) e diabéticos (B6+STZ) após tratamento com EPA, DHA ou PA

\begin{tabular}{|c|c|c|c|c|c|c|c|c|c|c|}
\hline NO (uM) & \multicolumn{5}{|c|}{ Controles (B6) } & \multicolumn{5}{c|}{ Diabéticos (B6+STZ) } \\
\hline 30 Dias & Meio & LPS & EPA+LPS & DHA+LPS & PA+LPS & Meio & LPS & EPA+LPS & DHA+LPS & PA+LPS \\
\hline Animal 1 & 12,13 & 29,38 & 5,73 & 2,90 & 0,55 & 11,31 & 27,08 & 21,55 & 12,37 & 23,64 \\
\hline Animal 2 & 8,55 & 19,66 & 8,61 & 1,74 & 12,48 & 12,40 & 26,86 & 12,24 & 11,02 & 25,41 \\
\hline Animal 3 & 13,49 & 24,58 & 6,50 & 0,60 & 10,26 & 10,58 & 29,28 & 0,69 & 9,92 & 21,58 \\
\hline Animal 4 & 11,63 & 16,65 & 3,52 & 20,01 & 18,14 & 15,01 & 14,91 & 10,99 & 11,02 & 20,44 \\
\hline Animal 5 & 14,78 & 12,10 & 0,80 & 0,21 & 0,72 & 20,04 & 21,39 & 13,51 & 16,10 & 31,65 \\
\hline Animal 6 & 10,26 & 26,48 & 13,35 & 1,60 & 1,87 & 17,10 & 16,89 & 8,08 & 8,45 & 22,18 \\
\hline Animal 7 & 7,13 & 23,48 & 10,42 & 5,30 & 8,75 & 19,19 & 21,65 & 28,32 & 0,70 & 20,43 \\
\hline Animal 8 & 8,47 & 21,59 & 7,88 & 8,15 & 12,55 & 15,52 & 9,20 & 11,80 & 20,43 & 9,92 \\
\hline Média & $\mathbf{1 0 , 8 0}$ & $\mathbf{2 1 , 7 4}$ & $\mathbf{7 , 1 0}$ & $\mathbf{5 , 0 6}$ & $\mathbf{8 , 1 6}$ & $\mathbf{1 5 , 1 4}$ & $\mathbf{2 0 , 9 1}$ & $\mathbf{1 3 , 4 0}$ & $\mathbf{1 1 , 2 5}$ & $\mathbf{2 1 , 9 0}$ \\
\hline DP & $\mathbf{2 , 6 7}$ & $\mathbf{5 , 5 4}$ & $\mathbf{3 , 9 2}$ & $\mathbf{6 , 5 9}$ & $\mathbf{6 , 4 9}$ & $\mathbf{3 , 5 3}$ & $\mathbf{6 , 9 0}$ & $\mathbf{8 , 3 5}$ & $\mathbf{5 , 7 3}$ & $\mathbf{6 , 0 8}$ \\
\hline EPM & $\mathbf{0 , 9 4}$ & $\mathbf{1 , 9 6}$ & $\mathbf{1 , 3 9}$ & $\mathbf{2 , 3 3}$ & $\mathbf{2 , 3 0}$ & $\mathbf{1 , 2 5}$ & $\mathbf{2 , 4 4}$ & $\mathbf{2 , 9 5}$ & $\mathbf{2 , 0 3}$ & $\mathbf{2 , 1 5}$ \\
\hline
\end{tabular}

Tabela A32. Valores individuais, média, desvio padrão (DP) e erro padrão da média (EPM) referentes à Figura 9B da seção Resultados: Produção IL-1 $\beta$ (pg/mL) pelos macrófagos peritoneais residentes de animais controles (B6) e diabéticos (B6+STZ) após tratamento com EPA, DHA ou PA

\begin{tabular}{|c|c|c|c|c|c|c|c|c|c|c|}
\hline IL-1 $\boldsymbol{\beta}$ & \multicolumn{4}{|c|}{ Controles (B6) } & \multicolumn{4}{c|}{ Diabéticos (B6+STZ) } \\
\hline 30 Dias & Meio & LPS & EPA+LPS & DHA+LPS & PA+LPS & Meio & LPS & EPA+LPS & DHA+LPS & PA+LPS \\
\hline Animal 1 & 35,27 & 377,23 & 16,50 & 114,32 & 188,10 & 28,31 & 126,93 & 422,16 & 299,98 & 579,09 \\
\hline Animal 2 & 27,15 & 399,97 & 128,08 & 53,79 & 78,05 & 58,26 & 1053,43 & 740,09 & 476,37 & 616,28 \\
\hline Animal 3 & 26,47 & 567,14 & 48,90 & 108,31 & 219,28 & 32,58 & 336,84 & 245,06 & 223,15 & 335,65 \\
\hline Animal 4 & 19,51 & 268,24 & 220,40 & 26,99 & 240,47 & 48,22 & 166,93 & 25,57 & 70,10 & 60,62 \\
\hline Animal 5 & & & & & & - & 212,50 & 575,32 & 526,41 & 379,47 \\
\hline Animal 6 & & & & & & - & 458,17 & 417,37 & 327,09 & 619,75 \\
\hline Média & $\mathbf{2 7 , 1 0}$ & $\mathbf{4 0 3 , 1 4}$ & $\mathbf{1 0 3 , 4 7}$ & $\mathbf{7 5 , 8 5}$ & $\mathbf{1 8 1 , 4 7}$ & $\mathbf{4 1 , 8 4}$ & $\mathbf{3 9 2 , 4 7}$ & $\mathbf{4 0 4 , 2 6}$ & $\mathbf{3 2 0 , 5 2}$ & $\mathbf{4 3 1 , 8 1}$ \\
\hline DP & $\mathbf{6 , 4 5}$ & $\mathbf{1 2 3 , 5 3}$ & $\mathbf{9 0 , 9 6}$ & $\mathbf{4 2 , 4 5}$ & $\mathbf{7 2 , 2 3}$ & $\mathbf{1 3 , 8 9}$ & $\mathbf{3 4 5 , 8 5}$ & $\mathbf{2 4 9 , 5 1}$ & $\mathbf{1 6 6 , 9 3}$ & $\mathbf{2 1 9 , 4 6}$ \\
\hline EPM & $\mathbf{3 , 2 2}$ & $\mathbf{6 1 , 7 6}$ & $\mathbf{4 5 , 4 8}$ & $\mathbf{2 1 , 2 3}$ & $\mathbf{3 6 , 1 2}$ & $\mathbf{6 , 9 5}$ & $\mathbf{1 4 1 , 1 9}$ & $\mathbf{1 0 1 , 8 6}$ & $\mathbf{6 8 , 1 5}$ & $\mathbf{8 9 , 5 9}$ \\
\hline
\end{tabular}


Tabela A33. Valores individuais, média, desvio padrão (DP) e erro padrão da média (EPM) referentes à Figura 9C da seção Resultados: Produção de IL-6 (pg/mL) pelos macrófagos peritoneais residentes de animais controles (B6) e diabéticos (B6+STZ) após tratamento com EPA, DHA ou PA

\begin{tabular}{|c|c|c|c|c|c|c|c|c|c|c|}
\hline IL-6 & \multicolumn{5}{|c|}{ Controles (B6) } & \multicolumn{5}{c|}{ Diabéticos (B6+STZ) } \\
\hline 30 Dias & Meio & LPS & EPA+LPS & DHA+LPS & PA+LPS & Meio & LPS & EPA+LPS & DHA+LPS & PA+LPS \\
\hline Animal 1 & 768,72 & 17874,16 & 13092 & 1411,6 & 11240,4 & 1147,12 & 11933,76 & 8745,6 & 9588,4 & 3644,08 \\
\hline Animal 2 & 2924,56 & 23306,64 & 7255,36 & 5275,52 & 7026,48 & 1336 & 15107,04 & 10164 & 8057,2 & 15029,36 \\
\hline Animal 3 & 124,8 & 12473,92 & 13517,44 & 8783,84 & 28812,96 & 1033,52 & 24298,64 & 16274 & 18069,76 & 14059,52 \\
\hline Animal 4 & 124,8 & 20345,28 & 8669,04 & 7407,92 & 12628,32 & 1071,28 & 14718,8 & 10548,08 & 13788,4 & 58141,76 \\
\hline Animal 5 & & & & & & 9895,28 & 16118,24 & 20187,92 & 14524,8 & 16274 \\
\hline Animal 6 & & & & & & 3606,16 & 34477,2 & 7560,64 & 15767,92 & 31837,44 \\
\hline Média & $\mathbf{9 8 5 , 7 2}$ & $\mathbf{1 8 5 0 0 , 0 0}$ & $\mathbf{1 0 6 3 3 , 4 6}$ & $\mathbf{5 7 1 9 , 7 2}$ & $\mathbf{1 4 9 2 7 , 0 4}$ & $\mathbf{3 0 1 4 , 8 9}$ & $\mathbf{1 9 4 4 2 , 2 8}$ & $\mathbf{1 2 2 4 6 , 7 1}$ & $\mathbf{1 3 2 9 9 , 4 1}$ & $\mathbf{2 3 1 6 4 , 3 6}$ \\
\hline DP & $\mathbf{1 3 2 7 , 7 2}$ & $\mathbf{4 5 9 0 , 3 6}$ & $\mathbf{3 1 4 2 , 8 4}$ & $\mathbf{3 2 1 4 , 3 5}$ & $\mathbf{9 5 5 8 , 8 2}$ & $\mathbf{3 5 1 2 , 8 4}$ & $\mathbf{8 4 6 3 , 6 4}$ & $\mathbf{4 9 1 3 , 6 9}$ & $\mathbf{3 7 9 0 , 5 9}$ & $\mathbf{1 9 3 7 1 , 3 0}$ \\
\hline EPM & $\mathbf{6 6 3 , 8 6}$ & $\mathbf{2 2 9 5 , 1 8}$ & $\mathbf{1 5 7 1 , 4 2}$ & $\mathbf{1 6 0 7 , 1 7}$ & $\mathbf{4 7 7 9 , 4 1}$ & $\mathbf{1 4 3 4 , 1 1}$ & $\mathbf{3 4 5 5 , 2 7}$ & $\mathbf{2 0 0 6 , 0 1}$ & $\mathbf{1 5 4 7 , 5 0}$ & $\mathbf{7 9 0 8 , 3 0}$ \\
\hline
\end{tabular}

Tabela A34. Valores individuais, média, desvio padrão (DP) e erro padrão da média (EPM) referentes à Figura 14A da seção Resultados: Evolução da glicemia (mg/dL) ao longo do período de estudo dos animais C57BL/6 controles (B6).

\begin{tabular}{|c|c|c|c|c|c|c|c|c|c|c|c|}
\hline \multicolumn{10}{|c|}{ Evolução da glicemia dos animais C57BL/6 controles (B6) ao longo do período estudado } \\
\hline Dias & $\begin{array}{c}\text { Animal } \\
1\end{array}$ & $\begin{array}{c}\text { Animal } \\
2\end{array}$ & $\begin{array}{c}\text { Animal } \\
3\end{array}$ & $\begin{array}{c}\text { Animal } \\
4\end{array}$ & $\begin{array}{c}\text { Animal } \\
5\end{array}$ & $\begin{array}{c}\text { Animal } \\
6\end{array}$ & $\begin{array}{c}\text { Animal } \\
7\end{array}$ & $\begin{array}{c}\text { Animal } \\
8\end{array}$ & Média & DP & EPM \\
\hline-5 & 197 & 159 & 103 & 193 & 175 & 136 & 105 & 185 & $\mathbf{1 5 6 , 6 3}$ & $\mathbf{3 7 , 9 2}$ & $\mathbf{1 3 , 4 1}$ \\
\hline-1 & 138 & 155 & 157 & 187 & 170 & 130 & 122 & 130 & $\mathbf{1 4 8 , 6 3}$ & $\mathbf{2 2 , 5 4}$ & $\mathbf{7 , 9 7}$ \\
\hline 7 & 165 & 208 & 159 & 180 & 159 & 161 & 215 & 170 & $\mathbf{1 7 7 , 1 3}$ & $\mathbf{2 2 , 4 0}$ & $\mathbf{7 , 9 2}$ \\
\hline 14 & 202 & 177 & 196 & 167 & 180 & 155 & 138 & 144 & $\mathbf{1 6 9 , 8 8}$ & $\mathbf{2 3 , 2 5}$ & $\mathbf{8 , 2 2}$ \\
\hline 21 & 168 & 199 & 144 & 140 & 137 & 121 & 103 & 154 & $\mathbf{1 4 5 , 7 5}$ & $\mathbf{2 9 , 1 6}$ & $\mathbf{1 0 , 3 1}$ \\
\hline 28 & 157 & 149 & 123 & 166 & 116 & 153 & 122 & 179 & $\mathbf{1 4 5 , 6 3}$ & $\mathbf{2 2 , 9 0}$ & $\mathbf{8 , 1 0}$ \\
\hline
\end{tabular}


Tabela A35. Valores individuais, média, desvio padrão (DP) e erro padrão da média (EPM) referentes à Figura 14A da seção Resultados: Evolução da glicemia (mg/dL) ao longo do período de estudo dos animais C57BL/6 diabéticos (B6+STZ).

\begin{tabular}{|c|c|c|c|c|c|c|c|c|c|c|c|}
\hline \multicolumn{8}{|c|}{ Evolução da glicemia dos animais C57BL/6 diabéticos (B6+STZ) ao longo do período estudado } \\
\hline Dias & $\begin{array}{c}\text { Animal } \\
1\end{array}$ & $\begin{array}{c}\text { Animal } \\
2\end{array}$ & $\begin{array}{c}\text { Animal } \\
\text { Animal }\end{array}$ & $\begin{array}{c}\text { Animal } \\
\text { Animal }\end{array}$ & 5 & 6 & $\begin{array}{c}\text { Animal } \\
7\end{array}$ & $\begin{array}{c}\text { Animal } \\
8\end{array}$ & Média & DP & EPM \\
\hline-5 & 147 & 137 & 121 & 103 & 160 & 186 & 90 & 140 & $\mathbf{1 3 5 , 5 0}$ & $\mathbf{3 0 , 8 0}$ & $\mathbf{1 0 , 8 9}$ \\
\hline-1 & 175 & 177 & 197 & 128 & 153 & 253 & 227 & 142 & $\mathbf{1 8 1 , 5 0}$ & $\mathbf{4 2 , 6 3}$ & $\mathbf{1 5 , 0 7}$ \\
\hline 7 & 238 & 316 & 508 & 361 & 351 & 422 & 397 & 371 & $\mathbf{3 7 0 , 5 0}$ & $\mathbf{7 8 , 6 1}$ & $\mathbf{2 7 , 7 9}$ \\
\hline 14 & 335 & 480 & 466 & 320 & 354 & 414 & 445 & 446 & $\mathbf{4 0 7 , 5 0}$ & $\mathbf{6 2 , 5 5}$ & $\mathbf{2 2 , 1 1}$ \\
\hline 21 & 290 & 481 & 328 & 279 & 352 & 498 & 486 & 482 & $\mathbf{3 9 9 , 5 0}$ & $\mathbf{9 6 , 0 0}$ & $\mathbf{3 3 , 9 4}$ \\
\hline 28 & 255 & 366 & 481 & 450 & 478 & 462 & 453 & 441 & $\mathbf{4 2 3 , 2 5}$ & $\mathbf{7 6 , 8 4}$ & $\mathbf{2 7 , 1 7}$ \\
\hline
\end{tabular}

Tabela A36. Valores individuais, média, desvio padrão (DP) e erro padrão da média (EPM) referentes à Figura 14A da seção Resultados: Evolução da glicemia (mg/dL) ao longo do período de estudo dos animais NLRP3 controles (NLRP3 KO).

\begin{tabular}{|c|c|c|c|c|c|c|c|c|c|c|}
\hline \multicolumn{8}{|c|}{ Evolução da glicemia dos animais NLRP3 knockout controles (NLRP3 KO) ao longo do período estudado } \\
\hline Dias & $\begin{array}{c}\text { Animal } \\
1\end{array}$ & 2 & $\begin{array}{c}\text { Animal } \\
\text { Animal }\end{array}$ & $\begin{array}{c}\text { Animal } \\
4\end{array}$ & $\begin{array}{c}\text { Animal } \\
5\end{array}$ & $\begin{array}{c}\text { Animal } \\
6\end{array}$ & $\begin{array}{c}\text { Animal } \\
7\end{array}$ & Média & DP & EPM \\
\hline-5 & 128 & 164 & 92 & 135 & 160 & 119 & 161 & $\mathbf{1 3 7 , 0 0}$ & $\mathbf{2 6 , 6 7}$ & $\mathbf{1 0 , 0 8}$ \\
\hline-1 & 187 & 180 & 190 & 162 & 165 & 118 & 143 & $\mathbf{1 6 3 , 5 7}$ & $\mathbf{2 5 , 8 9}$ & $\mathbf{9 , 7 9}$ \\
\hline 7 & 180 & 175 & 185 & 195 & 129 & 180 & 168 & $\mathbf{1 7 3 , 1 4}$ & $\mathbf{2 1 , 1 8}$ & $\mathbf{8 , 0 0}$ \\
\hline 14 & 163 & 167 & 174 & 131 & 150 & 203 & 156 & $\mathbf{1 6 3 , 4 3}$ & $\mathbf{2 2 , 2 8}$ & $\mathbf{8 , 4 2}$ \\
\hline 21 & 161 & 174 & 169 & 154 & 130 & 180 & 174 & $\mathbf{1 6 3 , 1 4}$ & $\mathbf{1 7 , 0 3}$ & $\mathbf{6 , 4 4}$ \\
\hline 28 & 129 & 180 & 142 & 162 & 155 & 161 & 180 & $\mathbf{1 5 8 , 4 3}$ & $\mathbf{1 8 , 7 0}$ & $\mathbf{7 , 0 7}$ \\
\hline
\end{tabular}

Tabela A37. Valores individuais, média, desvio padrão (DP) e erro padrão da média (EPM) referentes à Figura 14A da seção Resultados: Evolução da glicemia (mg/dL) ao longo do período de estudo dos animais NLRP3 knockout diabéticos (NLRP3 KO+STZ).

\begin{tabular}{|c|c|c|c|c|c|c|c|c|c|c|c|}
\hline \multicolumn{10}{|c|}{ Evolução da glicemia dos animais NLRP3 knockout diabéticos (NLRP3 KO+STZ) ao longo do período estudado } \\
\hline Dias & $\begin{array}{c}\text { Animal } \\
1\end{array}$ & $\begin{array}{c}\text { Animal } \\
2\end{array}$ & $\begin{array}{c}\text { Animal } \\
3\end{array}$ & $\begin{array}{c}\text { Animal } \\
4\end{array}$ & $\begin{array}{c}\text { Animal } \\
5\end{array}$ & $\begin{array}{c}\text { Animal } \\
6\end{array}$ & $\begin{array}{c}\text { Animal } \\
7\end{array}$ & $\begin{array}{c}\text { Animal } \\
8\end{array}$ & Média & DP & EPM \\
\hline-5 & 154 & 174 & 212 & 182 & 149 & 162 & 181 & 159 & $\mathbf{1 7 1 , 6 3}$ & $\mathbf{2 0 , 3 7}$ & $\mathbf{7 , 2 0}$ \\
\hline-1 & 190 & 156 & 179 & 397 & 319 & 244 & 231 & 238 & $\mathbf{2 4 4 , 2 5}$ & $\mathbf{7 9 , 3 9}$ & $\mathbf{2 8 , 0 7}$ \\
\hline 7 & 162 & 286 & 283 & 470 & 472 & 375 & 406 & 371 & $\mathbf{3 5 3 , 1 3}$ & $\mathbf{1 0 5 , 1 1}$ & $\mathbf{3 7 , 1 6}$ \\
\hline 14 & 188 & 314 & 337 & 468 & 467 & 522 & 543 & 428 & $\mathbf{4 0 8 , 3 8}$ & $\mathbf{1 2 0 , 1 1}$ & $\mathbf{4 2 , 4 6}$ \\
\hline 21 & 249 & 450 & 324 & 574 & 560 & 480 & 596 & 427 & $\mathbf{4 5 7 , 5 0}$ & $\mathbf{1 2 3 , 0 8}$ & $\mathbf{4 3 , 5 2}$ \\
\hline 28 & 208 & 387 & 289 & 580 & 590 & 538 & 590 & 480 & $\mathbf{4 5 7 , 7 5}$ & $\mathbf{1 4 7 , 7 1}$ & $\mathbf{5 2 , 2 2}$ \\
\hline
\end{tabular}


Tabela A38. Valores individuais, média, desvio padrão (DP) e erro padrão da média (EPM) referentes à Figura 14A da seção Resultados: Evolução da glicemia (mg/dL) ao longo do período de estudo dos animais RAGE knockout controles (RAGE KO).

\begin{tabular}{|c|c|c|c|c|c|c|c|}
\hline \multicolumn{7}{|c|}{ Evolução da glicemia dos animais RAGE knockout controles (RAGE KO) ao longo do período estudado } \\
\hline Dias & Animal 1 & Animal 2 & Animal 3 & Animal 4 & Média & DP & EPM \\
\hline-5 & 148 & 146 & 113 & 137 & $\mathbf{1 3 6 , 0 0}$ & $\mathbf{1 6 , 0 6}$ & $\mathbf{8 , 0 3}$ \\
\hline-1 & 130 & 144 & 179 & 145 & $\mathbf{1 4 9 , 5 0}$ & $\mathbf{2 0 , 8 2}$ & $\mathbf{1 0 , 4 1}$ \\
\hline 7 & 202 & 153 & 136 & 160 & $\mathbf{1 6 2 , 7 5}$ & $\mathbf{2 8 , 0 4}$ & $\mathbf{1 4 , 0 2}$ \\
\hline 14 & 115 & 131 & 187 & 133 & $\mathbf{1 4 1 , 5 0}$ & $\mathbf{3 1 , 3 8}$ & $\mathbf{1 5 , 6 9}$ \\
\hline 21 & 159 & 133 & 133 & 124 & $\mathbf{1 3 7 , 2 5}$ & $\mathbf{1 5 , 1 1}$ & $\mathbf{7 , 5 5}$ \\
\hline 28 & 171 & 143 & 150 & 105 & $\mathbf{1 4 2 , 2 5}$ & $\mathbf{2 7 , 5 4}$ & $\mathbf{1 3 , 7 7}$ \\
\hline
\end{tabular}

Tabela A39. Valores individuais, média, desvio padrão (DP) e erro padrão da média (EPM) referentes à Figura 14A da seção Resultados: Evolução da glicemia $(\mathrm{mg} / \mathrm{dL})$ ao longo do período de estudo dos animais RAGE knockout diabéticos (RAGE KO+STZ).

\begin{tabular}{|c|c|c|c|c|c|c|c|c|c|}
\hline \multicolumn{7}{|c|}{ Evolução da glicemia dos animais RAGE knockout diabéticos (RAGE KO+STZ) ao longo do período estudado } \\
\hline Dias & Animal 1 & Animal 2 & Animal 3 & Animal 4 & Animal 5 & Animal 6 & Média & DP & EPM \\
\hline-5 & 121 & 159 & 138 & 189 & 178 & 196 & $\mathbf{1 6 3 , 5 0}$ & $\mathbf{2 9 , 6 4}$ & $\mathbf{1 2 , 1 0}$ \\
\hline-1 & 322 & 250 & 274 & 314 & 293 & 270 & $\mathbf{2 8 7 , 1 7}$ & $\mathbf{2 7 , 6 3}$ & $\mathbf{1 1 , 2 8}$ \\
\hline 7 & 437 & 351 & 389 & 246 & 255 & 337 & $\mathbf{3 3 5 , 8 3}$ & $\mathbf{7 4 , 7 0}$ & $\mathbf{3 0 , 4 9}$ \\
\hline 14 & 500 & 336 & 367 & 473 & 473 & 544 & $\mathbf{4 4 8 , 8 3}$ & $\mathbf{8 0 , 3 4}$ & $\mathbf{3 2 , 8 0}$ \\
\hline 21 & 449 & 399 & 502 & 589 & 370 & 499 & $\mathbf{4 6 8 , 0 0}$ & $\mathbf{7 9 , 3 5}$ & $\mathbf{3 2 , 4 0}$ \\
\hline 28 & 430 & 400 & 423 & 524 & 249 & 377 & $\mathbf{4 0 0 , 5 0}$ & $\mathbf{8 9 , 5 9}$ & $\mathbf{3 6 , 5 8}$ \\
\hline
\end{tabular}

Tabela A40. Valores individuais, média, desvio padrão (DP) e erro padrão da média $(\mathrm{EPM})$ referentes à Figura 14B da seção Resultados: Evolução da massa corporal (g) ao longo do período de estudo dos animais C57BL/6 controles (B6).

\begin{tabular}{|c|c|c|c|c|c|c|c|c|c|c|c|}
\hline \multicolumn{8}{|c|}{ Evolução da massa corporal dos animais C57BL/6 controles (B6) ao longo do período estudado } \\
\hline Dias & $\begin{array}{c}\text { Animal } \\
1\end{array}$ & $\begin{array}{c}\text { Animal } \\
2\end{array}$ & $\begin{array}{c}\text { Animal } \\
3\end{array}$ & $\begin{array}{c}\text { Animal } \\
4\end{array}$ & $\begin{array}{c}\text { Animal } \\
5\end{array}$ & $\begin{array}{c}\text { Animal } \\
6\end{array}$ & $\begin{array}{c}\text { Animal } \\
7\end{array}$ & $\begin{array}{c}\text { Animal } \\
8\end{array}$ & Média & DP & EPM \\
\hline-5 & 23 & 24,5 & 23 & 24,4 & 24 & 23 & 23 & 23,2 & $\mathbf{2 3 , 5 1}$ & $\mathbf{0 , 6 7}$ & $\mathbf{0 , 2 4}$ \\
\hline-1 & 22,8 & 24,6 & 23,9 & 24,8 & 23,9 & 23 & 23 & 23,3 & $\mathbf{2 3 , 6 6}$ & $\mathbf{0 , 7 6}$ & $\mathbf{0 , 2 7}$ \\
\hline 7 & 24,2 & 25,2 & 26,3 & 26,2 & 25,2 & 24,1 & 24,8 & 24,8 & $\mathbf{2 5 , 1 0}$ & $\mathbf{0 , 8 2}$ & $\mathbf{0 , 2 9}$ \\
\hline 14 & 25,7 & 25,7 & 28 & 27 & 25,5 & 24,7 & 25,8 & 25,5 & $\mathbf{2 5 , 9 9}$ & $\mathbf{1 , 0 3}$ & $\mathbf{0 , 3 6}$ \\
\hline 21 & 28 & 27 & 28,2 & 27,8 & 25,9 & 24,5 & 26 & 25,4 & $\mathbf{2 6 , 6 0}$ & $\mathbf{1 , 3 5}$ & $\mathbf{0 , 4 8}$ \\
\hline 28 & 27,9 & 28 & 29,3 & 28,8 & 26,9 & 25,4 & 27,5 & 26,4 & $\mathbf{2 7 , 5 3}$ & $\mathbf{1 , 2 7}$ & $\mathbf{0 , 4 5}$ \\
\hline
\end{tabular}


Tabela A41. Valores individuais, média, desvio padrão (DP) e erro padrão da média (EPM) referentes à Figura 14B da seção Resultados: Evolução da massa corporal (g) ao longo do período de estudo dos animais C57BL/6 diabéticos (B6+STZ).

\begin{tabular}{|c|c|c|c|c|c|c|c|c|c|c|c|}
\hline \multicolumn{8}{|c|}{ Evolução da massa corporal dos animais 57 B $/ 6$ diabéticos (B6+STZ) ao longo do período estudado } \\
\hline Dias & $\begin{array}{c}\text { Animal } \\
1\end{array}$ & $\begin{array}{c}\text { Animal } \\
2\end{array}$ & $\begin{array}{c}\text { Animal } \\
3\end{array}$ & $\begin{array}{c}\text { Animal } \\
\text { Animal }\end{array}$ & $\begin{array}{c}\text { Animal } \\
6\end{array}$ & $\begin{array}{c}\text { Animal } \\
7\end{array}$ & $\begin{array}{c}\text { Animal } \\
8\end{array}$ & Média & DP & EPM \\
\hline-5 & 23,4 & 23,9 & 23,6 & 23,2 & 24,2 & 23,7 & 23 & 24 & $\mathbf{2 3 , 6 3}$ & $\mathbf{0 , 4 1}$ & $\mathbf{0 , 1 4}$ \\
\hline-1 & 23,2 & 23,9 & 22,1 & 21,6 & 23,2 & 22,8 & 21,2 & 22,9 & $\mathbf{2 2 , 6 1}$ & $\mathbf{0 , 9 1}$ & $\mathbf{0 , 3 2}$ \\
\hline 7 & 23,4 & 24,2 & 22,2 & 22,6 & 24,5 & 23,6 & 22,1 & 23,7 & $\mathbf{2 3 , 2 9}$ & $\mathbf{0 , 9 0}$ & $\mathbf{0 , 3 2}$ \\
\hline 14 & 24,8 & 24,7 & 21,7 & 23 & 24,7 & 23,8 & 22,6 & 24,5 & $\mathbf{2 3 , 7 3}$ & $\mathbf{1 , 1 7}$ & $\mathbf{0 , 4 1}$ \\
\hline 21 & 25 & 24,7 & 22,1 & 23,2 & 24,9 & 23,3 & 23,2 & 24,1 & $\mathbf{2 3 , 8 1}$ & $\mathbf{1 , 0 3}$ & $\mathbf{0 , 3 6}$ \\
\hline 28 & 25,5 & 25,3 & 22,3 & 23,3 & 25,3 & 23,5 & 23,3 & 24,8 & $\mathbf{2 4 , 1 6}$ & $\mathbf{1 , 2 1}$ & $\mathbf{0 , 4 3}$ \\
\hline
\end{tabular}

Tabela A42. Valores individuais, média, desvio padrão (DP) e erro padrão da média (EPM) referentes à Figura 14B da seção Resultados: Evolução da massa corporal (g) ao longo do período de estudo dos animais NLRP3 controles (NLRP3 KO).

\begin{tabular}{|c|c|c|c|c|c|c|c|c|c|c|}
\hline \multicolumn{8}{|c|}{ Evolução da massa corporal dos animais NLRP3 knockout controles (NLRP3 KO) ao longo do período estudado } \\
\hline Dias & $\begin{array}{c}\text { Animal } \\
1\end{array}$ & $\begin{array}{c}\text { Animal } \\
2\end{array}$ & $\begin{array}{c}\text { Animal } \\
3\end{array}$ & $\begin{array}{c}\text { Animal } \\
4\end{array}$ & $\begin{array}{c}\text { Animal } \\
5\end{array}$ & $\begin{array}{c}\text { Animal } \\
6\end{array}$ & $\begin{array}{c}\text { Animal } \\
7\end{array}$ & Média & DP & EPM \\
\hline-5 & 32,2 & 34,8 & 32,8 & 24 & 24,3 & 23 & 26,8 & $\mathbf{2 8 , 2 7}$ & $\mathbf{4 , 8 7}$ & $\mathbf{1 , 7 2}$ \\
\hline-1 & 33 & 34 & 34 & 23,8 & 24,6 & 23,3 & 26,5 & $\mathbf{2 8 , 4 6}$ & $\mathbf{4 , 9 8}$ & $\mathbf{1 , 7 6}$ \\
\hline 7 & 33,7 & 35 & 33,8 & 24,8 & 26,1 & 24,8 & 27,8 & $\mathbf{2 9 , 4 3}$ & $\mathbf{4 , 5 6}$ & $\mathbf{1 , 6 1}$ \\
\hline 14 & 33,8 & 35,2 & 34,1 & 26,9 & 26,8 & 25,9 & 28,3 & $\mathbf{3 0 , 1 4}$ & $\mathbf{4 , 0 4}$ & $\mathbf{1 , 4 3}$ \\
\hline 21 & 33,2 & 35,4 & 32,8 & 26,3 & 26,9 & 25,8 & 28,4 & $\mathbf{2 9 , 8 3}$ & $\mathbf{3 , 8 8}$ & $\mathbf{1 , 3 7}$ \\
\hline 28 & 33,1 & 36,8 & 33,2 & 27 & 27,4 & 26,8 & 29 & $\mathbf{3 0 , 4 7}$ & $\mathbf{3 , 9 1}$ & $\mathbf{1 , 3 8}$ \\
\hline
\end{tabular}

Tabela A43. Valores individuais, média, desvio padrão (DP) e erro padrão da média (EPM) referentes à Figura 14B da seção Resultados: Evolução da massa corporal (g) ao longo do período de estudo dos animais NLRP3 knockout diabéticos (NLRP3 KO+STZ).

\begin{tabular}{|c|c|c|c|c|c|c|c|c|c|c|c|}
\hline \multicolumn{8}{|c|}{ Evolução da massa corporal dos animais NLRP3 knockout diabéticos (NLRP3 KO+STZ) ao longo do período estudado } \\
\hline Dias & $\begin{array}{c}\text { Animal } \\
1\end{array}$ & $\begin{array}{c}\text { Animal } \\
2\end{array}$ & $\begin{array}{c}\text { Animal } \\
3\end{array}$ & $\begin{array}{c}\text { Animal } \\
4\end{array}$ & $\begin{array}{c}\text { Animal } \\
5\end{array}$ & $\begin{array}{c}\text { Animal } \\
6\end{array}$ & $\begin{array}{c}\text { Animal } \\
7\end{array}$ & $\begin{array}{c}\text { Animal } \\
8\end{array}$ & Média & DP & EPM \\
\hline-5 & 31 & 30,2 & 29 & 23,8 & 26 & 24,5 & 24,2 & 23,1 & $\mathbf{2 6 , 4 8}$ & $\mathbf{3 , 1 3}$ & $\mathbf{1 , 1 1}$ \\
\hline-1 & 30,2 & 30 & 29 & 22,2 & 24,1 & 22,5 & 23 & 21,6 & $\mathbf{2 5 , 3 3}$ & $\mathbf{3 , 7 4}$ & $\mathbf{1 , 3 2}$ \\
\hline 7 & 29,8 & 30 & 28,8 & 23,4 & 25,3 & 24,2 & 24 & 22,5 & $\mathbf{2 6 , 0 0}$ & $\mathbf{3 , 0 5}$ & $\mathbf{1 , 0 8}$ \\
\hline 14 & 30 & 31,8 & 29,9 & 23,8 & 26 & 25 & 25,4 & 23,5 & $\mathbf{2 6 , 9 3}$ & $\mathbf{3 , 1 7}$ & $\mathbf{1 , 1 2}$ \\
\hline 21 & 30,5 & 32,3 & 30,9 & 23,1 & 25 & 24,7 & 25,2 & 23,5 & $\mathbf{2 6 , 9 0}$ & $\mathbf{3 , 6 9}$ & $\mathbf{1 , 3 1}$ \\
\hline 28 & 30,3 & 31,8 & 30,8 & 23,7 & 25,6 & 25 & 25 & 23,5 & $\mathbf{2 6 , 9 6}$ & $\mathbf{3 , 4 1}$ & $\mathbf{1 , 2 1}$ \\
\hline
\end{tabular}


Tabela A44. Valores individuais, média, desvio padrão (DP) e erro padrão da média (EPM) referentes à Figura 14B da seção Resultados: Evolução da massa corporal (g) ao longo do período de estudo dos animais RAGE knockout controles (RAGE KO).

\begin{tabular}{|c|c|c|c|c|c|c|c|}
\hline \multicolumn{1}{|c|}{ Evolução da massa corporal dos animais RAGE knockout controles (RAGE KO) ao longo do período estudado } \\
\hline Dias & Animal 1 & Animal 2 & Animal 3 & Animal 4 & Média & DP & EPM \\
\hline-5 & 24 & 23,4 & 23,5 & 23 & $\mathbf{2 3 , 4 8}$ & $\mathbf{0 , 4 1}$ & $\mathbf{0 , 1 5}$ \\
\hline-1 & 24,3 & 22,9 & 23,5 & 22,8 & $\mathbf{2 3 , 3 8}$ & $\mathbf{0 , 6 9}$ & $\mathbf{0 , 2 4}$ \\
\hline 7 & 24,8 & 23,6 & 24,7 & 24,5 & $\mathbf{2 4 , 4 0}$ & $\mathbf{0 , 5 5}$ & $\mathbf{0 , 1 9}$ \\
\hline 14 & 25,2 & 24,5 & 24,4 & 23,8 & $\mathbf{2 4 , 4 8}$ & $\mathbf{0 , 5 7}$ & $\mathbf{0 , 2 0}$ \\
\hline 21 & 25,9 & 25,7 & 25,7 & 24,3 & $\mathbf{2 5 , 4 0}$ & $\mathbf{0 , 7 4}$ & $\mathbf{0 , 2 6}$ \\
\hline 28 & 26,9 & 25,6 & 26,1 & 24,6 & $\mathbf{2 5 , 8 0}$ & $\mathbf{0 , 9 6}$ & $\mathbf{0 , 3 4}$ \\
\hline
\end{tabular}

Tabela A45. Valores individuais, média, desvio padrão (DP) e erro padrão da média (EPM) referentes à Figura 14B da seção Resultados: Evolução da massa corporal (g) ao longo do período de estudo dos animais RAGE knockout diabéticos (RAGE KO+STZ).

\begin{tabular}{|c|c|c|c|c|c|c|c|c|c|}
\hline \multicolumn{8}{|c|}{ Evolução da massa corporal dos animais RAGE knockout diabéticos (RAGE KO+STZ) ao longo do período estudado } \\
\hline Dias & Animal 1 & Animal 2 & Animal 3 & Animal 4 & Animal 5 & Animal 6 & Média & DP & EPM \\
\hline-5 & 25 & 22,5 & 25 & 26,3 & 26,7 & 22,8 & $\mathbf{2 4 , 7 2}$ & $\mathbf{1 , 7 4}$ & $\mathbf{0 , 6 2}$ \\
\hline-1 & 23,8 & 21,8 & 24 & 24,7 & 25,2 & 22,7 & $\mathbf{2 3 , 7 0}$ & $\mathbf{1 , 2 6}$ & $\mathbf{0 , 4 5}$ \\
\hline 7 & 22,7 & 21 & 24,1 & 21,6 & 21,8 & 20,4 & $\mathbf{2 1 , 9 3}$ & $\mathbf{1 , 3 1}$ & $\mathbf{0 , 4 6}$ \\
\hline 14 & 22,6 & 21,4 & 24 & 22,8 & 24,3 & 20,8 & $\mathbf{2 2 , 6 5}$ & $\mathbf{1 , 3 8}$ & $\mathbf{0 , 4 9}$ \\
\hline 21 & 22,3 & 20,8 & 24,1 & 22,6 & 24,5 & 21,5 & $\mathbf{2 2 , 6 3}$ & $\mathbf{1 , 4 4}$ & $\mathbf{0 , 5 1}$ \\
\hline 28 & 23,8 & 21,4 & 24,7 & 23,8 & 25 & 21,3 & $\mathbf{2 3 , 3 3}$ & $\mathbf{1 , 6 1}$ & $\mathbf{0 , 5 7}$ \\
\hline
\end{tabular}

Tabela A46. Valores individuais, média, desvio padrão (DP) e erro padrão da média (EPM) referentes à Figura $14 \mathrm{C}$ da seção Resultados: Determinação de insulina (ng/mL) no soro dos animais controles e diabéticos ao fim de 30 dias de indução da doença.

\begin{tabular}{|c|c|c|c|c|c|c|}
\hline & B6 & B6+STZ & NLRP3 KO & NLRP3 KO+STZ & RAGE KO & RAGE KO+STZ \\
\hline Animal 1 & 2,77 & 0,02 & 2,15 & 0,34 & 4,10 & 1,64 \\
\hline Animal 2 & 2,93 & 1,84 & 1,20 & 0,32 & 2,99 & 0,96 \\
\hline Animal 3 & 1,77 & 1,71 & 1,31 & ND & 2,11 & 0,61 \\
\hline Animal 4 & 4,46 & 0,79 & 1,22 & 1,17 & 1,52 & 1,55 \\
\hline Animal 5 & 2,62 & 0,87 & 1,82 & 1,78 & & 2,46 \\
\hline Animal 6 & 3,81 & 0,41 & - & 0,22 & & ND \\
\hline Animal 7 & 0,90 & 1,11 & - & ND & & \\
\hline Animal 8 & - & 0,41 & & ND & & \\
\hline Média & 2,75 & $\mathbf{0 , 8 9}$ & 1,54 & $\mathbf{0 , 6 3}$ & 2,68 & 1,44 \\
\hline DP & 1,19 & 0,64 & $\mathbf{0 , 4 3}$ & 0,69 & 1,13 & 0,71 \\
\hline EPM & 0,45 & $\mathbf{0 , 2 3}$ & 0,19 & 0,28 & 0,56 & $\mathbf{0 , 3 2}$ \\
\hline
\end{tabular}

(-): dado perdido/ ND: valores de insulina no soro abaixo do limite de confiança de detecção do ensaio (menor que $0,2 \mathrm{ng} / \mathrm{mL}$ ). 
Tabela A47. Valores individuais, média, desvio padrão (DP) e erro padrão da média (EPM) referentes à Figura 14D da seção Resultados: Determinação de AGEs (ug/mL) no soro dos animais controles e diabéticos ao fim de 30 dias de indução da doença.

\begin{tabular}{|c|c|c|c|c|c|c|}
\hline AGEs & B6 & B6+STZ & NLRP3 KO & NLRP3 KO+STZ & RAGE KO & RAGE KO+STZ \\
\hline Animal 1 & 0,147 & 0,185 & 0,061 & 0,399 & 0,575 & 0,191 \\
\hline Animal 2 & 0,199 & 0,238 & 0,226 & 0,159 & 0,221 & 0,273 \\
\hline Animal 3 & 0,113 & 0,382 & 0,229 & 0,076 & 1,018 & 0,152 \\
\hline Animal 4 & 0,188 & 0,175 & 0,5 & 0,369 & 0,257 & 0,281 \\
\hline Animal 5 & 0,743 & 0,201 & - & 0,142 & & 0,523 \\
\hline Animal 6 & 0,298 & 0,177 & - & 0,483 & & - \\
\hline Animal 7 & 0,125 & 0,335 & - & 0,988 & & \\
\hline Animal 8 & 0,46 & 0,265 & & 0,844 & & \\
\hline Média & $\mathbf{0 , 2 8}$ & $\mathbf{0 , 2 4}$ & $\mathbf{0 , 2 5}$ & $\mathbf{0 , 4 3}$ & $\mathbf{0 , 5 2}$ & $\mathbf{0 , 2 8}$ \\
\hline DP & $\mathbf{0 , 2 2}$ & $\mathbf{0 , 0 8}$ & $\mathbf{0 , 1 8}$ & $\mathbf{0 , 3 3}$ & $\mathbf{0 , 3 7}$ & $\mathbf{0 , 1 4}$ \\
\hline EPM & $\mathbf{0 , 0 8}$ & $\mathbf{0 , 0 3}$ & $\mathbf{0 , 0 9}$ & $\mathbf{0 , 1 2}$ & $\mathbf{0 , 1 8}$ & $\mathbf{0 , 0 6}$ \\
\hline
\end{tabular}

(-): dado perdido

Tabela A48. Valores individuais, média, desvio padrão (DP) e erro padrão da média (EPM) referentes à Figura 15A da seção Resultados: Concentração de citocinas e quimiocinas no soro dos animais C57BL/6, NLRP3 KO e RAGE KO após 30 dias da indução de diabetes.

\begin{tabular}{|c|c|c|c|c|c|c|}
\hline IL-1 $\boldsymbol{\beta}$ & B6 & B6+STZ & NLRP3 KO & NLRP3 KO+STZ & RAGE KO & RAGE KO+STZ \\
\hline Animal 1 & 24,09 & 34,83 & 33,35 & 15,29 & 10,66 & 14,39 \\
\hline Animal 2 & 15,29 & 30,91 & 30,91 & 40,53 & 34,83 & 15,29 \\
\hline Animal 3 & 14,39 & 0,43 & 28,66 & 2,18 & - & 30,91 \\
\hline Animal 4 & 15,29 & 34,83 & 40,09 & 12,87 & - & 24,09 \\
\hline Animal 5 & 33,35 & 31,93 & 2,18 & 28,66 & & 0,43 \\
\hline Animal 6 & 33,35 & 24,09 & 2,18 & 8,06 & & \\
\hline Animal 7 & 12,87 & 28,66 & & 8,06 & & \\
\hline Animal 8 & & 12,87 & & 37,57 & & \\
\hline Animal 9 & & 30,91 & & 8,06 & & \\
\hline Média & $\mathbf{2 1 , 2 3}$ & $\mathbf{2 5 , 5 0}$ & $\mathbf{2 2 , 9 0}$ & $\mathbf{1 9 , 1 5}$ & & $\mathbf{1 7 , 0 2}$ \\
\hline DP & $\mathbf{9 , 0 3}$ & $\mathbf{1 1 , 5 9}$ & $\mathbf{1 6 , 5 0}$ & $\mathbf{1 4 , 5 2}$ & & $\mathbf{1 1 , 4 9}$ \\
\hline EPM & $\mathbf{3 , 4 1}$ & $\mathbf{3 , 8 6}$ & $\mathbf{6 , 7 3}$ & $\mathbf{5 , 1 3}$ & & $\mathbf{5 , 1 4}$ \\
\hline
\end{tabular}

(-): dado perdido 
Tabela A49. Valores individuais, média, desvio padrão (DP) e erro padrão da média (EPM) referentes à Figura $15 \mathrm{~B}$ da seção Resultados: Concentração de citocinas e quimiocinas no soro dos animais C57BL/6, NLRP3 KO e RAGE KO após 30 dias da indução de diabetes.

\begin{tabular}{|c|c|c|c|c|c|c|}
\hline IL-1 $\alpha$ & B6 & B6+STZ & NLRP3 KO & NLRP3 KO+STZ & RAGE KO & RAGE KO+STZ \\
\hline Animal 1 & 0,5 & 0,58 & 0,76 & 0,5 & 2,41 & 0,58 \\
\hline Animal 2 & 0,76 & 0,67 & 0,58 & 0,58 & 0,58 & 0,76 \\
\hline Animal 3 & 0,67 & 0,37 & 0,86 & 1,33 & - & 0,43 \\
\hline Animal 4 & 0,5 & 0,67 & 0,67 & 0,58 & - & 0,5 \\
\hline Animal 5 & 0,67 & 0,5 & 2 & 0,58 & & 0,5 \\
\hline Animal 6 & 0,86 & 0,43 & 0,37 & 4,85 & & \\
\hline Animal 7 & 0,76 & 0,43 & 1,08 & 0,58 & & \\
\hline Animal 8 & & 0,43 & 0,31 & 0,58 & & \\
\hline Animal 9 & & 0,58 & & 0,43 & & \\
\hline Média & $\mathbf{0 , 6 7}$ & $\mathbf{0 , 5 2}$ & $\mathbf{0 , 8 7}$ & $\mathbf{1 , 2 0}$ & & $\mathbf{0 , 5 5}$ \\
\hline DP & $\mathbf{0 , 1 4}$ & $\mathbf{0 , 1 1}$ & $\mathbf{0 , 5 8}$ & $\mathbf{1 , 5 0}$ & & $\mathbf{0 , 1 3}$ \\
\hline EPM & $\mathbf{0 , 0 5}$ & $\mathbf{0 , 0 4}$ & $\mathbf{0 , 2 4}$ & $\mathbf{0 , 5 3}$ & & $\mathbf{0 , 0 6}$ \\
\hline
\end{tabular}

(-): dado perdido

Tabela A50. Valores individuais, média, desvio padrão (DP) e erro padrão da média (EPM) referentes à Figura $15 \mathrm{C}$ da seção Resultados: Concentração de citocinas e quimiocinas no soro dos animais C57BL/6, NLRP3 KO e RAGE KO após 30 dias da indução de diabetes.

\begin{tabular}{|c|c|c|c|c|c|c|}
\hline IL-18 & B6 & B6+STZ & NLRP3 KO & NLRP3 KO+STZ & RAGE KO & RAGE KO+STZ \\
\hline Animal 1 & 4,75 & 9,7 & 4,55 & 4,36 & 6,16 & 34,08 \\
\hline Animal 2 & 3,57 & 5,29 & 4,75 & 7,01 & 5,65 & 14,32 \\
\hline Animal 3 & 7,01 & 8,33 & 1,35 & 22,58 & - & 29,28 \\
\hline Animal 4 & 0,63 & 6,29 & 5,59 & 10,58 & - & 10,58 \\
\hline Animal 5 & 4,36 & 9,49 & 16,67 & 16,31 & & 11,79 \\
\hline Animal 6 & 0,28 & 9,09 & 10,35 & 19,82 & & \\
\hline Animal 7 & 1,35 & 10,35 & 4,85 & 6,5 & & \\
\hline Animal 8 & & 17,22 & & 4,75 & & \\
\hline Animal 9 & & 22,09 & & 8,33 & & \\
\hline Média & $\mathbf{3 , 1 4}$ & $\mathbf{1 0 , 8 7}$ & $\mathbf{7 , 2 1}$ & $\mathbf{1 1 , 4 9}$ & & $\mathbf{2 0 , 0 1}$ \\
\hline DP & $\mathbf{2 , 4 8}$ & $\mathbf{5 , 3 8}$ & $\mathbf{5 , 4 7}$ & $\mathbf{7 , 1 5}$ & & $\mathbf{1 0 , 8 7}$ \\
\hline EPM & $\mathbf{0 , 9 4}$ & $\mathbf{1 , 7 9}$ & $\mathbf{2 , 2 3}$ & $\mathbf{2 , 5 3}$ & & $\mathbf{4 , 8 6}$ \\
\hline
\end{tabular}

(-): dado perdido 
Tabela A51. Valores individuais, média, desvio padrão (DP) e erro padrão da média (EPM) referentes à Figura $15 \mathrm{D}$ da seção Resultados: Concentração de citocinas e quimiocinas no soro dos animais C57BL/6, NLRP3 KO e RAGE KO após 30 dias da indução de diabetes.

\begin{tabular}{|c|c|c|c|c|c|c|}
\hline IL-6 & B6 & B6+STZ & $\begin{array}{c}\text { NLRP3 } \\
\text { KO }\end{array}$ & $\begin{array}{c}\text { NLRP3 } \\
\text { KO+STZ }\end{array}$ & $\begin{array}{c}\text { RAGE } \\
\text { KO }\end{array}$ & $\begin{array}{c}\text { RAGE } \\
\text { KO+STZ }\end{array}$ \\
\hline Animal 1 & 2,11 & 2,11 & 1,71 & 5,88 & 0,98 & 1,08 \\
\hline Animal 2 & 1,33 & 4,14 & 1,89 & 1,66 & 1,89 & 1,28 \\
\hline Animal 3 & 1,49 & 0,98 & 1,71 & 2,54 & - & 1,38 \\
\hline Animal 4 & 1,28 & 3,21 & 1,38 & 3,74 & - & 1,71 \\
\hline Animal 5 & 2,34 & 1,28 & 0,89 & 1,97 & & 0,98 \\
\hline Animal 6 & 2,44 & 1,38 & 1,08 & 0,98 & & \\
\hline Animal 7 & 1,18 & 1,6 & & 1,18 & & \\
\hline Animal 8 & & 1,49 & & 1,83 & & \\
\hline Animal 9 & & 2,18 & & 1,6 & & \\
\hline Média & $\mathbf{1 , 7 4}$ & $\mathbf{2 , 0 4}$ & $\mathbf{1 , 4 4}$ & $\mathbf{2 , 4 7}$ & & $\mathbf{1 , 2 9}$ \\
\hline DP & $\mathbf{0 , 5 4}$ & $\mathbf{1 , 0 3}$ & $\mathbf{0 , 4 0}$ & $\mathbf{1 , 6 2}$ & & $\mathbf{0 , 2 8}$ \\
\hline EPM & $\mathbf{0 , 2 0}$ & $\mathbf{0 , 3 4}$ & $\mathbf{0 , 1 6}$ & $\mathbf{0 , 5 7}$ & & $\mathbf{0 , 1 3}$ \\
\hline
\end{tabular}

(-): dado perdido

Tabela A52. Valores individuais, média, desvio padrão (DP) e erro padrão da média (EPM) referentes à Figura 15E da seção Resultados: Concentração de citocinas e quimiocinas no soro dos animais C57BL/6, NLRP3 KO e RAGE KO após 30 dias da indução de diabetes.

\begin{tabular}{|c|c|c|c|c|c|c|}
\hline TNF- $\boldsymbol{\alpha}$ & B6 & B6+STZ & NLRP3 KO & NLRP3 KO+STZ & RAGE KO & RAGE KO+STZ \\
\hline Animal 1 & 7,98 & 24,1 & 17,03 & 8,52 & 2,64 & 14,32 \\
\hline Animal 2 & 8,52 & 24,09 & 22,58 & 31,93 & 3,75 & 19,4 \\
\hline Animal 3 & 17,03 & 24,09 & 13,13 & 0,18 & - & 22,58 \\
\hline Animal 4 & 9,7 & 7,16 & 13,26 & 6,86 & - & 25,16 \\
\hline Animal 5 & 19,4 & 19,4 & 0,42 & 29,92 & & \\
\hline Animal 6 & 29,92 & 28,66 & 2,64 & 0,42 & & \\
\hline Animal 7 & 17,79 & 22,09 & & 26,85 & & \\
\hline Animal 8 & & 15,96 & & 25,16 & & \\
\hline Animal 9 & & 6,29 & & - & & \\
\hline Média & $\mathbf{1 5 , 7 6}$ & $\mathbf{1 9 , 0 9}$ & $\mathbf{1 1 , 5 1}$ & $\mathbf{1 6 , 2 3}$ & & $\mathbf{2 0 , 3 7}$ \\
\hline DP & $\mathbf{7 , 8 4}$ & $\mathbf{7 , 8 4}$ & $\mathbf{8 , 4 9}$ & $\mathbf{1 3 , 5 3}$ & & $\mathbf{4 , 6 7}$ \\
\hline EPM & $\mathbf{2 , 9 6}$ & $\mathbf{2 , 6 1}$ & $\mathbf{3 , 4 7}$ & $\mathbf{4 , 7 8}$ & & $\mathbf{2 , 3 3}$ \\
\hline
\end{tabular}


Tabela A53. Valores individuais, média, desvio padrão (DP) e erro padrão da média (EPM) referentes à Figura $15 \mathrm{~F}$ da seção Resultados: Concentração de citocinas e quimiocinas no soro dos animais C57BL/6, NLRP3 KO e RAGE KO após 30 dias da indução de diabetes.

\begin{tabular}{|c|c|c|c|c|c|c|}
\hline CXCL1 & B6 & B6+STZ & NLRP3 KO & NLRP3 KO+STZ & RAGE KO & RAGE KO+STZ \\
\hline Animal 1 & 14,96 & 28,66 & 15,79 & 142,35 & 25,71 & 25,71 \\
\hline Animal 2 & 60,5 & 17,41 & 14,96 & 17,41 & 18,58 & 24,09 \\
\hline Animal 3 & 84,64 & 25,99 & 24,09 & 56,7 & - & 21,39 \\
\hline Animal 4 & 14,96 & 45,16 & 16,67 & 22,09 & - & 23,58 \\
\hline Animal 5 & 9,7 & 19,82 & 18,18 & 27,44 & & 25,71 \\
\hline Animal 6 & 18,18 & 21,16 & 17,79 & 59,21 & & \\
\hline Animal 7 & 17,03 & 15,96 & & 14,96 & & \\
\hline Animal 8 & & 18,18 & & 14,96 & & \\
\hline Animal 9 & & 18,98 & & 18,45 & & \\
\hline Média & $\mathbf{3 1 , 4 2}$ & $\mathbf{2 3 , 4 8}$ & $\mathbf{1 7 , 9 1}$ & $\mathbf{4 4 , 3 9}$ & & $\mathbf{2 4 , 1 0}$ \\
\hline DP & $\mathbf{2 9 , 0 8}$ & $\mathbf{9 , 1 1}$ & $\mathbf{3 , 2 6}$ & $\mathbf{4 3 , 4 4}$ & & $\mathbf{1 , 7 9}$ \\
\hline EPM & $\mathbf{1 0 , 9 9}$ & $\mathbf{3 , 0 4}$ & $\mathbf{1 , 3 3}$ & $\mathbf{1 5 , 3 6}$ & & $\mathbf{0 , 8 0}$ \\
\hline
\end{tabular}

(-): dado perdido

Tabela A54. Valores individuais, média, desvio padrão (DP) e erro padrão da média (EPM) referentes à Figura $15 \mathrm{G}$ da seção Resultados: Concentração de citocinas e quimiocinas no soro dos animais C57BL/6, NLRP3 KO e RAGE KO após 30 dias da indução de diabetes.

\begin{tabular}{|c|c|c|c|c|c|c|}
\hline CCL2 & B6 & B6+STZ & NLRP3 KO & NLRP3 KO+STZ & RAGE KO & RAGE KO+STZ \\
\hline Animal 1 & 23,32 & 87,44 & 37,16 & 307,12 & 44,2 & 81,05 \\
\hline Animal 2 & 40,53 & 33,35 & 34,08 & 54,88 & 37,16 & 72,73 \\
\hline Animal 3 & 80,18 & 42,32 & 64,56 & 103,98 & - & 58,57 \\
\hline Animal 4 & 50,33 & 108,58 & 34,08 & 210,22 & - & 59,85 \\
\hline Animal 5 & 50,33 & 46,15 & 65,27 & 66,7 & & 52,56 \\
\hline Animal 6 & 59,85 & 58,57 & 59,85 & 65,27 & & \\
\hline Animal 7 & 32,63 & 56,08 & & 84,64 & & \\
\hline Animal 8 & & 35,59 & & 63,18 & & \\
\hline Animal 9 & & 59,85 & & 46,15 & & \\
\hline Média & $\mathbf{4 8 , 1 7}$ & $\mathbf{5 8 , 6 6}$ & $\mathbf{4 9 , 1 7}$ & $\mathbf{1 1 9 , 5 0}$ & & $\mathbf{6 4 , 9 5}$ \\
\hline DP & $\mathbf{1 8 , 6 5}$ & $\mathbf{2 4 , 8 1}$ & $\mathbf{1 5 , 5 5}$ & $\mathbf{9 1 , 0 0}$ & & $\mathbf{1 1 , 6 2}$ \\
\hline EPM & $\mathbf{7 , 0 5}$ & $\mathbf{8 , 2 7}$ & $\mathbf{6 , 3 5}$ & $\mathbf{3 2 , 1 7}$ & & $\mathbf{5 , 2 0}$ \\
\hline
\end{tabular}

(-): dado perdido 
Tabela A55. Valores individuais, média, desvio padrão (DP) e erro padrão da média (EPM) referentes à Figura $15 \mathrm{H}$ da seção Resultados: Concentração de citocinas e quimiocinas no soro dos animais C57BL/6, NLRP3 KO e RAGE KO após 30 dias da indução de diabetes.

\begin{tabular}{|c|c|c|c|c|c|c|}
\hline IL-10 & B6 & B6+STZ & NLRP3 KO & NLRP3 KO+STZ & RAGE KO & RAGE KO+STZ \\
\hline Animal 1 & 4,59 & 3,74 & 6,72 & 2,91 & 1,69 & 1,95 \\
\hline Animal 2 & 1,81 & 5,61 & 5,61 & 12,42 & 2,78 & 1,95 \\
\hline Animal 3 & 1,81 & 1,03 & 2,26 & 1,69 & - & 2,91 \\
\hline Animal 4 & 3,37 & 2,78 & 2,91 & 2,26 & - & 2,54 \\
\hline Animal 5 & 4,59 & 1,81 & 1,44 & 3,74 & & 1,03 \\
\hline Animal 6 & 6,16 & 2,54 & 1,03 & 1,69 & & \\
\hline Animal 7 & 2,54 & 2,91 & & 1,22 & & \\
\hline Animal 8 & & 1,95 & & 2,26 & & \\
\hline Animal 9 & & 3,74 & & 2,78 & & \\
\hline Média & $\mathbf{3 , 5 5}$ & $\mathbf{2 , 9 0}$ & $\mathbf{3 , 3 3}$ & $\mathbf{3 , 5 2}$ & & $\mathbf{2 , 0 8}$ \\
\hline DP & $\mathbf{1 , 6 4}$ & $\mathbf{1 , 3 5}$ & $\mathbf{2 , 3 2}$ & $\mathbf{3 , 6 8}$ & & $\mathbf{0 , 7 1}$ \\
\hline EPM & $\mathbf{0 , 6 2}$ & $\mathbf{0 , 4 5}$ & $\mathbf{0 , 9 5}$ & $\mathbf{1 , 3 0}$ & & $\mathbf{0 , 3 2}$ \\
\hline
\end{tabular}

(-): dado perdido

Tabela A56. Valores individuais referentes à Figura 16 da seção Resultados: Quantificação de citocinas e quimiocinas na meio de cultura de células nucleadas da medula óssea dos animais C57BL/6 controles (B6) após 30 dias de diabetes.

\begin{tabular}{|c|c|c|c|c|c|c|c|c|c|c|c|}
\hline & Tratamento & NO & IL-1 $\beta$ & IL-6 & TNF- $\alpha$ & CXCL1 & IL-10 & CCL2 & IL-12p40 & IL-1 $\alpha$ & IL-18 \\
\hline \multirow{3}{*}{$\begin{array}{c}\text { Animal } \\
1\end{array}$} & NT & 2,646 & ND & ND & ND & 2,15 & 2,05 & 4,3 & 0 & 1,73 & 3,29 \\
\hline & LPS & 8,324 & 55,355 & 10567,74 & 1007,70 & 5,89 & 75,95 & 353,55 & 0,01 & 2,1 & 4,52 \\
\hline & DHA & 4,95 & 34,94 & 8890,78 & 747,96 & 8,52 & 107,41 & 297,3 & 0,01 & 1,98 & 3,77 \\
\hline \multirow{3}{*}{$\begin{array}{c}\text { Animal } \\
2\end{array}$} & NT & 1,74 & ND & ND & ND & 2,15 & 2,05 & 11,98 & 0 & 1,86 & 3,41 \\
\hline & LPS & 9,629 & 43,027 & 9441,16 & 1005,33 & 6,64 & 155,23 & 353,55 & 0 & 2,1 & 3,77 \\
\hline & DHA & 6,461 & 32,766 & 12032,6 & 822,78 & 12,29 & 176,78 & 522,8 & 0,01 & 2,1 & 3,77 \\
\hline \multirow{3}{*}{$\begin{array}{c}\text { Animal } \\
3\end{array}$} & NT & 2,273 & ND & ND & ND & 2,15 & 2,05 & 5,74 & 0 & 1,98 & 3,17 \\
\hline & LPS & 2,567 & 22,661 & 5049,8 & 569,12 & 12,92 & 79,32 & 278,6 & 0 & 1,98 & 3,29 \\
\hline & DHA & 1,501 & 26,182 & 4054,5 & 641,86 & 17,03 & 92,3 & 297,3 & 0 & 2,1 & 3,17 \\
\hline \multirow{3}{*}{$\begin{array}{c}\text { Animal } \\
4\end{array}$} & NT & 2,194 & ND & ND & ND & 2,15 & 1,69 & 4,26 & 0 & 1,86 & 3,06 \\
\hline & LPS & 1,322 & 27,478 & 2688,04 & 337,36 & 12,29 & 58,57 & 261,07 & 0 & 1,98 & 3,65 \\
\hline & DHA & 1,342 & 27,923 & 1892,32 & 368,45 & 16,31 & 61,16 & 210,22 & 0 & 1,98 & 3,17 \\
\hline
\end{tabular}

ND: valores abaixo do limite de confiança de detecção do ensaio 
Tabela A57. Valores individuais referentes à Figura 16 da seção Resultados: Quantificação de citocinas e quimiocinas na meio de cultura de células nucleadas da medula óssea dos animais C57BL/6 diabéticos (B6+STZ) após 30 dias de diabetes.

\begin{tabular}{|c|c|c|c|c|c|c|c|c|c|c|c|}
\hline & Tratamento & NO & IL-1 $\beta$ & IL-6 & TNF- $\alpha$ & CXCL1 & IL-10 & CCL2 & IL-12p40 & IL-1 $\alpha$ & IL-18 \\
\hline \multirow{3}{*}{$\begin{array}{c}\text { Animal } \\
1\end{array}$} & NT & 3,153 & ND & ND & ND & 2,15 & 1,69 & 3,12 & 0 & 1,61 & 3,23 \\
\hline & LPS & 3,153 & 24,921 & 5900,56 & 608,35 & 10,58 & 63,87 & 272,63 & 0,01 & 2,1 & 4 \\
\hline & DHA & 1,839 & 20,98 & 5131,72 & 536,64 & 13,25 & 63,18 & 188,65 & 0 & 1,98 & 3,17 \\
\hline \multirow{3}{*}{$\begin{array}{c}\text { Animal } \\
2\end{array}$} & NT & 1,422 & ND & ND & ND & 1,9 & 1,37 & 2,83 & 0 & 1,73 & 3,29 \\
\hline & LPS & 2,234 & 29,2 & 3599,36 & 524,64 & 9,63 & 56,08 & 255,47 & 0,07 & 2,1 & 3,88 \\
\hline & DHA & 2,096 & 25,73 & 2919,04 & 479,23 & 19,19 & 68,16 & 234,27 & 0,01 & 1,98 & 3,88 \\
\hline \multirow{3}{*}{$\begin{array}{c}\text { Animal } \\
3\end{array}$} & NT & 1,938 & ND & $\mathrm{ND}$ & ND & 1,78 & 1,69 & 3,42 & 0 & 1,67 & 3,53 \\
\hline & LPS & 4,988 & 32,29 & 6114,1 & 575,00 & 10,08 & 71,17 & 353,55 & 0 & 2,1 & 4,29 \\
\hline & DHA & 1,879 & 30,85 & 5871,7 & 415,43 & 10,58 & 69,65 & 261,07 & 0 & 2,1 & 3,77 \\
\hline \multirow{3}{*}{$\begin{array}{c}\text { Animal } \\
4\end{array}$} & NT & 1,958 & $\mathrm{ND}$ & $\mathrm{ND}$ & ND & 1,9 & 2,05 & 5,09 & 0 & 1,86 & 3,17 \\
\hline & LPS & 1,601 & 22,556 & 4126,74 & 316,28 & 8,85 & 48,19 & 255,47 & 0 & 2,1 & 3,41 \\
\hline & DHA & 0,736 & 11,989 & 3860,76 & 301,87 & 17,03 & 71,17 & 244,64 & 0,01 & 2,1 & 3,88 \\
\hline \multirow{3}{*}{$\begin{array}{c}\text { Animal } \\
5\end{array}$} & NT & 2,509 & ND & $\mathrm{ND}$ & ND & 2,41 & 1,69 & 7,59 & 0 & 1,73 & 3,06 \\
\hline & LPS & 2,861 & 19,153 & 5195,76 & 330,30 & 8,24 & 43,25 & 219,53 & 0 & 1,98 & 3,53 \\
\hline & DHA & 2,017 & 12,175 & 4255,1 & 363,31 & 12,92 & 68,16 & 255,47 & 0 & 2,1 & 3,65 \\
\hline \multirow{3}{*}{$\begin{array}{c}\text { Animal } \\
6\end{array}$} & NT & 1,422 & ND & $\mathrm{ND}$ & ND & 2,41 & 1,69 & 3,49 & 0 & 1,73 & 2,93 \\
\hline & LPS & 2,743 & 25,326 & 4594,16 & 270,46 & 13,58 & 59,85 & 297,3 & 0 & 1,98 & 4,12 \\
\hline & DHA & 1,302 & 20,286 & 4302,44 & 260,75 & 13,92 & 59,85 & 229,25 & 0 & 1,98 & 3,88 \\
\hline
\end{tabular}

ND: valores abaixo do limite de confiança de detecção do ensaio

Tabela A58. Valores individuais referentes à Figura 16 da seção Resultados: Quantificação de citocinas e quimiocinas na meio de cultura de células nucleadas da medula óssea dos animais NLRP3 KO controles (NLRP3 KO) após 30 dias de diabetes.

\begin{tabular}{|c|c|c|c|c|c|c|c|c|c|c|c|}
\hline & Tratamento & NO & IL-1 $\beta$ & IL-6 & TNF- $\alpha$ & CXCL1 & IL-10 & CCL2 & IL-12p40 & IL-1 $\alpha$ & IL-18 \\
\hline \multirow{3}{*}{$\begin{array}{c}\text { Animal } \\
1\end{array}$} & NT & 2,43 & ND & ND & ND & 1,9 & 1,52 & 5,62 & 0 & 1,86 & 2,81 \\
\hline & LPS & 6,728 & 9,143 & 9130,16 & 466,59 & 19,19 & 100,66 & 353,55 & 0,03 & 2,1 & 3,65 \\
\hline & DHA & 6,918 & 11,171 & 9094 & 602,94 & 18,18 & 119,7 & 324,21 & 0,01 & 2,47 & 3,12 \\
\hline \multirow{3}{*}{$\begin{array}{c}\text { Animal } \\
2\end{array}$} & NT & 0,51 & ND & ND & ND & 1,9 & 2,46 & 10,84 & 0 & 1,61 & 3,06 \\
\hline & LPS & 8,115 & 17,724 & 11742,54 & 715,18 & 10,58 & 96,39 & 353,55 & 0,2 & 2,47 & 4,46 \\
\hline & DHA & 3,638 & 12,175 & 9929,92 & 569,13 & 14,26 & 114,63 & 324,21 & 0,01 & 2,22 & 3,23 \\
\hline \multirow{3}{*}{$\begin{array}{c}\text { Animal } \\
3\end{array}$} & NT & 2,332 & ND & ND & ND & 2,15 & 1,69 & 2,47 & 0 & 1,98 & 3,06 \\
\hline & LPS & 10,987 & 20,554 & 6820,84 & 962,52 & 10,58 & 65,27 & 284,7 & 0,01 & 2,1 & 3,41 \\
\hline & DHA & 6,537 & 16,205 & 6637,02 & 834,69 & 13,25 & 82,83 & 244,64 & 0,01 & 1,98 & 3,17 \\
\hline \multirow{3}{*}{$\begin{array}{c}\text { Animal } \\
4\end{array}$} & NT & 3,153 & ND & ND & ND & 1,66 & 2,46 & 6,36 & 0 & 1,86 & 2,93 \\
\hline & LPS & 11,44 & 21,456 & 9300,08 & 823,48 & 11,68 & 100,66 & 284,7 & 0,02 & 2,47 & 3,53 \\
\hline & DHA & 6,289 & 9,678 & 6713,32 & 822,78 & 17,03 & 114,63 & 244,64 & 0,02 & 1,98 & 3,17 \\
\hline
\end{tabular}

ND: valores abaixo do limite de confiança de detecção do ensaio 
Tabela A59. Valores individuais referentes à Figura 16 da seção Resultados: Quantificação de citocinas e quimiocinas na meio de cultura de células nucleadas da medula óssea dos animais NLRP3 KO diabéticos (NLRP3 KO+STZ) após 30 dias de diabetes.

\begin{tabular}{|c|c|c|c|c|c|c|c|c|c|c|c|}
\hline & Tratamento & NO & IL-1 $\beta$ & IL-6 & TNF- $\alpha$ & CXCL1 & IL-10 & CCL2 & IL-12p40 & IL-1 $\alpha$ & IL-18 \\
\hline \multirow{3}{*}{$\begin{array}{c}\text { Animal } \\
1\end{array}$} & NT & 5,391 & ND & 26,66 & ND & 1,78 & 2,05 & 7,9 & 0 & 1,86 & 3,53 \\
\hline & LPS & 13,226 & 21,139 & 7280,42 & 1028,42 & 8,85 & 69,65 & 297,3 & 0,06 & 2,41 & 3,29 \\
\hline & DHA & 9,742 & 26,632 & 6192,56 & 725,59 & 10,84 & 82,83 & 244,64 & 0,01 & 2,78 & 3,06 \\
\hline \multirow{3}{*}{$\begin{array}{c}\text { Animal } \\
2\end{array}$} & NT & 3,153 & $\mathrm{ND}$ & ND & ND & 1,66 & 1,69 & 6,11 & 0 & 1,73 & 3,47 \\
\hline & LPS & 6,137 & 8,041 & 4033,32 & 677,43 & 6,26 & 52,56 & 284,7 & 0,02 & 2,22 & 3,12 \\
\hline & DHA & 4,661 & 11,362 & 3844,02 & 509,35 & 8,85 & 69,65 & 234,27 & 0,01 & 2,22 & 3,06 \\
\hline \multirow{3}{*}{$\begin{array}{c}\text { Animal } \\
3\end{array}$} & NT & 2,997 & ND & ND & ND & 1,9 & 1,69 & 6,62 & 0,01 & 1,73 & 3,65 \\
\hline & LPS & 9,289 & 21,929 & 5553,2 & 534,92 & 6,64 & 52,56 & 244,64 & 0,03 & 1,98 & 3,53 \\
\hline & DHA & 8,361 & 16,375 & 5982,68 & 1014,05 & 7,41 & 63,87 & 221,92 & 0,01 & 2,1 & 2,93 \\
\hline \multirow{3}{*}{$\begin{array}{c}\text { Animal } \\
4\end{array}$} & NT & 1,918 & $\mathrm{ND}$ & ND & ND & 1,9 & 1,37 & 19,82 & 0 & 1,67 & 3,17 \\
\hline & LPS & 6,671 & 9,412 & 6759,3 & 668,62 & 7,41 & 72,73 & 297,3 & 0,02 & 2,1 & 3,06 \\
\hline & DHA & 4,892 & 9,877 & 6556,1 & 625,32 & 11,11 & 88,39 & 297,3 & 0 & 2,1 & 3,06 \\
\hline \multirow{3}{*}{$\begin{array}{c}\text { Animal } \\
5\end{array}$} & NT & 2,528 & $\mathrm{ND}$ & $\mathrm{ND}$ & ND & 1,66 & 2,05 & 2,83 & 0 & 1,86 & 2,87 \\
\hline & LPS & 13,339 & 22,504 & 12418 & 1017,23 & 5,18 & 81,05 & 247,31 & 0,01 & 2,16 & 3,17 \\
\hline & DHA & 9,875 & 21,35 & 11164,52 & 903,85 & 5,89 & 96,39 & 420,45 & 0,02 & 2,22 & 3,06 \\
\hline
\end{tabular}

ND: valores abaixo do limite de confiança de detecção do ensaio

Tabela A60. Valores individuais referentes à Figura 16 da seção Resultados: Quantificação de citocinas e quimiocinas na meio de cultura de células nucleadas da medula óssea dos animais RAGE KO controles (RAGE KO) após 30 dias de diabetes.

\begin{tabular}{|c|c|c|c|c|c|c|c|c|c|c|c|}
\hline & Tratamento & NO & IL-1 $\beta$ & IL-6 & TNF- $\alpha$ & CXCL1 & IL-10 & CCL2 & IL-12p40 & IL-1 $\alpha$ & IL-18 \\
\hline \multirow{3}{*}{$\begin{array}{c}\text { Animal } \\
1\end{array}$} & NT & 2,548 & ND & 395,98 & 37,65 & 2,68 & 3,71 & 33,35 & 0 & 1,98 & 3,17 \\
\hline & LPS & 11,872 & 44,691 & 7179,92 & 1038,88 & 15,28 & 86,49 & 284,7 & 0 & 2,22 & 4 \\
\hline & DHA & 11,948 & 41,625 & 7488,92 & 1083,13 & 18,18 & 105,11 & 261,07 & 0,01 & 2,34 & 3,77 \\
\hline \multirow{3}{*}{$\begin{array}{c}\text { Animal } \\
2\end{array}$} & NT & 1,581 & ND & 269,74 & ND & 2,68 & 2,46 & 28,66 & 0 & 1,86 & 3,17 \\
\hline & LPS & 9,572 & 38,242 & 13740,08 & 1031,63 & 24,09 & 130,53 & 420,45 & 0,02 & 2,59 & 3,77 \\
\hline & DHA & 5,352 & 41,353 & 9166,4 & 955,63 & 24,62 & 114,63 & 324,21 & 0,02 & 2,71 & 3,88 \\
\hline \multirow{3}{*}{$\begin{array}{c}\text { Animal } \\
3\end{array}$} & NT & 2,646 & ND & 207,06 & 16,31 & 2,68 & 2,05 & 18,58 & 0 & 1,73 & 3,17 \\
\hline & LPS & 10,856 & 62,222 & 9502,92 & 996,68 & 8,24 & 50,33 & 184,6 & 0,05 & 1,98 & 4,23 \\
\hline & DHA & 8,948 & 64,709 & 7954,18 & 1457,49 & 11,68 & 82,83 & 229,25 & 0,36 & 2,34 & 4 \\
\hline \multirow{3}{*}{$\begin{array}{c}\text { Animal } \\
4\end{array}$} & NT & 2,273 & ND & 171,18 & 28,19 & 2,15 & 2,46 & 12,92 & 0 & 1,79 & 2,69 \\
\hline & LPS & 4,141 & 51,645 & 6903,3 & 738,05 & 15,96 & 47,16 & 217,17 & 0 & 1,98 & 3,65 \\
\hline & DHA & 2,704 & 35,362 & 5732,96 & 986,50 & 20,7 & 49,25 & 205,72 & 0 & 2,1 & 3,41 \\
\hline
\end{tabular}

ND: valores abaixo do limite de confiança de detecção do ensaio 
Tabela A61. Valores individuais referentes à Figura 16 da seção Resultados: Quantificação de citocinas e quimiocinas na meio de cultura de células nucleadas da medula óssea dos animais RAGE KO diabéticos (RAGE KO+STZ) após 30 dias de diabetes.

\begin{tabular}{|c|c|c|c|c|c|c|c|c|c|c|c|}
\hline & Tratamento & NO & IL-1 $\beta$ & IL-6 & TNF- $\alpha$ & CXCL1 & IL-10 & CCL2 & IL-12p40 & IL-1 $\alpha$ & IL-18 \\
\hline \multirow{3}{*}{$\begin{array}{c}\text { Animal } \\
\quad 1\end{array}$} & NT & 1,7 & ND & 312,18 & 24,123 & 2,68 & 2,25 & 24,09 & 0 & 1,86 & 3,06 \\
\hline & LPS & 9,119 & 39,757 & 14253,92 & 1109,973 & 10,08 & 84,64 & 272,63 & 0,02 & 2,1 & 3,77 \\
\hline & DHA & 8,57 & 36,483 & 12843,96 & 1197,936 & 12,29 & 114,63 & 385,55 & 0,04 & 2,34 & 4,58 \\
\hline \multirow{3}{*}{$\begin{array}{c}\text { Animal } \\
2\end{array}$} & NT & 2,743 & ND & 388,42 & 66,04 & 2,54 & 3,17 & 36,37 & 0 & 1,86 & 3,29 \\
\hline & LPS & 18,212 & 47,056 & 11556,9 & 1346,373 & 6,26 & 77,62 & 205,72 & 0,16 & 2,22 & 3,53 \\
\hline & DHA & 16,733 & 58,82 & 10038,62 & 1380,219 & 8,24 & 81,05 & 174,87 & 0,27 & 2,59 & 4,12 \\
\hline \multirow{3}{*}{$\begin{array}{c}\text { Animal } \\
3\end{array}$} & NT & 0,593 & ND & ND & ND & 2,28 & 2,05 & 9,63 & 0 & 1,98 & 3,77 \\
\hline & LPS & 3,367 & 52,477 & 7264,5 & 810,964 & 8,52 & 48,19 & 210,22 & 0,01 & 2,1 & 4,12 \\
\hline & DHA & 1,898 & 49,931 & 6192,56 & 710,007 & 16,31 & 69,65 & 176,78 & 0,11 & 2,47 & 4,35 \\
\hline \multirow{3}{*}{$\begin{array}{c}\text { Animal } \\
4\end{array}$} & NT & 3,503 & ND & 105,66 & ND & 2,68 & 2,25 & 14,6 & 0 & 1,86 & 3,35 \\
\hline & LPS & 7,337 & 60,631 & 12790,06 & 764,632 & 26,28 & 44,2 & 214,83 & 0 & 4,22 & 3,29 \\
\hline & DHA & 6,003 & 74,26 & 6754,2 & 518,394 & 22,58 & 52,56 & 178,7 & 0 & 2,59 & 3,17 \\
\hline \multirow{3}{*}{$\begin{array}{c}\text { Animal } \\
5\end{array}$} & NT & 1,938 & ND & 150,98 & 57,963 & 1,9 & 2,46 & 25,71 & 0 & 1,86 & 4 \\
\hline & LPS & 6,328 & 30,85 & 8992,04 & 1041,301 & 5,89 & 48,19 & 261,07 & 0,01 & 2,34 & 4,81 \\
\hline & DHA & 4,18 & 31,235 & 10251,92 & 786,252 & 9,63 & 53,71 & 194,88 & 0,01 & 2,47 & 4,81 \\
\hline \multirow{3}{*}{ Animal } & NT & 2,841 & ND & 433,7 & 30,199 & 2,15 & 2,92 & 37,16 & 0 & 1,92 & 3,41 \\
\hline & LPS & 11,477 & 36,947 & 12493,22 & 984,166 & 8,52 & 114,63 & 420,45 & 0,13 & 2,34 & 4 \\
\hline & DHA & 4,623 & 44,825 & 10064,32 & 865,985 & 10,58 & 94,32 & 184,6 & 0,04 & 2,1 & 4 \\
\hline
\end{tabular}

ND: valores abaixo do limite de confiança de detecção do ensaio 
Tabela A62. Valores individuais referentes à Figura 17 da seção Resultados: Produção de nitrito, citocinas e quimiocinas pelos macrófagos peritoneais dos animais C57BL/6 controles (B6) após 30 dias da indução de diabetes.

\begin{tabular}{|c|c|c|c|c|c|c|c|c|c|c|c|}
\hline & Tratamento & NO & IL-1 $\beta$ & IL-6 & TNF- $\alpha$ & CXCL1 & IL-10 & CCL2 & IL-12p40 & IL-1 $\alpha$ & IL-18 \\
\hline \multirow{3}{*}{$\begin{array}{c}\text { Animal } \\
1\end{array}$} & NT & 0,485 & 8,814 & 1235,12 & 176,225 & 2265 & 33,35 & 162,1 & 0,3 & 1,29 & 1,62 \\
\hline & LPS & 20,71 & 352,009 & 45991,82 & 3997,885 & 5694 & 361,3 & 420,45 & 2,92 & 369,21 & 4,45 \\
\hline & DHA & 0,238 & 152,853 & 41695,1 & 2033,65 & 5360 & 186,61 & 303,81 & 1,11 & 176,78 & 2,3 \\
\hline \multirow{3}{*}{$\begin{array}{c}\text { Animal } \\
2\end{array}$} & NT & 0,461 & 4,981 & 274,82 & 76,465 & 1179 & 33,35 & 169,28 & 0,36 & 1,61 & 2,41 \\
\hline & LPS & 2,811 & 109,651 & 23410,34 & 2297,33 & 5434 & 236,82 & 324,21 & 0,85 & 127,74 & 2,41 \\
\hline & DHA & 0,828 & 106,283 & 15591,34 & 2180,075 & 5709 & 188,65 & 324,21 & 1,16 & 197 & 2,71 \\
\hline \multirow{3}{*}{$\begin{array}{c}\text { Animal } \\
3\end{array}$} & NT & ND & 31,192 & 3149,28 & 242,21 & 4039 & 53,13 & 231,75 & 0,35 & 4,45 & 1,62 \\
\hline & LPS & 0,485 & 132,409 & 32851,66 & 2021,39 & 5243 & 294,1 & 324,21 & 1,82 & 188,65 & 2,85 \\
\hline & DHA & ND & 125,363 & 31797,16 & 2674,11 & 5395 & 510,95 & 338,56 & 1,82 & 205,72 & 3,4 \\
\hline \multirow{3}{*}{$\begin{array}{c}\text { Animal } \\
4\end{array}$} & NT & 0,555 & 0,687 & 263,54 & 171,43 & 978,57 & 40,09 & 158,63 & 0,4 & 1 & 1,51 \\
\hline & LPS & 17,769 & 114,922 & 33970,66 & 4076,665 & 5389 & 361,3 & 353,55 & 2,06 & 169,28 & 2,71 \\
\hline & DHA & 1,11 & 128,595 & 35373,76 & 4571,03 & 5627 & 439,06 & 353,55 & 1,76 & 184,6 & 2,58 \\
\hline
\end{tabular}

ND: valores abaixo do limite de confiança de detecção do ensaio

Tabela A63. Valores individuais referentes à Figura 17 da seção Resultados: Produção de nitrito, citocinas e quimiocinas pelos macrófagos peritoneais dos animais C57BL/6 diabéticos (B6+STZ) após 30 dias da indução de diabetes.

\begin{tabular}{|c|c|c|c|c|c|c|c|c|c|c|c|}
\hline & Tratamento & NO & IL-1 $\beta$ & IL-6 & TNF- $\alpha$ & CXCL1 & IL-10 & CCL2 & IL-12p40 & IL-1 $\alpha$ & IL-18 \\
\hline \multirow{3}{*}{$\begin{array}{c}\text { Animal } \\
1\end{array}$} & NT & ND & ND & 205,92 & 62,41 & 677,13 & 3,23 & 17,41 & 0,19 & 4,65 & 1,31 \\
\hline & LPS & ND & 116,69 & 24988,72 & 1681,14 & 6000 & 65,27 & 255,47 & 1,31 & 172,99 & 3,95 \\
\hline & DHA & ND & 61,65 & 12437,92 & 1390,11 & 5354 & 34,08 & 53,71 & 0,62 & 66,7 & 2,58 \\
\hline \multirow{3}{*}{$\begin{array}{c}\text { Animal } \\
2\end{array}$} & NT & 0,56 & 12,15 & 414,12 & 177,83 & 2645 & 14,32 & 34,83 & 0,27 & 1,39 & 1,62 \\
\hline & LPS & 17,77 & 756,28 & 46323,64 & 6400,91 & 5742 & 385,55 & 385,55 & 8,89 & 385,55 & 5,29 \\
\hline & DHA & 1,11 & 767,80 & 41414,68 & 6239,59 & 3292 & 234,27 & 214,83 & 0,93 & 172,99 & 3 \\
\hline \multirow{3}{*}{$\begin{array}{c}\text { Animal } \\
3\end{array}$} & NT & 2,15 & 13,24 & 726,3 & 187,44 & 2465 & 20,26 & 61,83 & 0,35 & 1,61 & 1,73 \\
\hline & LPS & 45,91 & 438,60 & 43318,8 & 5531,49 & 6171 & 317,26 & 420,45 & 2,64 & 234,27 & 3,23 \\
\hline & DHA & 10,19 & 575,70 & 39270,84 & 4864,81 & 5742 & 290,93 & 385,55 & 1,82 & 272,63 & 4,85 \\
\hline \multirow{3}{*}{$\begin{array}{c}\text { Animal } \\
4\end{array}$} & NT & 1,57 & 19,53 & 642,34 & 106,33 & 1549 & 7,16 & 52,56 & 0,32 & 3,82 & 1,41 \\
\hline & LPS & 12,25 & 211,16 & 43692,14 & 4711,43 & 5937 & 180,65 & 353,55 & 0,97 & 142,35 & 2,41 \\
\hline & DHA & 0,44 & 186,51 & 34710,22 & 3234,11 & 5935 & 114,63 & 338,56 & 0,62 & 130,53 & 2,21 \\
\hline \multirow{3}{*}{$\begin{array}{c}\text { Animal } \\
5\end{array}$} & NT & 3,14 & 16,71 & 430,82 & 177,83 & 2015 & 8,52 & 41,87 & 0,3 & 1,29 & 1,62 \\
\hline & LPS & 24,75 & 290,25 & 42056,36 & 6484,06 & 6427 & 290,93 & 1477 & 11,53 & 317,26 & 4,17 \\
\hline & DHA & 0,51 & 317,79 & 39196,02 & 4862,05 & 5999 & 205,72 & 385,55 & 1,36 & 266,79 & 3,74 \\
\hline \multirow{3}{*}{$\begin{array}{c}\text { Animal } \\
6\end{array}$} & NT & 1,26 & 6,99 & 359,88 & 131,63 & 1659 & 12,58 & 44,2 & 0,32 & 1,19 & 1,41 \\
\hline & LPS & 36,86 & 244,71 & 40803,42 & 6982,90 & 5821 & 381,4 & 420,45 & 2,78 & 284,7 & 3,4 \\
\hline & DHA & 18,18 & 616,96 & 41897,98 & 8668,96 & 6042 & 377,29 & 420,45 & 3,23 & 411,44 & 4,08 \\
\hline
\end{tabular}

ND: valores abaixo do limite de confiança de detecção do ensaio 
Tabela A64. Valores individuais referentes à Figura 17 da seção Resultados: Produção de nitrito, citocinas e quimiocinas pelos macrófagos peritoneais dos animais NLRP3 KO controles (NLRP3 KO) após 30 dias da indução de diabetes.

\begin{tabular}{|c|c|c|c|c|c|c|c|c|c|c|c|}
\hline & Tratamento & NO & IL-1 $\beta$ & IL-6 & TNF- $\alpha$ & CXCL1 & IL-10 & CCL2 & IL-12p40 & IL-1 $\alpha$ & IL-18 \\
\hline \multirow{3}{*}{$\begin{array}{c}\text { Animal } \\
1\end{array}$} & NT & ND & ND & 909 & 120,54 & 2336 & 14,32 & 172,99 & 0,24 & 2,3 & 1,73 \\
\hline & LPS & 5,174 & 67,15 & 37765,5 & 7667,13 & 5929 & 345,98 & 353,55 & 1,42 & 255,47 & 3,65 \\
\hline & DHA & ND & 29,89 & 29164,52 & 5817,65 & 5675 & 186,61 & 353,55 & 0,62 & 107,41 & 2,21 \\
\hline \multirow{3}{*}{$\begin{array}{c}\text { Animal } \\
2\end{array}$} & NT & 0,289 & ND & 680,32 & 100,02 & 2098 & 8,52 & 139,3 & 0,23 & 1,5 & 1,51 \\
\hline & LPS & 2,112 & 93,76 & 40539,08 & 7084,00 & 5563 & 239,4 & 331,31 & 1,02 & 197 & 2,85 \\
\hline & DHA & ND & 42,49 & 27263,4 & 5481,61 & 5942 & 59,85 & 353,55 & 0,52 & 54,88 & 1,97 \\
\hline \multirow{3}{*}{$\begin{array}{c}\text { Animal } \\
3\end{array}$} & NT & 1,59 & ND & 88,84 & 57,73 & 3709 & 14,32 & 269,69 & 0,32 & 5,29 & 1,41 \\
\hline & LPS & 11,077 & 174,07 & 44127,28 & 7857,29 & 5962 & 342,25 & 310,46 & 2,85 & 278,6 & 3,07 \\
\hline & DHA & 3,659 & 146,06 & 36137,14 & 5068,26 & 5629 & 231,75 & 338,56 & 0,97 & 210,22 & 2,85 \\
\hline \multirow{3}{*}{$\begin{array}{c}\text { Animal } \\
4\end{array}$} & NT & 0,158 & ND & 295,24 & 157,07 & 1865 & 24,09 & 219,53 & 0,35 & 0,91 & 1,62 \\
\hline & LPS & 32,573 & 71,67 & 40737,2 & 9857,04 & 6026 & 957,6 & 369,21 & 9,29 & 197 & 2,58 \\
\hline & DHA & 19,922 & 217,11 & 40969,36 & 10736,06 & 5778 & 1441 & 420,45 & 8,52 & 261,07 & 3,23 \\
\hline
\end{tabular}

ND: valores abaixo do limite de confiança de detecção do ensaio

Tabela A65. Valores individuais referentes à Figura 17 da seção Resultados: Produção de nitrito, citocinas e quimiocinas pelos macrófagos peritoneais dos animais NLRP3 KO diabéticos (NLRP3 KO+STZ) após 30 dias da indução de diabetes.

\begin{tabular}{|c|c|c|c|c|c|c|c|c|c|c|c|}
\hline & Tratamento & NO & IL-1 $\beta$ & IL-6 & TNF- $\alpha$ & CXCL1 & IL-10 & CCL2 & IL-12p40 & IL-1 $\alpha$ & IL-18 \\
\hline \multirow{3}{*}{$\begin{array}{c}\text { Animal } \\
1\end{array}$} & NT & 0,314 & ND & 210,3 & 73,335 & 361,3 & 0,62 & 7,64 & 0,16 & 1,61 & 1,57 \\
\hline & LPS & ND & 38,90 & 38046,04 & 8922,99 & 5926 & 19,4 & 284,7 & 0,49 & 46,65 & 2,21 \\
\hline & DHA & - & - & - & - & - & - & - & - & - & - \\
\hline \multirow{3}{*}{$\begin{array}{c}\text { Animal } \\
2\end{array}$} & NT & 0,761 & ND & 486,26 & 87,44 & 738,41 & 1,5 & 53,13 & 0,13 & 2,92 & 1,22 \\
\hline & LPS & ND & 40,09 & 37786,22 & 4549,61 & 5861 & 53,71 & 331,31 & 0,81 & 127,74 & 2,58 \\
\hline & DHA & ND & 22,33 & 27004,84 & 3302,13 & 5672 & 33,35 & 297,3 & 0,21 & 37,16 & 1,84 \\
\hline \multirow{3}{*}{$\begin{array}{c}\text { Animal } \\
3\end{array}$} & NT & ND & ND & 440,4 & 53,065 & 1070 & 1,5 & 38,81 & 0,17 & 2,64 & 1,22 \\
\hline & LPS & 0,828 & 79,08 & 34982,26 & 5793,51 & 5619 & 41,41 & 317,26 & 0,35 & 84,64 & 2,21 \\
\hline & DHA & ND & 51,16 & 31634,44 & 4763,21 & 5666 & 33,35 & 297,3 & 0,3 & 46,15 & 1,84 \\
\hline \multirow{3}{*}{$\begin{array}{c}\text { Animal } \\
4\end{array}$} & NT & 2,033 & ND & 121,1 & 51,51 & 4598 & 3,82 & 239,4 & 0,58 & 12,58 & 1,22 \\
\hline & LPS & 2,406 & 71,90 & 44984,94 & 5902,57 & 5866 & 65,27 & 369,21 & 2,78 & 234,27 & 2,41 \\
\hline & DHA & 1,342 & 308,46 & 47043,68 & 7973,59 & 5899 & 63,87 & 324,21 & 2,13 & 290,93 & 2,41 \\
\hline \multirow{3}{*}{$\begin{array}{c}\text { Animal } \\
5\end{array}$} & NT & 2,348 & 8,98 & 123,16 & \#VALOR! & 1800 & 4,65 & 139,3 & 0,35 & 1,39 & 1,41 \\
\hline & LPS & 9,207 & 300,04 & 46311,32 & 11478,70 & 6047 & 57,31 & 385,55 & 303,81 & 278,6 & 2,41 \\
\hline & DHA & - & - & - & - & - & - & - & - & - & - \\
\hline
\end{tabular}

ND: valores abaixo do limite de confiança de detecção do ensaio/ (-): número de células insuficientes. 
Tabela A66. Valores individuais referentes à Figura 17 da seção Resultados: Produção de nitrito, citocinas e quimiocinas pelos macrófagos peritoneais dos animais RAGE KO controles (RAGE KO) após 30 dias da indução de diabetes.

\begin{tabular}{|c|c|c|c|c|c|c|c|c|c|c|c|}
\hline & Tratamento & NO & IL-1 $\beta$ & IL-6 & TNF- $\alpha$ & CXCL1 & IL-10 & CCL2 & IL-12p40 & IL-1 $\alpha$ & IL-18 \\
\hline \multirow{3}{*}{$\begin{array}{c}\text { Animal } \\
1\end{array}$} & NT & ND & 3,05 & 428,44 & 62,41 & 1096 & 15,96 & 29,92 & 0,23 & 0,91 & 1,51 \\
\hline & LPS & ND & 124,12 & 36801,86 & 6353,22 & 5787 & 217,17 & 338,56 & 0,62 & 169,28 & 2,21 \\
\hline & DHA & 0,211 & 80,75 & 26780 & 4557,64 & 5496 & 176,78 & 239,4 & 0,65 & 84,64 & 1,51 \\
\hline \multirow{3}{*}{$\begin{array}{c}\text { Animal } \\
2\end{array}$} & NT & ND & ND & 127,28 & 42,20 & 859,31 & 13,72 & 32,63 & 0,17 & 0,83 & 1,41 \\
\hline & LPS & ND & 86,64 & 26263 & 2960,05 & 4978 & 194,88 & 272,63 & 0,43 & 74,33 & 1,84 \\
\hline & DHA & ND & 20,44 & 13136,86 & 2113,78 & 6001 & 169,28 & 234,27 & 0,46 & 48,19 & 1,51 \\
\hline \multirow{3}{*}{$\begin{array}{c}\text { Animal } \\
3\end{array}$} & NT & 0,211 & ND & 250,1 & 48,41 & 978,57 & 3,82 & 35,98 & 0,21 & 0,83 & 1,31 \\
\hline & LPS & 6,896 & 422,55 & 50052,6 & 6049,70 & 5888 & 192,78 & 369,21 & 3,23 & 317,26 & 3,74 \\
\hline & DHA & 1,259 & 402,98 & 48565,5 & 7918,93 & 6199 & 219,53 & 458,5 & 2,78 & 420,45 & 4,75 \\
\hline \multirow{3}{*}{$\begin{array}{c}\text { Animal } \\
4\end{array}$} & NT & 1,174 & ND & 318,14 & 71,78 & 4545 & 26,28 & 187,63 & 0,19 & 3,23 & 1,46 \\
\hline & LPS & 1,853 & 92,36 & 33799,54 & 3349,34 & 5756 & 114,63 & 297,3 & 0,62 & 92,3 & 2,21 \\
\hline & DHA & - & - & - & - & - & - & - & - & - & - \\
\hline
\end{tabular}

ND: valores abaixo do limite de confiança de detecção do ensaio/ (-): número de células insuficientes.

Tabela A67. Valores individuais referentes à Figura 17 da seção Resultados: Produção de nitrito, citocinas e quimiocinas pelos macrófagos peritoneais dos animais RAGE KO diabéticos (RAGE KO+STZ) após 30 dias da indução de diabetes.

\begin{tabular}{|c|c|c|c|c|c|c|c|c|c|c|c|}
\hline & Tratamento & NO & IL-1 $\beta$ & IL-6 & TNF- $\alpha$ & CXCL1 & IL-10 & CCL2 & IL-12p40 & IL-1 $\alpha$ & IL-18 \\
\hline \multirow{3}{*}{$\begin{array}{c}\text { Animal } \\
1\end{array}$} & NT & ND & ND & 277,08 & 81,17 & 989,23 & 4,65 & 21,16 & 0,55 & 1 & 1,41 \\
\hline & LPS & ND & 24,82 & 22764,4 & 2267,87 & 6167 & 22,09 & 221,92 & 1,45 & 48,19 & 1,62 \\
\hline & DHA & ND & 18,01 & 22136,9 & 3620,55 & 5809 & 38,81 & 239,4 & 1,16 & 139,3 & 2,06 \\
\hline \multirow{3}{*}{$\begin{array}{c}\text { Animal } \\
2\end{array}$} & NT & 0,29 & ND & 208,1 & 67,09 & 677,13 & 5,53 & 34,83 & 1,53 & 1,09 & 1,31 \\
\hline & LPS & 0,26 & 49,23 & 23432,3 & 2789,20 & 5687 & 39,23 & 226,78 & 2,35 & 44,68 & 1,62 \\
\hline & DHA & 0,34 & 8,48 & 6000,52 & 1529,52 & 5846 & 11,53 & 33,71 & 1,79 & 14,96 & 1,51 \\
\hline \multirow{3}{*}{$\begin{array}{c}\text { Animal } \\
3\end{array}$} & NT & ND & ND & 61,68 & 53,07 & 4888 & 3,23 & 162,1 & 0,25 & 7,32 & 1,41 \\
\hline & LPS & 0,44 & 184,09 & 39046,74 & 4619,41 & 5784 & 4,65 & 278,6 & 2,92 & 165,65 & 1,73 \\
\hline & DHA & 2,15 & 132,54 & 28640,84 & 6037,36 & 5956 & 8,52 & 255,47 & 1,07 & 172,99 & 2,41 \\
\hline \multirow{3}{*}{$\begin{array}{c}\text { Animal } \\
4\end{array}$} & NT & 2,14 & ND & 297,52 & 222,82 & 2537 & 12,58 & 49,79 & 0,32 & 0,91 & 1,41 \\
\hline & LPS & 33,01 & 424,52 & 41638,88 & 13598,41 & 6118 & 263,91 & 439,06 & 3,57 & 369,21 & 2,71 \\
\hline & DHA & 15,74 & 719,39 & 43610,22 & 7785,17 & 6102 & 258,26 & 385,55 & 2,3 & 385,55 & 3,07 \\
\hline \multirow{3}{*}{$\begin{array}{c}\text { Animal } \\
5\end{array}$} & NT & 1,25 & 25,03 & 6491,44 & 562,52 & 4960 & 31,93 & 140,82 & 0,21 & 5,53 & 1,62 \\
\hline & LPS & 12,10 & 1155,08 & 37394,06 & 7501,03 & 5616 & 303,81 & 369,21 & 1,11 & 978,57 & 4,17 \\
\hline & DHA & 2,45 & 993,92 & 40936,12 & 7158,71 & 5769 & 205,72 & 353,55 & 1,59 & 458,5 & 2,92 \\
\hline
\end{tabular}

ND: valores abaixo do limite de confiança de detecção do ensaio. 
Tabela A68. Valores individuais referentes à Figura 18 da seção Resultados: Expressão da iNOS em relação a expressão de beta actina nos macrófagos dos animais C57BL/6 e NLRP3 KO após 30 dias da indução de diabetes.

\begin{tabular}{|l|c|c|c|c|c|c|c|c|c|c|c|c|c|c|}
\hline Inos & \multicolumn{3}{|c|}{ B6 (U.A.) } & \multicolumn{3}{c|}{ B6+STZ (U.A.) } & \multicolumn{4}{c|}{ NLRP3 KO (U.A.) } & \multicolumn{3}{c|}{ NLRP3 KO+STZ (U.A.) } \\
\hline NT & 0,109 & 0,033 & 0,084 & 0,020 & 0,050 & 0,012 & 0,092 & 0,052 & & & 0,173 & 0,105 & & \\
\hline LPS & 0,233 & 0,099 & 0,113 & 1,486 & 1,031 & 0,985 & 0,291 & 0,272 & 0,152 & 0,176 & 0,629 & 0,361 & 0,135 & 0,141 \\
\hline LPS+DHA & 0,204 & 0,088 & & 0,634 & 0,126 & & 0,031 & 0,161 & & & 0,092 & 0,165 & & \\
\hline
\end{tabular}

U.A.:unidades arbitrárias

Tabela A69. Valores individuais referentes à Figura 19 da seção Resultados: Expressão de NLRP3 em relação a expressão de beta actina nos macrófagos dos animais C57BL/6 e NLRP3 KO após 30 dias da indução de diabetes.

\begin{tabular}{|l|c|c|c|c|c|c|c|c|}
\hline NLRP3 & \multicolumn{4}{|c|}{ B6 (U.A) } & \multicolumn{4}{c|}{ B6+STZ (U.A.) } \\
\hline NT & 0,148 & 0,156 & 0,100 & 0,619 & 0,275 & 0,293 & 0,266 & 0,656 \\
\hline LPS & 0,684 & 0,957 & 0,539 & 0,720 & 0,901 & 0,978 & 1,025 & 1,019 \\
\hline LPS+DHA & 0,516 & 1,142 & & 0,914 & 0,903 & 0,677 & & 0,974 \\
\hline
\end{tabular}

U.A: unidades arbitrárias

Tabela A70. Valores individuais referentes à Figura 20 da seção Resultados: Expressão de PARP1 total em relação a expressão de beta actina nos macrófagos dos animais C57BL/6 e NLRP3 KO após 30 dias da indução de diabetes.

\begin{tabular}{|l|c|c|c|c|c|c|}
\hline PARP1 T & B6 (U.A.) & B6+STZ (U.A.) & \multicolumn{2}{|c|}{ NLRP3 KO (U.A.) } & \multicolumn{2}{|c|}{ NLRP3 KO+STZ (U.A.) } \\
\hline NT & 0,095 & 0,045 & 0,093 & & 0,172 & \\
\hline LPS & 0,169 & 0,470 & 0,125 & 0,137 & 0,450 & 0,284 \\
\hline LPS+DHA & & & 0,284 & 0,040 & 0,169 & 0,109 \\
\hline
\end{tabular}

U.A: unidades arbitrárias

Tabela A71. Valores individuais referentes à Figura 20 da seção Resultados: Expressão de PARP1 clivada em relação a expressão de beta actina nos macrófagos dos animais C57BL/6 e NLRP3 KO após 30 dias da indução de diabetes.

\begin{tabular}{|l|c|c|c|c|c|c|}
\hline PARP1 C & B6 (U.A.) & B6+STZ (U.A.) & \multicolumn{2}{|c|}{ NLRP3 KO (U.A.) } & \multicolumn{2}{|c|}{ NLRP3 KO+STZ (U.A.) } \\
\hline NT & 0,394 & 0,186 & 0,420 & & 0,912 & \\
\hline LPS & 0,482 & 1,447 & 0,585 & 0,441 & 1,127 & 0,688 \\
\hline LPS+DHA & & & 0,404 & 0,772 & 0,096 & 0,661 \\
\hline
\end{tabular}

U.A: unidades arbitrárias 


\section{B - Apêndice 2. Descrição resumida dos resultados encontrados na avaliação dos efeitos do diabetes mellitus tipo I em macrófagos peritoneais residentes dos animais NODs (non obese diabetic)}

Tabela A1. Evolução da glicemia (mg/dL) ao longo do período de estudo dos animais NODs.

\begin{tabular}{|c|c|c|c|c|c|c|c|c|c|c|c|c|}
\hline \multicolumn{13}{|c|}{ Evolução da glicemia dos animais NODs ao longo do período estudado } \\
\hline $\begin{array}{c}\text { Semanas } \\
\text { pós- } \\
\text { nascimento }\end{array}$ & $\begin{array}{c}\text { Animal } \\
899 \\
\end{array}$ & $\begin{array}{c}\text { Animal } \\
900 \\
\end{array}$ & $\begin{array}{c}\text { Animal } \\
902 \\
\end{array}$ & $\begin{array}{c}\text { Animal } \\
901 \\
\end{array}$ & $\begin{array}{c}\text { Animal } \\
903 \\
\end{array}$ & $\begin{array}{c}\text { Animal } \\
904 \\
\end{array}$ & $\begin{array}{c}\text { Animal } \\
905 \\
\end{array}$ & $\begin{array}{c}\text { Animal } \\
906 \\
\end{array}$ & $\begin{array}{c}\text { Animal } \\
907 \\
\end{array}$ & $\begin{array}{c}\text { Animal } \\
908 \\
\end{array}$ & $\begin{array}{c}\text { Animal } \\
909 \\
\end{array}$ & $\begin{array}{c}\text { Animal } \\
910 \\
\end{array}$ \\
\hline 15 & 84 & 91 & 114 & 88 & NR & 95 & 108 & 110 & 100 & 90 & 91 & 95 \\
\hline 16 & 111 & 100 & 135 & NR & 99 & 95 & 108 & 334 & 116 & 95 & 111 & 115 \\
\hline 17 & 99 & 97 & 112 & 100 & 116 & 93 & 103 & 523 & 94 & 99 & 121 & 126 \\
\hline 18 & 122 & 86 & 83 & 90 & 97 & 87 & 97 & 591 & 92 & 99 & 431 & 96 \\
\hline 20 & 423 & 92 & 110 & 95 & 125 & 93 & $\#$ & $\#$ & 95 & 111 & 497 & 127 \\
\hline 21 & 550 & 116 & 160 & 123 & 185 & 132 & & & 113 & 135 & 482 & 115 \\
\hline 22 & $\#$ & $\#$ & 186 & 110 & 101 & 103 & & & 99 & 212 & $\#$ & 86 \\
\hline 23 & & & 107 & 99 & 119 & 160 & & & 139 & 529 & & 99 \\
\hline
\end{tabular}

NR: não realizado, (\#): animal eutanasiado.

Tabela A2. Avaliação da glicemia (mg/dL) dos animais NOD não-diabético (NOD ND) e NOD diabéticos (NOD D) no dia da eutanásia.

\begin{tabular}{cc}
\hline NOD ND & NOD D \\
\hline 99 & 529 \\
\hline 139 & 550 \\
\hline 107 & 322 \\
\hline 119 & $>600$ \\
\hline 99 & 350
\end{tabular}

Camundongos foram acompanhados durante 63 dias, e após duas avaliações de glicemia não consecutivas, com valores mais elevados que $250 \mathrm{mg} / \mathrm{dL}$ na ausência de jejum, os animais foram eutanasiados.

Tabela A3. Valores individuais, média, desvio padrão (DP) e erro padrão da média (EPM) referentes à secreção de $\mathrm{IL}-1 \beta(\mathrm{pg} / \mathrm{mL})$ pelos macrófagos peritoneais residentes de animais controles C57BL/6, NOD não-diabético (NOD ND) e NOD diabético (NOD D) na presença ou não (NT) de lipopolissacarídeo (2,5 ug/mL de LPS).

\begin{tabular}{|c|c|c|c|c|c|c|}
\hline & \multicolumn{3}{|c|}{ C57BL/6 } & Média & DV & EPM \\
\hline NT & 57.81 & 49.40 & 10.75 & 39.32 & 25.10 & 14.49 \\
\hline \multirow[t]{2}{*}{ LPS } & 187.37 & 174.54 & 50.75 & 137.56 & 75.44 & 43.56 \\
\hline & \multicolumn{3}{|c|}{ NOD ND } & Média & DV & EPM \\
\hline NT & 4.95 & 6.45 & 0 & 3.80 & 3.38 & 1.95 \\
\hline \multirow[t]{2}{*}{ LPS } & 258.15 & 360.00 & 263.99 & 294.05 & 57.19 & 33.02 \\
\hline & \multicolumn{3}{|c|}{ NOD D } & Média & DV & EPM \\
\hline NT & 91.12 & 94.48 & 90.07 & 91.89 & 2.30 & 1.33 \\
\hline LPS & 616.02 & 594.02 & 529.828 & 579.96 & 44.79 & 25.86 \\
\hline
\end{tabular}


Tabela A4. Valores individuais, média, desvio padrão (DP) e erro padrão da média (EPM) referentes à secreção de IL-1 $\beta$, IL-18, IL-1 $\alpha$, TNF- $\alpha$, IL-10, IL-6 E MCP-1 (pg/mL) pelos macrófagos peritoneais residentes de animais NOD não-diabético (NOD ND) e NOD diabético (NOD D) na presença ou não (NT) de lipopolissacarídeo (LPS).

\begin{tabular}{|c|c|c|c|c|c|c|c|c|c|c|c|c|c|c|}
\hline & \multicolumn{14}{|c|}{ NOD NÃO-DIABÉTICO } \\
\hline & \multicolumn{2}{|c|}{ IL-1 $\beta$} & \multicolumn{2}{|c|}{ IL-18 } & \multicolumn{2}{|c|}{ IL-1 $\alpha$} & \multicolumn{2}{|c|}{ TNF- $a$} & \multicolumn{2}{|c|}{ IL-10 } & \multicolumn{2}{|c|}{ IL-6 } & \multicolumn{2}{|c|}{ MCP-1 } \\
\hline & NT & LPS & NT & LPS & NT & LPS & NT & LPS & NT & LPS & NT & LPS & NT & LPS \\
\hline Animal 1 & 9.28 & 83.6 & 0 & 135.76 & 4.28 & 155.07 & 55.76 & 676.62 & 42.66 & 294.61 & 1931 & 27300 & 696.12 & 1891 \\
\hline Animal 2 & 7.89 & 97.77 & 0 & 103.78 & 5.59 & 177.17 & 37.32 & 787.09 & 7.65 & 280.66 & 537.27 & 43000 & 103.59 & 2143 \\
\hline Média & 8.58 & 90.68 & 0 & 119.77 & 4.93 & 166.12 & 46.54 & 731.85 & 25.15 & 287.63 & 1234.13 & 35150 & 399.85 & 2017 \\
\hline DV & 0.98 & 10.02 & 0.00 & 22.61 & 0.93 & 15.63 & 13.04 & 78.11 & 24.76 & 9.86 & 985.52 & 11101.58 & 418.98 & 178.19 \\
\hline EPM & 0.70 & 7.09 & 0.00 & 15.99 & 0.65 & 11.05 & 9.22 & 55.24 & 17.51 & 6.97 & 696.87 & 7850.00 & 296.27 & 126.00 \\
\hline
\end{tabular}

\begin{tabular}{|c|c|c|c|c|c|c|c|c|c|c|c|c|c|c|}
\hline & \multicolumn{14}{|c|}{ NOD DIABÉTICO } \\
\hline & \multicolumn{2}{|c|}{ IL-1 $\beta$} & \multicolumn{2}{|c|}{ IL-18 } & \multicolumn{2}{|c|}{ IL-1a } & \multicolumn{2}{|c|}{ TNF- $\alpha$} & \multicolumn{2}{|c|}{ IL-10 } & \multicolumn{2}{|c|}{ IL-6 } & \multicolumn{2}{|c|}{ MCP-1 } \\
\hline & NT & LPS & NT & LPS & NT & LPS & NT & LPS & NT & LPS & NT & LPS & NT & LPS \\
\hline Animal 1 & 120.06 & 315.18 & 103.78 & 135.76 & 111.9 & 255.73 & 222.99 & 241.42 & 103.86 & 249.95 & 2376 & 19851.2 & 1390 & 1888 \\
\hline Animal 2 & 32.57 & 118.8 & 0 & 103.78 & 18.48 & 117.31 & 96.01 & 541.05 & 35.96 & 205.58 & 978.02 & 20380 & 319.12 & 1932 \\
\hline Animal 3 & 7.89 & 87.47 & 0 & 103.78 & 4.28 & 225.3 & 72.59 & 1559 & 18.9 & 283.25 & $\mathrm{CNR}$ & CNR & 567.77 & 2212 \\
\hline Média & 53.51 & 173.82 & 34.59 & 114.44 & 44.89 & 199.45 & 130.53 & 780.49 & 52.91 & 246.26 & 1677.01 & 20115.60 & 758.96 & 2010.67 \\
\hline DV & 58.94 & 123.42 & 59.92 & 18.46 & 58.47 & 72.74 & 80.92 & 690.65 & 44.94 & 38.97 & 988.52 & 373.92 & 560.46 & 175.74 \\
\hline EPM & 34.03 & 71.26 & 34.59 & 10.66 & 33.76 & 42.00 & 46.72 & 398.75 & 25.95 & 22.50 & 570.72 & 215.88 & 323.58 & 101.46 \\
\hline
\end{tabular}

CNR: cinética não responsiva

A

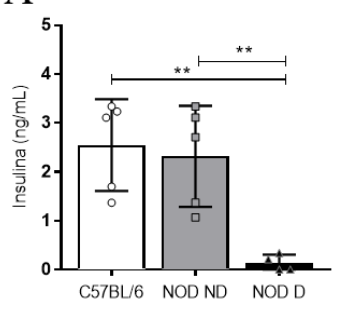

B

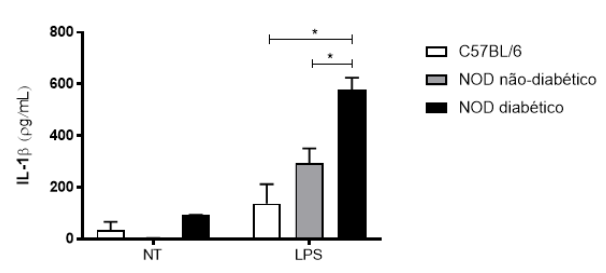

$\mathrm{C}$

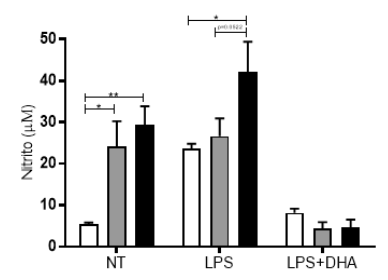

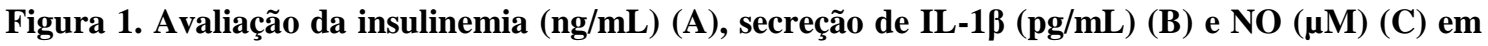
macrófagos peritoneais residentes de animais C57BL/6, NOD não-diabético (NOD ND) ou NOD diabéticos (NOD D). Camundongos NODs foram acompanhados durante 63 dias. Após duas avaliações não consecutivas de glicemia com valores acima de $250 \mathrm{mg} / \mathrm{dL}$, na ausência de jejum, os animais foram eutanasiados. Os animais tiveram os macrófagos peritoneais residentes coletados e tratados somente com lipopolissacarídeo - LPS $(2,5 \mu \mathrm{g} / \mathrm{mL})$ ou LPS $(2,5 \mu \mathrm{g} / \mathrm{mL})$ e ácido docosaexaenóico-DHA $(25 \mu \mathrm{M})$ durante 24 horas. A secreção de IL-1 $\beta$ e NO foi avaliada por ELISA e Griess, respectivamente. Os dados representam a média \pm erro padrão da média de 3-5 animais por grupo experimental. NT: meio RPMI suplementado com $10 \%$ soro fetal bovino; LPS: RPMI suplementado com $10 \%$ soro fetal bovino e LPS $(2,5 \mu \mathrm{g} / \mathrm{mL})$; LPS+DHA: RPMI suplementado com $10 \%$ soro fetal bovino, LPS $(2,5 \mu \mathrm{g} / \mathrm{mL})$ e DHA $(25$ $\mu \mathrm{M})$. 
Tabela A5. Valores individuais, média, desvio padrão (DP) e erro padrão da média (EPM) referentes à taxa de acidificação extracelular, avaliação da glicólise e da capacidade glicolítica (mpH/min) dos macrófagos peritoneais residentes de animais C57BL/6, NOD não-diabético (NOD ND) e NOD diabéticos (NOD D).

\begin{tabular}{|c|c|c|c|c|c|c|}
\hline & \multicolumn{3}{|c|}{ Glicólise } & \multicolumn{3}{c|}{ Capacidade glicolítica } \\
\hline & C57BL/6 & NOD ND & NOD D & C57BL/6 & NOD ND & NOD D \\
\hline Animal 1 & 5.1 & 8.5 & 12.07 & 5.02 & 8.26 & 12.21 \\
\hline Animal 2 & 6.57 & 9.51 & 16.22 & 8.41 & 10.14 & 12.31 \\
\hline Animal 3 & 4.52 & 14.51 & 6.2 & 5.97 & 12.36 & 6.82 \\
\hline Animal 4 & & 10.33 & 6.24 & & 10.88 & 6.86 \\
\hline Média & 5.40 & 10.71 & 10.18 & 6.47 & 10.41 & 9.55 \\
\hline DV & 1.06 & 2.64 & 4.88 & 1.75 & 1.70 & 3.13 \\
\hline EPM & 0.61 & 1.32 & 2.44 & 1.01 & 0.85 & 1.56 \\
\hline
\end{tabular}

Tabela A6. Comparação entre os valores de glicemia $(\mathrm{mg} / \mathrm{dL})$ dos animais NOD diabéticos e a glicólise ( $\mathrm{mpH} / \mathrm{min})$ e a capacidade glicolítica $(\mathrm{mpH} / \mathrm{min})$ dos macrófagos dos animais NOD diabéticos.

\begin{tabular}{l|c|c|c}
\hline & \multicolumn{3}{|c}{ NOD D } \\
\hline & Glicemia & Glicólise & Capacidade Glicolítica \\
\hline Animal 1 & 550 & 12.07 & 12.21 \\
\hline Animal 2 & $>600$ & 16.22 & 12.31 \\
\hline Animal 3 & 350 & 6.2 & 6.82 \\
\hline Animal 4 & 322 & 6.24 & 6.86 \\
\hline
\end{tabular}

Camundongos NODs diabéticos ou NODs não-diabéticos foram acompanhados durante 63 dias, e após duas avaliações de glicemia não consecutivas, com valores mais elevados que $250 \mathrm{mg} / \mathrm{dL}$ na ausência de jejum, os animais foram eutanasiados. As células peritoneais foram coletadas, aderidas em placas XF96 e após 2 horas foram lavadas para obtenção dos macrófagos peritoneais. As concentrações finais utilizadas durante a avaliação da acidificação extracelular foram de $10 \mathrm{mM}$ de glicose, $1 \mathrm{uM}$ de oligomicina e $0.1 \mathrm{M}$ de 2-DG (2-Deoxi-D-Glucose).

A

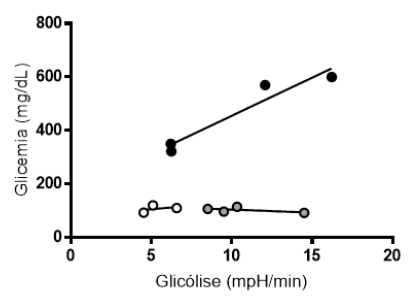

B

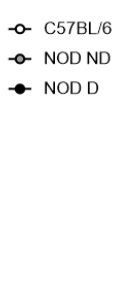

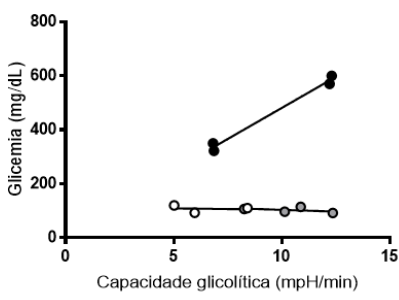

Figura 2. Relação entre a glicólise (A) e a capacidade glicolítica (B) em macrófagos peritoneais residentes de animais NOD não-diabético (NOD ND) ou NOD diabéticos (NOD D) com a glicemia. Camundongos NODs foram acompanhados durante 63 dias. Após duas avaliações não consecutivas de glicemia com valores acima de $250 \mathrm{mg} / \mathrm{dL}$, na ausência de jejum, os animais foram eutanasiados. Camundongos NODs diabéticos ou NODs não-diabéticos foram acompanhados durante 63 dias, e após duas avaliações de glicemia não consecutivas, com valores mais elevados que $250 \mathrm{mg} / \mathrm{dL}$ na ausência de jejum, os animais foram eutanasiados. As células peritoneais foram coletadas, aderidas em placas XF96 e após 2 horas foram lavadas para obtenção dos macrófagos peritoneais. As concentrações finais utilizadas durante a avaliação da acidificação extracelular foram de $10 \mathrm{mM}$ de glicose, $1 \mathrm{uM}$ de oligomicina e $0.1 \mathrm{M}$ de 2-DG (2-Deoxi-D-Glucose). 
C - Apêndice 3. Caracterização dos macrófagos residentes peritoneais e das condições de cultura utilizadas

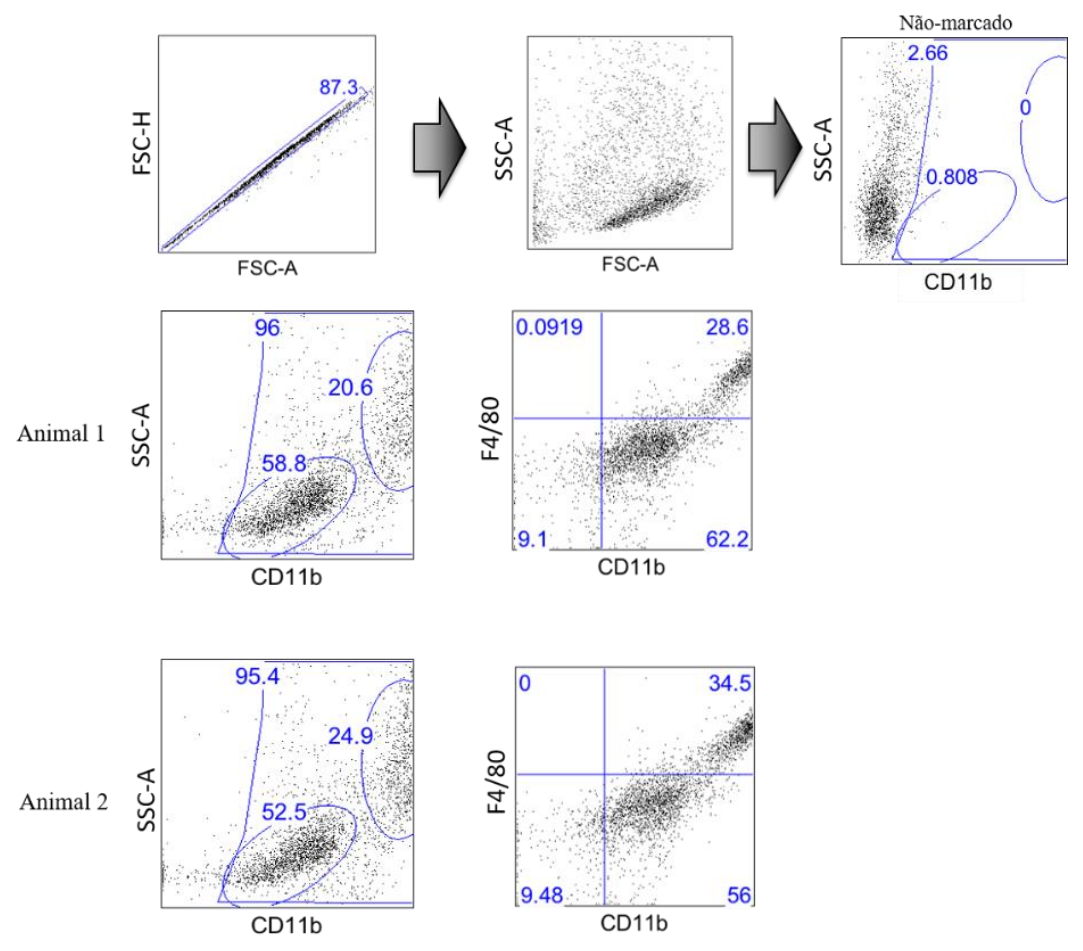

Figura A1. Análise da população de macrófagos residentes peritoneais após 2 horas de adesão. Foi realizado a coleta das células peritoneais de animais C57BL/6 com PBS, centrifugadas, contadas e plaqueadas. Após 2 horas de adesão, as células foram descoladas com Accutase e processadas para citometria de fluxo. Inicialmente foi realizado a exclusão de duplets, seguida pela análise de células com tamanho (FSC) por granulosidade (SSC) correspondente às células vivas. A positividade da marcação foi baseada no tubo de células sem anticorpo. Os macrófagos peritoneais foram caracterizados através da marcação de CD11b e F4/80.

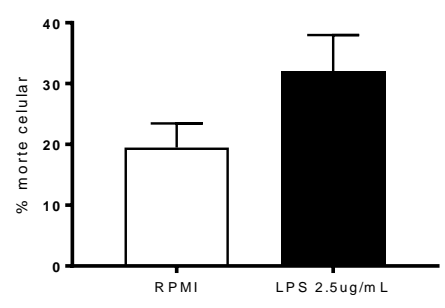

Figura A2. Avaliação de morte celular após 24 horas em cultura. Foi realizado a coleta das células peritoneais com PBS, centrifugadas, contadas e plaqueadas. Após 2 horas de adesão, as células foram lavadas estimuladas (LPS, $2,5 \mathrm{ug} / \mathrm{mL}$ ) ou não (RPMI) com LPS. Após 24 horas, o sobrenadante foi coletado e foi realizado o ensaio de citotoxicidade através da quantificação de lactato desidrogenase (LDH Cytotoxicity Assay Kit, Thermo Fisher). 


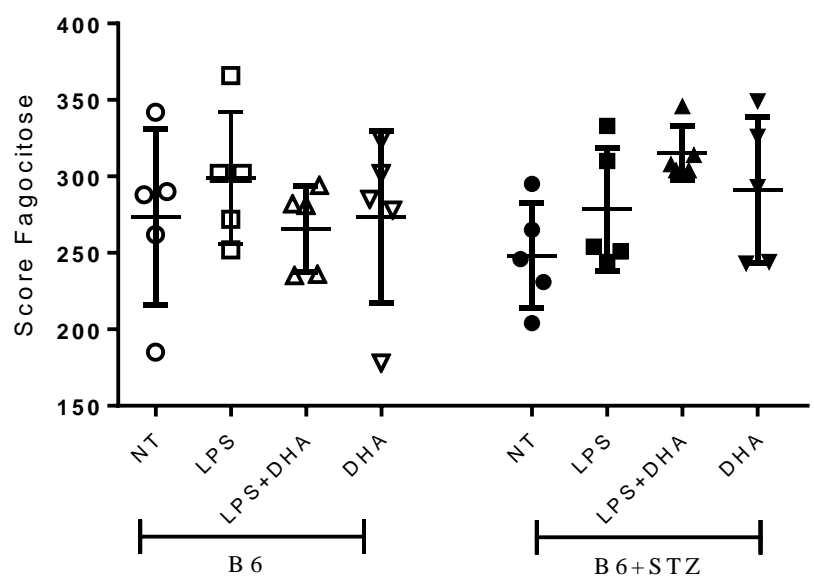

Figura A3. Avaliação do número de partículas fagocitadas pelos macrófagos peritoneais. Foi realizado a coleta das células peritoneais com PBS, centrifugadas, contadas e plaqueadas. Durante o espraiamento, os macrófagos foram tratados com LPS, LPS+DHA ou DHA, durante 2 horas. Os macrófagos peritoneais foram incubados com as partículas de zymosan opsnozizadas ( 1 célula para 5 partículas de zymosan). Após 40 minutos, à $37^{\circ} \mathrm{C}$, as lâminas foram lavadas, coradas e através de microscopia ótica a quantidade de células que tiveram partículas fagocitadas foram contadas. De acordo com a quantidade de partículas fagocitadas, um valor (score) foi atribuído para a contagem. NT: não-tratado, LPS: lipopolissacarídeo $(2,5 \mu \mathrm{g} / \mathrm{mL})$ e DHA: ácido docosaexaenoico $(25 \mu \mathrm{M})$.

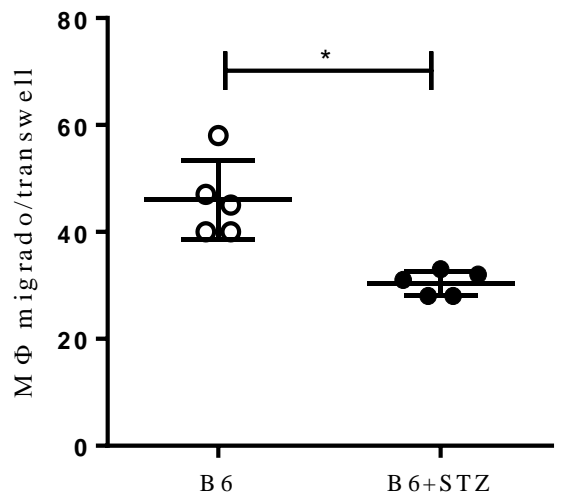

Figura A4. Avaliação da migração de macrófagos peritoneais. Foi realizado a coleta das células peritoneais com PBS, centrifugadas, contadas e plaqueadas à concentração final de $1 \%$ de soro fetal bovino. O ensaio de migração foi realizado através de placas de transwell. As células migraram em resposta a $10 \%$ de soro fetal bovino na parte inferior da placa (concentração final). Após 8 horas, à $37^{\circ} \mathrm{C}$, as lâminas foram lavadas, coradas e através de microscopia ótica a quantidade de células encontradas na parte inferior da placa (células que migraram) foram contadas. 